\title{
Physical education's contribution to levels of physical activity in children and adolescents
}

Citation for published version (APA):

Slingerland, M. (2014). Physical education's contribution to levels of physical activity in children and adolescents. [Doctoral Thesis, Maastricht University]. Maastricht University. https://doi.org/10.26481/dis.20140416ms

Document status and date:

Published: 01/01/2014

DOI:

10.26481/dis.20140416ms

Document Version:

Publisher's PDF, also known as Version of record

\section{Please check the document version of this publication:}

- A submitted manuscript is the version of the article upon submission and before peer-review. There can be important differences between the submitted version and the official published version of record. People interested in the research are advised to contact the author for the final version of the publication, or visit the DOI to the publisher's website.

- The final author version and the galley proof are versions of the publication after peer review.

- The final published version features the final layout of the paper including the volume, issue and page numbers.

Link to publication

\footnotetext{
General rights rights.

- You may freely distribute the URL identifying the publication in the public portal. please follow below link for the End User Agreement:

www.umlib.nl/taverne-license

Take down policy

If you believe that this document breaches copyright please contact us at:

repository@maastrichtuniversity.nl

providing details and we will investigate your claim.
}

Copyright and moral rights for the publications made accessible in the public portal are retained by the authors and/or other copyright owners and it is a condition of accessing publications that users recognise and abide by the legal requirements associated with these

- Users may download and print one copy of any publication from the public portal for the purpose of private study or research.

- You may not further distribute the material or use it for any profit-making activity or commercial gain

If the publication is distributed under the terms of Article $25 \mathrm{fa}$ of the Dutch Copyright Act, indicated by the "Taverne" license above, 


\section{PHYSICAL EDUCATION'S CONTRIBUTION TO LEVELS OF PHYSICAL ACTIVITY IN CHILDREN AND ADOLESCENTS MENNO SLINGERLAND}

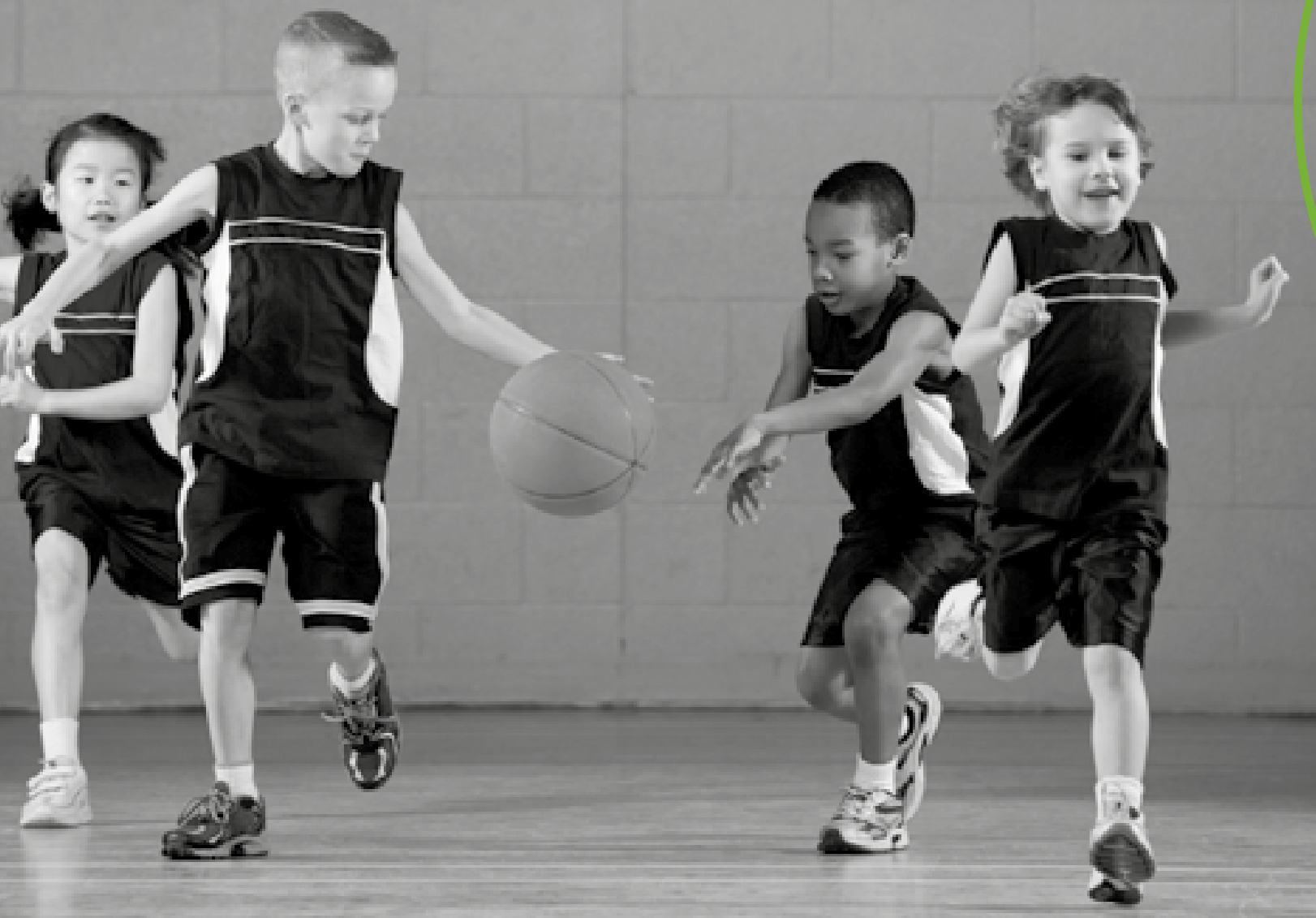




\section{PHYSICAL EDUCATION'S \\ CONTRIBUTION TO LEVELS OF PHYSICAL ACTIVITY IN \\ CHILDREN AND ADOLESCENTS}

DISSERTATION

MENNO SLINGERLAND

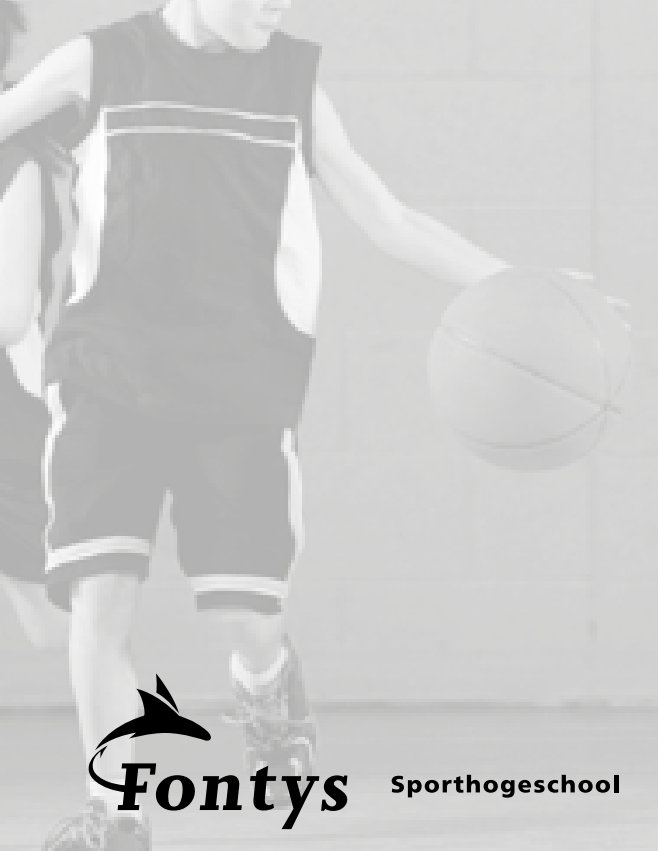

Maastricht University 


\section{ISBN:}

\section{Design:}

Grafische Producties, Dienst Marketing \& Communicatie, Fontys Hogescholen

(C) Copyright M. Slingerland, Maastricht 2014

All rights reserved (including those of translation into other languages) to the author with exception of those chapters published by the journals referred to. No parts of this dissertation may be reproduced in any other form by photo print, digital copy or any other means - without written permission from the author or the copyright owning journal. 


\section{PHYSICAL EDUCATION'S CONTRIBUTION TO LEVELS OF PHYSICAL ACTIVITY IN CHILDREN AND ADOLESCENTS DISSERTATION}

To obtain the degree of Doctor at Maastricht University, on the authority of the Rector Magnificus, Prof. dr. L.L.G. Soete, in accordance with the decision of the Board of Deans, to be defended in public on Wednesday 16 April 2014 at $14.00 \mathrm{hrs}$

by

MENNO SLINGERLAND

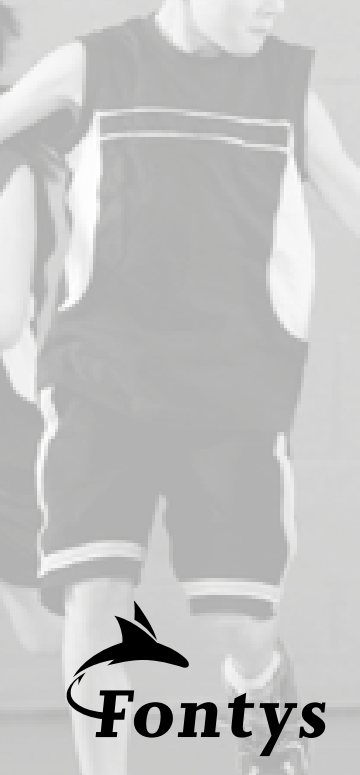




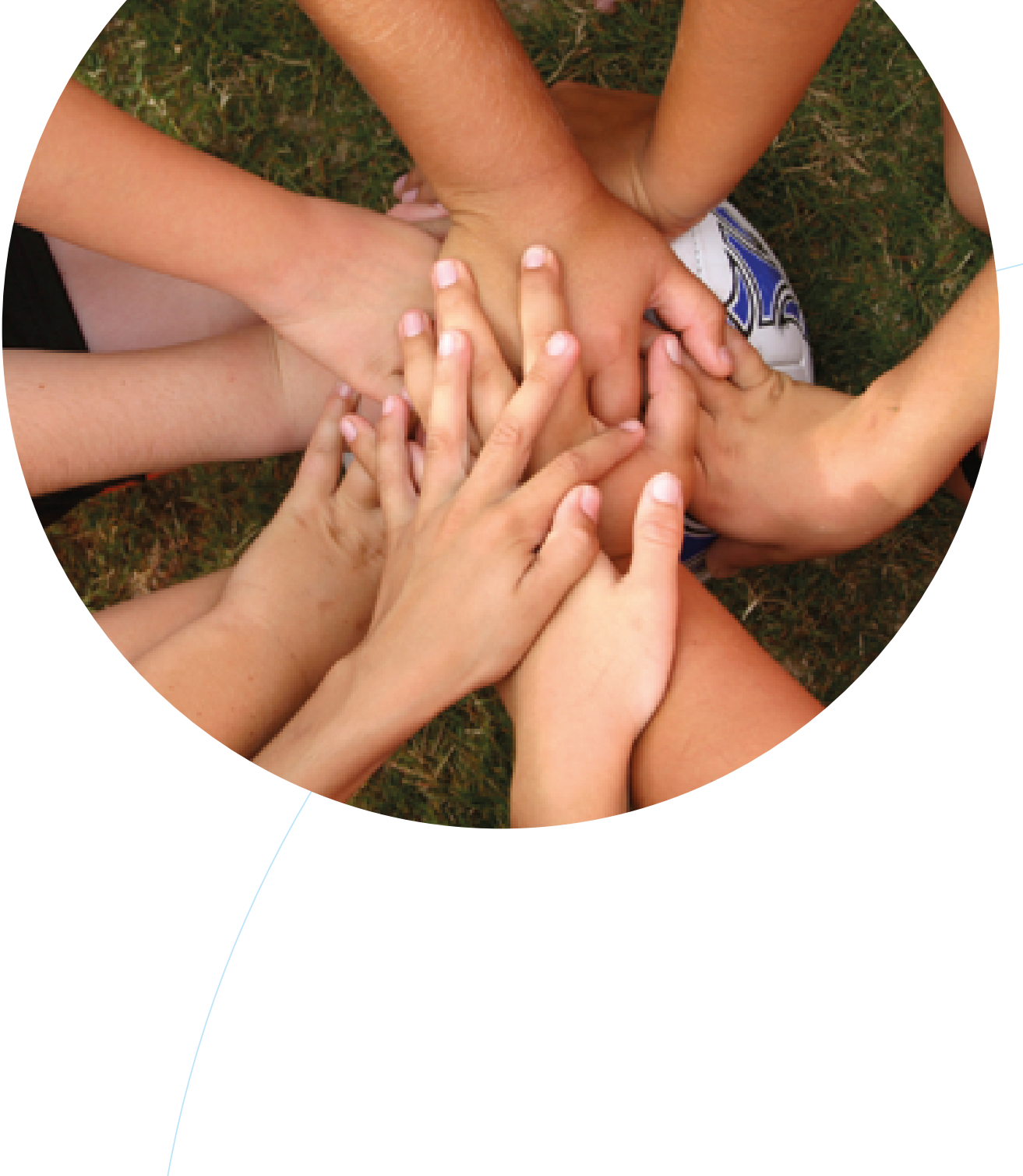

\section{Supervisor:}

Prof. dr. M. K. C. Hesselink

\section{Co-supervisor:}

Dr. L.B. Borghouts

\section{Assessment Committee:}

Prof. dr. S. P. J. Kremers (chair)

Dr. K. Meijer

Prof. dr. C. Visscher (Rijksuniversiteit Groningen)

Dr. J. Seghers (Katholieke Universiteit Leuven)

\section{Paranimfen:}

Joost Oomen

Willem Gosens 


\section{Contents}

Chapter 1 I General Introduction 7

Chapter 2 | Direct and Indirect Influence of

Physical Education-Based

Interventions on Physical

Activity: A Review

Chapter 3 | Physical Activity Energy

Expenditure in Dutch

Adolescents: Contribution of

Active Transport to School,

Physical Education and Leisure

Time Activities

Chapter 4 I Physical Activity Levels during

Primary and Secondary

School Physical Education

Chapter 5 I Increasing In-Class Physical

Activity during Coeducational

Secondary School Physical

Education

Chapter 6 I Is Autonomous Motivation for

Physical Education Related to

Higher Levels of Physical Activity

Energy Expenditure in Dutch

Adolescents?

Chapter 7 । Differences in Perceived

Competence and Physical

Activity Levels during Single-

Gender Modified Basketball Game

Play in Middle School Physical

Education

Chapter 8 I General Discussion

Nederlandse samenvatting (Dutch Summary)

Dankwoord (Acknowledgements)

Curriculum Vitae \& Publications

Stellingen (Propositions) 


\section{CHAPTER 1}

\section{GENERAL INTRODUCTION}

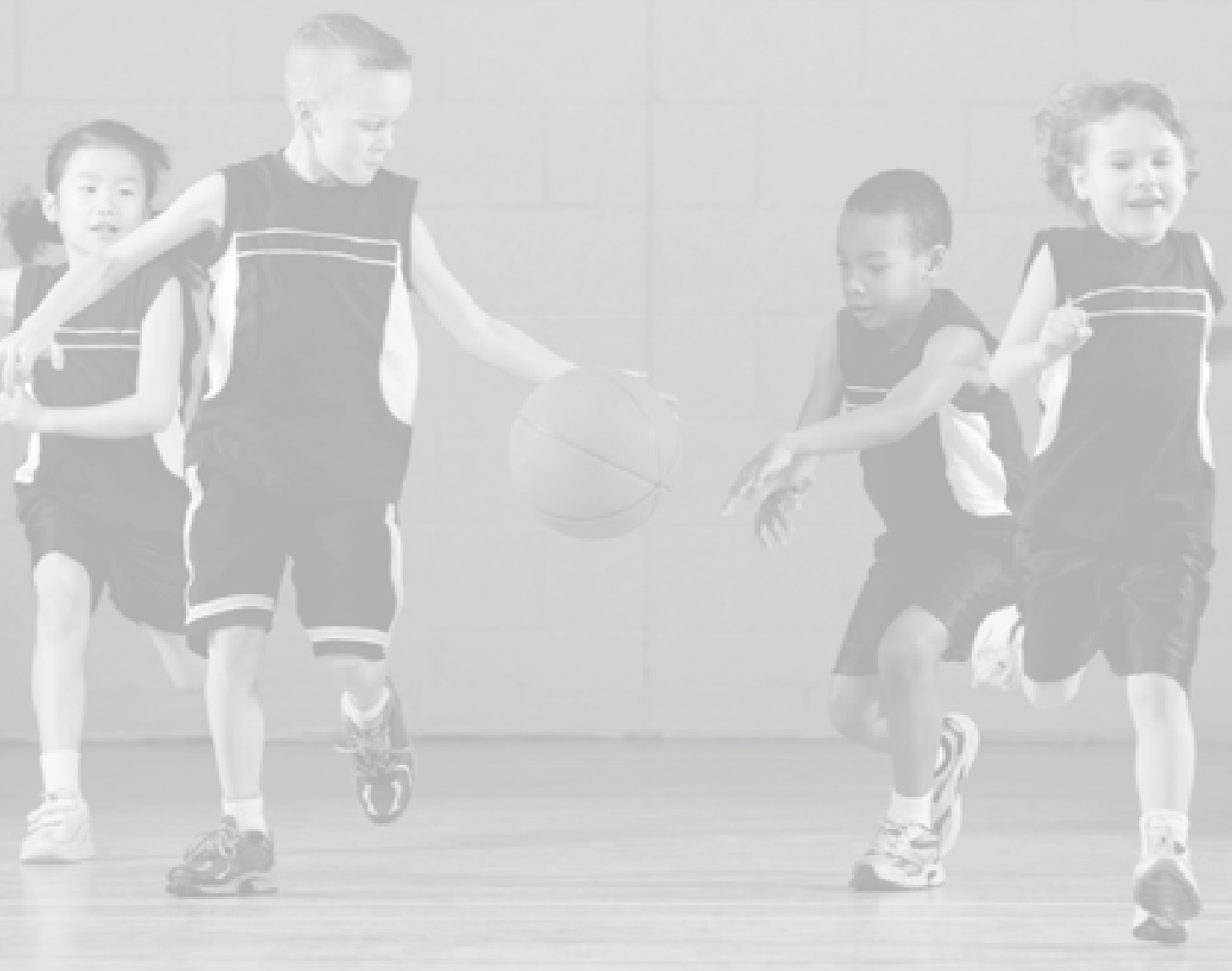




\section{Background}

The promotion of physical activity in children and adolescents has received ample attention in the past two decades, mainly due to the rising prevalence of overweight and obesity among children and young people (Andersen et al., 2006; Ness et al., 2007). Declining levels of physical activity contribute, at least in part, to this problem and schools are deemed a promising environment in this respect (Ferreira et al., 2007; Naylor \& McKay, 2009). Schools are able to provide large groups of children and adolescents with physical activity, for example through physical education, school sports, active recess periods and active transportation to school. The main theme of this thesis is to identify the contribution of school-related physical activity to total physical activity levels among children and adolescents in general, and the role of physical education in particular.

\section{Physical Activity and Health in Youth}

Physical activity levels are declining and physical inactivity is now the fourth leading risk factor for global mortality in adults (WHO, 2010). It is associated with adverse health outcomes such as cardiovascular disease, diabetes, cancer, hypertension, obesity, depression, osteoporosis and premature death (Warburton, Nicol, \& Bredin, 2006). Previous research has also produced convincing evidence in children and adolescents relating sufficient levels of physical activity to both short- and long-term health improvements in blood pressure, adiposity, cardiovascular health, mental health and musculoskeletal health (Janssen \& Leblanc, 2010; Strong et al., 2005). Nevertheless in most Western countries youth physical activity levels have declined in the past decades (Biddle, Gorely, \& Stensel, 2004). Therefore, the continuing decline in physical activity levels in children and adolescents is a major reason for concern. Physical activity behaviour during the younger years tends to carry-over into adulthood (Malina, 2006), which stresses the importance of establishing healthy physical activity behaviour during childhood and adolescence (Mechelen, Twisk, Post, Snel, \& Kemper, 2000). According to Health Behaviour in School-aged Children (HBSC) survey data from 41 countries and regions across north America and Europe less than half of the youth population currently meets the recommended daily 60 minutes of moderate-to-vigorous physical activity (Currie et al., 2008). Boys consistently report higher levels of physical activity than girls and physical activity tends to decline with increasing age. In the Netherlands a similar trend can be observed with only $22 \%$ of youth between 4-17 years reporting one hour of MVPA per day in 2009 (de Vries \& Chorus, 2010). 


\section{Physical Activity Guidelines for Children and Adolescents}

These declining physical activity levels in children and adolescents have led to the development of physical activity guidelines in order to inform the youth population as well as various stakeholders (e.g. parents, schools, healthworkers) on the recommended amount of physical activity in youth. Similar guidelines have been developed in various countries (table 1.1), some of which have received recent updates (Biddle, Sallis, \& Cavill, 1998; Janssen \& Leblanc, 2010; Strong et al., 2005). The current physical activity recommendation for Dutch youth states that: all youth should accrue one hour of moderate-to-vigorous physical activity per day, with activities aimed at enhancing or sustaining physical fitness (strength, flexibility, coordination) twice a week. Moderate intensity is defined as at least five metabolic equivalents (five times the rest metabolism or $5 \mathrm{METs}$ ). However, an updated version of this guideline will be published in the near future. Nevertheless, and as opposed to the adult guidelines on physical activity, the rationale for minimal and optimal doses needed for health benefits in youth are less clear. To illustrate, the current youth physical activity guideline states that physical activity can be accrued in 5-10 minute bouts, reflecting the intermittent physical activity pattern in most children. However, to date no conclusive evidence was found on how long an activity bout should last to produce health benefits in children and adolescents.

This also raises the question of how moderate and vigorous physical activities are defined in terms of energy expenditure. Physical activity intensity is commonly defined using metabolic equivalents or METs (Ainsworth et al., 2000). One MET representing an individual's energy expenditure while sitting quietly. An adult walking at normal speed (3 mph on a flat surface) expends about 3.3 METs, hence the term moderate physical activity as recommended in the physical activity guideline for adults. Moderate physical activity in adults is defined as 3-6 METs, while physical activity <3 METs is defined as light and physical activity $>3$ METs is defined as vigorous. However, a review of the literature on youth guidelines does not provide a decisive answer on how to define moderate and vigorous physical activity in youth in terms of MET values. Janssen and Leblanc (Janssen \& Leblanc, 2010) state in their review that moderate physical activity can be defined as 4 METs, although they also notice that a threshold of 3 METs is not uncommon for investigators, whereas in other studies a threshold of 5 METs is used (De Vries et al., 2009; Strong et al., 2005). Thus, the operationalization of moderate and vigorous physical activity can have a large impact on the extent to which youth populations comply to the physical activity guideline. This is clearly indicated in a study by De Vries et al. (2009) who found that, using accelerometers, the percentage of children meeting the 60-minute guideline varied from 0-100\% according to the intensity threshold used, the activity bout used (1, 5 or 10 minute bouts) and whether the guideline needed to be met on each day or could be averaged over multiple days. 
Table 1.1. Physical Activity Guidelines for Youth for the Netherlands, the United States, Canada and the United Kingdom

\begin{tabular}{|l|l|l|l|} 
& $\begin{array}{l}\text { Moderate/ } \\
\text { vigorous intensity PA }\end{array}$ & Vigorous intensity PA & $\begin{array}{l}\text { Moderate intensity } \\
\text { threshold }\end{array}$ \\
\hline $\begin{array}{l}\text { The Netherlands } \\
\text { (Kemper, Ooijendijk, \& } \\
\text { Stiggelbout, 2000) }\end{array}$ & $\geq 60 \mathrm{~min} /$ day & $\geq 3$ days / wk & $5 \mathrm{METs}$ \\
\hline $\begin{array}{l}\text { United States } \\
\text { (Strong et al., 2005) }\end{array}$ & $\geq 60 \mathrm{~min} /$ day & $\geq 3$ days / wk & $5 \mathrm{METs}$ \\
\hline $\begin{array}{l}\text { Canada1 } \\
\text { (Janssen \& Leblanc, 2010) }\end{array}$ & $\geq 60 \mathrm{~min} /$ day & $\geq 3$ days / wk & $4 \mathrm{METs}^{2}$ \\
\hline $\begin{array}{l}\text { United States } \\
\text { (Biddle, Sallis, \& Cavill, } \\
\text { 1998) }\end{array}$ & $\geq 60 \mathrm{~min} /$ day & $\geq 3$ days / wk & $5 \mathrm{METs}$ \\
\hline
\end{tabular}

Given the existing international differences between PA guidelines for youth, and the problems arising when translating physical activity research data into whether these guidelines are met, it should be noted that physical activity guidelines were not specifically designed to be used as a scientific point of reference but rather as an informative, easy-to-understand recommendation to the general population on how much physical activity is needed to obtain health benefits.

\section{Physical activity measurement in children and adolescents}

Methods to assess physical activity can be roughly split up in subjective and objective assessment-instruments. Subjective measures include questionnaires, interviews, activity diaries and direct observation, while objective measures include devices such as heart rate monitoring, accelerometry, pedometry and combined heart rate monitoring and accelerometry (combined sensing). However, physical activity behaviour consists of different dimensions, which include intensity, frequency and duration (which together comprise the volume of physical activity) as well as activity type and activity setting. Unfortunately, not one single method of physical activity assessment is able to capture all these dimensions simultaneously, since each method has distinct advantages and disadvantages (Welk, 2002; Welk, Corbin, \& Dale, 2000).

1 The recommendation was intentionally composed of two recommendations since the 60 minute guideline was estimated to be intimidating for very inactive youth, a group that obtains substantial health benefits already at a lower volume of physical activity. The other recommendation is that some health benefits can be obtained at 30 minutes of moderate physical activity per day.

2 Although the authors note that it is not uncommon for investigators to use 3 METs.

3 Because exercise energy expenditure per unit of body mass is higher in children and adolescents than in adults these MET values have limitations. 
In choosing an appropriate method of physical activity assessment in youth the research question of interest and the feasibility of the instrument in a particular situation (i.e. a free-living versus a laboratory setting) are most important (Corder, Ekelund, Steele, Wareham, \& Brage, 2008; Welk et al., 2000). The majority of studies that investigated physical activity levels in youth have used self-report measures, mainly due to their excellent costeffectiveness, which enables reaching a large research sample at relatively low costs (Naylor \& McKay, 2009; Sluijs, McMinn, \& Griffin, 2008). However, questionnaires are dependent on the recall capabilities of the respondents, and on language skills, which can both be problematic in young people (Chinapaw, Mokkink, van Poppel, van Mechelen, \& Terwee, 2010). Activity diaries can provide valuable information about the type and setting of physical activity. However, they also place a significant burden on the participant, might affect the behaviour of interest and intervals might be too long to capture short-term activities. If the specific outcome of interest is rather the type of physical activity and the setting or context in which the activity takes place, observation methods are more appropriate (McKenzie, Sallis, \& Nader, 1992). On the other hand, if the researcher is more interested in an accurate and time-stamped assessment of energy expenditure as an indicator of the amount of physical activity, combined sensing methods are available using branched equation modelling (Brage, Brage, Franks, Ekelund, \& Wareham, 2005; Brage et al., 2004; Corder, Brage, Wareham, \& Ekelund, 2005). An overview of advantages and disadvantages of objective methods to assess physical activity is depicted in table 1.2.

When measuring physical activity in young children one has to take into account that movement patterns in this population are very transitory and intermittent, with bouts of activity lasting only 10 seconds on average (Baquet, Stratton, Van Praagh, \& Berthoin, 2007). This has implications for the desired epoch length of objective instruments, and consequently for data storage capacity. Ultimately, to decide which instrument is most applicable, within the research question of interest a comparative assessment should be made of the validity of an instrument versus the feasibility of the instrument in the given situation.

\section{The school as an environment for increasing physical activity}

Since children and adolescents spend more than half of their waking hours in school for a sustained period of 6 to 12 years, schools have been designated as a promising context for combating the physical activity decline in children and adolescents (Ferreira et al., 2007; Naylor \& McKay, 2009). Schools are able to provide an environment for immediate improvements in physical activity and health, for example through physical education (Corbin, 2002a; Fairclough \& Stratton, 2005; Mckenzie \& Lounsbery, 2009), physical activity breaks in the classroom, recess periods (Verstraete, Cardon, De Clercq, \& De Bourdeaudhuij, 2006), extracurricular sports (Bocarro, Kanters, Casper, \& Forrester, 2008), active transportation to school (Chillón, Evenson, Vaughn, \& Ward, 2011; Tudor-Locke, Ainsworth, \& Popkin, 2001) and leisure time use of facilities. In addition, in order to establish a behavioural change towards a physically active lifestyle schools are also considered an important setting, for example through physical education (Corbin, 2002b; Haerens, Kirk, Cardon, \& Bourdeaudhuij, 2011; Mckenzie \& Lounsbery, 2009) and health education (Kahn et al., 2002). The potential of schools for increasing physical activity levels in children and adolescents is reflected in a considerable increase in the number of school-based physical activity intervention studies in recent years (see Demetriou \& Höner (2012) for an overview). The majority of these interventions were found successful in significantly increasing physical activity levels in children and adolescents, which demonstrates that schools can indeed exert influence on student physical activity (Demetriou \& Höner, 2012). 
Table 1.2. Summary characteristics of objective assessment methods for free-living physical activity in youth (adapted, with permission, from Corder et al. 2007)

\begin{tabular}{|c|c|c|c|c|}
\hline & Pedometry & Accelerometry & HR-monitoring & $\begin{array}{l}\text { Combined HR } \\
\text { and movement } \\
\text { registration }\end{array}$ \\
\hline Invasiveness & Not invasive & Not invasive & Can be bulky & Not invasive \\
\hline Cost & Inexpensive & Moderate & Moderate & Moderate to expensive \\
\hline Dimensions assessed & $\begin{array}{l}\text { Total steps: total daily } \\
\text { ambulatory PA }\end{array}$ & $\begin{array}{l}\text { Activity counts: total } \\
\text { daily PA, intensity, } \\
\text { frequency, duration }\end{array}$ & $\begin{array}{l}\text { Total daily PA, intensity, } \\
\text { frequency, duration }\end{array}$ & $\begin{array}{l}\text { Total daily PA, intensity, } \\
\text { frequency, duration }\end{array}$ \\
\hline Epoch length & Not applicable & $\begin{array}{l}\text { As short as possible, } \\
\text { preferably } \leq 5 \mathrm{~s}\end{array}$ & $\begin{array}{l}\text { As short as possible, } \\
\text { preferably } \leq 15 \mathrm{~s}\end{array}$ & $\begin{array}{l}\text { As short as possible, } \\
\text { preferably } \leq 15 \mathrm{~s}\end{array}$ \\
\hline $\begin{array}{l}\text { Length of } \\
\text { measurement }\end{array}$ & $\begin{array}{l}\text { Recommended at least } \\
4 \text { full days of } \\
\text { measurement with one } \\
\text { weekend day }\end{array}$ & $\begin{array}{l}\text { Recommended at least } \\
4 \text { full days of } \\
\text { measurement with one } \\
\text { weekend day }\end{array}$ & $\begin{array}{l}\text { Recommended at least } \\
4 \text { full days of } \\
\text { measurement with one } \\
\text { weekend day }\end{array}$ & $\begin{array}{l}\text { Recommended at least } \\
4 \text { full days of } \\
\text { measurement with one } \\
\text { weekend day }\end{array}$ \\
\hline \multirow[t]{2}{*}{ Recommended output } & Total steps per day & $\begin{array}{l}\text { Acceleration, time spent } \\
\text { at different movement } \\
\text { intensities }\end{array}$ & $\begin{array}{l}\text { Net HR, time spent at } \\
\text { different physiological } \\
\text { intensities }\end{array}$ & $\begin{array}{l}\text { Acceleration and Net } \\
\text { HR, time spent at } \\
\text { different physiological } \\
\text { and movement } \\
\text { intensities }\end{array}$ \\
\hline & & $\begin{array}{l}\text { More distal: daily PAEE } \\
\text { prediction }\end{array}$ & $\begin{array}{l}\text { More distal: } \\
\text { Instantaneous PAEE } \\
\text { prediction over } \\
\text { moderate intensity PAEE } \\
\text { prediction }\end{array}$ & $\begin{array}{l}\text { More distal: } \\
\text { Instantaneous and daily } \\
\text { PAEE prediction }\end{array}$ \\
\hline Application & $\begin{array}{l}\text { Large scale studies } \\
\text { assessing ambulatory PA }\end{array}$ & $\begin{array}{l}\text { Medium to large studies } \\
\text { assessing overall PA, } \\
\text { intensity frequency, or } \\
\text { duration }\end{array}$ & $\begin{array}{l}\text { Medium to large studies } \\
\text { assessing overall PA, } \\
\text { intensity frequency, or } \\
\text { duration }\end{array}$ & $\begin{array}{l}\text { Moderate-size studies } \\
\text { requiring an assessment } \\
\text { of PAEE }\end{array}$ \\
\hline $\begin{array}{l}\text { Validated during free } \\
\text { living in youth }\end{array}$ & Yes & Yes & Yes & Yes $^{4}$ \\
\hline Accuracy & $\begin{array}{l}\text { Accurate for assessing } \\
\text { steps during most } \\
\text { walking speeds }\end{array}$ & $\begin{array}{l}\text { Accurate estimation of } \\
\text { instantaneous PAEE } \\
\text { during flat locomotion } \\
\text { and sedentary activities, } \\
\text { variable accuracy in } \\
\text { other activities (heavily } \\
\text { dependent of inference } \\
\text { model) }\end{array}$ & $\begin{array}{l}\text { Accurate estimation of } \\
\text { instantaneous PAEE at } \\
\text { higher activity } \\
\text { intensities, especially } \\
\text { with good individual } \\
\text { calibration. In general, } \\
\text { poor accuracy at low } \\
\text { activity intensities }\end{array}$ & $\begin{array}{l}\text { Accurate estimation of } \\
\text { instantaneous PAEE } \\
\text { across all intensity levels }\end{array}$ \\
\hline
\end{tabular}

4 PAEE, physical activity energy expenditure, in a sample of college students 


\section{Physical education as a specific setting to increase physical activity}

Physical education could be of importance when aiming to increase physical activity levels in children and adolescents (Corbin, 2002a; Mckenzie \& Lounsbery, 2009; Pace, O'Neill, \& Mclver, 2011). Although varying in terms of lesson frequency and duration, physical education (PE) is compulsory in most Western school systems and thereby reaches virtually all youth. However, perhaps more than any other school subject, the primary aims of PE remain an on-going subject of debate. This is most likely due to the variety of different educational and societal benefits that are attributed to PE.

According to Bailey (2009) PE has the potential to contribute to children's development in four broad domains: physical, affective, social and cognitive. With regard to the physical domain some authors have reservations regarding the health claims attributed to PE (e.g. Evans, 2003) while others advocate a central role for physical education in stimulating physical activity and an active lifestyle (e.g. Corbin, 2002a; Fairclough \& Stratton, 2005; Haerens et al., 2011; Mckenzie \& Lounsbery, 2009). As a consequence health related PE goals have been adopted within position statement papers in the US (USDHHS, 2000) and the UK (AfPE, 2008) and, more recently, in the Netherlands (Brouwer et al., 2011). In short, the general aim of PE in the Netherlands has been defined as developing skills and attitudes in youth in order to facilitate their participation in different sports- and movement activities, employed from a pedagogical perspective and as part of a healthy and physically active lifestyle (Brouwer et al., 2011). More specifically, PE should introduce young people within a diversity of movement activities as well as develop various other skills such as organising, companionship, and knowledge and understanding of sport and movement activities.

Since PE has been put forward as a vehicle to stimulate youth to adopt a physically active lifestyle, there has been an increased interest in understanding the motivational processes underlying behaviour and psychological wellbeing in PE (Ntoumanis \& Standage, 2009). Most of the research in this area has been employed using the selfdetermination theory (SDT) as a theoretical framework. SDT is a comprehensive theory of human motivation (Deci \& Ryan, 2000; 1985; Ryan \& Deci, 2000) which assumes that if a person engages in an activity with a sense of volition or because the activity is estimated to be inherently interesting or personally valuable the motivation to engage in this behaviour is self-determined (autonomous) and will lead to more adaptive outcomes, such as greater psychological well-being and more persistent behaviour (Ryan \& Deci, 2000). The extent in which the social environment (e.g. a PE class) supports or nourishes the basic psychological needs for competence, autonomy and relatedness determines if people experience a sense of self-determination of behaviour (Deci \& Ryan, 2000).

Applied to a PE context this implies that if a student feels (physically) competent within PE, experiences freedom and choice and has a good relationship with the teacher and his peers he will be more intrinsically motivated and self-determined to put an effort into PE. SDT distinguishes itself from other motivational theories (e.g. self-efficacy theory (Bandura, 1989) because it takes into account not only the quantity but also the quality of motivation (Vansteenkiste, Sierens, Soenens, Luyckx, \& Lens, 2009). For example, a student that is highly motivated to pay attention in PE class due to a controlling measure taken by the teacher (i.e. punishment) will still show maladaptive behavioural outcomes since the quality of motivation is low (comes from an external source). 
The attractiveness of SDT in the context of PE is not surprising since its central tenets are highly relevant to the domain of PE (Ryan \& Deci, 2007). Using SDT as a starting point allows for an investigation into the impact of the social environment (e.g. teachers-student interactions, lesson subjects, pedagogy) on student motivation and on subsequent student behaviour. For example, studies grounded in SDT have provided evidence that an increased sense of autonomy in students is associated with higher autonomous motivation and higher physical activity levels during PE (Lonsdale, Sabiston, Raedeke, Ha, \& Sum, 2009), that an autonomy-supportive PE environment is associated with higher intentions to exercise and higher self-reported physical activity levels (Chatzisarantis \& Hagger, 2009; Hagger \& Chatzisarantis, 2007). Evidence also exists that higher levels of autonomous motivation for PE are associated with higher levels of autonomous motivation for exercise (Standage, Gillision, Ntoumanis, \& Treasure, 2012) and more physical activity as a young adult (Haerens, Kirk, Cardon, De Bourdeaudhuij, \& Vansteenkiste, 2010). Despite the large body of that has emerged from the SDT-based literature on the topic of PE several important issues remain unsolved. These include the effectiveness of interventions that adapt the PE environment to better fulfil students' need for competence, especially in low-ability and at-risk student populations. Also, studies investigating the association of autonomous motivation for PE and actual physical activity behaviour have almost exclusively relied on self-report measures, which calls for studies investigating this relation using more objective instruments (Ntoumanis \& Standage, 2009).

\section{Aims of the thesis}

Although schools and in particular PE are deemed important in combating decreasing physical activity levels, the evidence to support its effectiveness is still scarce. Therefore the main aim of this thesis is to explore the potential of physical education as a school subject to contribute to and impact on physical activity levels in youth.

\section{The main study objectives were:}

1. to determine the contribution of PE lessons to recommended physical activity levels in children and adolescents.

2. to determine the contribution of PE and other physical activity opportunities, such as active transportation and leisure time sports to total physical activity levels.

3. to identify effective strategies to increase physical activity levels during PE.

4. to explore the role of motivation for PE in adopting a physically active lifestyle.

\section{Outline of the thesis}

Chapter 2 is a narrative review of intervention studies that have used a PE component. A distinction is made between the potential direct and indirect effect on physical activity levels in children and adolescents. The effectiveness of various PE-based physical activity interventions is reviewed and critically discussed. The study in Chapter 3 provides insight into the contribution of $\mathrm{PE}$, active transport and leisure time activities to total physical activity energy expenditure in adolescents. Chapter 4 then specifically focuses on the contribution of primary and secondary school PE to recommended levels of physical activity in children and adolescents and reports on various lesson characteristics of influence. Chapter 5 describes an intervention study employing different strategies to increase physical activity levels during secondary school. Employing the data from Chapter 3, Chapter 7 then goes on to explore the relationship between motivation for PE and levels of physical activity in different contexts. Subsequently, chapter 6 investigates the effect of a single gender grouping strategy as compared to a traditional mixed-gender grouping strategy on perceived competence and physical activity in girls. In chapter 8 the research findings in this thesis are put into a broader perspective and are critically discussed. Practical recommendations to the field of PE are made as well as recommendations for future research. 


\section{References}

Association for Physical Education (afPE) (2008). "Health Position Paper." Physical Education Matters, 3, 8-12.

Ainsworth, B., Haskell, W., Whitt, M., Irwin, M., Swartz, A., Strath, S., et al. (2000). Compendium of physical activities: an update of activity codes and MET intensities. Medicine And Science In Sports And Exercise, 32(9 Suppl (Print)), S498-504.

Andersen, L. B., Harro, M., Sardinha, L. B., Froberg, K., Ekelund, U., Brage, S., \& Anderssen, S. A. (2006). Physical activity and clustered cardiovascular risk in children: a cross-sectional study (The European Youth Heart Study). The Lancet, 368(9532), 299-304. doi:10.1016/S0140-6736(06)69075-2

Bailey, R., Armour, K., Kirk, D., Jess, M., Pickup, I., \& Sandford, R. (2009). The educational benefits claimed for physical education and school sport: an academic review. Research Papers in Education, 24(1), 1-27.

Bandura, A. (1989). Human Agency in Social Cognitive Theory. American Psychologist, 44(9), 1175-11751 184.

Baquet, G., Stratton, G., Van Praagh, E., \& Berthoin, S. (2007). Improving physical activity assessment in prepubertal children with high-frequency accelerometry monitoring: A methodological issue. Preventive Medicine, 44(2), 143-147. doi:10.1016/j.ypmed.2006.10.004

Biddle, S. J. H., Gorely, T., \& Stensel, D. J. (2004). Health-enhancing physical activity and sedentary behaviour in children and adolescents. Journal of Sports Sciences, 22(8), 679-701.

Biddle, S., Sallis, J., \& Cavill, N. (1998). Young and active? Young people and health-enhancing physical activity evidence and implications. Health Education Authority, 1-182. doi:http://www.nice.org.uk/502301

Bocarro, J., Kanters, M., Casper, J., \& Forrester, S. (2008). School Physical Education, Extracurricular Sports, and Lifelong Active Living. Journal of Teaching in Physical Education, 27(2), 155-166.

Brage, S., Brage, N., Franks, P., Ekelund, U., \& Wareham, N. (2005). Reliability and validity of the combined heart rate and movement sensor Actiheart. European Journal of Clinical Nutrition, 59(4), 561-570.

Brage, S., Brage, N., Franks, P., Ekelund, U., Wong, M., Andersen, L., et al. (2004). Branched equation modeling of simultaneous accelerometry and heart rate monitoring improves estimate of directly measured physical activity energy expenditure. Journal Of Applied Physiology, 96(1), 343.

Brouwer, B., Aldershof, A., Bax, H., van Berkel, M., van Dokkum, G., Mulder, M. J., \& Nienhuis, J. (2011). Human movement and sports in 2028. Een blik in de toekomst van lichamelijke opvoeding/bewegingsonderwijs en sport op school. (B. Brouwer, Ed.), 1-80.

Chatzisarantis, N., \& Hagger, M. (2009). Effects of an intervention based on self-determination theory on selfreported leisure-time physical activity participation. Psychology \& Health, 24.

Chillón, P., Evenson, K. R., Vaughn, A., \& Ward, D. S. (2011). A systematic review of interventions for promoting active transportation to school. International Journal of Behavioral Nutrition and Physical Activity, 8(1), 10. doi:10.1186/1479-5868-8-10

Chinapaw, M. J. M., Mokkink, L. B., van Poppel, M. N. M., van Mechelen, W., \& Terwee, C. B. (2010). Physical activity questionnaires for youth: a systematic review of measurement properties. Sports Medicine, 40(7), 539-563.

Corbin, C. (2002a). Physical Activity for Everyone: What Every Educator Should Know About Promoting Lifelong Physical Activity. Journal of Teaching in Physical Education, 21(2), 128-144.

Corbin, C. (2002b). Physical Education as an Agent of Change. Quest, 54(3), 181-195.

Corder, K., Brage, S. R., Wareham, N., \& Ekelund, U. (2005). Comparison of PAEE from Combined and Separate Heart Rate and Movement Models in Children. Medicine And Science In Sports And Exercise, 37(10), 17611767. 
Corder, K., Ekelund, U., Steele, R., Wareham, N., \& Brage, S. (2008). Assessment of physical activity in youth. Journal Of Applied Physiology, 105(3), 977-987.

Currie, C., Gabhain, S. N., Godeau, E., Roberts, C., Smith, R., Currie, D., et al. (2008). Inequalities in young people's health: HBSC international report from the 2005/2006 Survey. Health Policy for Children and Adolescents, (No. 5), 1-224.

De Vries, S. I., Hopman-Rock, M., Bakker, I., \& van Mechelen, W. (2009). Meeting the 60-min physical activity guideline: effect of operationalization. Medicine And Science In Sports And Exercise, 41(1), 81-86. doi:10.1249/MSS.0b013e318184c931

De Vries, S., \& Chorus, A. (2010). Bewegen in Nederland: jeugdigen van 4-17 jaar. In V. H. Hildebrandt, A. M. J. Chorus, \& J. H. Stubbe (Eds.), Trendrapport Bewegen en Gezondheid 2008/2009 (pp. 57-76). Leiden: De Bink, Leiden, the Netherlands.

Deci, E. L., \& Ryan, R. M. (2000). The" what" and" why" of goal pursuits: Human needs and the selfdetermination of behavior. Psychological Inquiry, 11(4), 227-268.

Deci, E., \& Ryan, R. (1985). Intrinsic motivation and self-determination in human behavior. Berlin: Springer.

Demetriou, Y., \& Höner, O. (2012). Physical activity interventions in the school setting: A systematic review. Psychology of Sport and Exercise, 13(2), 186-196. doi:10.1016/j.psychsport.2011.11.006

Evans, J. (2003). Physical Education and Health: a Polemic or "Let Them Eat Cake!." European Physical Education Review, 9(1), 87-101. doi:10.1177/1356336X03009001182

Fairclough, S., \& Stratton, G. (2005). Physical Activity Levels in Middle and High School Physical Education: A Review. Pediatric Exercise Science, 17(3), 217-236.

Ferreira, I., van der Horst, K., Wendel Vos, W., Kremers, S., Van Lenthe, F., \& Brug, J. (2007). Environmental correlates of physical activity in youth-a review and update. Obesity Reviews, 8(2), 129-154.

Haerens, L., Kirk, D., Cardon, G., \& Bourdeaudhuij, I. D. (2011). Toward the Development of a Pedagogical Model for Health-Based Physical Education. Quest, 63, 321-338.

Haerens, L., Kirk, D., Cardon, G., De Bourdeaudhuij, I., \& Vansteenkiste, M. (2010). Motivational Profiles for Secondary School Physical Education and Its Relationship to the Adoption of a Physically Active Lifestyle among University Students. European Physical Education Review, 16(2), 117-139.

Hagger, M. S., \& Chatzisarantis, N. L. D. (2007). The Trans-Contextual Model of Motivation. In M. S. Hagger \& N. L. D. Chatzisarantis (Eds.), Intrinisic Motivation and Self-Determination in Exercise and Sport (pp. 53-70). Champaign, IL: Human Kinetics.

Janssen, I., \& Leblanc, A. G. (2010). Systematic review of the health benefits of physical activity and fitness in school-aged children and youth. The International Journal Of Behavioral Nutrition And Physical Activity, 7(1), 40. doi:10.1186/1479-5868-7-40

Kahn, E., Ramsey, L., Brownson, R., Heath, G., Howze, E., Powell, K., et al. (2002).

The effectiveness of interventions to increase physical activity. A systematic review. American Journal of Preventive Medicine, 22(4 Suppl), 73-107.

Kemper, H., Ooijendijk, W., \& Stiggelbout, M. (2000). Consensus over de

Nederlandse Norm voor Gezond Bewegen. Tijdschr Soc Gezondheidsz, 78, 180-183.

Lonsdale, C., Sabiston, C., Raedeke, T., Ha, A., \& Sum, R. (2009). Self-determined motivation and students' physical activity during structured physical education lessons and free choice periods. Preventive Medicine, 48 , 69-73.

Malina, R. (2006). Youth Physical Activity: Implications for Adult Physical Activity and Health. Studies in Physical Culture \& Tourism, 13(Suppl.), 29-33. 
McKenzie, T. L., \& Lounsbery, M. A. F. (2009). School Physical Education: The Pill Not Taken. American Journal of Lifestyle Medicine, 3(3), 219-225. doi:10.1177/1559827609331562

McKenzie, T., Sallis, J., \& Nader, P. (1992). SOFIT: System for Observing Fitness Instruction Time. Journal of Teaching in Physical Education, 11(2), 195-205.

Mechelen, W., Twisk, J., Post, G., Snel, J., \& Kemper, H. (2000). Physical activity of young people: the Amsterdam Longitudinal Growth and Health Study. Medicine And Science In Sports And Exercise, 32(9), 1610-1616.

Naylor, P., \& McKay, H. (2009). Prevention in the first place: schools a setting for action on physical inactivity. British Journal of Sports Medicine, 43.

Ness, A. R., Leary, S. D., Mattocks, C., Blair, S. N., Reilly, J. J., Wells, J., et al. (2007). Objectively Measured Physical Activity and Fat Mass in a Large Cohort of Children. PLoS Medicine, 4(3), e97. doi:10.1371/journal. pmed.0040097

Ntoumanis, N., \& Standage, M. (2009). Motivation in physical education classes: A self-determination theory perspective. Theory and Research in Education, 7(2), 194-202.

Pate, R. R., O’Neill, J., \& Mclver, K. (2011). Physical Activity and Health: Does Physical Education Matter? Quest, 63, 19-35.

Ryan, R. M., \& Deci, E. L. (2000). Self-Determination Theory and the Facilitation of Intrinsic Motivation, Social Development, and Well-Being. American Psychologist, 55(1), 68-78.

Ryan, R. M., \& Deci, E. L. (2007). Active Human Nature: Self-Determination Theory and the Promotion and Maintenance of Sport, Exercise and Health. In M. D. Hagger \& N. L. D. Chatzisarantis (Eds.), Intrinsic motivation and self-determination in exercise and sport. Human Kinetics Publishers.

Sluijs, E., McMinn, A., \& Griffin, S. (2008). Effectiveness of interventions to promote physical activity in children and adolescents: systemic review of controlled trials. British Journal of Sports Medicine, 42(8), 653-657.

Standage, M., Gillision, F. B., Ntoumanis, N., \& Treasure, D. C. (2012). Predicting Students' Physical Activity and Health-Related Well-Being: A Prospective Cross-Domain Investigation of Motivation Across School Physical Education and Exercise Settings. Journal of Sport and Exercise Psychology, 34, 37-60.

Strong, W., Malina, R., Blimkie, C., Daniels, S., Dishman, R., Gutin, B., et al. (2005). Evidence based physical activity for school-age youth. The Journal Of Pediatrics, 146(6), 732-737.

Tudor-Locke, C., Ainsworth, B., \& Popkin, B. (2001). Active Commuting to School: An Overlooked Source of Childrens Physical Activity? Sports Medicine, 31(5), 309-313.

USDHHS. (2000). Healthy People 2010. Washington D.C.: Government Printing Office.

Vansteenkiste, M., Sierens, E., Soenens, B., Luyckx, K., \& Lens, W. (2009). Motivational profiles from a selfdetermination perspective: The quality of motivation matters. Journal of Educational Psychology, 101(3), 671-688. doi:10.1037/a0015083

Verstraete, S., Cardon, G., De Clercq, D., \& De Bourdeaudhuij, I. (2006). Increasing children's physical activity levels during recess periods in elementary schools: the effects of providing game equipment. European Journal of Public Health, 16(4), 415-419.

Warburton, D., Nicol, C., \& Bredin, S. (2006). Health benefits of physical activity: the evidence. Canadian Medical Association Journal, 174(6), 801-809.

Welk, G. (2002). Physical activity assessments for health-related research. Human Kinetics: Champaign, IL.

Welk, G., Corbin, C., \& Dale, D. (2000). Measurement Issues in the Assessment of Physical Activity in Children. Research Quarterly For Exercise And Sport, 71(2), 59-73.

WHO. (2010). Global Recommendations on Physical Activity for Health, 1-60. 


\section{CHAPTER 2}

\section{DIRECT AND INDIRECT INFLUENCE OF PHYSICAL EDUCATION-BASED INTERVENTIONS ON PHYSICAL ACTIVITY: A REVIEW}

SLINGERLAND, M. \& BORGHOUTS L.B.

JOURNAL OF PHYSICAL ACTIVITY AND HEALTH 2011 (8) 866-8781

1 The spelling and reference style in this chapter are in line with the guidelines of the Journal of Physical Activity and Health. The spelling and reference style in this chapter are in line with the guidelines of the Journalo 


\section{Summary}

Background: Physical education (PE) has the potential of stimulating physical activity (PA) in children and adolescents in a direct and an indirect manner. By providing in-class activity, PE could directly contribute to the accumulation of physical activity. In addition, it is often claimed that PE could have an effect on physical activity by stimulating out-of-class activity, or even physical activity in adult life.

Methods: We reviewed intervention studies using a PE component that directly or indirectly aimed to increase physical activity in primary and secondary school students. An electronic literature search was conducted and articles' reference lists were scanned for additional papers.

Results: Fourteen studies matched our criteria. A review of these studies showed that interventions are able to directly increase activity in PE classes with relatively simple modifications, whereas the evidence for increasing out-of-class PA through interventions utilizing PE as a component is less convincing.

Conclusions: We propose that evidence based interventions aimed at increasing PA in children and adolescents through PE should at this moment be aimed at the direct effect of PE. There is a need for high quality PE-based interventions directed at out-of-class activity and long-term active life style. 
Physical inactivity and overweight represent two of the greatest threats to public health in modern society. A large number of studies have reported physical activity (PA) as an important factor in the primary and secondary prevention of multiple chronic health conditions. ${ }^{1}$ It is an independent factor in the prevention of colon cancer, osteoporosis, depression and overweight.2, ${ }^{3}$ Overweight may lead to obesity, which is a leading risk factor for premature death and numerous chronic health conditions, such as type II diabetes and cardiovascular disease, that reduce the overall quality of life in adults. ${ }^{4}$ Overweight and obesity are also a rising problem in children and adolescents. ${ }^{5,6}$ Unfortunately childhood obesity has a tendency to track into adulthood. ${ }^{7,8}$ This makes it a major risk factor for developing type II diabetes at an early adult age with an increased risk for cardiovascular disease. ${ }^{9}$ A positive balance in energy consumed compared to energy expended results in weight gain, which may lead to obesity. Although the aetiology of obesity comprises a complex interaction between genetic and behavioral factors, increasing children's energy expenditure through PA and/or decreasing energy intake are key in the prevention of obesity. The underlying mechanisms that influence children's PA behaviour include determinants such as safe neighborhood environments, support from significant others and PA-related school policies. ${ }^{10}$ Rowland"1 concluded from a review of the literature that "the rationale for improving the long-term health of children by improving and maintaining habits of regular physical activity is well founded" (p. 935). Unfortunately, a large part of the youth population in North America, Great Britain and (South-) Western Europe does not meet the criteria for health-enhancing PA. ${ }^{12}$ Furthermore, activity in children and adolescents has a tendency to decrease with age. ${ }^{13-15}$ This stresses the importance of adopting a physically active lifestyle at an early age.

Physical Education (PE) has great potential to make a contribution to increasing PA in youth and therefore in reversing the trend of decreasing PA with age. PE, being an integrated part of the total school curriculum, has tremendous reach in terms of promoting PA because most children and adolescents regularly attend school. ${ }^{16}$ Therefore, it has been stated that PE programs, when combined with other school, family and community-based PA opportunities, can make a meaningful contribution to children's PA levels. ${ }^{17}$ It has been established in the PA literature that PE has the potential to contribute to the promotion of PA in youth in a direct and an indirect manner (figure 2.1). PE itself could be a source of PA by contributing directly to the daily accumulation of PA ${ }^{18,19}$, as advised in youth PA-guidelines ${ }^{20-22}$. Indirectly, PE could promote out-of-class PA and a sustained physically active lifestyle. ${ }^{23,24}$ The purpose of this paper is to review the evidence for the direct and indirect effects of PE-based interventions on PA. This may enhance our understanding of the potential role of PE in promoting PA. Finally, evidence based recommendations will be given on how to optimize the effect of PE on PA.

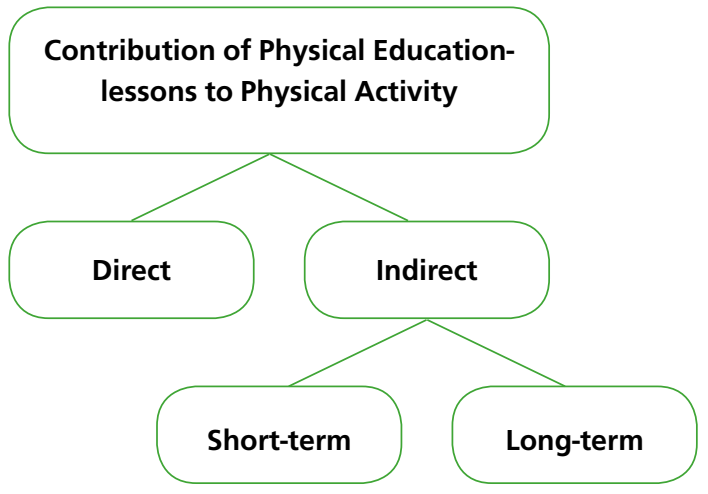

Figure 2.1 Direct and indirect contribution of physical education to physical activity 


\section{Method}

We carried out an electronic literature search using Medline, Academic Search Premier and SportDiscus. Inclusion criteria were the following: 1) the intervention was school-based, 2) used modified PE (content/frequency/ duration) as a component, 3) physical activity was reported 4) was published between 1989-2009 5) was reported in English. Combinations of the following search terms were entered into the databases: intervention, schools, physical education, moderate-to-vigorous physical activity (MVPA) and physical activity. Additionally, articles' reference lists were searched for additional papers. Initially 15 studies were included for analysis. However after further analysis 1 study was excluded because mean overall effect size and significance were not reported. ${ }^{25}$

\section{Direct effect: PE-interventions aimed at increasing in-class physical activity}

Specific physical activity guidelines for adolescents were first developed by Sallis and Patrick. ${ }^{21}$ In the UK, a Consensus Statement on Physical Activity Guidelines for children was published in 2001, which applied to youth 5-18 years of age. ${ }^{26}$ Although physical activity guidelines may differ slightly between countries, their outlines are usually similar. A minimum frequency, duration and intensity for physical activity, defined on a weekly basis. Recently, the US Department of Health and Human Services has published updated guidelines that state that children and adolescents (6-17 years of age) should do at least 60 minutes of moderate-to-vigorous physical activity (MVPA), with the addition that three times a week PA-intensity should at least be vigorous. ${ }^{22}$ At this moment in time, the focus is mainly on MVPA, although discussion is arising to also include guidelines on time spent in sedentary behaviour. ${ }^{27}$

If PE delivers a certain amount of MVPA, it would be interesting to quantify its contribution to the physical activity recommendations. School-based PE has the potential to provide a regular and structured context for PA in children and adolescents. It has been suggested that for some children PE may deliver the only MVPA they experience during a week. ${ }^{28,29}$ For example, according to Westerstahl30, 30\% of the 16-year olds in Sweden receive all of their MVPA from PE-lessons. If these investigations are correct, PE could potentially compensate for the increasing prevalence of inactivity of children outside of school. However, abovementioned studies relied on survey-methods to quantify MVPA from PE and other sources. These methods are notably inaccurate for the quantification of physical activity. ${ }^{31}$ There is only very limited evidence on the amount of activity that PE contributes to total MVPA in youth from objective measures, ranging from $8 \%$ based on accelerometry ${ }^{32}$ to $18 \%$ as pedometer step-counts. ${ }^{33}$ Taken together, research reports do suggest that if PE provides enough in-class physical activity, it could make a significant contribution to the daily accumulation of MVPA needed for health benefits according to the PA-guidelines, but more studies using objective methodology are needed to further support this view.

Several studies have determined the amount of MVPA in PE. In elementary school classes taught under non-intervention conditions, students engaged in MVPA for 34\% of lesson time. ${ }^{34}$ In middle and high school, students engaged in MVPA for $27 \%$ to $47 \%$ of regular non-intervention PE-class time. ${ }^{35}$ This has led to the conclusion that regular PE-classes do not contribute to a large extent to the PA-guidelines for children and adolescents. ${ }^{36}$ Nonetheless, in the US and the UK initiatives have been employed that call for a minimum engagement of $50 \%$ of PE lesson time in MVPA. ${ }^{37,38}$ We therefore deem it relevant to evaluate approaches that have been taken to increase PA during PE lessons. A number of interventions have been carried out aimed at increasing MVPA during PE. Table 2.1 provides insight into the magnitude of the effects in these PE-based interventions. 
Table 2.1. Primary \& secondary school interventions aimed at increasing MVPA during PE lessons

\begin{tabular}{|c|c|c|c|c|c|c|c|c|c|c|}
\hline & 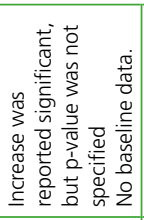 & & 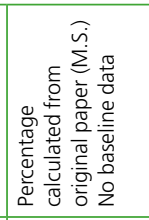 & & & & 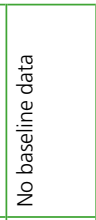 & & & \\
\hline & 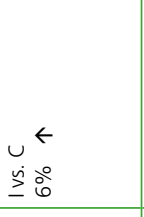 & 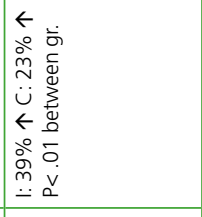 & 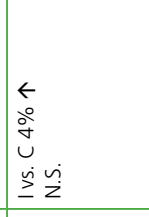 & 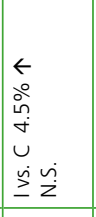 & 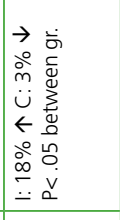 & 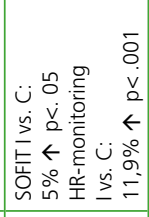 & 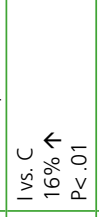 & 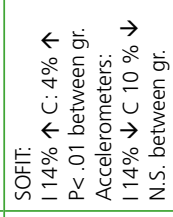 & 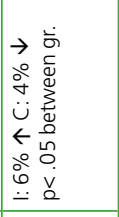 & \\
\hline & 营 & 咅 & 咅 & 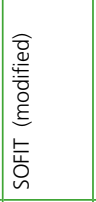 & 立 & 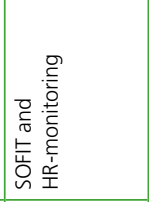 & 咅 & 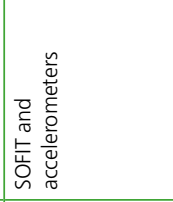 & 产 & \\
\hline & 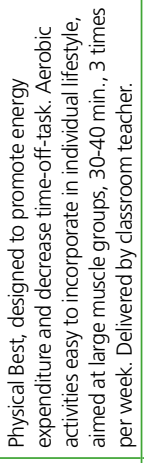 & 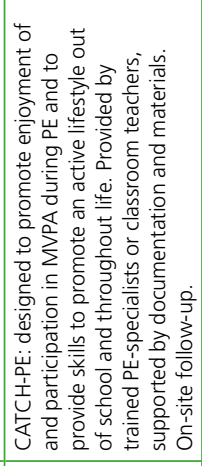 & 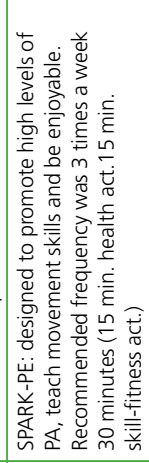 & 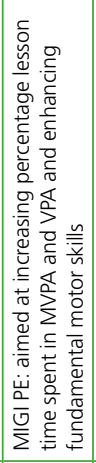 & 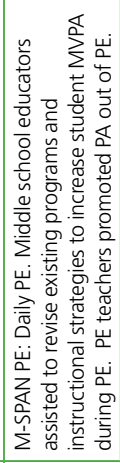 & 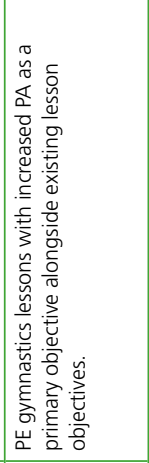 & 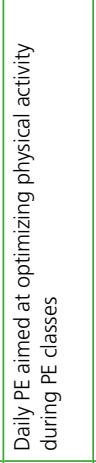 & 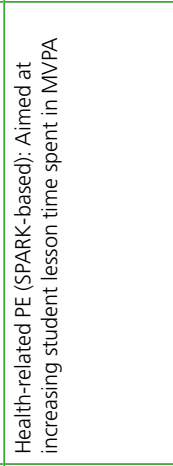 & 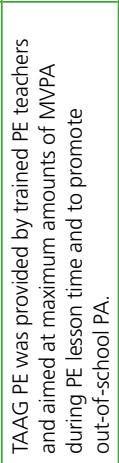 & \\
\hline & 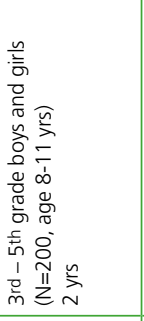 & 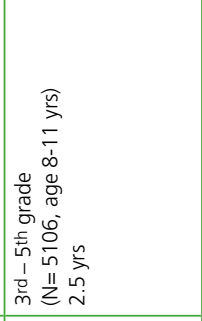 & 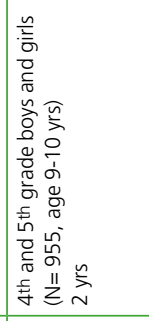 & 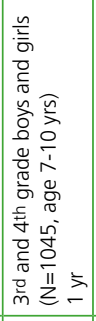 & 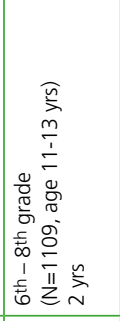 & 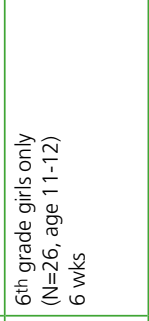 & 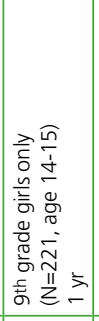 & 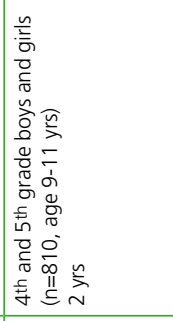 & 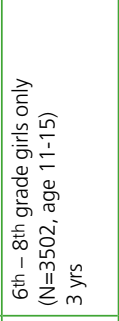 & 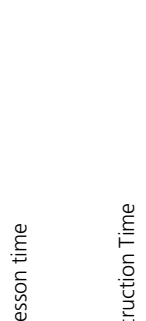 \\
\hline & 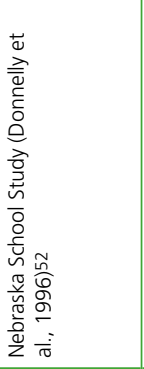 & 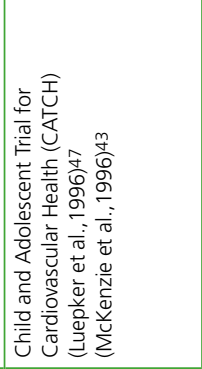 & 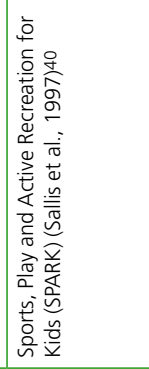 & 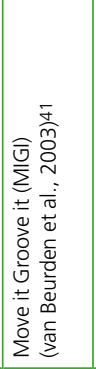 & 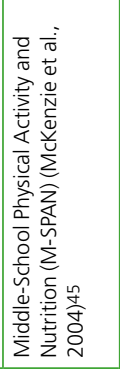 & 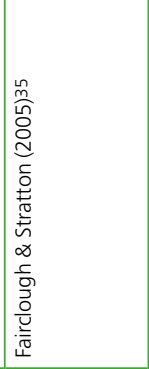 & 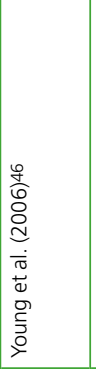 & 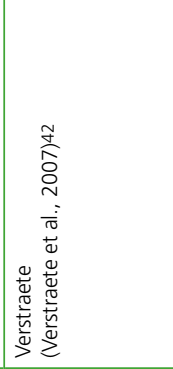 & 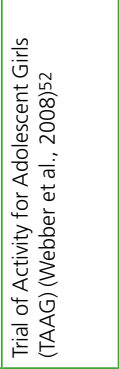 & 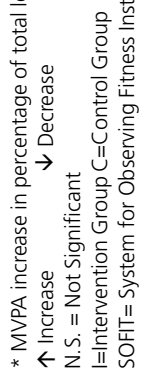 \\
\hline
\end{tabular}


With the exception of one study ${ }^{39}$, all included interventions were evaluated using SOFIT, which enables an accurate comparison of effects. With the exception of two studies ${ }^{40,41}$, all studies significantly increased in-class PA. Therefore, it appears that if lessons are planned and delivered with MVPA goals in mind, their contribution to the accumulation of PA in young people can be enhanced. Strategies that have been proven to be effective in increasing percentage lesson time in MVPA vary from maximizing inclusion by adjusting activities ${ }^{39,42}$, teaching PE teachers to better manage and organize PE classes ${ }^{39,43}$, providing a PE curriculum that increases intrinsic motivation in students ${ }^{34}$, to providing schools with specialized PE teachers ${ }^{41}$ and with more PE materials. ${ }^{42,43}$

At least three intervention studies mentioned in Table 2.1 surpassed the criterion of spending $50 \%$ of PE lesson time in MVPA ${ }^{42-44}$ while other interventions approached this criterion. ${ }^{45,}{ }^{46}$ The maximal increases in MVPA in intervention vs. control were $16 \%, 43,46,47$ However, the actual contribution to meeting children's PA guidelines (60 minutes per day) was relatively low. For example, the PE-specialist led condition in the SPARK program supplied an average of 40 minutes of MVPA per week, which is only $13.3 \%$ of the total amount of weekly MVPA recommended in the guidelines..$^{41}$ In the Flanders PE intervention, average total weekly MVPA provided by PE was 56 minutes, which is $18.6 \%$ of total weekly MVPA. Obviously, increasing scheduled PE time will have a much larger effect on PA than the described PE-lesson based interventions. Often however, schools will not be willing or able to increase PE time, mostly due to limited resources or a lack of governmental funding and support. Also schools are often afraid that by decreasing time spent on academic subjects, academic attainment will be reduced. There is, however, a strong body of evidence indicating that extra time allocated to PE does not compromise academic achievement, even if PE is introduced in place of academic class time. ${ }^{48}$ Interventions that manage to significantly increase MVPA in the limited time allocated to PE in the school curriculum can be considered successful. As a result, modifying school based-PE can be seen as an effective and evidence based intervention strategy for increasing levels of PA in children and adolescents.

\section{Indirect effect: PE-based interventions aimed at increasing out-of-class PA}

In the field of PE there seems to be a general consensus that one of the major aspirations of PE is to influence the next generation of adults to adopt a lifelong physically active lifestyle. ${ }^{17,49}$ Exposure to a broad variety of structured movement activities during PE is generally seen as the primary way to achieve this goal. For this reason and because virtually all children can be reached through schools, PE often plays a key role in interventions to improve sustained PA participation. ${ }^{50}$ Unfortunately, little is known about the effectiveness of PE in interventions aimed at promoting out-of-class PA. We identified 6 primary school studies and 7 secondary school studies that have included PE as an intervention component and were explicitly aimed at increasing out-of-class PA. However, part of these studies also targeted in-class PA levels. $41-43,45-47,51-54$. 
Table 2.2. Primary school-based interventions reporting out-of-class physical activity

\begin{tabular}{|c|c|c|c|c|c|}
\hline 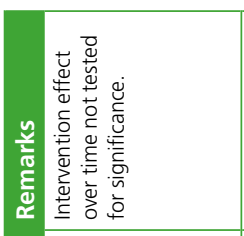 & 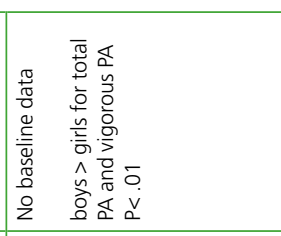 & 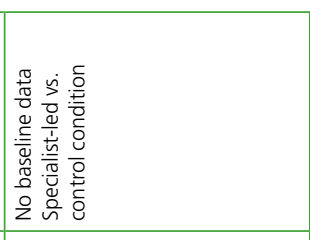 & & 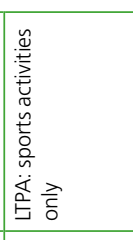 & 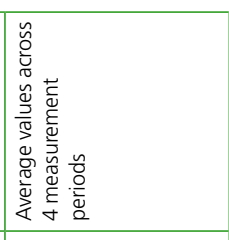 \\
\hline 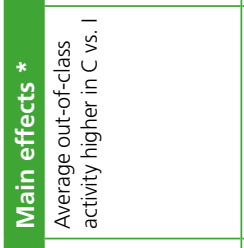 & 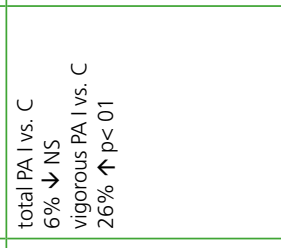 & 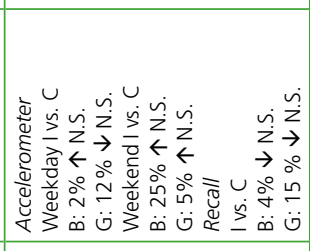 & 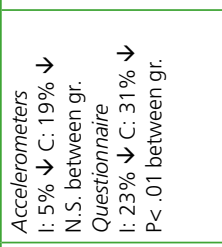 & 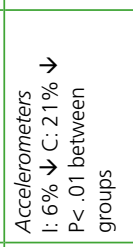 & 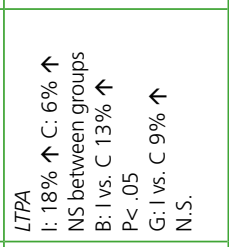 \\
\hline & 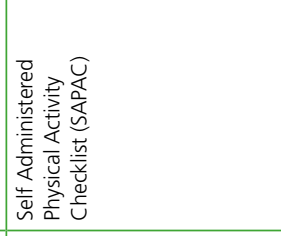 & 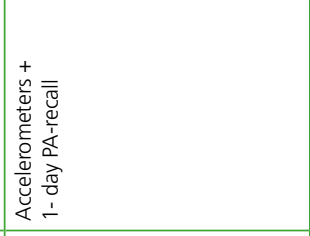 & 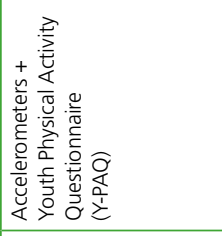 & 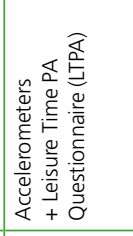 & 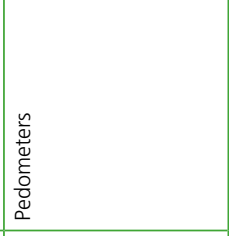 \\
\hline 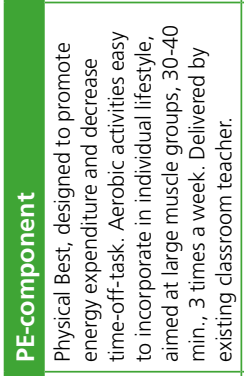 & 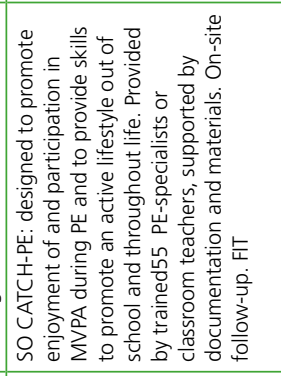 & 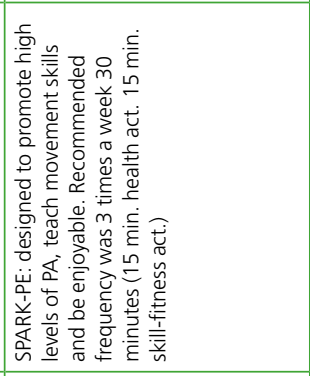 & 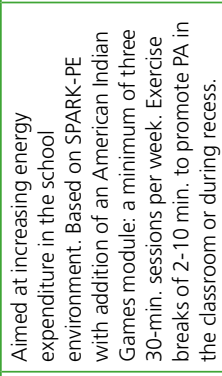 & 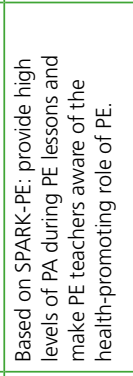 & 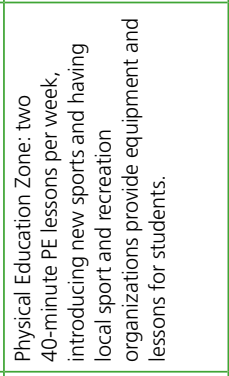 \\
\hline 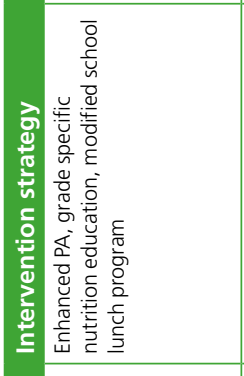 & 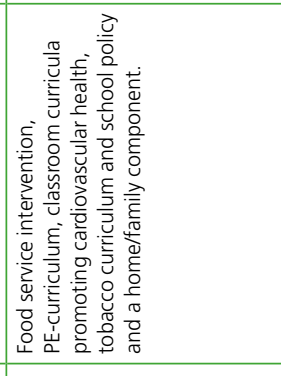 & 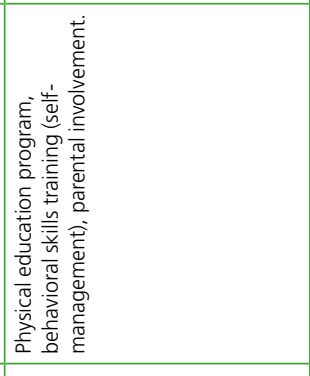 & 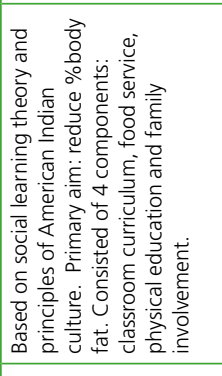 & 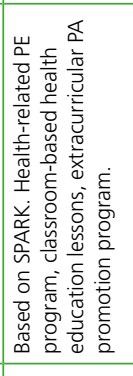 & 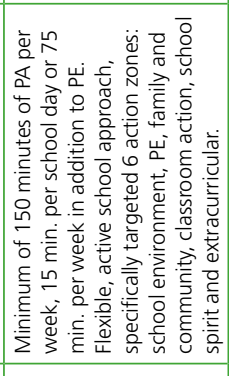 \\
\hline 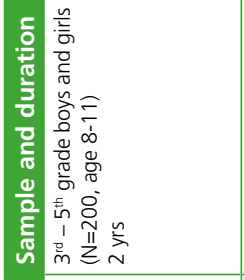 & 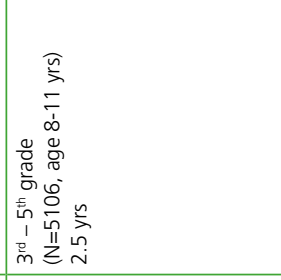 & 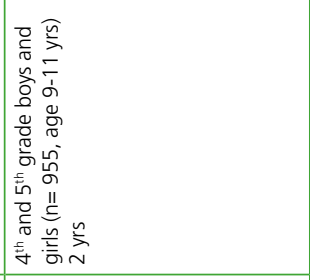 & 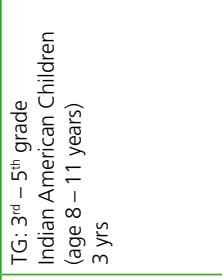 & 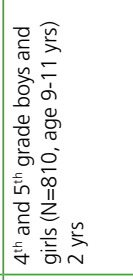 & 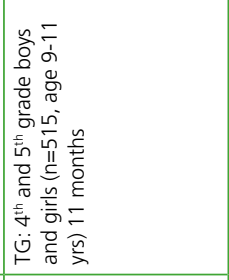 \\
\hline 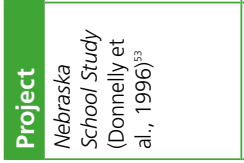 & 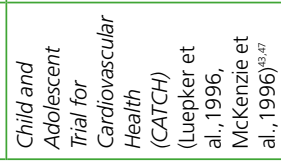 & 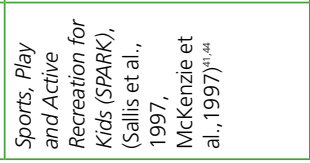 & 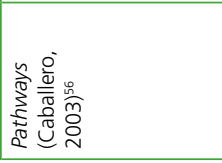 & 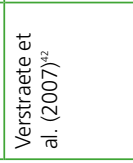 & 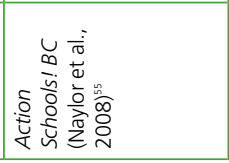 \\
\hline
\end{tabular}




\section{Primary school interventions.}

In Table 2.2 an overview is presented of the effects of primary school interventions aimed at increasing out-ofclass PA, which have included PE as an intervention component. Out of six studies, $\mathrm{CATCH}^{43,47}$ was the only study that reported higher levels of PA in the intervention group in both boys and girls, while Action Schools BC! reported higher PA levels in boys but not girls ${ }^{55}$. However, CATCH was essentially cross-sectional, since no pre-intervention (baseline) data were gathered. It therefore remains uncertain whether the reported differences were brought about by the intervention. In contrast, the design of the Pathways study ${ }^{56}$ and the SPARK-based study by Verstraete ${ }^{42,54}$ were longitudinal. Both reported decreases in PA over time, however these decreases were significantly smaller in the intervention groups. It is known that there is a trend for children to decrease their activity levels with advancing age ${ }^{57}$. These results could therefore be taken to suggest that this decline can be attenuated by PE-based interventions. The remaining two studies reported either no significant effects ${ }^{41}$ or an apparent adverse effect on $\mathrm{PA}^{53}$. Notably, the former study lacked baseline measurements while the latter failed to report a statistical test for the intervention effect over time. These results should therefore be interpreted with caution. All primary school interventions were focused on either grades 3 to 5 (age 8-11). We therefore suggest that more primary school intervention studies be targeted at younger children. It could tentatively be argued that establishing a sustained increase in out-of-class PA might be more effective if this behaviour was targeted at a younger age, since patterns of physical (in)activity may not yet have developed.

\section{Secondary school interventions.}

In Table 2.3 an overview is presented of the effects of secondary school-based interventions with a PE-component aimed at out-of-class PA. Seven interventions were identified. Project Active Teens ${ }^{58}$, M-SPAN ${ }^{45}$, 51, Planet Health ${ }^{59}$ and the Planning to be Active ${ }^{60}$ interventions were all aimed at both genders and most of these studies reported effects for boys and girls separately. Except for Planet Health, all studies reported modest but significant PA increases in the intervention over the control group in boys. However, none reported significant effects for girls. For instance, in M-SPAN boys increased their PA both during PE as well as out of PE, while the slight and nonsignificant increase in the overall PA in girls was caused mainly by the direct contribution of PE lessons. This indicates that primarily boys being more motivated to be physically active outside of PE class could explain the gender difference in M-SPAN. This increase in PA in boys was accompanied by a significant intervention effect on BMI.

The notable lack of effects in girls has in recent years lead to, various interventions explicitly aimed at increasing PA levels in girls. LEAP/LEAP $2^{61,62}$ and TAAG 52 both used a multi-component approach while another intervention ${ }^{46}$ solely focused on PE to increase out-of-class PA. The interventions using a multi-component approach were moderately successful in countering age-related decline in PA in girls. The PE-only based intervention, despite being successful in increasing in-class PA, showed no significant difference in out-of-class PA between intervention and control groups after one year. 
Table 2.3. Secondary school-based interventions reporting out-of-class physical activity

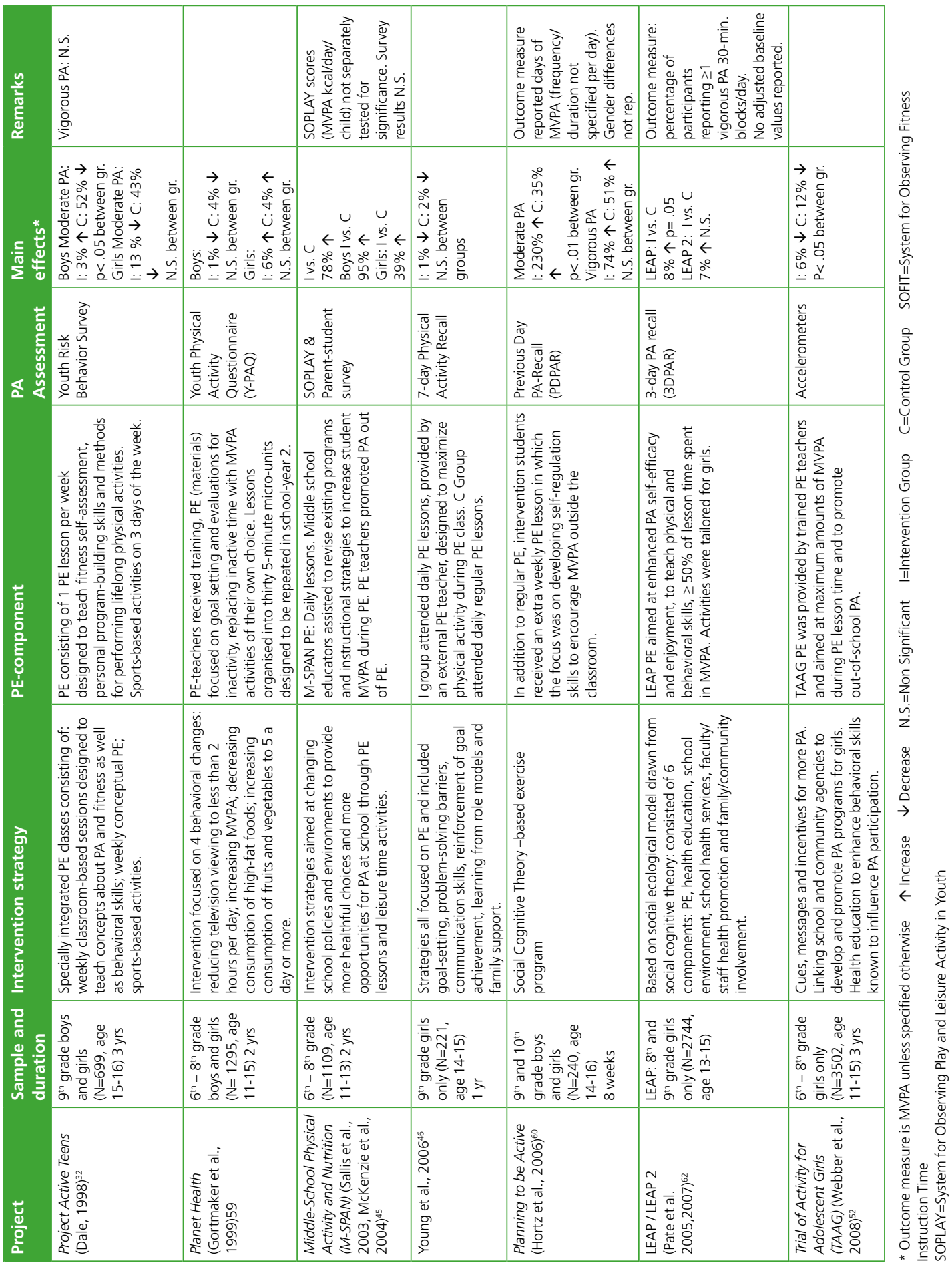


The studies described in tables 2.2 and 2.3 all applied modified PE, usually as a component of a broader intervention, to attain an increase in PA out-of-class. In most instances, their focus was on bringing about a sustained positive attitude towards PA, ultimately aimed at causing an increase in PA not only during PE and school sports but also during recess and leisure time. However, despite the fact that a number of these interventions were successful in increasing out-of-class PA, it remains difficult to determine the contribution of PE per se to this effect, since only two interventions were uniquely targeted at $P E^{46,60}$. Of course, it could be argued that the multidimensional character of PA in children and adolescents makes it unlikely that a modified PE program by itself will be able to increase PA out-of-class. Children are exposed to a multitude of variables that influence their PA and which may override any effects of PA provision through school-PE ${ }^{63}$. Nonetheless, in order to be able to develop effective interventions the distinct effects of PE on the PA-behaviour of students should be more thoroughly assessed. To this end, it would be of value to combine objective PA measurements with questionnaires or interviews to determine to what extent children and adolescents perceive PE to have contributed to their PA behaviour.

As mentioned above, the majority of interventions were aimed at increasing not only out-of-class PA but also in-class PA. Unfortunately, these effects are usually not separately reported. For example, if recall-methods are used to quantify PA, it is usually not clear if PE lessons are part of the self-reported PA. Similarly, in accelerometer studies it remains unclear whether accelerometers were worn during PE lessons. This makes interpretation of the separate contributions of in-class and out-of-class activity to total PA indeterminable. This is regrettable, since it has been suggested by Wilkin et al. ${ }^{64}$ that increasing PE lesson time could lead to a compensatory decrease in out-of-class PA. This compensation effect, where high intensity exercise is counteracted by a decrease in activity during the remaining day, has been proposed to exist in adults. ${ }^{65}$ However, in children evidence from intervention research is very limited. In a study by Dale et al. ${ }^{32}$ restricting physical activity during the school day did not lead to increased PA levels after school hours. These contradictory findings warrant future studies to more accurately determine and report the impact of increased PE levels on PA, discerning out-of-class PA from in-class PA.

\section{Indirect effect of PE: long term PA behaviour}

An important question when attempting to influence children's and adolescents' PA-behaviour, is whether PA-behaviour at a young age influences and is a predictor of PA-behaviour at an adult age. This process is called 'tracking' (or 'carry-over') and has been defined as the maintenance of relative rank or a position within a group over time. ${ }^{66}$ Applied to PA-research this implies that high tracking coefficients mean that physically active children become physically active adults, and sedentary children become sedentary adults. Although tracking of sedentary behaviour seems to be quite strong ${ }^{67}$, tracking of PA from childhood to adulthood seems to be weak or moderate at best, with correlation coefficients of around $0.3 .^{68-73}$ It is unclear to what extent the data from these PA-studies can be extrapolated to infer the impact of PE programs on adult PA. ${ }^{49}$ Mainly due to research limitations there is a lack of empirical evidence regarding the carry-over value of PE activities into adulthood.

A recent Australian study by Cleland et al. ${ }^{63}$ investigated the association of compulsory school PA (PE and school sports) at age 9-15 with PA at age 26-36 under non-intervention conditions. Results indicated no association between compulsory PE in primary and secondary school and PA at an adult age. The single known intervention study with long-term follow-up is the Trois-Rivières study. ${ }^{74}$ This study investigated the long-term effects of additional PE on PA. Between 1970 and 1977546 elementary school children were assigned to an experimental or a control group. The experimental group received 5 hours of PE per week, taught by specialist PE-teachers. The 
control group received a standard 40 min of PE per week, supervised by their classroom teacher. Intervention PE was aimed at high activity levels during lessons, enhancing aerobic capacity and muscular strength upon maturation and growth. The aim was also to maximize involvement in activities with a strong carry-over value into adult life. Short-term results indicated that out of school PA was slightly lower during weekdays compared to control students, but higher during weekends. Therefore, out-of-class PA was similar, but total PA levels were higher in the experimental group due to extra PE lessons. Twenty years later, the experimental group was compared to a newly recruited control group and PA was established by a single item from a questionnaire. Women who had received daily PE during elementary school, reported more involvement in physical activities later in life. In the male experimental group no long-term difference was observed. The authors note in their paper that it is difficult to explain the apparent effect in women since they reported no differences in intention to exercise, attitudes toward exercise, perception of social support and opportunities for exercise. Because a large number of group comparisons were made in the study, and given the inherent difficulty of assessing physical activity with a single item from a questionnaire, we believe it can not be ruled out that the significant effect in women was a chance finding. It is however the only study that has reported the long-term follow-up of a PE-intervention.

Given that there was no effect on PA in the study by Cleland et al. ${ }^{63}$ and a putative effect in women only in the Trois-Rivières study ${ }^{74}$, it can be stated that there is as yet no convincing evidence of a positive effect of PE on PA later in life. There seems to be a lack of studies investigating the long-term influence of (modified) PE on adult PA. Furthermore, to date no studies have been conducted to investigate long-term effects in multi-component PA intervention studies including PE.

\section{General conclusions}

To date, the evidence for an effect of PE per se on out-of-class PA remains inconclusive. Studies in which PE is part of a multi-component intervention have generally shown modest effects in boys but less so in girls. There is a lack of longitudinal studies aimed at the long-term effects of PE and therefore to date, there is no evidence to assume that PE stimulates an active life style as an adult. Based on the existing evidence, interventions should focus on PE's direct effects, for multiple studies have shown that PE has the potential make a significant contribution to the daily accumulation of MVPA. To maximally increase opportunities for students to increase their daily MVPA levels through PE, it is proposed that scheduled PE-time is increased and that lesson strategies that maximize student activity are implemented. 


\section{References}

1. Kiess W, Reich A, Muller G, et al. Clinical aspects of obesity in childhood and adolescence-diagnosis, treatment and prevention. Int J Obes Rel Metab Disorders. 2001;25:S75-S79.

2. Kohl III HW. Physical activity and cardiovascular disease: evidence for a dose response. Med Sci Sports Exerc. 2001;33(6 Suppl):S472-S483.

3. Warburton DER, Nicol CW, Bredin SSD. Health benefits of physical activity: the evidence. Can Med Assoc J. 2006;174(6):801-809.

4. Bouchard C, Blair SN, Haskell WL. Physical Activity and Health: Human Kinetics; 2007.

5. Janssen I, Katzmarzyk PT, Boyce WF, et al. Comparison of overweight and obesity prevalence in school-aged youth from 34 countries and their relationships with physical activity and dietary patterns. Obesity Reviews 2005;6(2):123-132.

6. Lobstein T, Frelut ML. Prevalence of overweight among children in Europe. Obesity Reviews 2003;4(4):195200.

7. Malina RM. Youth Physical Activity: Implications for Adult Physical Activity and Health. Stud Phys Cult Tourism. 2006 Supplement 2006;13(Suppl.):29-33.

8. Xiaolin Y, Telama R, Viikari J, Raitakari OT. Risk of Obesity in Relation to Physical Activity Tracking from Youth to Adulthood. Med Sci Sports Exerc. 2006;38(5):919-925.

9. Balagopal P. Physical activity and cardiovascular health in children. Pediatr Ann. 2006;35(11):814-821.

10. Ferreira I, van der Horst K, Wendel-Vos W, Kremers S, Lenthe van F, Brug J. Environmental correlates of physical activity in youth - a review and update. Obesity Reviews. Feb 7 2007;8:129-154.

11. Rowland TW. Promoting Physical Activity for Children's Health. Sports Med. 2007;37(11):929-936.

12. Biddle S, J. H., Gorely T, Stensel DJ. Health-enhancing physical activity and sedentary behaviour in children and adolescents. J Sports Sci. 2004;22(8):679-701.

13. Nader PR, Bradley RH, Houts RM, McRitchie SL, O'Brien M. Moderate-to-Vigorous Physical Activity From Ages 9 to 15 Years. J Am Med Assoc. 2008;300(3):295-305.

14. Pate RR, Freedson PS, Sallis JF, et al. Compliance with Physical Activity Guidelines: Prevalence in a Population of Children and Youth. Ann Epidemiol. 2002;12(5):303-308.

15. Salmon J, Timperio A. Prevalence, trends and environmental influences on child and youth physical activity. Med Sports Sci. 2007;50:183-199.

16. Tappe MK, Burgeson CR. Physical education: a cornerstone for physically active lifestyles. J Teach Phys Educ. 2004;23(4):281-299.

17. Fairclough S, Stratton G, Baldwin G. The contribution of secondary school physical education to lifetime physical activity. Eur Phys. Ed Rev. 2002;8(1):69-84.

18. Fairclough S, Stratton G. Physical Activity Levels in Middle and High School Physical Education: A Review. Pediatr Exerc Sci. 2005;17(3):217-236.

19. Fairclough S, Stratton G. A Review of Physical Activity Levels During Elementary School Physical Education. J Teach Phys Educ. 2006;25(2):239-257.

20. NASPE. Physical Activity for Children: Current Patterns and Guidelines. President's Council on Physical Fitness \& Sports Research Digest. 2004;5(2):1-8.

21. Sallis JF, Patrick K. A consensus on physical activity guidelines for adolescents. / Consensus sur les lignes directrices en matiere d'activite physique recommandee durant l'adolescence. CAHPERD-ACSEPLD Journal. Spring/printemps 1995 1995;61(1):38-40. 
22. USDHHS. Physical Activity Advisory Guidelines Committee Report 2008. Washington, DC: U.S. Department of Health and Human Services. 2008.

23. Wallhead T, Buckworth J. The role of physical education in the promotion of youth physical activity. Quest. 2004;56(3):285-301.

24. Corbin C. Physical Activity for Everyone: What Every Educator Should Know About Promoting Lifelong Physical Activity. J Teach Phys Educ. 2002;21(2):128.

25. Simons-Morton BG, Parcel GS, Baranowski T, Forthofer R, O'Hara NM. Promoting Physical Activity and a Healthful Diet among Children: Results of a School-Based Intervention Study. Am J Public Health. 1991;81(8):986-991.

26. Cavill N, Biddle S, Sallis JF. Health Enhancing Physical Activity for Young People: Statement of the United Kingdom Expert Consensus Conference. Pediatr Exerc Sci. 2001;13(1):12-25.

27. Hamilton MT, Healy GN, Dunstan DW, Zderic TW, Owen N. Too Little Exercise and Too Much Sitting: Inactivity Physiology and the Need for New Recommendations on Sedentary Behavior. Current Cardiovascular Risk Reports. 2008;2:292-298.

28. Trudeau F, Shephard RJ. Contribution of School Programmes to Physical Activity Levels and Attitudes in Children and Adults. Sports Med. 2005;35(2):89-105.

29. Tudor-Locke C, Ainsworth BE, Adair LS, Du S, Popkin BM. Physical activity and inactivity in Chinese schoolaged youth: the China Health and Nutrition Survey. Int J Obes. 2003;27(9):1093-1099.

30. Westerstahl M, Barnekow-Bergkvist M, Jansson, E (2005). Low physical activity among adolescents in practical education. Scand J Med \& Sci Sports, 15(5), 287-297.

31. Welk GJ. Physical activity assessments for health-related research. Champaign, Ill.; United States: Human Kinetics; 2002.

32. Dale D, Corbin CB, Dale KS. 'Restricting opportunities to be active during school time: do children compensate by increasing physical activity levels after school? / (Opportunites reduites d'etre actifs pendant le temps scolaire: les enfants compensent-ils par une augmentation du niveau d'activite physique apres l'ecole ?)'. Res Q Exerc Sport. 2000;71:240-248.

33. Wegis H, van der Mars H. Physical Education's Contribution to the Total Daily Physical Activity Levels of Middle School Students. (Abstract). Res Q Exerc Sport. 2006;77(1 Suppl):A-71.

34. Fairclough SJ, Stratton G. A Review of Physical Activity Levels During Elementary School Physical Education. J. Teach. Phys. Educ. 2006;25(2):239-257.

35. Fairclough SJ, Stratton G. Physical Activity Levels in Middle and High School Physical Education: A Review. Pediatr Exerc Sci. 2005;17(3):217-236.

36. Stratton G. Children's heart rates during physical education lessons: a review. / Frequences cardiaques des enfants pendant les cours d'education physique: revue. Pediatr. Exerc. Sci. 1996;8(3):215-233.

37. USDHHS. Healthy People 2010. Washington D.C.: Government Printing Office. 2000.

38. Association for Physical Education (afPE). Physical education's contribution to public health. afPE summary position paper. Physical Education Matters. 2008;3(1):8.

39. Fairclough S, Stratton G. Improving health-enhancing physical activity in girls' physical education. Health Educ Res. Aug 1 2005;20(4):448-457.

40. Beurden E, Barnett LM, Zask A, Dietrich UC, Brooks LO, Beard J. Can we skill and activate children through primary school physical education lessons? "Move it Groove it" a collaborative health promotion intervention. Prev Med. 2003;36(4):493-501. 
41. Sallis, McKenzie TL, Alcaraz JE, Kolody B, Faucette N, Hovell MF. The effects of a 2-year physical education program (SPARK) on physical activity and fitness in elementary school students. Am J Public Health. 1997;87(8):1328-1334.

42. Verstraete SJM, Cardon GM, De Clercq DLR, De Bourdeaudhuij IMM. Effectiveness of a Two-Year HealthRelated Physical Education Intervention in Elementary Schools. J Teach Phys Educ. 2007;26(1):20-34.

43. McKenzie TL, Nader PR, Strikmiller PK, et al. School physical education: effect of the Child and Adolescent Trial for Cardiovascular Health. Prev Med. 1996;25(4):423-431.

44. McKenzie TL, Sallis JF. Long-term effects of a physical education curriculum and staff development program: SPARK. Res Q Exerc Sport. 1997;68(4):280-291.

45. McKenzie, Sallis JF, Prochaska JJ, Conway TL, Marshall SJ, Rosengard P. Evaluation of a two-year middle-schoo' physical education intervention: M-SPAN. Med Sci Sports Exerc. 2004;36(8):1382-1388.

46. Young DR, Phillips JA, Yu T, Haythornthwaite JA. Effects of a life skills intervention for increasing physical activity in adolescent girls. Arch Pediatr Adolesc Med. 2006;160:1255-1261.

47. Luepker RV, Perry CL. Outcomes of a field trial to improve children's dietary patterns and physical activity. J Am Med Assoc. 1996;275(10):768-776.

48. Keeley JH, Fox KR. The impact of physical activity and fitness on academic achievement and cognitive performance in children. Int Rev of Sport and Exerc Psych. 2009;2(2):198-214.

49. Shephard RJ, Trudeau F. The legacy of physical education: influences on adult lifestyle. / L'heritage de I'education physique: influences sur le style de vie a l'age adulte. Pediatr Exerc Sci. 2000;12(1):34-50.

50. Kirk D. Physical education, youth sport and lifelong participation: the importance of early learning experiences. Eur Phys Ed Rev. 2005;11(3):239-255.

51. Sallis JF, McKenzie TL, Conway TL, et al. Environmental interventions for eating and physical activity: A randomized controlled trial in middle schools. Am J Prev Med. 2003;24:209-217.

52. Webber LS, Catellier DJ, Lytle LA, et al. Promoting Physical Activity in Middle School Girls: Trial of Activity for Adolescent Girls. Am J Prev Med. 2008;34:173-184.

53. Donnelly JE, Jacobsen DJ, Whatley JE, et al. Nutrition and physical activity program to attenuate obesity and promote physical and metabolic fitness in elementary school children. Obesity Reviews. 1996;4:229-243.

54. Verstraete SJM, Cardon GM, De Clercq DLR, De Bourdeaudhuij IMM. A comprehensive physical activity promotion programme at elementary school: the effects on physical activity, physical fitness and psychosocial correlates of physical activity. Pub Health Nutr. 2007;10.

55. Naylor PJ, Macdonald HM, Warburton DEA, Reed KE, McKay HA. An active school model to promote physical activity in elementary schools: Action schools! BC. Br J Sports Med. 2008;42:338-343.

56. Caballero B, Clay T, Davis SM, et al. Pathways: a school-based, randomized controlled trial for the prevention of obesity in American Indian schoolchildren. Am J Clin Nutr. 2003;78:1030-1038.

57. Mechelen W, Twisk JW, Post GB, Snel J, Kemper HC. Physical activity of young people: the Amsterdam Longitudinal Growth and Health Study. Med Sci Sports Exerc. 2000;32(9):1610-1616.

58. Dale D, Corbin CB, Cuddihy TF. Can conceptual physical education promote physically active lifestyles ? (L'education physique conceptuelle peut-elle promouvoir un mode de vie physiquement actif ?). Pediatr Exerc Sci. 1998;10:97-109.

59. Gortmaker SL, Peterson K, Wiecha J, et al. Reducing obesity via a school-based interdisciplinary intervention among youth: Planet Health. Arch Pediatr Adolesc Med. 1999;153:409-418.

60. Hortz B, Petosa R. Impact of the "Planning to be Active" leisure time physical exercise program on rural high school students. J Adolesc Health. 2006;39:530-535. 
61. Pate RR, Ward DS, Saunders RP, Felton G, Dishman RK, Dowda M. Promotion of Physical Activity Among HighSchool Girls: A Randomized Controlled Trial. Am J Public Health. 2005;95(9):1582-1587.

62. Pate RR, Saunders R, Dishman RK, Addy C, Dowda M, Ward DS. Long-term effects of a physical activity intervention in high school girls. Am J Prev Med. 2007;33(4):276-280.

63. Cleland V, Dwyer T, Blizzard L, Venn A. The provision of compulsory school physical activity: Associations with physical activity, fitness and overweight in childhood and twenty years later. Int J Behav Nutr Phys. Act. 2008;5:14.

64. Wilkin TJ, Mallam KM, Metcalf BS, Jeffery AN, Voss LD. Variation in physical activity lies with the child, not his environment: evidence for an 'activitystat' in young children (EarlyBird 16). Int J Obesity. 2006;30:1050-1055.

65. Westerterp KR. Pattern and intensity of physical activity. Nature. Mar 29 2001;410(6828):539.

66. Malina RM. Physical activity and fitness: pathways from childhood to adulthood. Am J Hum Biol. $2001 ; 13(2): 162-172$.

67. Scheerder J, Vanreusel B, Beunen G, et al. Lifetime adherence to sport and physical activity as a goal in physical education. In Physical Education Research. What's the evidence? 1'st ed. LeuvenNoorburg: Acco; 2008:29-40.

68. Janz KF, Burns TL, Levy SM. Tracking of Activity and Sedentary Behaviors in Childhood: The lowa Bone Development Study. Am J Prev Med 2005;29(3):171-178.

69. Kelly LA, Reilly JJ, Jackson DM, Montgomery C, Grant S, Paton JY. Tracking physical activity and sedentary behavior in young children. Pediatr Exerc Sci. 2007;19(1):51-60.

70. Raustorp A, Svenson K, Perlinger T. Tracking of pedometer-determined physical activity: a 5-year follow-up study of adolescents in Sweden. Pediatr Exerc Sci. 2007;19(2):228-238.

71. Telama R, Yang X, Viikari J, Välimäki I, Wanne O, Raitakari O. Physical activity from childhood to adulthood: $A$ 21-year tracking study. Am J Prev Med. 2005;28(3):267-273.

72. Trudeau F. Tracking of Physical Activity from Childhood to Adulthood. Med Sci Sports Exerc. 2004;36(11):19371943.

73. Kemper, $\mathrm{H}$ (ed.). Amsterdam Growth and Health Longitudinal Study (AGAHLS): A 23-Year Follow-Up from Teenager to Adult about Lifestyle and Health. Karger, Basel: Med and Sport Science, 2004(47).

74. Trudeau F, Laurencelle L, Tremblay J, Rajic M, Shephard RJ. A Long-Term Follow-Up of Participants in the TroisRivières Semi-Longitudinal Study of Growth and Development. Pediatr Exerc Sci. 1998;10(4):366-377. 


\section{CHAPTER 3}

PHYSICAL ACTIVITY ENERGY EXPENDITURE IN DUTCH ADOLESCENTS: CONTRIBUTION OF ACTIVE TRANSPORT TO SCHOOL, PHYSICAL EDUCATION AND LEISURE TIME ACTIVITIES

SLINGERLAND, M., BORGHOUTS L.B., HESSELINK, M.K.C.

JOURNAL OF ADOLESCENT HEALTH 2012 (82) 5: 225-232'

1 The spelling and reference style in this chapter are in line with the guidelines of the Journal of Adolescent Health. 


\section{Summary}

Background: Detailed knowledge about physical activity energy expenditure (PAEE) can guide the development of school-interventions aimed at reducing overweight in adolescents. However, relevant components of PAEE have never been objectively quantified in this population. Therefore, the purpose of this study was to investigate the contribution of active transport to and from school, physical education and leisure time activities to total PAEE during a regular school week in adolescents.

Methods: Seventy-three adolescents (mean age 15.7 years) wore an individually calibrated combined heartrateacceleration monitor and kept an activity diary during a regular school week. Branched equation modelling was used to calculate PAEE of the specific activity categories, and their relative contribution to total PAEE was determined.

Results: Active transport and physical education contributed $30.0 \%$ and $17.4 \%$ to school-related PAEE, respectively. Active transport to and from school contributed $15 \%$ to total PAEE. Subjects with a high Physical Activity Level (PAL) spent 4 hours less in sedentary behaviour than subjects with a medium or low PAL (F $=77.415$ $(2,70), p<.001)$ and had higher PAEE during leisure time sports $(F=9.135(2,70), p<.001)$ and work-related activities $(F=10.583(2,70), p<.001)$ than subjects with medium or low PAL values.

Conclusion: Active transport and PE contribute significantly to PAEE during school hours in adolescents. To achieve an increase in total PAEE in the least active group of adolescents, promising strategies might be to reduce inactive behaviour, increase participation in leisure time sports and possibly to replace inactive for active jobs. 
Intervention strategies aimed at reducing overweight in adolescents often focus on increasing physical activity energy expenditure (PAEE) in order to maintain or restore energy balance. School-based interventions have been designated as potentially important in this respect, since schools reach almost all youth. ${ }^{1}$ School-based interventions aim to enhance physical activity through various means, such as active transportation to and from school, physical education (PE) and participation in organised sports..$^{1-3}$ For example, physical education has been identified as an important source of physical activity ${ }^{3}$, with Dutch adolescents accumulating approximately one third of the advised daily physical activity within PE lessons. ${ }^{4}$ In Sweden, 30\% of the adolescents derive all moderate-to-vigorous physical activity from PE. ${ }^{5}$ Active transportation to school is a promising contributor to physical activity levels in youth ${ }^{6,7}$ with youth walking or cycling to school having highest overall physical activity levels..$^{8,9}$ Furthermore, during adolescence participation in extracurricular sports ${ }^{10}$ and leisure time sports seems to become an especially important contributor to overall physical activity levels. ${ }^{11}$ Although several studies have focused on assessing total PAEE in adolescents ${ }^{12-15}$ the contribution of these specific activities to total PAEE in adolescents is unknown, probably due to methodological difficulties in measuring PAEE in daily-living conditions. ${ }^{16,17}$ Such knowledge would however be of particular value when designing school-based interventions. With the fairly recent emergence of small, easy-to-wear combined-sensing instruments it is now possible to more accurately estimate PAEE in daily living on a minute-by-minute basis. ${ }^{18,19}$ Combining this technology with activity diaries makes it possible to accurately determine free-living PAEE for specific activities. The aims of the present study were therefore (1) to quantify the amount of PAEE in adolescents during a regular school week; (2) to determine the contribution of PE, active commuting to school, leisure time sports and paid work to total PAEE. Results of this study could provide guidance in the development of effective school-based interventions for increasing physical activity in this population.

\section{Method \\ Subjects}

The study was a cross-sectional examination of PAEE during a regular school week and weekend in a sample of $10^{\text {th }}$ grade students in the period October 2009 - June 2010. An initial sample of 180 students was randomly selected from three large secondary schools (average number of students $=1693$ ) located in a mid-sized city (204,924 inhabitants) in the south of the Netherlands. Schools were comparable in terms of ethnic population and socio-economic status of the parents. Subjects were offered the incentive of fifty euros upon measurement completion. One-hundred-and-fifty-four students returned completed forms and were all found eligible to participate in the study (i.e. no restrictions to be physically active due to injuries, illness or chronic diseases). Eighty subjects were randomly selected from this sample. 


\section{Instruments}

Combined heartrate and accelerometry (HR+ACC) using the Actiheart monitor (CamNTech, Cambridge, UK) was used to assess PAEE. In order to identify the energy expended within the activities of interest, subjects were provided with an activity diary during their measurement period. This allowed us to accurately combine HR+ACC data and activity diary data. All pre-test measurements took place inside the schools. Height and weight were measured using standardized procedures and body-mass index (BMI) was estimated from weight/height ${ }^{2}\left(\mathrm{~kg} / \mathrm{m}^{2}\right)$. Subjects filled out a short questionnaire in which they were asked about their number of minutes of PE per week, means of transport to school, and postal code. Participant's home address postal codes were used to determine their travel distance from home to school by entering the postal code and school address in Google maps.

\section{Physical activity energy expenditure.}

Physical activity energy expenditure is defined as all energy expended above basal metabolic rate. The combined HR+ACC monitor cancels out the limitations the instruments have when used separately and is therefore considered a more effective, feasible means of assessing PAEE. 18,19 The monitor is worn clipped on to two standard ECG-electrodes on the left side of the chest. Heart rate and accelerometer data were combined using branched equation techniques. ${ }^{20}$ In short, the branched equation relies largely on accelerometer data to account for calculation of low-intensity activity, while higher intensity activity is derived largely from heart rate. Subjects wore the monitor for 8 consecutive days and nights. However, because on the first and last measurement day the monitor was not worn for a full day, these days were omitted in the analysis, leaving 6 full measurement days (4 weekdays and 2 weekend days). Energy expenditure measured with the Actiheart monitor using branched equation has been validated against indirect calorimetry in a laboratory setting within a youth population ${ }^{21}$ as well as against criterion measures and other objective measures of PA in free-living conditions in a sample of college-students. ${ }^{22}$

\section{Activity diary.}

During the measurement period all subjects kept an activity diary in which they were asked to fill out all of their physical activities performed during each day of the measurement period. Subjects were instructed to precisely enter the times of beginning and end of all physical activities that lasted more than 5 minutes, such as cycling to school, having PE, walking the dog, shopping, doing paid work, organised sports etc. Besides these activities, subjects were allowed to describe any other physical activities performed during the week in the diary. Activities were recorded in the diary to the nearest minute and subjects were urged to fill out the diary directly after they had performed an activity. Subjects were also asked to enter any periods in the diary when the monitor was not worn (e.g. during swimming or bathing). The activity diary was conveniently small sized so that it could easily be kept within a bag or pocket.

\section{Procedures}

In order to increase PAEE estimation precision an individual calibration procedure was completed by all subjects, which consisted of an 8-minute step test. This is a built-in test within the Actiheart software and is designed to account for the variance in individual HR-PAEE relationships without the need for indirect calorimetry. Guided by an audible voice from the computer, subjects step up and down a $215 \mathrm{~mm}$ step, linearly increasing step rate from 15 to 33 step cycles per minute after the first minute. As the weight and step height are constant, the demanded energy is proportional to the step frequency. In this manner, an individual heart rate-energy expenditure relationship is derived, which is subsequently used by the branched equation model. The calibration procedure has been shown to result in a more accurate prediction of PAEE. ${ }^{23}$ After completion of the 8-day measurement period, 
average sleeping heart rate (SHR) was derived from the data and used afterwards in the PAEE-HR equation to calculate PAEE. The Actiheart was set to a $1 \mathrm{~min}$. measurement epoch. Data was trimmed to only include full days in the analysis, and was considered valid if at least 3 weekdays and 1 weekend day were present. If this criterion was not met, the subject was discarded and excluded from further analysis. All measurement days were then visually checked for outliers and erroneous values. A measurement day was considered invalid if less than twenty hours of data were present. Valid data was further examined using the Actiheart software. To replace missing HR values, first activity diaries were checked to determine if the monitor was worn at the time point of that specific value. Only one person reported not wearing the monitor for approximately one hour due to swimming (although the monitor is waterproof the manual advises not to wear the monitor during bathing of swimming). For this participant PAEE was calculated using youth-specific MET-values ${ }^{24}$ for the duration of the non-worn period (1 MET equals $1 \mathrm{kcal} \cdot \mathrm{kg}^{-1} \cdot \mathrm{h}^{-1}$ or $\left.4.184 \mathrm{~kJ} \cdot \mathrm{kg}^{-1} \cdot \mathrm{h}^{-1}\right)$.

\section{Data Analysis}

All data was initially pooled in Microsoft Excel spread sheets and means were calculated for total PAEE over 6 days $(\mathrm{kJ} / \mathrm{kg})$ and for total PAEE $(\mathrm{kJ} / \mathrm{kg})$ expended in the categories PE, active transport (leisure time and school), leisure time activities and work during the 6 days of measurement. Subsequently, the contribution of these categories to total PAEE was determined. Also the contribution of PE and active transport to total PAEE on school days was calculated. Physical Activity Level (PAL) values were calculated as total energy expenditure / basal metabolic rate, in which basal metabolic rate was estimated using the Schofield equation. ${ }^{25}$ Time spent inactive was derived directly from the Actiheart Software as < 1.5 METs. All variables were then entered into Predictive Analytic Software 18 (PASW) for further analysis. Paired sample t-tests were used to determine differences between weekdays and weekend days. Multiple regression analysis using the stepwise method, which is appropriate for exploratory model building ${ }^{26}$, was used to determine the contribution of all physical activity categories, gender and time spent inactive to total PAEE. A similar multiple regression analysis was conducted to determine the contribution of gender, PE and active transport to school, to total PAEE during school hours. In addition, to investigate which physical activities are responsible for differences between inactive, moderately active and very active students, three equally sized PAL groups were created based on 1 standard deviation above and below the mean resulting in low PAL $<1.49$, medium PAL $1.50-1.79$ and high PAL $>1.80$. Subsequently, ANOVA's with Bonferroni post-hoc tests were used to test for differences in PAEE within the different physical activity categories between the PAL groups. Statistical assumptions for all tests were met unless otherwise stated. 
Table 3.1. Means and 95\% confidence intervals for anthropometric characteristics, BMR, PAL values and total PAEE levels of boys and girls

\begin{tabular}{|c|c|c|c|c|}
\hline & & All $(N=73)$ & Boys $(N=37)$ & Girls $(\mathrm{N}=36)$ \\
\hline \multirow[t]{5}{*}{ Descriptives } & Age (yrs) & $15.7(15.6-15.9)$ & $15.9(15.6-16.2)$ & $15.6(15.4-15.8)$ \\
\hline & Height (m) & $1.75(1.72-1.77)$ & $1.81(1.79-1.83)$ & $1.68(1.65-1.70) * * *$ \\
\hline & Weight (kg) & $65.12(62.47-67.61)$ & $67.8(64-71.7)$ & $62.2(58.86-65.48)^{*}$ \\
\hline & BMI (kg/m2) & $21.33(20.6-22.2)$ & $20.66(19.65-21.71)$ & $22.13(20.95-23.31)$ \\
\hline & $\mathrm{BMR}(\mathrm{kJ})$ & 7034.5 (6801-7276) & $7052.2(6720-7485)$ & $7016.3(6673-7360)$ \\
\hline \multirow[t]{3}{*}{ PAL } & Week & $1.68(1.63-1.73)$ & $1.72(1.65-1.80)$ & $1.64(1.57-1.70)$ \\
\hline & Weekend & $1.65(1.59-1.71)$ & $1.70(1.60-1.80)$ & $1.60(1.52-1.68)$ \\
\hline & Overall & $1.67(1.62-1.71)$ & $1.71(1.64-1.78)$ & $1.62(1.56-1.69)$ \\
\hline \multirow{4}{*}{$\begin{array}{l}\text { Total PAEE } \\
(\mathrm{kJ} / \mathrm{kg})\end{array}$} & Weekdays (4 d) & $232.4(210.4-254.4) \ddagger$ & $269.6(234.4-303.6)$ & $194.6(172.4-216.4)^{* * *}$ \\
\hline & Weekend days (2 d) & $104.4(92.0-116.6)$ & $121.0(101.4-140.4)$ & $87.2(73.6-110.8)^{* *}$ \\
\hline & Overall (6 d) & $328.2(297.6-358.8)$ & $376.2(329.4-423)$ & $279.6(245.4-313.8)^{* *}$ \\
\hline & School hours (4 d) & $111.2(100.0-122.6)$ & $123.6(105.6-141.6)$ & $98.4(85.2-111.2)^{* *}$ \\
\hline
\end{tabular}

$*=p<.05^{* *}=p<.01 * * *=p<.001$ denote statistically significant differences between the sexes

$\dagger(p<.05) \neq(p<.001)$ denote a significant difference between weekdays and weekend days

$\mathrm{BMR}=$ Basal metabolic rate

$\mathrm{PAL}=$ total energy expenditure $/ \mathrm{BMR}$

School hours includes (active) transportation to and from school 


\section{Results}

Seven subjects were discarded due to erroneous or missing data, resulting in 73 subjects with valid measurements ( 37 boys, 36 girls). Approximately $96 \%$ of diary entry data could be matched with the corresponding HR+ACC data, the remaining $4 \%$ was considered as lost data. Age and physical characteristics, as well as PAL values and PAEE levels are shown in Table 3.1. Boys were significantly taller $(p<.001)$ and had higher body mass $(p<.05)$ than girls. Average BMI fell within the normal range for both boys and girls. Total PAEE (kJ/day) was significantly higher in boys than in girls overall $(p<.001)$, on weekdays $(p<.001)$, on weekend days $(p<.01)$ and during school time $(p<.05)$. These differences were irrespective of bodyweight. PAL values averaged around 1.70 for boys and 1.60 for girls, with no significant differences between sexes. However, a large inter-individual variability in physical activity levels was observed, with PAL ranging from $1.31-2.23$. Analysis of variance (ANOVA) with Bonferroni post-hoc tests on the stratified PAL groups (low, medium and high, figure 3.1) revealed that subjects with a high PAL value spent 4 hours less in sedentary behaviour than subjects with a medium or low PAL $(\mathrm{F}=$ $77.415(2,70), p<.001)$ and had higher PAEE during school hours than subjects with a low PAL $(F=5.089(2,70)$, $p<.01)$. Furthermore, subjects with high PAL values had higher PAEE during leisure time sports $(F=9.135(2,70)$, $p<.001)$ and work-related activities $(F=10.583(2,70), p<.001)$ than did subjects than subjects with medium or Iow PAL values. PAEE in active transport did not differ between the PAL groups.

Figure 3.2 shows total PAEE spent within the different physical activity categories and table 3.2 includes their contribution to PAEE during a weekday, weekend day and during school hours. Average PAEE expended during the 100 minute PE lesson was $18.1 \mathrm{~kJ} / \mathrm{kg}$, with boys having significantly higher PAEE during PE than girls $(p<.001)$. Thirty percent of PAEE on a weekday originated from PE when students had their PE lesson on that day. PAEE during active transport to school over four weekdays was $34.7 \mathrm{~kJ} / \mathrm{kg}$, which was $15 \%$ of total PAEE during weekdays and $30 \%$ of total PAEE during school hours. During weekend days $26 \%$ of PAEE originated from leisure time sports, which was higher than during weekdays $(p<.001)$. Work related activities contributed $11.5 \%$ to PAEE during a weekend day versus $5.5 \%$ during a weekday. Overall, subjects were more active during weekdays compared to weekend days (58.06 versus $52.15 \mathrm{~kJ} / \mathrm{kg} /$ day, $\mathrm{t}(72)=2,289, \mathrm{p}<.05)$.

Table 3.3 shows the multiple regression analyses. Gender, active transport, leisure time sports, work and inactive behaviour together were able to capture $92 \%$ of the variance in total PAEE (6 days, kJ/kg) ( $F=154.26(5,67)$, $p<.001)$, whereas PE was not a significant contributor to total PAEE. According to the $\beta$-values, time spent inactive was the most important negative predictor of total PAEE $(B=-.59, p<.001)$, whereas active transport during school and leisure time combined was the most important positive predictor $(B=.32, p<.001)$. During school hours, $73 \%$ of the variance in total PAEE could be explained by PE and active transport to school ( $F=92.77$ $(2,70), p<.001)$. Active transport to school was the most important predictor $(B=.75, p<.001)$ followed by $P E$ $(B=.25, p<.001)$, whereas gender was not a significant predictor for PAEE during school hours. 
Table 3.2. Total PAEE and $95 \%$ confidence intervals across 6 days $(\mathrm{kJ} / \mathrm{kg})$ during physical education (PE), active transport (AT) on weekdays and during school hours, and sports and work-related activities on weekdays and weekend days and the contribution to total PAEE.

\begin{tabular}{|c|c|c|c|}
\hline & All $(\mathrm{N}=73)$ & Boys $(\mathrm{N}=37)$ & Girls $(\mathrm{N}=36)$ \\
\hline PAEE in PE (kJ/kg) & $18.1(16.4-19.9)$ & $22.2(19.7-24.7)$ & $13.9(12.3-15.5)^{\star * *}$ \\
\hline$\%$ of PAEE on wkdays & $8.4(7.6-9.3)$ & $8.6(7.3-9.9)$ & $8.3(7.0-9.4)$ \\
\hline$\%$ of PAEE on wkday with PE & $29.8(26.7-32.9)$ & $33.2(28.6-37.9)$ & $26.1(22.2-30.0)^{\star}$ \\
\hline$\%$ of PAEE during school hrs & $17.4(15.8-19.0)$ & $17.8(15.5-20.2)$ & $16.9(14.5-19.2)$ \\
\hline PAEE in AT to school (kJ/kg) & $34.7(28.5-41.0)$ & $39.5(28.6-50.5)$ & $29.7(23.7-35.7)$ \\
\hline$\%$ of PAEE on wkdays & $15.3(13.3-17.4)$ & $15.3(11.9-18.6)$ & $15.4(12.8-18.1)$ \\
\hline$\%$ of PAEE during school hrs & $30(27.1-33.0)$ & $30.3(25.6-34.9)$ & $29.8(26.0-33.6)$ \\
\hline PAEE in LT AT (kJ/kg) & $23(19-27)$ & $16.4(11.3-21.5)$ & $29.7(24-35.5)^{* *}$ \\
\hline$\%$ of PAEE on wkdays & $5.1(3.8-6.4) \neq$ & $5.7(3.6-7.7)$ & $4.5(2.9-6.1)$ \\
\hline$\%$ of PAEE on wknd days & $36.3(27.8-44.8)$ & $34.9(22.1-47.7)$ & $37.8(26-49.6)$ \\
\hline PAEE in sports (kJ/kg) & $40.7(30.1-51.3)$ & $52.4(36.2-68.6)$ & $29.4(15.9-43.0)^{\star}$ \\
\hline$\%$ of PAEE on wkdays & $11(6.3-15.7) \ddagger$ & $16.1(7.2-25.0)$ & $6.1(2.9-9.3)^{\star}$ \\
\hline$\%$ of PAEE on wknd days & $26.7(17.0-36.4)$ & $33.4(16.2-50.7)$ & $20.2(10.6-29.7)$ \\
\hline PAEE in Work (kJ/kg) & $19.5(12.6-26.4)$ & $28.1(15.9-40.3)$ & $11.0(4.9-17.2)^{\star *}$ \\
\hline$\%$ of PAEE on wkdays & $5.5(2.6-7.4)$ & $5.9(3.0-9.1)$ & $5(2.5-7.5)$ \\
\hline$\%$ of PAEE on wknd days & $11.5(7.4-15.5)$ & $11.1(5.7-16.5)$ & $11.8(5.6-18.0)$ \\
\hline
\end{tabular}

${ }^{*}=p<.05^{* *}=p<.01 * * *=p<.001$ denote statistically significant differences between the sexes

‡significant difference between weekdays and weekend days $(p<.001)$

$\mathrm{PE}=$ physical education, $\mathrm{LT}=$ leisure time, $\mathrm{AT}=$ active transport.

School hours include transportation to school

$\%$ PAEE wkdays is based on 4 weekdays. 
Table 3.3. Regression models for total PAEE and PAEE during school hours.

1. Dependent Variable: Overall Physical Activity Energy Expenditure (6 days, kJ/kg)

\begin{tabular}{|c|c|c|c|c|c|}
\hline & $\mathbf{R}^{2}$ & $\Delta \mathbf{R}^{2}$ & B & SE B & B \\
\hline Model 1: $F_{\text {change }}(1,71)=164.62 p<.001$ & \multirow[t]{3}{*}{.70} & & & & \multirow[b]{3}{*}{$-.84^{*}$} \\
\hline Constant & & & 1159.34 & 64.84 & \\
\hline Inactive time & & & -46.74 & 3.64 & \\
\hline Model 2: $F_{\text {change }}(2,70)=123.24 p<.001$ & \multirow[t]{4}{*}{.77} & \multirow[t]{4}{*}{.07} & & & \\
\hline Constant & & & 1005.05 & 63.79 & \\
\hline Inactive time & & & -41.61 & 3.30 & $-.74 *$ \\
\hline AT school \& leisure time & & & 1.11 & 0.22 & $.30 *$ \\
\hline Model 3: $F_{\text {change }}(3,69)=132.21 p<.001$ & \multirow[t]{5}{*}{.85} & \multirow[t]{5}{*}{.08} & & & \\
\hline Constant & & & 878.92 & 56.86 & \\
\hline Inactive time & & & -36.93 & 2.84 & $-.66^{*}$ \\
\hline AT school \& leisure time & & & 1.26 & 0.18 & $.34 *$ \\
\hline $\begin{array}{rr}\text { Sports } \\
\end{array}$ & & & 4.96 & .85 & $.28^{*}$ \\
\hline Model 4: $F_{\text {change }}(4,68)=146.94 p<.001$ & \multirow[t]{6}{*}{.90} & \multirow[t]{6}{*}{.05} & & & \\
\hline Constant & & & 797.94 & 50.21 & \\
\hline Inactive time & & & -33.10 & 2.50 & $-.60 *$ \\
\hline AT school \& leisure time & & & 1.21 & .16 & $.33^{*}$ \\
\hline Sports & & & 4.50 & .72 & $.26^{*}$ \\
\hline Work & & & 1.03 & .19 & $.23^{*}$ \\
\hline Model $5: F_{\text {change }}(5,67)=154.26 p<.001$ & \multirow[t]{7}{*}{.92} & \multirow[t]{7}{*}{.02} & & & \\
\hline Constant & & & 870.53 & 47.29 & \\
\hline Inactive time & & & -33.02 & 2.21 & $-59 *$ \\
\hline AT school \& leisure time & & & 1.18 & .14 & $.32 *$ \\
\hline Sports & & & 3.81 & .66 & $.22 *$ \\
\hline Work & & & 0.87 & .17 & $.19 *$ \\
\hline Gender & & & -43.23 & 9.68 & $-.17^{*}$ \\
\hline
\end{tabular}

\section{Dependent Variable: Physical Activity Energy Expenditure during School Hours}

\begin{tabular}{|c|c|c|c|c|c|}
\hline & & & & & \\
\hline & $\mathbf{R}^{2}$ & $\Delta \mathbf{R}^{2}$ & B & SE B & B \\
\hline Model 1: $F_{\text {change }}(1,71)=142.18 p<.001$ & .67 & & & & \\
\hline Constant & & & 59.91 & 5.4 & \\
\hline AT school & & & 1.48 & .12 & $.82 *$ \\
\hline Model 2: $F_{\text {change }}(2,70)=92.77 p<.001$ & .73 & .05 & & & \\
\hline Constant & & & 34.50 & 8.20 & \\
\hline AT school & & & 1.36 & .12 & $.75^{*}$ \\
\hline PE & & & 1.62 & .42 & $.25^{*}$ \\
\hline
\end{tabular}

Regression 1 (total PAEE) - excluded PE: beta in $=.06,(p=.19)$

Regression 2 (PAEE school) - excluded Gender: beta in $=.02$, $(p=.76)$

Inactive time $=$ time spent $<1.5 \mathrm{METs}$

${ }^{*}=p<.001$ 
Figure 3.1. PAEE (se) for the three PAL groups in: physical education (PE), active transport to school (AT school), active transport in leisure time (AT LT), leisure time sports (LT sports) and Work

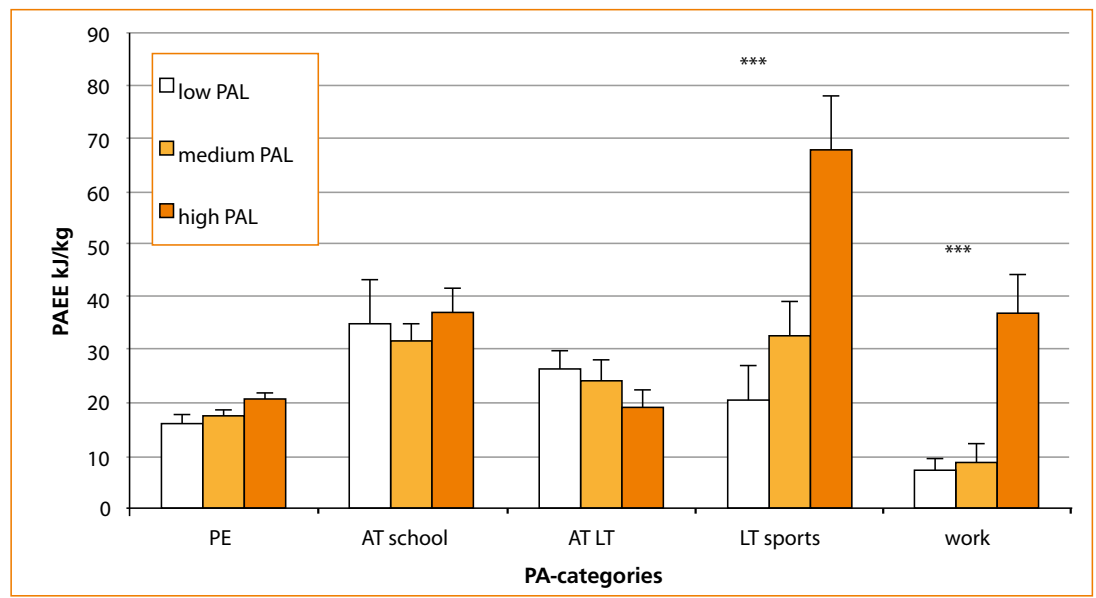

$* * *=$ high $\mathrm{PAL}>$ low PAL \& medium PAL $p<.001$

Figure 3.2. PAEE (se) for boys and girls in: physical education (PE), active transport to school (AT school) active transport during leisure time (AT LT), leisure time sports (LT sports) and Work

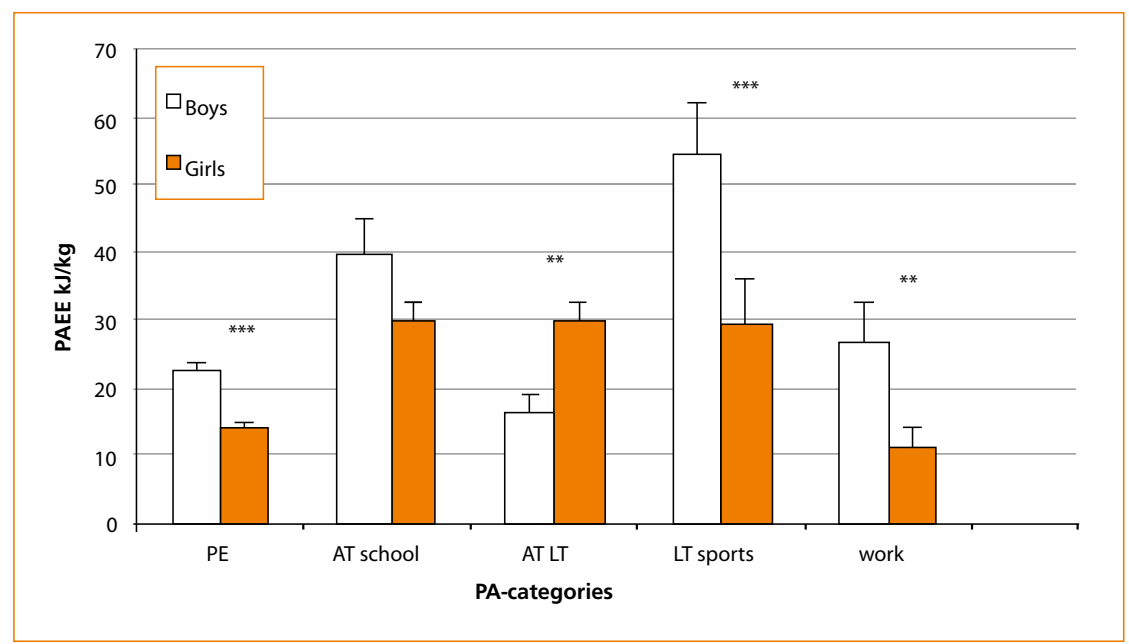

${ }^{*}=p<0.5^{* *}=p<.01 * * *=p<.001$ 


\section{Discussion}

The purpose of this study was to assesS PAEE in adolescents during a school week and to determine the contributions of PE, active transport and leisure time sports. This knowledge can be of particular value when designing school-based interventions. Total PAEE over 6 days was $376.2( \pm 140.4) \mathrm{kJ} / \mathrm{kg}$ for boys and 279.6 $( \pm 100.8) \mathrm{kJ} / \mathrm{kg}$ for girls. Multiple regression analysis showed that $92 \%$ of the variance in total PAEE could be explained by time spent inactive, active transport (school and leisure time), sports, work and gender. This confirms that we were able to capture the most important activities that comprise PAEE in this group in daily life. Boys were physically more active than girls, which is in line with other studies in this age-group..$^{12,13}$

According to Ferreira et al. ${ }^{1}$, in order to successfully increase PA in children and adolescents, priority should be given to studying determinants of PA in the school environment. In our study, PE and active transport together explained $73 \%$ of PAEE during school hours, which stresses the importance of these activities as promising PA-intervention components within school programs. On PE lesson days, PE contributed $30 \%$ to PAEE. However, the fact that PE was not a significant predictor of total PAEE shows that its impact is probably limited by the low frequency of one lesson per week. Since no differences were observed in PAEE during PE between low, medium and high PAL groups (figure 3.2), increasing the frequency of PE lessons might be an effective intervention to increase physical activity for all adolescents, given the obligatory nature of school PE. Confirming earlier findings $5^{4,27}$, boys were significantly more active during PE than girls. Therefore, special attention should be given to the suitability of the PE curriculum to maximize girls' participation.

Active commuting to school has also been identified as a potentially important school-related source of PA ${ }^{28,29}$ and has been related to higher fitness levels in children and adolescents. ${ }^{9}$ In the Netherlands, $97 \%$ of the adolescents own a bike, and cycle an average daily distance of approximately $6 \mathrm{~km} /$ day. ${ }^{30} \mathrm{In}$ our study $95 \%$ of the boys and $97 \%$ of the girls actively commuted to school, which is in sharp contrast with findings in the US where only $14 \%$ of all adolescents were reported to use active transport to school. ${ }^{31}$ The Netherlands is a densely populated, predominantly flat country where a long cycling tradition has led to an extensive cycling-friendly infrastructure in and between cities, providing an optimal environment for bike usage. In our sample, 30\% of PAEE during school hours originated from active transport to school, which underlines its potential in stimulating PA in adolescents. When active transport during leisure time was added to active transport to school, together they were responsible for one fifth of total PAEE. Although there are often barriers that need to be overcome in order to stimulate youth to use active transportation (e.g. road safety, separate biking lanes) ${ }^{7}$, our results show that stimulating the use of active transport to school and during leisure time is worthwhile in countries where active transportation rates are low. Notably, active transport during leisure time over all six measurement days was the only category where girls were significantly more active than boys. Qualitative analysis of the activity diary data suggested that girls spent more time walking than boys, mainly caused by strolling and shopping in the city centre.

An unexpected finding in our study was the impact work-related activities had on PAEE. In the Netherlands adolescents are allowed to perform certain forms of paid work (e.g. waiting at a bar or restaurant, paper delivery, or restocking supermarket shelves) from the age of 15 . About $52 \%$ of the adolescents in our study performed paid work, which resulted in almost $12 \%$ of PAEE during the weekend coming from work related activity. Although more specific research is needed in this area, the results in our study also suggest that work-related activities might be a significant, but often overlooked source of PA in adolescents. 
Compared to previous studies measuring PAEE in adolescents ${ }^{12-15}$, it seems that the Dutch adolescents in our sample expended average amounts of PAEE, although caution should be taken comparing studies using different methodology. It should also be noted that in all studies the inter-individual variability in PAEE was high. Pfeiffer et al. ${ }^{32}$ reported that large differences in PAEE are possible between adolescents for the same activity. These differences in PAEE are probably due to behavioural differences such as the duration and intensity of physical activities. ${ }^{12}$ Unlike previous studies, which only measured total PAEE, by using an activity diary we could identify the specific physical activity behaviours that constituted PAEE. We found that subjects with a high PAL also had higher PAEE during school hours and spent more PAEE during leisure time sports and work-related activities than did subjects in the low PAL category (figure 3.2). Active transportation however, was similar across all PAL groups. The latter can be explained by the fact that $96 \%$ of our study population used active transportation to school, which makes it an unlikely factor to discriminate between the three PAL-groups.

Recent evidence has shown that, independent of meeting physical activity guidelines, spending too much time

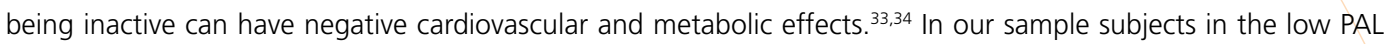
group spent 4 hours more being inactive compared to the high PAL group. This finding is similar to an earlier study. ${ }^{13}$ Interestingly, subjects in the low PAL group spent significantly less time in leisure time sports and workrelated activities, making these activities interesting candidates for reducing inactivity out-of-school. In this respect, it should be taken into account that Westerterp ${ }^{35}$ has suggested that substituting inactive or low-intensity activity behaviour for moderate-intensity physical activity might be preferable to substitution for vigorous physical activity (VPA), since time in VPA does not predict total energy expenditure.

\section{Limitations}

Although combing HR+ACC with activity diary data allowed us to analyse PAEE in free-living conditions while identifying the contribution of the various activities to total PAEE, our study needs confirmation in other samples; for example within different ethnic populations, primary school students, different educational levels, and overweight subjects. Also, bike-use was very high in our sample, which might be representative for the Netherlands but not for other countries. Therefore, although our results give good insight into the impact of active transportation on PAEE during school hours, caution should be taken in generalizing these findings to other populations.

\section{Conclusions}

To our knowledge, this is the first study that has determined free-living PAEE in adolescents within specific physical activity categories by combining energy expenditure data with activity diary data. The results of this study could guide the implementation of school interventions aimed at increasing physical activity in adolescents and inform policy makers on the potential effects of changes in the school environment. We found that during school hours PE and active transport had a large contribution to PAEE, while for total PAEE pronounced differences existed within leisure time sports and work-related activities between subjects with high and low PAL values. 


\section{Implications for school health}

School-based physical activity promotion has great potential in stimulating students to become active. During school hours PAEE consisted mostly of energy expended during PE and active transport, confirming the importance of these activities as targets for schools aiming to increase their students' physical activity levels. Although the amount of students using active transport to school reported in our study is rather uncommon in other countries, the results in this study do show the enormous impact active transportation can have on physical activity levels in adolescents. Programs aimed at increasing active transportation to school should therefore be advocated. This study also indicates that increasing the number of PE lessons is an effective strategy for enhancing physical activity levels during school time. Since this might be difficult to realize in most schools due to budget allocation restrictions, it is interesting to note that recent studies show that physical activity can be increased during existing PE-lessons, without neglecting other PE-goals, and that this is relatively easy to implement in all lessons. ${ }^{36}$ 


\section{References}

Ferreira I, van der Horst K, Wendel-Vos W, Kremers S, Lenthe van F, Brug J. Environmental correlates of physical activity in youth - a review and update. Obes Rev. 2007;8:129-54.

Pate RR, O'neill JR. After-school interventions to increase physical activity among youth. Brit J Sport Med. 2009;43(1):14-8.

Fairclough S, Stratton G. Physical Activity Levels in Middle and High School Physical Education: A Review. Pediatr Exerc Sci. 2005;17(3):217-36.

Slingerland M, Oomen J, Borghouts L. Physical activity levels during Dutch primary and secondary school physical education. Eur J Sport Sci. 2011;11(4):249-57.

Westerståhl M, Barnekow-Bergkvist M, Jansson E. Low physical activity among adolescents in practical education. Scand J Med Sci Sports. 2005;15(5):287-97.

Lee MC, Orenstein MR, Richardson MJ. Systematic review of active commuting to school and childrens physical activity and weight. J Phys Act Health. 2008;5(6):930.

Shephard R. Is Active Commuting the Answer to Population Health? Sports Med. 2008;38.

Sluijs VE, Fearne V, Mattocks $C$. The contribution of active travel to children's physical activity levels: Cross-sectional results from the ALSPAC study Prev Med. 2009;48(2):108-14.

Cooper AR, Wedderkopp N, Wang H, Andersen LBO, Froberg K, Page AS. Active travel to school and cardiovascular fitness in Danish children and adolescents. Med Sci Sport Exer. 2006;38(10):1724.

Silva P, Sousa M, Aires L, Seabra A, Ribeiro J, Welk G, et al. Physical activity patterns in Portuguese adolescents: The contribution of extracurricular sports. Eur Phys Educn Rev. 2010;16(2):171-81.

Mechelen W, Twisk J, Post G, Snel J, Kemper H. Physical activity of young people: the Amsterdam Longitudinal Growth and Health Study. Med Sci Sport Exer. 2000;32(9):1610-16.

Vermorel M, Vernet J, Bitar A, Fellmann N, Coudert J. Daily energy expenditure, activity patterns, and energy costs of the various activities in French 12-16-y-old adolescents in free living conditions. Eur I Clin Nutr. 2002;56(9):819-29.

Bratteby LE, Sandhagen B, Lötborn M, Samuelson G. Daily energy expenditure and physical activity assessed by an activity diary in 374 randomly selected 15-year-old adolescents. Eur J Clin Nutr. 1997;51(9):592-600.

Ekelund $U$, Sjostrom M. Total daily energy expenditure and pattern of physical activity measured by minute-byminute heart rate monitoring in 14--15 year old Swedish adolescents. Eur J Clin Nutr. 2000;54(3):195-202.

Corder K, Brage S, Wright A, Ramachandran A, Snehalatha C, Yamuna A, et al. Physical activity energy expenditure of adolescents in India. Obesity. 2010;18(11):2212-2219

Corder K, Ekelund U, Steele R, Wareham N, Brage S. Assessment of physical activity in youth. J Appl Physiol. 2008;105(3):977-87.

Welk G, Corbin C, Dale D. Measurement issues in the assessment of physical activity in children. Res Q Exercise Sport. 2000;71(2):59.

Brage S, Brage N, Franks P, Ekelund U, Wareham N. Reliability and validity of the combined heart rate and movement sensor Actiheart. Eur J Clin Nutr. 2005;59(4):561-70.

Corder K, Brage Sr, Wareham N, Ekelund U. Comparison of PAEE from Combined and Separate Heart Rate and Movement Models in Children. Med Sci Sports Exer. 2005;37(10):1761-67.

Brage S, Brage N, Franks P, Ekelund U, Wong M, Andersen L, et al. Branched equation modeling of simultaneous accelerometry and heart rate monitoring improves estimate of directly measured physical activity energy expenditure. J Appl Physiol. 2004;96(1):343. 
Corder K, Brage S, Mattocks C, Ness A, Riddoch C, Wareham N, et al. Comparison of Two Methods to Assess PAEE during Six Activities in Children. Med Sci Sports Exer. 2007;39(12):2180-88.

Barreira T, Kang M, Caputo J, Farley R, Renfrow M. Validation of the Actiheart Monitor for the measurement of physical activity. Int J Exer Sci. 2009;2(1):60-71.

Brage S, Ekelund U, Brage N, Hennings M, Froberg K, Franks P, et al. Hierarchy of individual calibration levels for heart rate and accelerometry to measure physical activity. J Appl Physiol. 2007;103(2):682-92.

Ridley K, Ainsworth BE, Olds, TS. Development of a compendium of energy expenditures for youth. Int J Behav Nutr Phys Act. 2008;5(1):45-53.

Schofield WN. Predicting basal metabolic rate, new standards and review of previous work. Hum Nutr Clin Nutr. 1985;39(Suppl):5-41.

Field A. Discovering statistics using SPSS second edition. London: Sage Publications, 2005:159-162

Laurson K, Brown D, Cullen R, Dennis K. Heart rates of high school physical education students during team sports, individual sports, and fitness activities. Res Q Exercise Sport. 2008;79(1):85-91.

Strong W, Malina R, Blimkie C, Daniels S, Dishman R, Gutin B, et al. Evidence based physical activity for school-age youth. J Pediatr 2005;146(6):732-37.

Tudor-Locke C, Ainsworth B, Popkin B. Active commuting to school: An overlooked source of childrens physical activity? Sports Med. 2001;31(5):309-13.

The Dutch Ministry of Transport, Public Works and Water Management. Mobility Survey Netherlands 2009. 2010:1-54.

Ham SA, Martin S, Kohl HW. Changes in the percentage of students who walk or bike to school-United States, 1969 and 2001. J Phys Act Health. 2008;5(2):205-15.

Pfeiffer KA, Schmitz KH, McMurray RG, Treuth MS, Murray DM, Pate RR. Physical activities in adolescent girls: variability in energy expenditure. Am J Prev Med. 2006;31(4):328-31.

Hamilton M, Healy G, Dunstan D, Zderic T, Owen N. Too little exercise and too much sitting: Inactivity physiology and the need for new recommendations on sedentary behavior. Curr Cardiovasc Risk Rep. 2008;2:292-98.

Healy GN, Wijndaele K, Dunstan DW, Shaw JE, Salmon J, Zimmet PZ, et al. Objectively measured sedentary time, physical activity, and metabolic risk: the Australian Diabetes, Obesity and Lifestyle Study (AusDiab). Diabetes Care. 2008;31(2):369-71.

Westerterp K. Pattern and intensity of physical activity. Nature. 2001;410:539.

Fairclough S, Stratton G. Effects of a physical education intervention to improve student activity levels. Phys Educ Sport Pedagog 2006;11(1):29-44 


\section{CHAPTER 4}

\section{PHYSICAL ACTIVITY LEVELS DURING DUTCH PRIMARY AND SECONDARY SCHOOL PHYSICAL EDUCATION}

SLINGERLAND, M., OOMEN J.M. \& BORGHOUTS L.B.

EUROPEAN JOURNAL OF SPORT SCIENCES 2011 (11) 4: 249-2571 


\section{Summary}

Background: Physical education (PE) has been attributed an important role in providing young people with physical activity. If sufficiently active, PE lessons could contribute to physical activity levels in youth. Therefore, the purpose of this study was to determine the overall intensity of Dutch primary and secondary school physical education (PE) lessons and the influence of various lesson characteristics on these intensity levels.

Methods: Heart rates were measured during PE lessons using the Polar Team System in a nationally distributed sample of 913 students in 40 schools in the Netherlands.

Results: Overall percentages lesson time in moderate-to-vigorous physical activity (MVPA) were $46.7 \%$ and $40.1 \%$ during primary school and secondary school PE respectively. Results indicated a sharp decline in girls' PE intensity levels at the beginning of secondary school. Furthermore, secondary school boys were more active than girls.

Discussion: The high prevalence of team games in the Dutch PE curricula might prevent secondary school girls from attaining similar physical activity levels during PE. 
Physical activity (PA) guidelines recommend that children and adolescents (6-18 years of age) should engage in at least a daily hour of moderate-to-vigorous physical activity (MVPA) in order to obtain various health benefits (Biddle, Sallis \& Cavill, 1998; Kemper, Ooijendijk, \& Stiggelbout, 2000; USDHHS, 2008). However youth guideline compliance is generally low across most western countries and Dutch youth are no exception to this. Thirty-two percent of 4-11 year old boys and girls, and 15\% of 12-17 year olds are currently meeting the PA-guideline recommendations (Hildebrandt, Ooijendijk, \& Hopman Rock, 2008). In 6 to 11 year old children living in urban areas with a low social-economic status, guideline compliance is low as $4 \%$ in native Dutch youngsters and $3 \%$ in youngsters with a different ethnicity (Hildebrandt, Ooijendijk, \& Hopman Rock, 2007).

Schools are considered an important setting to influence PA of youth given the amount of time spent at school and the potential of schools to reach large numbers of children/adolescents. Important components of school related physical activity include active school transport (Buliung, Mitra, \& Faulkner, 2009; Sluijs, Fearne, \& Mattocks, 2009), activity during recess (Colabianchi, Kinsella, Coulton, \& Moore, 2009; Ridgers, Tóth, \& Uvacsek, 2009) and physical education (Trudeau \& Shephard, 2005). Physical education (PE) has been attributed an important role in this respect, with an increase in number of PE lessons being characterised as a promising intervention strategy (Kahn, et al., 2002).

Physical education has the potential to effectively provide all children and adolescents with structured and regular physical activity, as virtually all children and adolescents attend school. Thus, for many children PE is an important source of physical activity (Trudeau \& Shephard, 2005). For example, 30\% of 16-year old Swedish adolescents in practical education report to get all of their MVPA out of PE (Westerstahl, Barnekow-Bergkvist, Hedberg, \& Jansson, 2003), whereas only $8 \%$ of Chinese students participate in MVPA outside of school (Tudor-Locke, Ainsworth, Adair, Du, \& Popkin, 2003,). In Dutch adolescent boys, increases of 3-25\% of total weekly physical activity have been reported by increasing the number of weekly PE lessons (Kemper, Verschuur, Ras, Snel, Splinter \& Tavecchio, 1976). Therefore it is often claimed that regular PE could make a meaningful contribution to the daily accumulation of physical activity needed for health benefits (Corbin \& Pangrazi, 2003; Sallis, et al., 1997). Physical activity obtained by participating in PE is hereby dependent on both the number of lessons provided and the intensity of these lessons. The US Department of Health has acknowledged this potential in their Healthy People 2010 national health objectives, by stating that schools should provide daily PE and by recommending that at least $50 \%$ of regular PE lesson time should be spent in MVPA intensity (USDHHS, 2008).

Two recent reviews by Fairclough and Stratton (Fairclough \& Stratton, 2005; Fairclough \& Stratton, 2006a) made clear that several studies have been conducted, most of them in the US and the UK, investigating the amount of active lesson time during elementary and secondary school PE. Results showed that during elementary school PE pupils engaged in MVPA for an average of $37.4 \%( \pm 15.7)$ of lesson time. In secondary schools the average percentage of class time spent in MVPA during PE lessons varied between $40 \%( \pm 13.8)$ for heart rate (HR) monitoring data and $27.7 \%( \pm 14.9)$ for observational data.

Despite the fact that the attention for a PA-stimulating role of PE is increasing, activity levels in non-intervention Dutch primary and secondary school PE lessons have never been investigated. Thus, the contribution of PE to the accumulation of physical activity in Dutch elementary and secondary school students is as yet unknown. Therefore, the primary aim of this study was to assess the amount of PE lesson time Dutch primary and secondary school students spend in MVPA. Furthermore, this study also aimed to examine the influence of moderating variables, such as gender, grade, group size, teacher type (specialist vs. classroom teacher), and lesson content on percentage of time spent in MVPA during PE-lessons. 


\section{Method}

\section{Subjects and setting}

Participants were Dutch primary $(N=461)$ and secondary $(N=452)$ school students from 40 schools in the Netherlands. Regular PE lessons were attended and per lesson the heart rates of 10 students were continuously measured. To obtain a nationally distributed research sample, schools were randomly selected from the databases of various PETE (Phiysical Education Teacher Education) schools in The Hague, Nijmegen, Groningen, Sittard and Tilburg. The schools' PE-teachers gave their consent for measurements to be carried out in their lessons. All schools taught the nationally established statutory PE programs, which consist of activities in 4 domains for primary schools (track \& field, gymnastics, games and dance) and of activities in 5 domains for secondary schools (track \& field, gymnastics, games, dance and self-defence). Provided lessons in the various domains were equally spread out over the school year. All schools, primary and secondary, taught PE in mixed-sex classes. Locations of the lessons varied from variously sized sport halls to outdoor locations. Teachers were asked not to deviate from their regular PE program and to carry out their lessons as they had planned. None of the lessons had a specifically planned physical activity intensity focus. Twenty primary schools participated in the study. Lessons were either taught by specialist $P E$ teachers $(N=11)$ or by classroom teachers $(N=9)$. These numbers reflect the current situation in the Netherlands, were $43 \%$ of the PE lessons are taught by specialists, with urban areas scoring higher than rural areas (81\% versus 30\%) (Werf \& Smeenk, 2007). Per primary school 1 PE-lesson was measured in each of the grades 4,5 and 6 (corresponding to 9-10, 10-11 and 11-12 years of age respectively). A preceding pilot-study showed serious HR transmitter fitting problems in grades 1,2 and 3, caused by the often small chest sizes of the children in this age group. These feasibility problems resulted in large chunks of missing HR data and therefore we decided not to assess grades 1,2 and 3 in the main study. Twenty secondary schools took part in the study of which 9 schools offered VMBO education and 11 schools offered VWO education. VWO is a 6-year education that prepares students for university and therefore demands a higher level of cognitive skills compared to VMBO, which is a 4-year education that prepares students for more practical professions in which demanded cognitive skills are lower but required practical skills are higher. All secondary school PE-lessons were taught by a specialist PE teacher, as is obligatory. PE-lessons were measured in VMBO grades 8 and 10 (13-14 and 15-16 years of age respectively) and in VWO 8, 10 and 12 (13-14, 15-16 and 17-18 years of age respectively).

\section{Instruments and procedures}

The study was approved by the institutional Research Ethics Committee. Per lesson, 10 randomly selected students ( 5 girls and 5 boys) were equipped with heart rate monitors. The type of heart rate monitor used was the Polar Team System (Polar Electro Oy, Finland). This chest worn system averaged and stored heart rate every 5 seconds onto an on-board chip for the duration of the whole lesson. HR transmitters were moisturized and fitted to the students prior to the beginning of the lesson. Monitors were activated automatically once a heart frequency signal was detected from the student wearing it, noticeable by a sound signal. After hearing the sound signal students entered their PE class. Fitting heart rate monitors was carried out before the scheduled start of the lessons in most instances. On average this took about 1 minute per student. The following variables were recorded on standardized observation sheets directly after the end of each assessed lesson: scheduled lesson time, class size, $\mathrm{PE}$-area (measured to the nearest $\mathrm{m} 2$ using a regular measuring tape), lesson content, and classroom teacher or specialist PE teacher 


\section{Data analyses}

Data was plotted and checked for outliers (heart rate values lower than 50 or higher than 220 were deleted). Erroneous values were removed and were imputed together with any lost data caused by a heart frequency signal loss of the monitor during the measurement. Data was imputed by using the HR values from all other students wearing a HR transmitter during that lesson. The mean HR over the corresponding time frame was used to replace the erroneous or missing value. Measurements of a student were discarded when imputed data exceeded $20 \%$ of active lesson time. Subsequently, values were calculated for absolute minutes in the categories light, vigorous, moderate and MVPA (vigorous + moderate) as well as for percentages of active lesson time. Heart Rate Reserve (HRR) was used to determine target heart rate zones for each group, as it accounts for age and sex differences. Heart rate cut-points for each group were based on the values as proposed by Stratton, who used estimated age-related minimum and maximum heart rate values (see table 4.1) (Stratton, 1996). These variables were then entered into SPSS 17.0 for further analysis. Prior to analysis, data was checked for acceptable values of normality (Kolmogorov-Smirnov test) and homogeneity of variance (Levene's test), the alpha level was set to .05 for all statistical analyses.

Table 4.1 Cut points for moderate and vigorous activity, based on Stratton (1996)

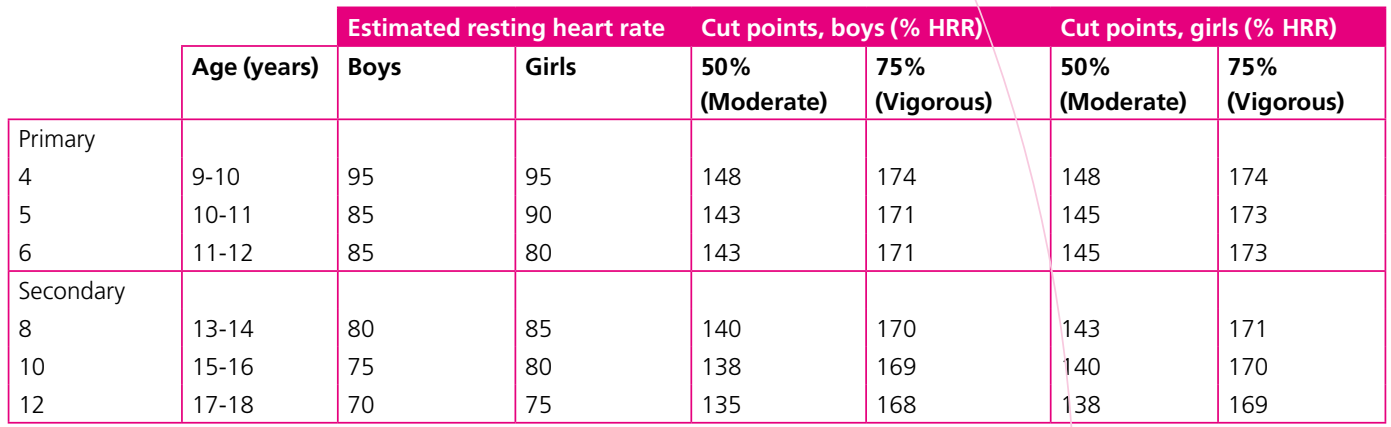

HRR - percentage heart rate reserve 
Table 4.2. \%MVPA by gender and grade (mean $\pm s)$

\begin{tabular}{|c|c|c|c|c|c|c|c|}
\hline & Grade (age) & $n$ & $\begin{array}{l}\text { \%MVPA } \\
\text { Overall }\end{array}$ & $n$ & $\begin{array}{l}\% \text { MVPA } \\
\text { Boys }\end{array}$ & $n$ & $\begin{array}{l}\% \text { MVPA } \\
\text { Girls }\end{array}$ \\
\hline Primary School & $\begin{array}{l}4(9-10) \\
5(10-11) \\
6(11-12) \\
\text { Combined }\end{array}$ & $\begin{array}{l}156 \\
162 \\
143 \\
461 \\
\end{array}$ & $\begin{array}{l}42.2 \pm 19.7 \\
53.0 \pm 17.0 * * \\
45.0 \pm 19.8 \\
46.7 \pm 20.0^{*}\end{array}$ & \begin{tabular}{|l|}
83 \\
81 \\
75 \\
239 \\
\end{tabular} & $\begin{array}{l}42.4 \pm 18.6 \\
54.0 \pm 19.0 * * * \\
44.8 \pm 19.2 \\
47.1 \pm 19.5\end{array}$ & $\begin{array}{l}73 \\
81 \\
68 \\
222 \\
\end{array}$ & $\begin{array}{l}41.9 \pm 21.0 \\
51.9 \pm 19.0 * * * * \\
44.3 \pm 20.7 \\
46.3 \pm 20.5 \neq\end{array}$ \\
\hline Secondary School & $\begin{array}{l}8(13-14) \\
10(15-16) \\
12(17-18) \\
\text { Combined }\end{array}$ & $\begin{array}{l}210 \\
196 \\
46 \\
452\end{array}$ & $\begin{array}{l}39.8 \pm 22.9 \\
38.1 \pm 21.6 \\
49.7 \pm 26.8^{\wedge} \\
40.1 \pm 23.0\end{array}$ & $\begin{array}{l}115 \\
100 \\
22 \\
237\end{array}$ & $\begin{array}{l}43.6 \pm 23.6 \\
40.7 \pm 21.6 \\
53.1 \pm 28.0 \\
43.2 \pm 23.4\end{array}$ & $\begin{array}{l}95 \\
96 \\
24 \\
215\end{array}$ & $\begin{array}{l}35.3 \pm 21.3 \\
35.4 \pm 21.3 \\
46.6 \pm 25.9 \\
36.6 \pm 22.0\end{array}$ \\
\hline
\end{tabular}

* overall primary school $>$ secondary school $p<.01$

$* * 5$ th $>4$ th $p<.001$ and 5 th $>6$ th $p<.001$

$* * * 5$ th $>4$ th $p<.001$ and 5 th $>6$ th $p<.01$

$* * * * 5$ th $>4$ th $\mathrm{p}<.01$

$\wedge 12$ th grade $>8$ th grade $p<.05$ and 12 th grade $>10$ th grade $p<.01$

$\int$ secondary school boys $>$ girls $p<.001$

₹ primary school girls $>$ secondary school girls $p<.001$

Descriptive statistics for scheduled and active lesson time were calculated together with absolute and relative values in the different intensity categories light, moderate, vigorous and MVPA. Three separate two-way (\%MVPA) as the dependent variable: A gender $\mathrm{x}$ school type ANOVA and two separate gender $\mathrm{x}$ grade ANOVAs, one for primary and one for secondary schools. Simple effect analyses were used to further explore significant interactions, while follow-up t-tests and one-way ANOVAs with Bonferroni post hoc tests were used to examine differences in any significant main effects. Class size and students per $\mathrm{m} 2$ were recoded into two-level variables, with their cut-off points determined by the mean. Principal lesson content was recoded into a three-level variable consisting of team games, individual activities and mixed lessons. Lesson subject was assigned to team games if there was some form of co-operation needed during the game between students (e.g. basketball, handball, volleyball, soccer). In individual activities students were in control of their own performance and/or timing (e.g. athletics, gymnastics, dance and fitness activities). Mixed lessons consisted partly of teamgames and partly of individual activities. Two-way independent ANOVA's (gender x lesson characteristic) were conducted for primary and secondary school students separately to test for interaction effects. Significant interaction effects were followed by simple effect analyses. independent ANOVAs were conducted with lesson time spent in MVPA (\%MVPA) as the dependent variable: A gender $x$ school type ANOVA and two separate gender $x$ grade ANOVAs, one for primary and one for secondary schools. Simple effect analyses were used to further explore significant interactions, while follow-up t-tests and one-way ANOVAs with Bonferroni post hoc tests were used to examine differences in any significant main effects. Class size and students per $\mathrm{m} 2$ were recoded into two-level variables, with their cut-off points determined by the mean. Principal lesson content was recoded into a three-level variable consisting of team games, individual activities and mixed lessons. Lesson subject was assigned to team games if there was some form of co-operation needed during the game between students (e.g. basketball, handball, volleyball, soccer). In individual activities students were in control of their own performance and/or timing (e.g. athletics, gymnastics, dance and fitness activities). Mixed lessons consisted partly of teamgames and partly of individual activities. Two-way 
independent ANOVA's (gender x lesson characteristic) were conducted for primary and secondary school students separately to test for interaction effects. Significant interaction effects were followed by simple effect analyses.

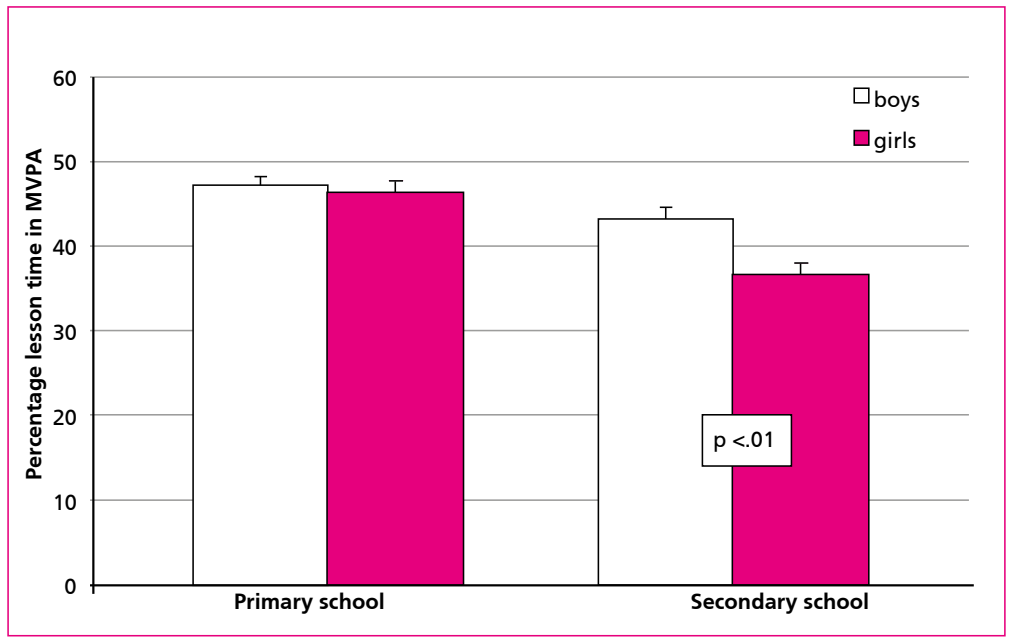

Figure 4.1. Means and standard errors for percentage lesson time spent in MVPA for primary and secondary school boys and girls.

\section{Results}

Data from 913 students were obtained during a total of 106 PE lessons. Scheduled lesson time was $49.39 \pm 7.53$ minutes (range 30-95) for primary school and $73.52 \pm 24.55$ minutes (range 40-120) for secondary school. Active lesson time was $39.55 \pm 10.14$ minutes (range 11-60) for primary schools and $57.07 \pm 23.13$ minutes (range 21-108) for secondary schools. The difference between scheduled and active lesson time was 19.9\% (9.84 minutes) and $22.4 \%$ (16.45 minutes) for primary and secondary schools respectively. Results for PE lesson time spent in MVPA are displayed in 4.2. Overall percentage of PE lesson time spent in MVPA was $46.7 \pm 20 \%$ for primary school students and $40.1 \pm 23 \%$ for secondary school students. These percentages correspond to an average of $18.34 \pm 9.19$ and $21.44 \pm 14.10$ minutes of MVPA for primary and secondary school students respectively. Consecutive mean values for the light, moderate and vigorous intensity categories were $53.3 \%, 29.1 \%$ and $17.6 \%$ respectively for primary school students and $60 \%, 27.5 \%$ and $12.5 \%$ for secondary school students.

The two-way independent ANOVA for primary and secondary school combined detected main effects for gender $(F(1,909)=6.907, p<.01)$ and school type $(F(1,909)=22.685, p<.001)$. Follow-up t-tests showed that primary school students engaged in significantly more MVPA $(t(890)=4.635, p<.001)$ than did secondary school students and that boys were more active during PE than girls $(\mathrm{t}(911)=2.546, \mathrm{p}<.05)$. The interaction of gender $\mathrm{x}$ school type on \%MVPA was also significant $(F(1,909)=4.221, p<.05)$. Subsequent simple mean effect analysis indicated that boys were more active than girls in secondary school $(F(1,912)=9,58, p<.01)$, but not in primary school (see 4.1). Furthermore, the difference in \%MVPA between primary and secondary school students was greater in girls $(46.3 \%$ vs. $36.6 \%$ respectively) than in boys ( $47.1 \%$ vs. $43.2 \%$ respectively, see figure 4.1$)$. 
The two-way independent ANOVA for primary school students indicated a main effect of grade $(F(2,455)=$ $13.351, p<.001)$, with a Bonferroni post-hoc analysis indicating that 5 th grade students were more active than 4 th grade $(p<.001)$ and 6 th grade students $(p<.001)$. The two-way independent ANOVA for secondary school students showed main effects for gender $(F(1,446)=6.217, p<.05)$ and for grade $(F(2,446)=5.200, p<.01)$, the interaction effect however was not significant. Follow-up analyses showed that secondary school boys engaged in more MVPA than girls $(p<.001)$ and that 12th grade students were more active than 8 th grade $(p<.05)$ and 10th grade students $(p<.01)$.

In table $4.3 \%$ MVPA is displayed for the various lesson characteristics. Two-way independent ANOVAs (gender $\mathrm{x}$ lesson characteristic) were conducted to test for main and interaction effects. In primary schools a main effect of lesson content was found. Post hoc tests revealed that individual activities were more active than team games $(p<.01)$ and mixed lessons $(p<.01)$. The interaction effect was not significant indicating there was no difference in $\%$ MVPA for boys and girls regarding lesson content. In secondary schools there were main gender effects for class size, students per $\mathrm{m} 2$ and educational level, confirming the previous finding that boys were more active than girls during secondary school PE. Furthermore, a main effect for educational level and gender was found, indicating that VWO students were more active during PE lessons than VBMO students and boys being more active than girls. However, the interaction effect was not significant, indicating that educational level influenced \%MVPA equally for boys and girls. Finally, a significant interaction effect was found for gender $\mathrm{x}$ lesson content in secondary schools $(F(2,446)=3.371, p<.05)$. Additional simple mean effect analysis indicated that boys were more active during team games than girls $(45.7 \%$ vs. $34.7 \% \mathrm{~F}(3,451)=16.31, \mathrm{p}<.001$, see figure 4.2$)$.

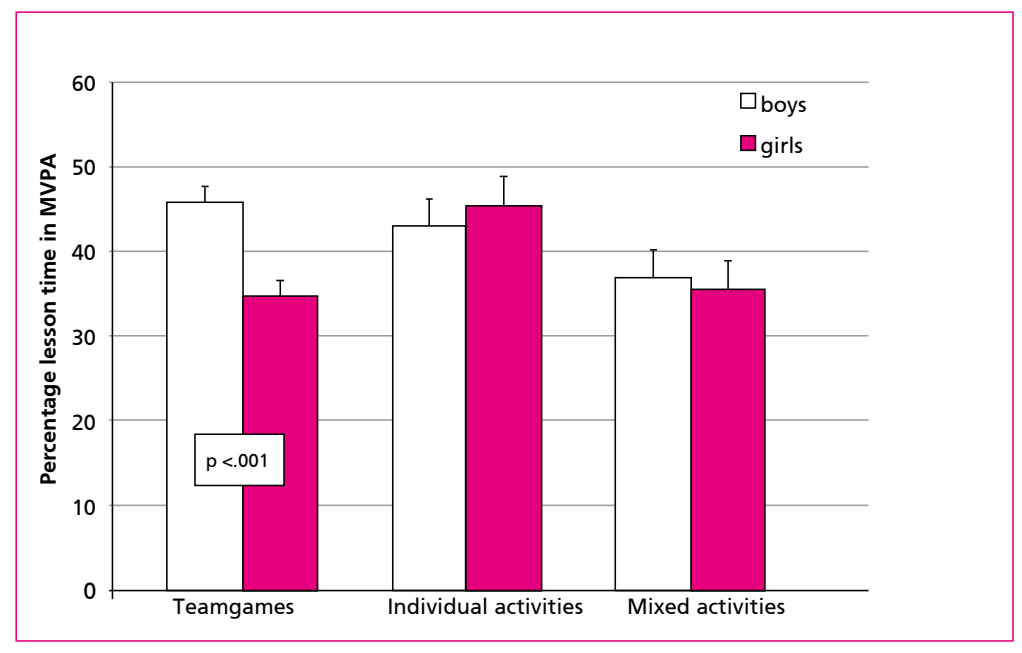

Figure 4.2. Means and standard errors for percentage lesson time spent in MVPA for secondary school boys and girls in team games, individual activities, and mixed lessons. 


\section{Discussion}

This study investigated the intensity of PE lessons in 913 primary and secondary school students 9-18 years of age. Notably, it is the first study that investigated the intensity of non-intervention PE lessons in the Netherlands. Overall findings showed that primary school students spent $46.6 \%$ of PE lesson time in MVPA, whereas secondary school students spent $40.1 \%$ of PE lesson time in MVPA. These values are similar to those reviewed elsewhere for PE lessons in the UK and US (Fairclough \& Stratton, 2005; Fairclough \& Stratton, 2006a). It has been suggested that PE could play a role in attaining physical activity guidelines (McKenzie \& Sallis, 1997). In our study, students accrued an average of 18.34 and 21.44 minutes of MVPA per lesson for primary and secondary school respectively, which is comparable to findings in other studies (Chow, McKenzie, \& Louie, 2008; Laurson, Brown, Cullen, \& Dennis, 2008). Given current curricular and time constraints in most schools, it is not realistic to consider PE as a stand-alone solution to combat inactivity. However, when combined with other school, family and communitybased physical activity opportunities PE could make a meaningful contribution to youths' physical activity levels (Fairclough \& Stratton, 2006a), especially since various intervention studies have shown that it is possible to increase active lesson time without compromising other PE-goals (McKenzie, et al., 2004; Verstraete, Cardon, De Clercq, \& De Bourdeaudhuij, 2007).

However, our results also show that one PE lesson roughly accounts for one-third of the daily amount of physical activity as prescribed by the activity guidelines. Therefore, increasing the number of weekly PE lessons seems an effective strategy to increase youth physical activity. In the Netherlands there is currently much political debate on this subject. Consequently, the results from this study might deliver an important, evidence-based argument to persuade policy makers to include more curriculum time for PE in national school programs. 
Table 4.3. \%MVPA (mean \pm s), main effects and interaction effects for the various lesson characteristics

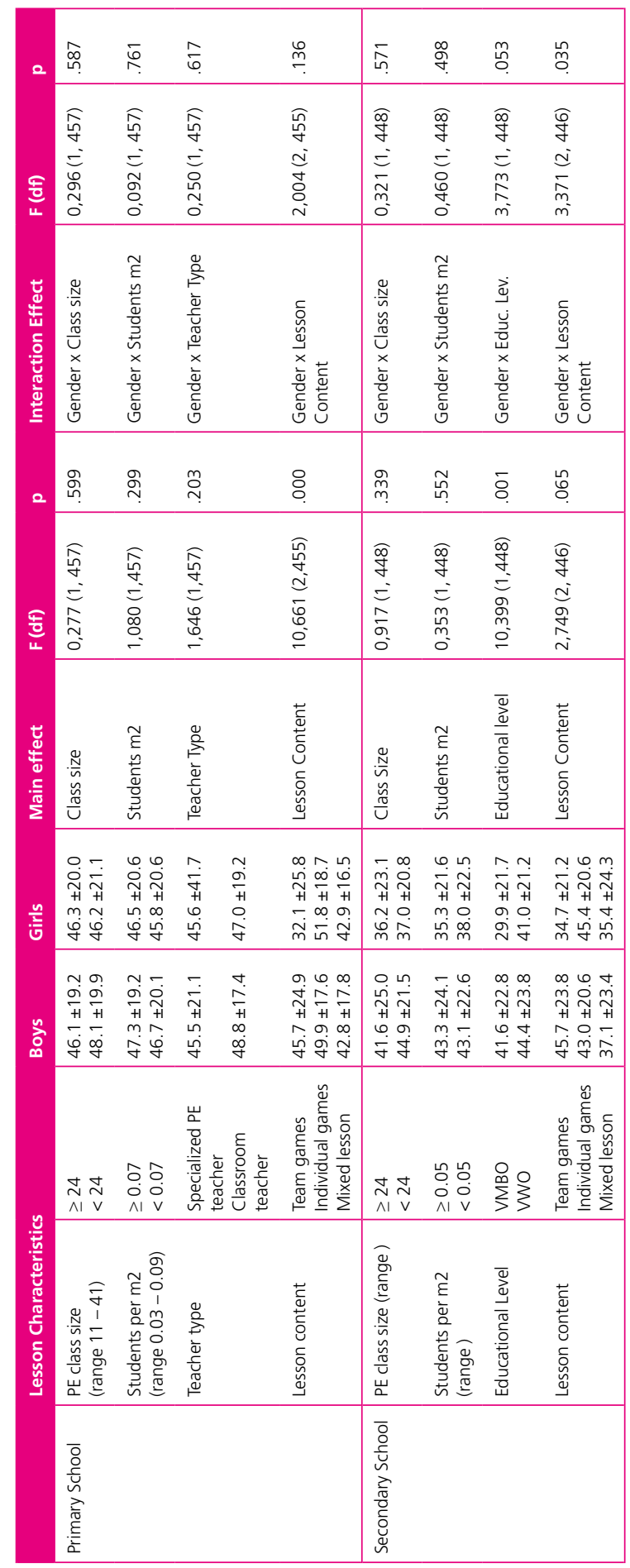


Overall, primary school students were significantly more active than secondary school students $(46.8 \%$ vs. $41.1 \%$, figure 4.1). Similar age-related decreases in physical activity during PE have been reported by others (Kulinna, Martin, Lai, Kliber, \& Reed, 2003; Stratton, 1997). Maturation might play a role here, as it has been shown that with increasing biological age, physical activity decreases (Sherar, 2007). In primary school, individual activities yielded more MVPA than did team games. MVPA levels in primary school individual activities might have been elevated because the individual activity lessons largely consisted of high intensity activities, such as playing tag, track \& field (especially relay forms) and fitness. Furthermore, primary school team games might have been less active due to lower skill levels in students. These skills (e.g. passing a ball) are usually in higher demand during team games.

Between primary and secondary school, the difference in MVPA engagement was $10 \%$ for girls whereas for boys this was only $4 \%$. Furthermore, in secondary school, boys were more active than girls during PE. This has previously been reported in other studies (Fairclough \& Stratton, 2005; McKenzie \& Marshall, 2000). It has been suggested that lesson content has a significant influence on boys' and girls' physical activity behaviour during PE, with boys being more active in team games and girls being more active in individual activities (Kulinna, et al., 2003; Laurson, et al., 2008). Our results confirm this suggestion. Secondary school girls engaged in $11 \%$ less MVPA during team games than boys (figure 4.2), while this gender difference was absent for individual and mixed lessons. A possible explanation for this phenomenon could be that in this study PE was exclusively taught in coeducational classes, with team games being the primary lesson subject in $61 \%$ of all secondary school lessons. Although primary school lessons were also exclusively coeducational, differences in physical development between boys and girls in primary school are still relatively small, whereas in secondary school these differences start to increase (Malina, 2004). In the Netherlands secondary school starts with the $7^{\text {th }}$ grade (12-13 years of age), which we did not assess. The youngest age group that we assessed in secondary school was 13-14 years of age, an age at which differences in strength and motor performance start to become apparent between boys and girls (Malina, 2004). Especially during team games, students with the highest fitness levels and motor skills will be dominant during play, which could result in the exclusion of girls from active play, thus preventing them from attaining similar physical activity levels. Consequently, this could result in feelings of incompetency and disappointment and ultimately in an aversion to certain PE activities or PE as a whole. Therefore, the large emphasis on team games over individual and lifetime activities we report here may be an alarming finding, since it would prevent secondary school girls from being sufficiently physically active during PE. In order to give girls the opportunity to attain MVPA levels similar to boys, team game play during PE lessons could be provided in single-gender lesson organizations. A previous study, which specifically focused on team game play, found no difference in MVPA levels between coeducational and single-gender lesson organizations (Hannon \& Ratliffe). This issue warrants future research for the Dutch context in order to examine the effects of single-gender lesson organizations on MVPA levels in girls.

Changing into sports clothes and moving from the classroom to the sports facilities appear to have a substantial impact on net lesson time. The difference between scheduled and net lesson time was around $20 \%$, which corresponds to an average loss of 10 and 16 minutes of lesson time for primary and secondary schools respectively. Similar findings have been reported in other studies (Chow, et al., 2008; McKenzie \& Marshall, 2000). Therefore, allocated time for PE should be used more efficiently to increase net lesson time. For example, using sport facilities in close vicinity to the school could reduce transport time or school policy could include an obligation for classroom teachers to timely end their lessons in order to give students sufficient time to change into their sport clothes before PE class. The results of this study might aid in convincing schools into making these changes. However, 
further research is needed on how to successfully influence school boards, teachers and students and also on how to successfully implement and evaluate such measures.

For PE tot substantially contribute to activity levels, more time should be allocated for PE. Our results show that one PE lesson roughly accounts for one-third of the daily amount of physical activity as prescribed by the activity guidelines. Therefore, the most effective strategy will be to increase the weekly number of PE lessons. It is now well documented that extra time allocated to PE does not compromise academic achievement, even if PE is introduced in place of academic class time (Trost, 2008, Sibley \& Etnier, 2003). Increased PE time has even been found to yield higher academic levels (Carols, 2008, Sibley \& Etnier, 2003). Consequently, the results from this study might deliver an important, evidence-based argument to persuade policy makers to include more curriculum time for PE in national school programs. A novel finding in this study is the difference in MVPA engagement between VMBO and VWO students. To our knowledge, no previous studies have reported MVPA engagement during PE according to educational level. Therefore, further studies are needed to confirm and explain this particular result.

The HR-classifications utilized by various studies to specify the different activity levels during PE sometimes complicate a direct mutual comparison of results. Applied classifications vary between mean heart rate (MNHR), a percentage of heart rate reserve (\%HRR) or a percentage of maximum heart rate (\%HRmax). As a result, the same absolute heart rate value might lead to different intensity classifications. For future research in this domain it might be useful to reach a consensus in the classification method used. We propose using \%HRR, for this accounts for sex and age differences. In our study, age-predicted resting and maximal heart rates were used, based on Stratton (Stratton, 1996). However, the application of this classification can be made more robust by obtaining actual rest and maximal heart rate values, which in our study was not possible due to organizational and time restrictions. In this study we decided to divide PE activities in three, rather broad, categories. It would have been interesting to relate MVPA levels to specific PE activities, such as volleyball or javelin. However, this would have resulted in unacceptably small sample sizes. Future studies could aim at relating MVPA levels to specific PE activities.

\section{Conclusions}

This study is the first to investigate non-intervention PE activity levels in the Netherlands. Overall findings showed that primary school students engaged in more MVPA (46.7\%) than secondary school students (40.1\%) during PE. A clear and alarming finding was the lower MVPA engagement of girls during secondary school PE. Findings suggest that the large emphasis on team games in secondary school PE-programs could be responsible for this phenomenon. Therefore, secondary school PE teachers in the Netherlands might need to re-evaluate their lesson programs in terms of lesson content and delivery so that both boys and girls will have the opportunity to be equally active. Finally, for PE to more substantially contribute to activity levels as prescribed by physical activity guidelines, we recommended that more curricular time could be assigned to PE, that schools use scheduled PE lesson time more efficiently and that PE teachers choose and deliver lesson content in a way that provides all students with the opportunity to be equally active. 


\section{References}

Cavill, N., Biddle, S., \& Sallis, J. (2001). Young and active? Policy framework for young people and health-enhancing physical activity. Health Education Authority. London.

Buliung, R., Mitra, R., \& Faulkner, G. (2009). Active school transportation in the Greater Toronto Area, Canada: An exploration of trends in space and time (1986-2006). Preventive medicine, 48(6), 507-512.

Carlson, S., Fulton, J., Lee, S., Maynard, M., Brown, D. Kohl III, H. \& Dietz, W. (2008) Physical Education and Academic Achievement in Elementary School: Data From the Early Childhood Longitudinal Study, American Journal of Public Health, 98(4), 721-727.

Chow, B., McKenzie, T., \& Louie, L. (2008). Children's Physical Activity and Environmental Influences During Elementary School Physical Education. Journal of Teaching in Physical Education, 27(1), 38-50.

Colabianchi, N., Kinsella, A., Coulton, C., \& Moore, S. (2009). Utilization and physical activity levels at renovated and unrenovated school playgrounds. Preventive medicine, 48(2), 140-143.

Corbin, C., \& Pangrazi, R. (2003). Guidelines for Appropriate Physical Activity for Elementary School Children 2003 Update. NASPE.

Fairclough, S., \& Stratton, G. (2005). Physical Activity Levels in Middle and High School Physical Education: A Review. Pediatric Exercise Science, 17(3), 217-236.

Fairclough, S., \& Stratton, G. (2005). 'Physical education makes you fit and healthy'. Physical education's contribution to young people's physical activity levels. Health Education Research, 20(1), 14-23.

Fairclough, S., \& Stratton, G. (2006a). A Review of Physical Activity Levels During Elementary School Physical Education. Journal of Teaching in Physical Education, 25(2), 239-257.

Fairclough, S., \& Stratton, G. (2006b). Effects of a physical education intervention to improve student activity levels. Physical Education \& Sport Pedagogy, 11(1), 29-44.

Hannon, J. \& Ratliffe, T. (2005) Physical Activity Levels in Coeducational and Single-Gender High School Physical Education Settings, Journal of Teaching in Physical Education 24(2), 149-164.

Hildebrandt, V. H., Ooijendijk, W. T. M., \& Hopman Rock, M. (2007). Trendrapport Bewegen en Gezondheid 2004/2005.

Hildebrandt, V. H., Ooijendijk, W. T. M., \& Hopman Rock, M. (2008). Trendrapport Bewegen en Gezondheid 2006/2007. TNO-KVL, Leiden.

Kahn, E., Ramsey, L., Brownson, R., Heath, G., Howze, E., Powell, K., et al. (2002). The effectiveness of interventions to increase physical activity. A systematic review. American Journal Of Preventive Medicine, 22(4 Suppl), 73-107.

Kemper, H., Ooijendijk, W., \& Stiggelbout, M. (2000). Consensus over de Nederlandse Norm voor Gezond Bewegen. Tijdschr Soc Gezondheidsz, 78, 180-183.

Kemper, H., Verschuur, R., Ras, K., Snel J., Splinter, P. \& Tavecchio, L. (1976). Effect of 5-versus 3-lessons-a-week physical education program upon the physical development of 12 and 13 year old schoolboys. Journal of Sports Medicine, 16, 319-326.

Kulinna, P., Martin, J., Lai, Q., Kliber, A., \& Reed, B. (2003). Student physical activity patterns: grade, gender, and activity influences. Journal of Teaching in Physical Education, 22, 298-310.

Laurson, K., Brown, D., Cullen, R., \& Dennis, K. (2008). Heart rates of high school physical education students during team sports, individual sports, and fitness activities. Research Quarterly for Exercise and Sport, 79, 85-91.

Malina, M., Bouchard C. \& Bar-Or, O. (2004) Growth, maturation, and physical activity. Human Kinetics, Champaign, IL.

McKenzie, T., Nader, P., Strikmiller, P., Yang, M., Stone, E., Perry, C., et al. (1996). School physical education: effect of the Child and Adolescent Trial for Cardiovascular Health. Preventive Medicine, 25(4), 423-431. 
McKenzie, T., \& Sallis, J. (1997). Long-term effects of a physical education curriculum and staff development program: SPARK. Research Quarterly for Exercise \& Sport, 68(4), 280-291.

McKenzie, T., \& Marshall, S. (2000). Student Activity Levels, Lesson Context, and Teacher Behavior During Middle School Physical. Research Quarterly for Exercise \& Sport, 71, 249-259.

McKenzie, T., Sallis, J., Prochaska, J., Conway, T., Marshall, S., \& Rosengard, P. (2004). Evaluation of a two-year middle-school physical education intervention: M-SPAN. Medicine \& Science in Sports \& Exercise, 36(8), 13821388.

McKenzie, T., Prochaska, J., Sallis, J. \& Lamaster, K. (2004) Coeducational and Single-Sex Physical Education in Middle Schools: Impact on Physical Activity, Research Quarterly for Exercise \& Sport 75(4), 446-449.

Ridgers, N., Tóth, M., \& Uvacsek, M. (2009). Physical activity levels of Hungarian children during school recess. Preventive medicine, 49(5), 410-412.

Sallis, McKenzie, T., Alcaraz, J., Kolody, B., Faucette, N., \& Hovell, M. (1997). The effects of a 2-year physical education program (SPARK) on physical activity and fitness in elementary school students. American Journal of Public Health, 87(8), 1328-1334.

Sherar, Esliger, Baxter-Jones \& Tremblay (2007). Age and gender differences in youth physical activity: does physical maturity matter? Medicine and Science in Sports and Exercise 39(5), 830-835.

Sibley, B. \& Etnier, J. (2003). The Relationship Between Physical Activity and Cognition in Children: A Meta-Analysis. Pediatric Exercise Science 15, 243-256.

Simons-Morton, B., Parcel, G., Baranowski, T., Forthofer, R., \& O'Hara, N. (1991). Promoting Physical Activity and a Healthful Diet among Children: Results of a School-Based Intervention Study. American Journal of Public Health, 81(8), 986-991.

Sluijs, v. E., Fearne, V., \& Mattocks, C. (2009). The contribution of active travel to children's physical activity levels: Cross-sectional results from the ALSPAC study Preventive medicine, 48(2), 108-114.

Stratton, G. (1996). Children's heart rates during physical education lessons: a review. / Frequences cardiaques des enfants pendant les cours d'education physique: revue. Pediatric Exercise Science, 8(3), 215-233.

Stratton, G. (1997). Children's heart rates during British physical education lessons. Journal of Teaching in Physical Education, 16(3), 357-367.

Trost, S. (2008) Physical Education, Physical Activity, and Academic Performance in Youth. Chronicle of Kinesiology \& Physical Education in Higher Education, 19(3), 33-38.

Trudeau, F., \& Shephard, R. (2005). Contribution of School Programmes to Physical Activity Levels and Attitudes in Children and Adults. Sports Medicine, 35(2), 89-105.

Tudor-Locke, C., Ainsworth, B., Adair, L., Du, S., \& Popkin, B. (2003). Physical activity and inactivity in Chinese schoolaged youth: the China Health and Nutrition Survey. International Journal of Obesity And Related Metabolic Disorders, 27(9), 1093-1099.

USDHHS (2008). Physical Activity Advisory Guidelines Committee Report 2008. Washington, DC: U.S. Department of Health and Human Services.

Verstraete, S., Cardon, G., De Clercq, D., \& De Bourdeaudhuij, I. (2007). Effectiveness of a Two-Year Health-Related Physical Education Intervention in Elementary Schools. Journal of Teaching in Physical Education, 26(1), 20-34.

Werff, H. v. d., \& Smeenk, S. (2007). Volop Beweging: eerste evaluatie van de Leergang Bewegingsonderwijs. Deelrapport scholen PO, NISB.

Westerstahl, M., Barnekow-Bergkvist \& Jansson, E. (2005). Low physical activity among adolescents in practical education. Scandinavian Journal of Medicine \& Science in Sports, 15(5), 287-297. 


\section{CHAPTER 5}

\section{INCREASING IN-CLASS PHYSICAL ACTIVITY DURING COEDUCATIONAL SECONDARY SCHOOL PHYSICAL EDUCATION}

SLINGERLAND, M. \& BORGHOUTS L.B.

THIS CHAPTER IS SUBMITTED FOR PUBLICATION 


\section{Summary}

Background: Physical education (PE) can be a valuable source of physical activity for adolescents. However, often PE lessons are needlessly inactive due to ineffective didactical approaches and lesson organization.

Unfortunately, research on strategies to increase in-class physical activity during coeducational secondary school $\mathrm{PE}$ are scarce. The purpose of this study was to evaluate the effectiveness of strategies to increase in-class physical activity levels during secondary school PE.

Methods: Twelve PE teachers first taught a regular PE lesson in their usual way which served as a baseline lesson. Then, after receiving instruction on intervention strategies for increasing in-class physical activity, teachers taught the same lesson with a physical activity strategy applied. Special attention was given to preserving other lesson goals. Systematic observation was employed to identify differences in physical activity and lesson context.

Results: Time spent in MVPA increased from $12.6 \%$ of lesson time (5.7 minutes) in the regular lessons to $26.2 \%$ of lesson time (11.3 minutes) during the intervention lessons. Time devoted to class management and knowledge decreased in the intervention lessons, whereas time spent in gameplay forms increased.

Conclusions: Although currently PE cannot be a standalone solution to combat physical inactivity due to timetable restrictions, intensified PE lessons can be a valuable source of physical activity on schooldays with PE and can be a valuable addition to school-based physical activity programs. Therefore it is recommended that PE teachers routinely apply strategies as presented in this study to increase lesson intensity alongside other lesson objectives. 
Regular physical activity is associated with numerous health benefits in children and adolescents, such as lower prevalence of overweight and obesity, type-2 diabetes and cardiovascular disease and increased bone health and mental health (Stensel, Gorely, \& Biddle, 2008; Strong et al., 2005). To obtain these health benefits, there is a general consensus that youths should participate in at least 60 minutes of moderate-to-vigorous physical activity (MVPA) per day (Strong et al., 2005). Unfortunately, youth physical activity levels are declining in almost all Western countries, especially in adolescents (Biddle, Gorely, \& Stensel, 2004). In attempts to reverse this decline, schools have been designated as a key setting for increasing physical activity levels in children and adolescents (Ferreira et al., 2007). Various authors claim that physical education (PE) could play an important role in this respect (Mckenzie \& Lounsbery, 2009; Pate, O'Neill, \& Mclver, 2011). PE has the potential to contribute to students' physical activity levels in a direct and indirect manner (Slingerland \& Borghouts, 2011). Indirectly, PE aims to motivate young people to be physically active out-of-school as well as during their adult life (Haerens, Kirk, Cardon, De Bourdeaudhuij, \& Vansteenkiste, 2010). To reach this goal students develop adequate movement skills during $\mathrm{PE}$, which enables them to participate in a variety of movement activities that are offered within the curriculum as well as outside of the school context. On the other hand, the PE lesson itself can also be considered a valuable source of physical activity that directly contributes to students' physical activity levels (Fairclough \& Stratton, 2005b; McKenzie \& Marshall, 2000; Verstraete, Cardon, De Clercq, \& De Bourdeaudhuij, 2007). Hence, PE can provide valuable physical activity for all students, and might be especially important for children and adolescents that lack the opportunity to be physically active outside of school. For example, in a sample of Dutch adolescents PE contributed 30\% to total physical activity on a school day (Slingerland, Borghouts, \& Hesselink, 2012), whereas $30 \%$ of the Swedish students enrolled in practical education accumulated all of their weekly MVPA through PE (Westerståhl, Barnekow-Bergkvist, \& Jansson, 2005). For many American children and adolescents PE was found the only place where they could accrue vigorous physical activity (Mckenzie \& Lounsbery, 2009; Young, Phillips, Yu, \& Haythornthwaite, 2006). In a recent PE paper Sallis et al. (2012) introduced the term health-optimizing physical education or HOPE. They proposed that HOPE encompasses "curriculum and lessons focused on health-related physical activity and fitness; keeps students active for at least $50 \%$ of class time; engages all students, regardless of physical ability; and significantly contributes to students' overall physical activity participation" (Sallis et al., 2012). Since scheduled time for PE is limited in most schools and increasing the frequency or duration of PE is difficult within existing school programs, optimal and efficient use of time for PE is imperative to promote physical activity through PE. In the US (USDHHS, 2000) and the UK (AfPE, 2008), national guidelines recommend that students spend at least $50 \%$ of their PE lesson time in MVPA. Although scores vary based on the method of assessment, Fairclough \& Stratton (2005) reported in their review that in a regular secondary school PE lesson usually $27-40 \%$ of lesson time is spent in MVPA. A recent investigation of Dutch adolescents found similar results, with secondary school students spending $40 \%$ of lesson time in MVPA (Slingerland, Oomen, \& Borghouts, 2011).

The amount of physical activity during PE depends on various factors such as student ability level (Fairclough \& Stratton, 2005a; Fairclough \& Stratton, 2006), lesson theme\{Slingerland:2011dq\}, gender \{Slingerland:2011dq\} \{Chow:2009ws\}, lesson context (McKenzie \& Marshall, 2000; Mersh \& Fairclough, 2010)\{Chow:2009ws\}, available resources (Levin, McKenzie, Hussey, Kelder, \& Lytle, 2001), teacher specialization (Sallis et al., 1997) and class size (McKenzie \& Marshall, 2000). Although some of these variables cannot be altered (e.g., gender), or are difficult to modify in the short-term (e.g., class size, available resources, student ability level), other variables are relatively easy to influence by the teacher (e.g., lesson context, lesson theme, mode of delivery). For example, Baquet et al. (2001) changed the content of the PE lessons so that it included only intermittent running and jumping exercises in order 
to elicit high heart rates in adolescents during PE. Although the intervention was successful in enhancing MVPA levels, this approach is questionable from a pedagogical perspective while it is neglecting other important physical, social, affective and cognitive aspects that PE aims to develop (Bailey et al., 2009). Other studies have shown however, that it is possible to intensify secondary school PE lessons without compromising other PE goals (Fairclough \& Stratton, 2006). It is therefore encouraging that how a lesson is planned and taught (e.g., lesson objectives, efficiency of instruction, class management and providing accurate feedback) has the largest impact on the amount of MVPA that students accrue during PE (Mersh \& Fairclough, 2010).

Various interventions aimed at enhancing MVPA during PE have been conducted and most of these approaches have proven to be effective in enhancing MVPA during PE lessons (Fairclough \& Stratton, 2005b; Slingerland \& Borghouts, 2011). An overview of the strategies that were adopted within these studies is provided in Table 5.1. However, most of these studies were conducted in a primary school setting, and the studies that did focus on increasing MVPA during secondary school PE mainly targeted females within single gender classes (Fairclough \& Stratton, 2005a; Fairclough \& Stratton, 2006; Webber et al., 2008; Young et al., 2006). Nevertheless, the common educational setting in most western countries is coeducation and therefore evidence on effective strategies to maximize physical activity involvement within secondary school PE in boys and girls within coeducational classes is required. In the present study we focused on strategies to increase in-class physical activity during co-educational secondary school PE. We adopted a teacher-centred strategy in which, rather than imposing a specific lesson plan, teachers had substantial freedom in the construction of their own lesson plans, which were based on a number of general principles. The aim was to evaluate the overall effectiveness of lesson strategies to increase time spent in MVPA during coeducation secondary school PE.

\section{Method \\ Participants}

A group of PE teachers was randomly selected from the university internship school database (situated in the region of Tilburg, in the south of the Netherlands). Inclusion criterion for teachers to participate in the study was that they held a bachelors degree in PE, which is the highest qualification for PE teachers in the Netherlands. A total of twelve teachers from twelve different secondary schools were selected. The teacher had an average age of 34.6 years (range $24-56$ ) with an average of 11.8 years of teaching experience (range $2-30$ ). Informed consent to participate in the study was obtained from all teachers. The schools were situated in the south of the Netherlands and offered similar educational levels (all schools taught all three educational levels that are present within the Dutch educational system). All year 1 and 2 students (12-15 years of age) in this study had three compulsory PE lessons per week (150 minutes), whereas for years 3 to 6 (15-19 years of age) two compulsory PE lessons were scheduled (100 minutes). In all schools PE was taught through the multi-activity curriculum, which is the common curriculum in the Netherlands. Furthermore, all schools taught PE in coeducational classes, overall $45 \%$ of students were female. Prior to the study the institutional research ethics committee and school directors approved of the study. 


\section{Table 5.1. Strategies for Increasing Physical Activity Levels During PE Class}

\section{During the lesson:}

Didactical approach (mode of delivery)

- Include physical activity as a primary lesson objective, alongside existing ones, rather than as a 'add-on' (Fairclough \& Stratton, 2005a)

- Match the skill level of students with the nature/difficulty of the game (Mersh \& Fairclough, 2010)

- Avoid an emphasis on technical skills (Verstraete, 2006)

- Provide skill-drills in small groups (e.g., 3 on 3 basketball) (Young et al., 2006)

- Maximize time on task (Fairclough, 2005)

- Avoid activities were students can be eliminated from the game (Verstraete, 2006)

o Avoid an emphasis on competitive activities, especially in girls and low-ability students (Slingerland and Borghouts, 2011, Verstraete, 2006)

- Create different levels within an activity so that every student can be active despite of his/her ability level

- Organise gameplay by gender or ability level (Acker, Costa, Bourdeaudhuij, Cardon, \& Haerens, 2010)

- Use modified gameplay forms to maximize student opportunities to be active (Acker et al., 2010), for example Teaching Games for Understanding or the Tactical Games model for invasion games.

\section{Lesson content}

- Provide interesting side-tasks if waiting is unavoidable (Verstraete et al., 2007)

- Outdoor lesson activities generally elicit more MVPA than indoor lessons (Fairclough \& Stratton, 2005b)

- Teach units that are active in nature (e.g., soccer, basketball, handball etc.) (Kulinna, Martin, Lai, Kliber, \& Reed, 2003)

- Provide activities that are interesting and challenging, with special attention for girls (Verstraete, 2006).

- Make activities fun to do, especially vigorous ones (i.e. warm-up / cool-down) (Fairclough \& Stratton, 2005a)

- Teach skills for competency rather than for proficiency (Young et al., 2006)

\section{Class management}

- Avoid complicated lesson transitions (Fairclough \& Stratton, 2005a; Young et al., 2006), preferably use one organization for the duration of the whole lesson (e.g., groups of students stay the same during the course of the lesson).

- Efficient role taking and student grouping (McKenzie \& Marshall, 2000)

- Increase the number of activities and reduce the number of students per team / group

- Avoid queuing for an activity (Verstraete, 2006)

- Enlarge the playing area if possible (Verstraete, 2006)

- Use all of the available space, material and resources at hand (McKenzie et al., 2006)

- Use active grouping strategies (Verstraete, 2006)

\section{Instruction}

- Keep instruction brief (Mersh \& Fairclough, 2010)

- Plan instruction so that it can be delivered more efficiently during the lesson

- Provide positive feedback in the vicinity of the student, however deliver feedback efficiently and effectively while keeping it short (Verstraete, 2006)

- Transfer knowledge while students are in motion (i.e. knowledge on physical activity and health during warm-up or cool down) (McKenzie \& Marshall, 2000)

\section{Before the lesson:}

Lesson preparation

- Around $20 \%$ of scheduled PE lesson time is lost, allocated time for PE should be used more efficiently (Mckenzie \& Lounsbery, 2009; Slingerland \& Borghouts, 2011):

o Improved site-based management: i.e. by ensuring classroom teachers timely end their lessons, providing students with time to change into sports clothes before the lesson starts.

- By efficiently organizing transportation to the sports hall

o By preparing the sports hall as much as possible prior to lesson commencement. 


\section{Intervention and study design}

All teachers were asked to choose one content area in which they intended to increase in-class physical activity levels. Next, teachers taught one lesson within their chosen lesson content area to 3 - 6 classes using their habitual lesson plan which served as a baseline lesson. In total 49 baseline lessons and 49 intervention lessons were observed, which consisted of 19 outdoor lessons, which were all softball lessons. Although teachers were informed that student physical activity during the lesson was the primary study objective, they were urged not to deviate from their lesson plans and objectives (i.e. developing motor skills, social skills, knowledge etc.). One week later, teachers were asked to provide the same lesson again to the same classes. However, prior to this lesson teachers were instructed during a 2-hour teacher-training on how to increase in-class physical activity by adopting and implementing various lesson strategies as depicted in Table 5.1. The strategies for increasing in-class physical activity during PE originate from previous studies on this topic and were selected based on their effectiveness alongside the possibility to be implemented without substantial investments in terms of time, money or other resources. An overview of the various strategies to increase in-class physical activity during PE is shown in Table 5.1. The intervention strategies were first explained by the principal investigator who has extensive practical and theoretical knowledge on this topic. Then, in consideration with the principal investigator, teachers were asked to choose one or two main topics, for example class management and instruction, and apply the strategies within that topic they deemed to be most effective. By doing so, teachers constructed a new lesson plan within the same lesson subject using an identical lesson structure (i.e. same time for warm-up, practice, gameplay and similar lesson objectives), however with the strategies for increasing in-class physical activity applied. Teachers were urged again not to deviate from their objectives within the lesson. The newly constructed, intensified lesson plan was checked one more time prior to the lesson by the principal investigator and small adjustments were made if deemed necessary, however again in consultation with the PE teacher. For example, adjustments were made if the intervention lesson differed from the baseline lesson in terms of scheduled time for warm-up, cooling down, or if the lesson objective differed from the one in the baseline lesson. Subsequently, PE teachers taught the lesson to the same classes using their new lesson plan.

\section{Materials and Procedure}

Physical activity and lesson context were assessed using the System for Observing Fitness Instruction Time (SOFIT) (McKenzie, Sallis, \& Nader, 1992), which is a momentary time sampling observation method. Direct observation has the advantage that physical activity as well as the physical and social environment in which the activity takes place can be simultaneously recorded (Welk, Corbin, \& Dale, 2000). SOFIT has been extensively used in other PE studies (Fairclough \& Stratton, 2005a; Mersh \& Fairclough, 2010) and has been validated with high school students against heart rate monitors and indirect calorimetry (Pope, Coleman, Gonzalez, Barron, \& Heath, 2002; Rowe, van der Mars, Schuldheisz, \& Fox, 2004). The SOFIT instrument is able to capture type of physical activity, the context in which the activity took place as well as teacher behaviour. The original SOFIT instrument is scored code 1 - 4 for body position (respectively lying down, sitting, standing and walking) and code 5 for any activity more vigorous than walking (e.g., running, jumping). However, Pope et al (2002) found that using a scale with six activity categories was more sensitive in measuring variations in light and moderate physical activity during PE. In this instrument (the SOFIT6) a sixth category is added by dividing the original code 5 in light activities (i.e. slow walk, easy stretching, code 4) and moderate activities (brisk walking, light jogging, code 5), whereas the vigorous category remained unchanged (code 6). Although the original SOFIT assesses two additional categories besides physical activity; lesson context and teacher behaviour, we decided not to assess teacher behaviour in our study for two reasons. First of all observers had no prior experience using systematic observation and, based on the 
results of an earlier pilot study, we estimated observing and coding a total of 18 categories within a 20 second time-frame would result in reduced reliability. Additionally, previous studies found it difficult to accurately assess teacher behaviour since the observer is in a fixed spot and therefore could not always accurately hear the teacher (McKenzie et al., 2004). Lesson context was coded in six categories: management (i.e. lesson transitions, grouping procedures), knowledge (i.e. instruction on rules, backgrounds), fitness (activities where the specific intention is to improve physical fitness), skill drills (activities where the specific goal is to improve skills), game play (application of skills within a game or competitive setting) and free play (students have the choice to participate in an activity or not).

Twelve observers, all pre-service teachers, were each assigned to one school. Prior to commencement of the study observers received two three-hour observation training sessions. During the first session coding categories were extensively discussed and practiced using pre-coded videos of specific activities. Subsequently, a second session was employed to thoroughly practice the instrument using pre-coded videos of lesson parts and through field practice in order to further master the coding categories and the research protocol. Upon completion of the SOFIT training the observers coded a "gold-standard" video taped PE lesson while being cued by the same audio signal. Inter observer agreement ((IOA: (number of agreements / number of agreements + disagreements) x 100)) was calculated. All observations surpassed the $85 \%$ IOA criterion (McKenzie et al., 1992) for both the physical activity and the lesson context. During the measurement period one baseline lesson at each school was coded by two observers to determine the IOA again. Again all observations surpassed the $85 \%$ IOA criterion for physical activity and lesson context.

Each PE lesson was assessed by one observer who placed himself discretely at the perimeter of the gymnasium to minimize student reactivity. Upon entrance of the students, five students were randomly selected (student $\mathrm{nr}$. 5, 10, 15, 20 and 25 in classes with $>25$ students and student nr. 4, 8, 12, 16 and 20 in classes with < 25 students) and observed on a rotational basis. Student nr. 5 was used as a backup, in case the student being under observation left the class for any reason whatsoever. The lesson officially started when all students were seated in front of the teacher. Then, physical activity for the selected students and the general lesson context were scored on a standardized observation form. Observers wore headphones and were paced by an MP3 audio signal. Each student was coded for the duration of 12 intervals of 20 seconds. After 4 minutes the observer switched to student nr. 2 and continued likewise until the end of coding student nr. 4. Then observing and coding rotated back to the first student. This procedure was repeated until the teacher had officially ended the lesson and 51 percent of the students had left the instructional setting.

\section{Data analysis}

SOFIT physical activity and lesson context observation scores were entered into Microsoft Excel spread sheets, where total lesson time, percentage of lesson time in light (SOFIT categories lying down, sitting and standing), moderate (SOFIT category moderate), vigorous (SOFIT category vigorous) and MVPA (SOFIT category moderate and vigorous combined) were calculated for the non-intervention and intervention condition. Furthermore, the percentage of total lesson time within the various lesson contexts as well as the percentage of lesson time in MVPA within the various lesson contexts was calculated. These data was then entered into SPSS 19.0.0 for statistical analysis. Since exploration of the data revealed non-normal distributions for both physical activity and lesson context variables the Wilcoxon signed-rank test was applied to test for differences between the non-intervention and intervention condition. Reported scores are median scores and effect sizes. 
Table 5.2. Overview of Content Areas and Adopted Strategies per Teacher

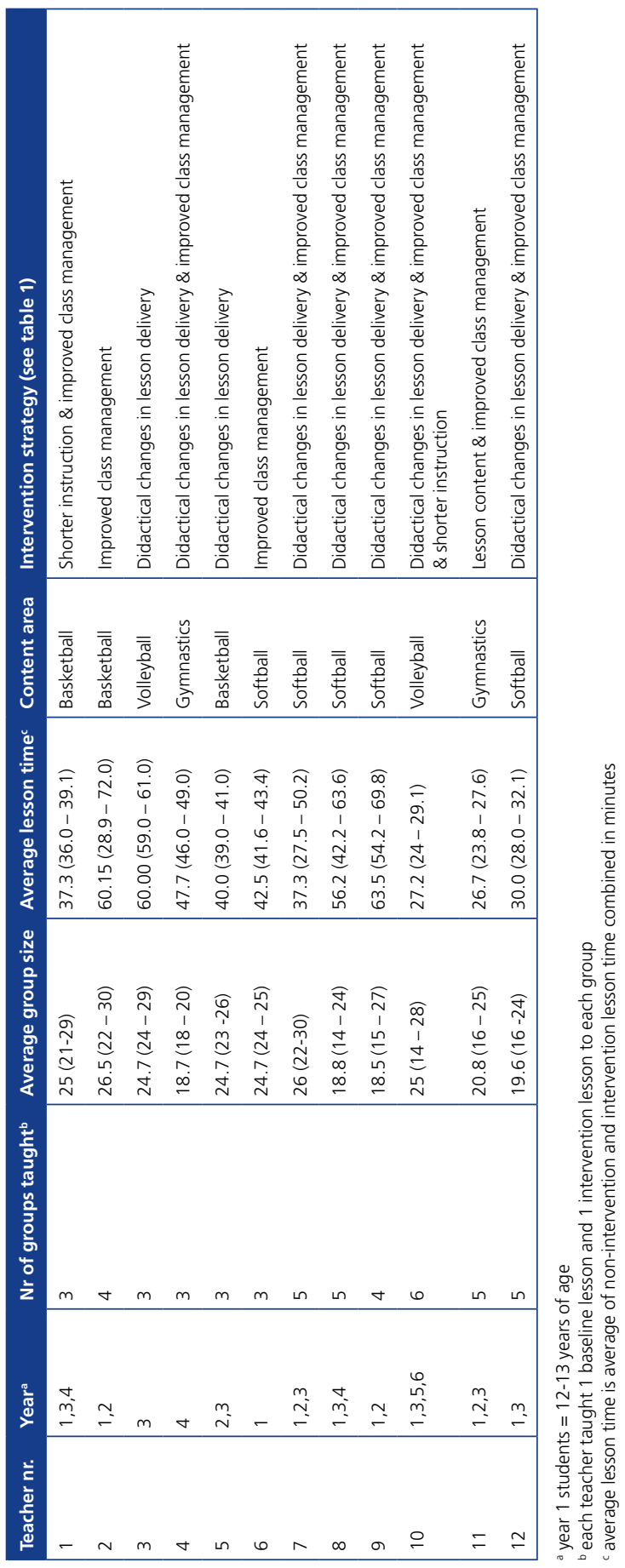




\section{Results}

Table 5.2 provides an overview of the lesson themes and adopted strategies per teacher. Average class size was $21.5(S D=4.59)$ students. Average lesson time was 45.4 minutes in the non-intervention condition $(S D=16.7)$ and 43.0 minutes $(S D=15.2)$ in the intervention condition. The intervention significantly improved MVPA ( $M d n=$ $26.2 \%$ during the intervention versus $12.6 \%$ at baseline), $T=3, p<.001, r=-0.61$, whereas time spent in the light intensity category significantly decreased (figure 1). An average of 5.7 minutes of MVPA were accumulated in the non-intervention condition compared to 11.3 minutes in the intervention condition. The percentage of total lesson time spent within the observed lesson contexts fitness, skill drills and free play did not differ between both conditions (Table 5.3 upper part), however, time spent on class management was lower in the intervention condition (15.2\% versus $12.4 \%), T=291.5, p<.01, r=-0.3$ as was time spent on knowledge transfer $(19.7 \%$ versus $15.6 \%), T=341, p<.05, r=-.26$. Total lesson time spent in gameplay significantly increased during the intervention lessons ( $29 \%$ versus $38 \%$ ), $T=182.5, p<.001, r=-0.37$. Table 5.3 (lower part) also shows the distribution of MVPA within the different lesson contexts. For example, $8.7 \%$ of total time spent on skill drills consisted of MVPA. Results show that the amount of MVPA significantly increased in the intervention condition versus the regular condition during fitness $(5.56 \%$ versus $1.76 \%), T=9.5$, $p<.01, r=-0.29$, skill drills $(12.5 \%$ versus $6.4 \%) \mathrm{T}=209.5, \mathrm{p}<.001, r=-.38$ and gameplay $(14.3 \%$ versus 4.8 $\%) \mathrm{T}=32, \mathrm{p}<.001, \mathrm{r}=-0.55$. 
Table 5.3. Percentage of total lesson time spent in the different lesson contexts and percentage of lesson time in MVPA in each lesson context.Outcomes are median and interquartile range (between brackets)

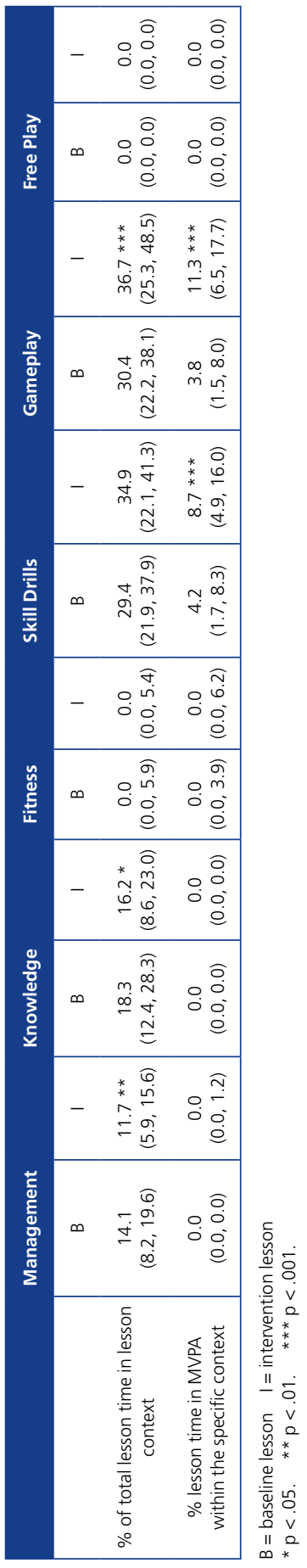




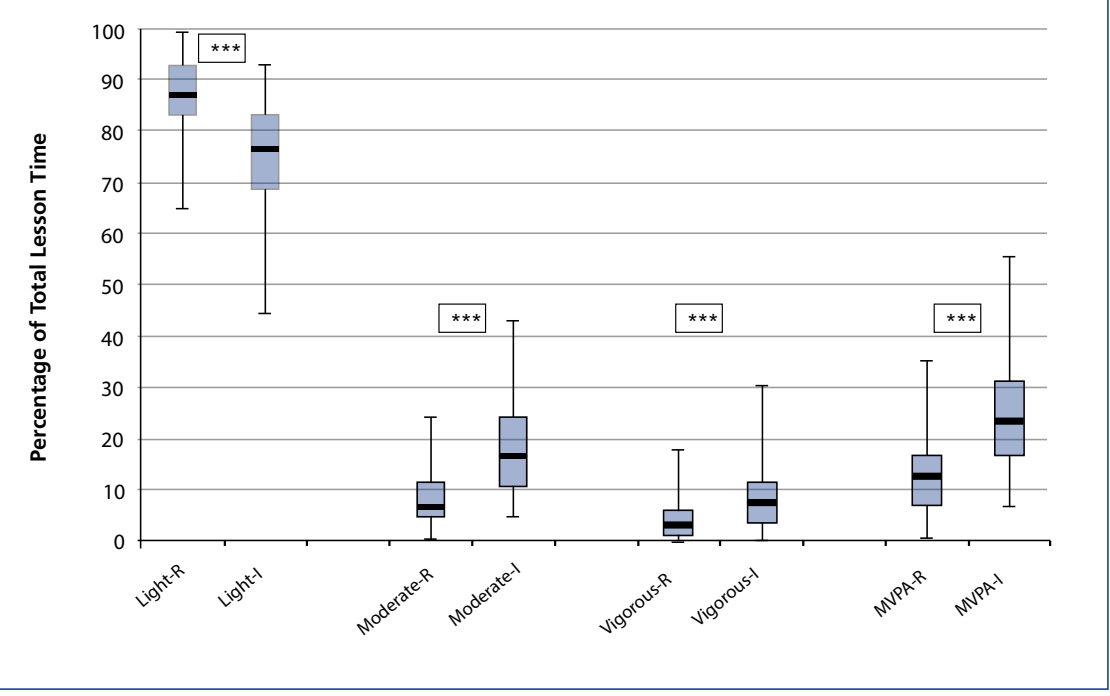

Figure 5.1. Boxplots (median, 25th percentile, 75th percentile, minimum, maximum) of total lesson time spent within light, moderate, vigorous and moderate-to-vigorous (MVPA) physical activity.

$\mathrm{R}=$ regular lesson, $\mathrm{I}=$ Intervention lesson

$* * * p<.001$

\section{Discussion}

Modifying PE lessons to yield more physical activity resulted in an increase in MVPA from $12.6 \%$ of lesson time in the non-intervention condition to $26.2 \%$ of lesson time in the intervention condition. Total lesson time spent in MVPA in our study was lower than that in some other PE adolescent studies. The 2-year multicomponent school intervention program M-SPAN (McKenzie et al., 2004) led to intervention classes spending an average of $52 \%$ of lesson time in MVPA as opposed to $48 \%$ in control schools. In an intervention study aimed at girls by Young et al. (2006) 46.9\% of lesson time was spent in MVPA within intervention classes, whereas the control classes spent $30.5 \%$ in MVPA. The Trial of Activity for Adolescent Girls (TAAG) (Webber et al., 2008), a middle school intervention study that also targeted girls used a similar approach which resulted in intervention classes spending around $40 \%$ of lesson time in MVPA, whereas for control classes this was around $36 \%$. The higher percentages of lesson time within MVPA in these studies compared to the present study can be explained by the fact that teachers in our study were free to choose their preferred content area in which they wanted to increase student physical activity. Not surprisingly, the majority of the teachers chose content areas that, in their experience, were usually rather inactive in nature, such as volleyball, softball and gymnastics. In the abovementioned studies a wide variety of content areas was observed and were sometimes even intentionally chosen due to their suitability to evoke high levels of physical activity. In comparison, in a study more similar to the present one, an intervention in two PE gymnastics classes in British adolescent girls (Fairclough \& Stratton, 2005a) resulted in 18.5\% of lesson time in the intervention group being spent in MVPA. Furthermore, all three abovementioned studies used the original SOFIT instrument whereas in our study we used the modified SOFIT6. Pope et al. (2002) found that the original SOFIT overestimated MVPA levels since light activities were coded as moderate activity, whereas the SOFIT6 is more sensitive in assessing physical activity intensity due to the added 'light' category (code 4). Also the SOFIT6 criteria for vigorous physical activity are more stringent than those of the original SOFIT instrument. 
The results of this study indicate that by implementing relatively simple strategies, PE teachers are able to increase their student's physical activity. This is important, since physical activity during PE lessons in secondary school students is generally low (Fairclough \& Stratton, 2005b) and PE is one of the few opportunities to be physically active for a substantial portion of the adolescent population (Mckenzie \& Lounsbery, 2009; Westerståhl et al., 2005). Nevertheless, the percentage of lesson time spent in MVPA in the intervention condition was still considerably lower than the $50 \%$ of class time criterion proposed in US and UK guidelines (AfPE, 2008; USDHHS, 2000). Although intervention lessons were successful in increasing lesson time spent in MVPA, on average they still provided only an average of 11 minutes of MVPA per lesson. Hence, in terms of contributing to physical activity guidelines and adolescent health, increasing in-class physical activity during PE cannot be seen as a standalone solution in combating low physical activity levels in adolescents, especially since in most schools PE is maximized to two lessons per week. Nevertheless, a study in Dutch adolescents found that in a cross-sectional sample regular (non-intensified) PE lessons were responsible for $30 \%$ of the total physical activity energy expenditure on that day (Slingerland et al., 2012), which indicates that PE does contribute significantly to total physical activity and that efficient use of PE lesson time can be a valuable addition to other physical activity increasing school initiatives. Obviously, as was the case in our study, the content area is a major influencing factor here (McKenzie et al., 2004; Mersh \& Fairclough, 2010) since some activities naturally contain more activity (e.g. invasion games, field-run, relay) than others (e.g. softball, throwing in track \& field, gymnastics). Therefore, if PE is deliberately employed to increase physical activity it is especially important that low-intensity activities are taught in altered forms. An example of this is playing adapted softball forms in small groups with modified rules that evoke higher levels of MVPA.

The lesson context also has a large influence on the amount of physical activity that is accumulated during a PE lesson. For example, physical activity is generally lowest during periods of general instruction and class management (McKenzie et al., 2004; Mersh \& Fairclough, 2010). In our study time within gameplay increased while time spent in class management and transfer of knowledge decreased (Table 2). This might be related to the majority of teachers applying a didactical approach during games lessons (basketball, volleyball, softball) that implied more time for adapted gameplay situations. During these lessons students played in small teams, sometimes with adapted rules and on a smaller playing field. This approach is somewhat similar to the Teaching Games for Understanding (TGfU) principles (Forrest, Webb, \& Pearson, 2006), which aim at increasing physical activity levels, engagement, motivation and enjoyment in physical education lessons besides aiming at generating greater understanding of all aspects of games. In our study this approach seems to have led to less time being spent on class management and transfer of knowledge (where the whole class stops their activity and listens) in favour of time spent on actual gameplay and learning through playing. More studies are required to confirm that a TGfU-based approach indeed leads to increased physical activity during PE games lessons.

Interestingly, MVPA levels significantly improved not only during gameplay but also during skill drills even though total lesson time within skill drills was similar in both conditions (table 2). Most teachers in our study still used skill drills in their intervention lessons, however they restructured the organization of these activities to ensure all students were active. For example, instead of two students throwing a softball while standing still a form was used where four students had to chase after their ball or had to do an active side-task during inactive periods. MVPA also increased in the intervention lesson during the fitness context, although total lesson time spent within this context was very low (3\% of total lesson time). Observers recorded fitness only when activities were specifically aimed at improving flexibility, muscle strength or cardiorespiratory fitness. However, since the majority 
of lessons consisted of games, in which fitness promotion has been found to be very low (Mersh \& Fairclough, 2010), and since in general fitness promotion is not regarded a main priority in the Dutch PE curriculum these findings reflected our expectations. Within M-SPAN (McKenzie et al., 2004) teachers first went through a period of change to understand, accept and implement the new teaching methods, before significant results were attained. Although in our study we did not use a process evaluation to gain insight into teachers' experiences in delivering the intervention lessons we obtained significant improvements over the course of only one lesson. This is encouraging, since effects might even be larger when teachers get more accustomed to applying different lesson strategies for increasing physical activity within PE lessons. Nevertheless, interventions are at risk of being less and less effective as the novelty of the intervention wears off. However, we believe that most of the strategies to improve in-class physical activity presented here are independent of these effects.

A positive outcome in our study was that, while lessons elicited more physical activity, teachers could still attain their PE goals, since lesson theme, lesson structure and lesson objectives remained unchanged within the intervention lessons. This is important because, although increasing in-class physical activity is a worthwhile goal to pursue, it is at least equally important to simultaneously develop students' skills, knowledge and attitudes during PE in order to adequately prepare them for lifelong physical activity participation. Our study also showed that it is possible to increase in-class physical activity in PE without large investments in staff training, material and other resources. All teachers in our intervention were engaged and passionate professionals. Therefore, to assure a smooth lesson implementation and to add to a more sustained and effective use of strategies to increase in-class physical activity, teachers were given a free rein in making their own choices regarding lesson content and intervention.

Despite these strengths, this study is not without limitations. First of all, intervention effects for increasing MVPA during PE have been found to be different for boys and for girls (McKenzie et al., 2004). Although we assessed coeducational classes, we did not separately assess physical activity in boys and girls. Future studies could target boys and girls separately. Secondly, we did not assess changes in student enjoyment. Although anecdotal evidence reported by the teachers suggested that the intervention lessons were indeed more enjoyable for the students than the non-intervention lessons, future studies could use a combination of quantitative and qualitative methods in order to determine changes in student enjoyment as well as in learning improvement and student motivation. Thirdly, in our study it was unavoidable that teachers were aware of the study aims when providing the non-intervention lesson. This could have led to teachers providing more or perhaps less active non-intervention lessons, which could have affected intervention effectiveness. Also, although we explained in the methods why we did not assess teacher feedback, this could be of influence regarding students' physical activity levels. In addition, although all observers received extensive training and a reliability check using the SOFIT instrument prior to the study, due to a limited number of observers we were unable to obtain any reliabilities during the field observations. Finally, all 49 observed lessons were part of the mandatory secondary school Dutch PE curriculum. Therefore caution should be taken when generalizing the data to other educational systems in different countries. 


\section{Conclusion and Recommendations}

Strategies to increase physical activity during PE are especially effective within lesson themes that are usually inactive, but can be effectively applied in any PE situation to improve physical activity. This study showed that it is possible to increase physical activity during coeducational PE without large investments in staff training, materials or changes in additional PE time and within a purposeful learning environment. It is recommended that PE teachers strive to successfully implement intensifying strategies within different educational PE settings and routinely adopt optimal levels of physical activity as a lesson goal besides other PE goals.

\section{References}

Acker, R., Costa, F. D., Bourdeaudhuij, I. D., Cardon, G., \& Haerens, L. (2010). Sex equity and physical activity levels in coeducational physical education: Exploring the potential of modified game forms. Physical Education and Sport Pedagogy, 15(2), 159-173.

Association for Physical Education (afPE) (2008). "Health Position Paper." Physical Education Matters, 3, 8-12.

Bailey, R., Armour, K., Kirk, D., Jess, M., Pickup, I., \& Sandford, R. (2009). The educational benefits claimed for physical education and school sport: An academic review. Research Papers in Education, 24(1), 1-27.

Biddle, S. J. H., Gorely, T., \& Stensel, D. J. (2004). Health-enhancing physical activity and sedentary behaviour in children and adolescents. Journal of Sports Sciences, 22(8), 679-701.

Fairclough, S, \& Stratton, G. (2005a). Improving health-enhancing physical activity in girls' physical education. Health Education Research, 20(4), 448-457. doi:10.1093/her/cyg137

Fairclough, S., \& Stratton, G. (2005b). Physical activity levels in middle and high school physical education: A review. Pediatric Exercise Science, 17(3), 217-236.

Fairclough, S., \& Stratton, G. (2006). Effects of a physical education intervention to improve student activity levels. Physical Education and Sport Pedagogy, 11(1), 29-44.

Ferreira, I., van der Horst, K., Wendel Vos, W., Kremers, S., Van Lenthe, F., \& Brug, J. (2007). Environmental correlates of physical activity in youth-a review and update. Obesity Reviews, 8(2), 129-154.

Forrest, G., Webb, P., \& Pearson, P. (2006). Teaching games for understanding (TGfU): A model for pre service teachers. Paper Presented at ICHPER-SD International Conference for Health, Physical Education, Recreation, Sport and Dance, 1st Oceanic Congress Wellington, New Zealand, 2006 (1-4 October), 1-10.

Haerens, L., Kirk, D., Cardon, G., De Bourdeaudhuij, I., \& Vansteenkiste, M. (2010). Motivational profiles for secondary school physical education and its relationship to the adoption of a physically active lifestyle among university students. European Physical Education Review, 16(2), 117-139.

Kulinna, P., Martin, J., Lai, Q., Kliber, A., \& Reed, B. (2003). Student physical activity patterns: Grade, gender, and activity influences. Journal of Teaching in Physical Education, 22, 298-310.

Levin, S., McKenzie, T., Hussey, J., Kelder, S., \& Lytle, L. (2001). Variability of physical activity during physical education lessons across elementary school grades. Measurement in Physical Education and Exercise Science, 5(4), 207-218.

McKenzie, Sallis, J., Prochaska, J., Conway, T., Marshall, S., \& Rosengard, P. (2004). Evaluation of a two-year middle-school physical education intervention: M-SPAN. Medicine and Science in Sports and Exercise, 36(8), 1382-1388.

Mckenzie, T. L., \& Lounsbery, M. A. F. (2009). School physical education: The pill not taken. American Journal of Lifestyle Medicine, 3(3), 219-225. doi:10.1177/1559827609331562 
McKenzie, T. L., Catellier, D. J., Conway, T., Lytle, L. A., Grieser, M., Webber, L. A., Pratt, C. A., Elder, J. P.. (2006). Girls' activity levels and lesson contexts in middle school PE. Medicine and Science in Sports and Exercise, 38(7), 1229-1235. doi:10.1249/01.mss.0000227307.34149.f3

McKenzie, T., \& Marshall, S. (2000). Student activity levels, lesson context, and teacher behavior during middle school physical education. Research Quarterly for Exercise and Sport, 71, 249-259.

McKenzie, T., Sallis, J., \& Nader, P. (1992). SOFIT: System for observing fitness instruction time. Journal of Teaching in Physical Education, 11(2), 195-205.

Mersh, R., \& Fairclough, S. (2010). Physical activity, lesson context and teacher behaviours within the revised English national curriculum for physical education: A case study of one school. European Physical Education Review, 16(1), 29-45.

Pate, R. R., O’Neill, J., \& Mclver, K. (2011). Physical activity and health: does physical education matter? Quest, 63, $19-35$.

Pope, R., Coleman, K., Gonzalez, E., Barron, F., \& Heath, E. (2002). Validity of a revised system for observing fitness instruction time (SOFIT). Pediatric Exercise Science, 14(2), 135-146.

Rowe, P., van der Mars, H., Schuldheisz, J., \& Fox, S. (2004). Measuring students' physical activity levels: Validating SOFIT for use with high-school students. Journal of Teaching in Physical Education, 23(3), 235-251.

Sallis, J. F., McKenzie, T. L., Beets, M. W., Beighle, A., Erwin, H., \& Lee, S. M. (2012). Physical education's role in public health: Steps forward and backward over 20 years and HOPE for the Future. Research Quarterly for Exercise and Sport, 125-135.

Sallis, J. F., McKenzie, T., Alcaraz, J., Kolody, B., Faucette, N., \& Hovell, M. (1997). The effects of a 2-year physical education program (SPARK) on physical activity and fitness in elementary school students. American Journal of Public Health, 87(8), 1328-1334.

Slingerland, M., \& Borghouts, L. (2011). Direct and indirect influence of physical education-based interventions on physical activity: A review. Journal of Physical Activity \& Health, 8(6), 866-878.

Slingerland, M., Borghouts, L. B., \& Hesselink, M. K. C. (2012). Physical activity energy expenditure in Dutch adolescents: Contribution of active transport to school, physical education and leisure time activities. Journal of School Health, 82(5), 225-232.

Slingerland, M., Oomen, J., \& Borghouts, L. (2011). Physical activity levels during Dutch primary and secondary school physical education. European Journal of Sport Science, 11(4), 249-257. doi:10.1080/17461391.2010. 506661

Stensel, D. J., Gorely, J., \& Biddle, S. (2008). Youth health outcomes. In Smith, A. L. \& Biddle, S. (Eds.) Youth physical activity and sedentary behavior (pp. 31-57). Champaign, IL: Human Kinetics.

Strong, W., Malina, R., Blimkie, C., Daniels, S., Dishman, R., Gutin, B., Hergenroeder A.C., Must, A., Nixon, P. A., Pivarnik J. M., Rowland, T., Trost, S., Trudeau, F. (2005). Evidence based physical activity for school-age youth. The Journal of Pediatrics, 146(6), 732-737.

USDHHS. (2000). Healthy People 2010. Washington D.C.: Government Printing Office.

Verstraete, S. (2006). Meer en beter bewegen binnen en buiten de School (Move more within- and outside of school). Monografie Voor Lichamelijke Opvoeding.

Verstraete, S., Cardon, G., De Clercq, D., \& De Bourdeaudhuij, I. (2007). Effectiveness of a two-year health-related physical education intervention in elementary schools. Journal of Teaching in Physical Education, 26(1), 20-34. 
Webber, L. S., Catellier, D. J., Lytle, L. A., Murray, D. M., Pratt, C. A., Young, D. R., Elder, J. P., Lohmann, T. G., Stevens, J., Jobe, J. B., Pate, R. R. (2008). Promoting physical activity in middle school girls: Trial of activity for adolescent girls. American Journal of Preventive Medicine, 34(3), 173-184. doi:10.1016/j. amepre.2007.11.018

Welk, G., Corbin, C., \& Dale, D. (2000). Measurement issues in the assessment of physical activity in children. Research Quarterly for Exercise and Sport, 71(2), 59-73.

Westerståhl, M., Barnekow-Bergkvist, M., \& Jansson, E. (2005). Low physical activity among adolescents in practical education. Scandinavian Journal of Medicine and Science in Sports, 15(5), 287-297. doi:10.1111/j.1600-0838.2004.00420.x

Young, D., Phillips, J., Yu, T., \& Haythornthwaite, J. (2006). Effects of a life skills intervention for increasing physical activity in adolescent girls. Archives of Pediatrics \& Adolescent Medicine, 160, 1255-1261. 


\section{CHAPTER 6}

\section{IS AUTONOMOUS MOTIVATION FOR PHYSICAL EDUCATION RELATED TO HIGHER LEVELS OF PHYSICAL ACTIVITY ENERGY EXPENDITURE IN DUTCH ADOLESCENTS?}

SLINGERLAND, M. \& BORGHOUTS L.B.

THIS CHAPTER IS SUBMITTED FOR PUBLICATION 


\section{Summary}

Background: One of the important aims of physical education (PE) is to establish a transfer of skills, attitudes and knowledge from the school context to a leisure time context, in order to stimulate youth to adopt and maintain a physically active lifestyle. This study aimed to explore to what extent motivation within a PE context was associated with motivation outside of the school context and with objectively measured Physical Activity Energy Expenditure in Dutch adolescents.

Methods: Eighty adolescents (age 15-16 years) wore a combined heart rate and accelerometer during a regular school week and filled in a daily activity diary. Prior to the measurement week, participants filled in a survey containing measures of motivation for PE and physical activity.

Results: Overall, boys scored higher on both motivation and PAEE outcome variables. Gender explained 15\% variance in total PAEE with no additional variance explained through RAI-PE and RAI-PA. Gender and RAI-PA together explained $19 \%$ of PAEE within leisure time sports with no additional variance explained through PE.

Discussion: Gender differences in motivation for PE, LTPA and in physical activity behaviour were observed. In line with these findings, gender was a more influential factor in predicting total physical activity and physical activity during both PE and leisure time sports than autonomous motivation for PE. The findings in this study are discussed in light of the effectiveness of the current PE curriculum to stimulate an active lifestyle. 
Promoting an active and healthy lifestyle is an important goal within physical education (PE) curricula in most Western countries (Pühse \& Gerber, 2004). In a recent PE position statement paper in the Netherlands, stimulating a healthy and active lifestyle was designated as an important aim in the Dutch PE curriculum

(Brouwer et al., 2011). This pronounced focus on developing healthy physical activity behaviour through PE is not surprising since various studies have shown that PE can be an important vehicle for increasing physical activity levels in children and adolescents (Cavill, Biddle, \& Sallis, 2001; Corbin, 2002; Fairclough \& Stratton, 2005; Mckenzie \& Lounsbery, 2009). In order to attain these health-related goals, PE attempts to establish a transfer of what is learned in PE to the knowledge, skills and attitudes that are needed to effectively and successfully participate in a leisure time physical activity context out of school and later in life (Haerens, Kirk, Cardon, De Bourdeaudhuij, \& Vansteenkiste, 2010). Nevertheless, scientific evidence on the impact of what is learned in PE on short-term and long-term physical activity behaviour beyond the school is scarce (Pate, O'Neill, \& Mclver, 2011; Slingerland \& Borghouts, 2011).

In the last decade, an increasing number of studies that aimed at investigating health-related PE outcomes have adopted a motivational approach, mainly drawing from the tenets of self-determination theory (SDT) (Deci \& Ryan, 2000; Ryan \& Deci, 2000; 2007) as a theoretical framework (e.g. Nikos Chatzisarantis \& Hagger, 2009; Haerens et al., 2010; Lim \& Wang, 2009; McDavid, Cox, \& Amorose, 2012; Taylor, Ntoumanis, Standage, \& Spray, 2010). SDT is a comprehensive theory of human motivation which maps out why people engage and persist in certain behaviours. The attractiveness of SDT lies herein that the quality of motivation is deemed equally important as is the quantity of motivation, whereas other popular theories of motivation (i.e. self-efficacy theory; Bandura, 1989) hold motivation as a unitary, quantitative construct where increased levels of motivation always result in more optimal outcomes (Deci \& Ryan, 2000; Vansteenkiste, Sierens, Soenens, Luyckx, \& Lens, 2009). Rather than the amount of motivation, SDT focuses on the degree in which behaviour is self-determined in nature. For example, if a student is highly motivated to be on time for class only because of the fear of being punished or fear of a low grade, this student is very motivated (high quantity of motivation), however the motivation comes from an external source or pressure and thus is low in quality. According to SDT this student has an externally regulated motivational profile that is not likely to lead to sustained positive behavioural outcomes. On the other hand, if the behaviour is intrinsically regulated it will lead to more favourable outcomes. In this respect, Deci \& Ryan (Deci \& Ryan, 1991) have proposed that the regulation of human behaviour can either be autonomous, controlled or amotivated. On a decreasing motivational quality scale from self-determined (autonomous) to controlled, first comes intrinsic regulation, followed by identified regulation, introjected regulation and external regulation. Intrinsic regulation can be seen as the most desirable and self-determined type of motivation. Applied to a PE context intrinsic motivation occurs if students engage in PE for the sheer fun and inherent pleasure it provides. Identified regulation occurs when a student believes that putting an effort in PE will lead to a certain personally valued outcome, for example when a student believes that PE will provide health benefits, will make him feel more fit, or will prepare him better for the weekend football match. Introjected regulation occurs if a student imposes an external pressure on to himself, for example by taking part in PE to avoid feelings of guilt or to comply with certain values he has as a person. Extrinsic regulation of behaviour takes place when a person solely engages in certain behaviour because of external rewards or punishment that are linked to the behaviour. For example a student that puts an effort in PE only out of fear for low grades, or the contrary, only to obtain high grades. Posited on the far side of the motivation continuum is amotivation, which is a state in which motivation is absent and a person lacks any intention to show the desired behaviour (Deci \& Ryan, 2000). 
According to Vallerand's hierarchical model of intrinsic and extrinsic motivation (Vallerand, 1997), motivation within a specific context is able to influence motivation outside of that context. This implies that motivation from a PE context could transfer into a leisure time physical activity (LTPA) context. Indeed, emerging from SDT-based PE studies is evidence that students with more autonomous motivational profiles show more adaptive behaviour outside of the PE context. To illustrate, autonomously motivated students in PE have been found having higher intentions to be physically active (Standage, Duda, \& Ntoumanis, 2003; Taylor et al., 2010), showing higher selfreported LTPA behaviour (Nikos Chatzisarantis \& Hagger, 2009; Haerens et al., 2010; Hagger et al., 2003; Taylor et al., 2010) and are more physically active later in life (Haerens et al., 2010). Autonomous motivation for PE has further been associated with higher levels of physical activity during PE lessons (Lonsdale, Sabiston, Raedeke, Ha, \& Sum, 2009) and has also been linked to higher participation rates in leisure time sports (Haerens et al., 2010).

However, despite an increasing body of evidence that links autonomous motivation in PE to physical activity during leisure time, almost all studies on this subject have relied exclusively on self-report physical activity measures (e.g. Cox, Williams, \& Smith, 2007; Fairclough, Hilland, Stratton, \& Ridgers, 2012; Haerens et al., 2010; Taylor et al., 2010). Although such measures have the advantage of being easily administered to large groups at relatively low costs in terms of materials, personnel and time, they also possess some distinct disadvantages. Self-report measures of physical activity are often subject to error and bias due to varying cognitive abilities and recall problems (Welk, 2008) and, although self-report measures are useful in determining the activity setting and mode of activity in youth (Corder, Ekelund, Steele, Wareham, \& Brage, 2008) they are unable to identify the intensity of movement, which makes accurate measurement of physical activity problematic. One study investigating the impact of the social context and motivational outcomes in a PE environment on motivation for LTPA and actual LTPA used pedometers (Standage, Gillision, Ntoumanis, \& Treasure, 2012), which provide an objective assessment of the total amount of steps taken as an estimate for the total volume of physical activity. However, since pedometers can only capture ambulatory activities, and are unable to take into account the intensity of an activity, they are limited in determining the total volume of physical activity. In contrast, a fairly recent method for objectively assessing physical activity is combined sensing. This method combines data-input from both acceleration and heart rate and as such provides a more accurate and feasible method for assessing LTPA in free living subjects. A distinct advantage of combined sensing is that it can reliably estimate levels of physical activity energy expenditure (PAEE) (Corder, Brage, Wareham, \& Ekelund, 2005). Moreover, when used in conjunction with activity diaries, detailed information can be obtained on the specific physical activities (such as PE or leisure time sports) that comprise it.

The present study aimed to explore to what extent motivation for PE was associated with objectively measured PAEE in Dutch adolescents. Therefore, we used combined sensing together with an activity diary in order to objectively assess total PAEE and PAEE from PE and leisure time sports separately. Simultaneously, we measured motivation regulation styles both in a PE context and in a leisure time physical activity context. Following the assumptions made by SDT and based on the previous literature on this topic, we propose the following hypotheses: a more autonomous motivational profile for PE is related to (1) a higher overall PAEE (2) more PAEE during the PE lesson itself (3) higher PAEE during leisure time sports. 


\section{Method}

\section{Participants and setting}

An initial sample of 180 adolescents was randomly selected from three secondary schools that were comparable in terms of ethnic population and socio-economic status of the parents. One-hundred-and-fifty-four students returned completed forms and were all found eligible to participate in the study (i.e. no restrictions to be physically active due to injuries, illness or chronic diseases). From this sample 80 participants (age 15-16 yrs.) were randomly selected to take part in the study. The Maastricht University Medical Research Ethics Committee approved the study and informed consent was obtained from parents/guardians and participants. All school principals gave their approval to carry out the study.

\section{Materials and Procedures}

All measurements took place within the school environment. Height and weight were measured using standardized procedures and body-mass index (BMI) was estimated from weight/height ${ }^{2}\left(\mathrm{~kg} / \mathrm{m}^{2}\right)$. Questionnaires were administered prior to commencement of the measurement week.

\section{Physical activity energy expenditure (PAEE).}

Actiheart monitors (Camntech, Cambridge) were used to assess PAEE. The Actiheart is a lightweight device (8 grams) that is worn on the chest using two standard electrodes. The Actiheart device combines heart rate and accelerometer data (HR+ACC). When used separately accelerometers are unable to pick up upper body movement and generally fail to distinguish between walking on the flat or uphill whereas heart monitors are inaccurate in estimating PAEE. of light activities and are susceptible to elevated heart rate due to psychological stress. However, when data of both instruments is combined using branched equation modelling (Brage et al., 2004), these disadvantages are absent, which enables estimating PAEE with more precision. The branched equation models in the Actiheart software were used to estimate energy expenditure above rest. Please revert to chapter 3 for a more detailed discussion on this topic. Sleeping heart rate was obtained in order to calibrate the monitor to the participant's resting value. To further increase PAEE estimation precision the HR+ACC monitor was individually calibrated for each participant through an 8-minute step test prior to the measurement week. This exercise test is designed to account for the variance in individual HR-PAEE relationships without the need for indirect calorimetry (Camntech, 2010). During the test, the student was guided by an audible voice from the computer, and stepped up and down a $215 \mathrm{~mm}$ step, linearly increasing step rate from 15 to 33 step cycles per minute after the first minute. As the weight and step height are constant, the demanded energy is proportional to the step frequency. The calibration procedure has been shown to result in a more accurate prediction of PAEE (Brage et al., 2007). Energy expenditure measured with the Actiheart monitor has been validated in a youth population against indirect calorimetry in a laboratory setting (Corder et al., 2007) and has been validated against criterion measures and other objective measures of PA in free-living conditions in a sample of college-students (Barreira, Kang, Caputo, Farley, \& Renfrow, 2009). A 1-minute epoch was used which enabled the monitor being worn day and night for 8 consecutive days, comprising a regular school week and weekend. Since only full measurement days were included, the analyses are based on 4 weekdays and 2 weekend days. 


\section{Activity diary.}

Each participant was asked to fill in an activity diary during their measurement week in which they reported the time and duration of all physical activities undertaken that week. Examples of such activities were PE, leisure time sports, active transport to school, paid work etc. The activity diary was conveniently small so that participants could keep it with them at all times. After measurement completion PAEE data could then be linked to the activity diary data, which allowed us to obtain the amount of energy expended within different physical activities over the course of the measurement week.

\section{Motivation for PE.}

In order to probe participants' motivation regulation styles in PE the Behavioral Regulations in Physical Education (BRPEQ) was employed (Aelterman et al., 2012) which is an adapted Dutch version of the Behavioral Regulation in Exercise Questionnaire (BREQ-2; (Markland \& Tobin, 2004). The BRPEQ consists of 20 items that assess external, introjected, identified and intrinsic regulation as well as amotivation and uses the following stem: 'I participate in PE because...' Answers are scored on a 5-point Likert scale ranging from 1 to 5 . The BRPEQ has been found to have good factorial validity (Aelterman et al., 2012). Cronbach's alpha values in our study were acceptable with autonomous motivation $\alpha=.93$, controlled motivation $\alpha=.72$ and amotivation $\alpha=.87$.

\section{Motivation for leisure time physical activity (LTPA)}

The Behavioral Regulation in Exercise Questionnaire 2 (BREQ-2; (Markland \& Tobin, 2004) was employed to assess motivation for leisure time physical activity (LTPA) using the stem 'I participate in physical activities because...'. Answers were scored on a Likert scale ranging from 1 to 5 . The BREQ-2 consists of 25 items and has been found to have good factorial validity (Markland \& Tobin, 2004) and has been previously employed to measure motivational regulation styles for LTPA in other studies (Haerens et al., 2010). Internal consistencies in our study were autonomous motivation $\alpha=.81$, controlled motivation $\alpha=.75$ and amotivation $\alpha=.68$.

\section{Data analysis}

First, data were examined and assumptions related to linear regression analysis were checked. Unless stated otherwise, all assumptions were met. Then, descriptive statistics, alpha coefficients and bivariate correlations between study variables were computed. Since previous studies have identified gender-differences in motivation for PE (Johnson, Prusak, Pennington, \& Wilkinson, 2011; Silverman \& Subramaniam, 1999), in motivation to participate in leisure time physical activities (Gillison, Osborn, Standage, \& Skevington, 2009) and in physical activity behaviour (Biddle, Gorely, \& Stensel, 2004; Hearst, Patnode, Sirard, Farbakhsh, \& Lytle, 2012), we employed a MANOVA with all outcome variables as dependent variables and gender as the independent variable to identify any gender differences.

To address the main research questions, three separate multiple regression analyses were employed with the independent variables being PAEE, PAEE during sports and PAEE during PE. According to Field (Field, 2009) a sample size of 80 participants allows a maximum of three predictors to be used in order to detect at least a medium effect. Therefore, and in concordance with previous studies (e.g. Cox, Smith, \& Williams, 2008; Standage et al., 2012; Standage, Duda, \& Ntoumanis, 2006), the separate motivational regulations (intrinsic motivation, identified regulation, introjected regulation, external regulation and amotivation) were summed to form a relative autonomy index (RAI) score. The formation of such a score is allowed if the distinct motivational regulations form a quasisimplex pattern with adjacent regulations along the motivation-continuum most highly correlated (Markland \& Ingledew, 2007) as was the case in our study and is shown in table 6.2. The RAl is composed by assigning weights to 
the BREQ-2 subscales as follows: amotivation * -3 , external regulation * -2 , introjected regulation * -1 , identified regulation * 2, intrinsic regulation * 3 (Markland \& Ingledew, 2007). The maximum possible score when applying these weights to the BREQ-2 subscale scores is 20 and the minimum is -24 with higher scores on the RAl representing higher autonomous motivation whereas lower scores represent a more controlling motivational style. Since the BRPEQ is an adapted version of the BREQ-2 a similar score was composed for motivation towards PE. Thus, two RAI score variables were ultimately computed, RAI-PE and RAI-LTPA. Nevertheless, in order to provide insight into the separate motivational regulations they are computed and displayed in the descriptive statistics. As stated above, since previous studies have indicate gender differences on the outcome variables in our study all regression analyses were controlled for gender. Also, to control for any general motivational profiles for LTPA behaviour, RAI-LTPA was entered as a second controlling variable in the regression analyses for total PAEE and for PAEE during sport. A hierarchical regression (blockwise entry) was employed since this method is seen as the most appropriate in the case where predictors are based on solid theoretical grounding (Field, 2009). Gender was entered in the first block, RAI-LTPA was entered in the second block and RAI-PE in the third block. In order to investigate the difference that each predictor made when added to the model the significance of the accompanying F-values were examined.

Table 6.1 Scores and 95\% confidence intervals (CI) for all study variables

\begin{tabular}{|c|c|c|c|c|c|c|c|}
\hline & $\begin{array}{l}\text { Group } \\
n=73\end{array}$ & $95 \% \mathrm{Cl}$ & $\begin{array}{l}\text { Boys } \\
n=37\end{array}$ & $95 \% \mathrm{Cl}$ & $\begin{array}{l}\text { Girls } \\
n=36\end{array}$ & $95 \% \mathrm{Cl}$ & \\
\hline RAI score PE & 6.96 & $(5.22-8.69)$ & 10.14 & $(7.94-12.35)$ & 3.68 & $(1.44-5.92)$ & $A$ \\
\hline RAI score LTPA & 11.10 & $(10.02-12.18)$ & 12.44 & $(10.98-13.89)$ & 9.73 & $(8.25-11.20)$ & $A$ \\
\hline Intrinsic regulation PE & 3.47 & $(3.23-3.72)$ & 3.95 & $(3.65-4.26)$ & 2.98 & $(2.67-3.29)$ & $A$ \\
\hline Identified regulation PE & 3.21 & $(3.98-3.43)$ & 3.45 & $(3.14-3.75)$ & 2.96 & $(2.65-3.27)$ & A \\
\hline Introjected regulation PE & 1.47 & (1.37 - 1.59) & 1.44 & $(1.28-1.59)$ & 1.52 & $(1.37-1.68)$ & \\
\hline External regulation PE & 1.52 & $(1.41-1.63)$ & 1.40 & $(1.25-1.55)$ & 1.65 & $(1.50-1.80)$ & \\
\hline Amotivation PE & 1.78 & $(1.58-1.99)$ & 1.46 & $(1.19-1.73)$ & 2.12 & $(1.84-2.40)$ & B \\
\hline Intrinsic regulation LTPA & 4.16 & $(4.01-4.32)$ & 4.37 & $(4.16-4.58)$ & 3.95 & $(3.74-4.16)$ & A \\
\hline Identified regulation LTPA & 3.56 & $(3.36-3.76)$ & 3.60 & (3.32 - 3.89) & 3.52 & $(3.23-3.81)$ & \\
\hline Introjected regulation LTPA & 1.63 & $(1.45-1.80)$ & 1.44 & $(1.21-1.68)$ & 1.82 & $(1.58-2.05)$ & B \\
\hline External regulation LTPA & 1.41 & $(1.27-1.55)$ & 1.36 & $(1.17-1.56)$ & 1.46 & $(1.26-1.66)$ & \\
\hline Amotivation LTPA & 1.36 & $(1.24-1.48)$ & 1.24 & $(1.07-1.40)$ & 1.48 & $(1.31-1.65)$ & B \\
\hline PAEE 6d (kJ/kg) & 334.65 & $(303.91-365.39)$ & 384.95 & $(337.80-432.1)$ & 282.94 & $(249.60-316.29)$ & A \\
\hline PAEE PE lesson (kJ/kg) & 18.12 & $(16.38-19.87)$ & 22.23 & $(19.74-24.72)$ & 13.90 & $(12.29-15.50)$ & A \\
\hline PAEE sport (kJ/kg) & 42.00 & $(31.50-52.50)$ & 54.26 & $(38.67-69.86)$ & 29.40 & $(15.90-42.90)$ & A \\
\hline
\end{tabular}

$A=$ boys $>$ girls

$\mathrm{B}=$ girls $>$ boys

RAI = Relative Autonomy Index score, a composite score consisting of the average weighted scores of all subscales within the BREQ-2 questionnaire

LTPA = Leisure time physical activity

PE $=$ Physical education

PAEE $=$ Physical activity energy expenditure 
CHAPTER 6

Table 6.2. Bivariate Correlations Among the Study Variables

\begin{tabular}{|c|c|c|c|c|c|c|c|c|c|c|c|c|c|c|c|c|c|c|}
\hline \multicolumn{19}{|l|}{$\underline{\varphi}$} \\
\hline$\stackrel{\llcorner}{\stackrel{n}{2}}$ & & & & & & & & & & & & & & & & & & $\stackrel{\infty}{\leftarrow}$ \\
\hline$\stackrel{\nabla}{\perp}$ & & & & & & & & & & & & & & & & & 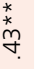 & $\stackrel{*}{*} \underset{f}{*}$ \\
\hline$\stackrel{m}{\underline{m}}$ & & & & & & & & & & & & & & & & & $\stackrel{*}{*}$ & $\stackrel{\infty}{\infty}$ \\
\hline$\simeq$ & & & & & & & & & & & & & , & 7 & & & $\stackrel{\sigma}{\div}$ & $\stackrel{\circ}{i}$ \\
\hline$=$ & & & & & & & & & & & & & $\stackrel{*}{\sim}$ & $c$ & $\bar{c}$ & & $\stackrel{n}{0}$ & $\stackrel{\nabla}{\because}$ \\
\hline 으 & & & & & & & & & & & , & 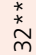 & $\stackrel{m}{n}$ & ¿ & $y$ & & N̦ & $\tilde{O}_{i}$ \\
\hline$\sigma$ & & & & & & & & & & & **** & ¿ & $\stackrel{?}{?}$ & $\stackrel{*}{N}$ & 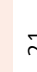 & & 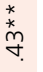 & $\stackrel{*}{\sim}$ \\
\hline$\infty$ & & & & & & & & ' & & $\frac{n}{i}$ & $\underset{\sim}{\tilde{N}}$ & $\stackrel{+}{\leftarrow}$ & $\stackrel{*}{\underset{\sim}{*}}$ & $\stackrel{*}{\sim}$ & $\stackrel{0}{0}^{*}$ & & $\underset{i}{i}$ & $\stackrel{*}{\stackrel{*}{p}}$ \\
\hline$\wedge$ & & & & & & & & & & ț & $\ddot{n}_{i}$ & 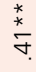 & $\approx$ & $\stackrel{\alpha}{a}$ & $\stackrel{n}{n}$ & & $\hat{o}_{i}$ & $\stackrel{*}{*} \underset{m}{m}$ \\
\hline 6 & & & & & & , & 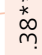 & $\frac{m}{7}$ & & סִ & $\stackrel{*}{n}$ & 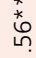 & $=$ & $\tilde{c}$ & 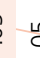 & & $\stackrel{m}{o}_{i}$ & 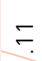 \\
\hline ـ & & & & & & $\approx$ & \begin{tabular}{l}
$*$ \\
\multirow{6}{*}{} \\
$\stackrel{8}{0}$
\end{tabular} & $\stackrel{*}{*}+$ & & vִ & 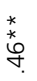 & $\stackrel{n}{\circ}$ & 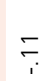 & $\stackrel{\text { * }}{*}$ & $\stackrel{*}{\lambda}$ & & ô. & શิ \\
\hline$\nabla$ & & & & , & $\stackrel{*}{*}$ & $\stackrel{9}{\leftarrow}$ & \begin{tabular}{l}
$*$ \\
\multirow{2}{*}{} \\
$\stackrel{0}{n}$
\end{tabular} & ث. & & 党 & $\stackrel{*}{\stackrel{*}{n}}$ & $\stackrel{\simeq}{\simeq}$ & ô & $\stackrel{*}{\circ}$ & $\stackrel{*}{\circ}$ & & $\stackrel{m}{r}$ & \begin{tabular}{l}
$*$ \\
$*$ \\
\multirow{2}{*}{} \\
$\stackrel{0}{0}$
\end{tabular} \\
\hline$m$ & & & & \begin{tabular}{l}
$*$ \\
\multirow{*}{*}{} \\
$\infty$ \\
$m$
\end{tabular} & \begin{tabular}{l}
$*$ \\
\multirow{2}{*}{} \\
$\vartheta$
\end{tabular} & $\stackrel{n}{0}$ & $\overbrace{i}$ & $\stackrel{*}{\stackrel{*}{m}}$ & & $\frac{x}{6}$ & ? & $\bar{i}_{i}$ & \begin{tabular}{l}
$*$ \\
\multirow{0}{*}{} \\
$\overbrace{1}^{\prime}$
\end{tabular} & $\stackrel{*}{\pi}$ & ণ & & \begin{tabular}{l}
$*$ \\
$*$ \\
$*$ \\
\multirow{\sigma}{*}{}
\end{tabular} & $\subsetneq$ \\
\hline$\sim$ & , & $\stackrel{*}{*}$ & & \begin{tabular}{l}
$*$ \\
\multirow{*}{*}{} \\
$\sigma$
\end{tabular} & 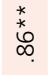 & oิ & 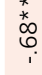 & 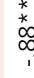 & & ?. & 苂 & ণి & $\stackrel{\infty}{?}$ & $\stackrel{*}{\text { * }}$ & $\stackrel{*}{i}$ & & 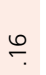 & \begin{tabular}{l} 
* \\
\multirow{2}{*}{}
\end{tabular} \\
\hline- & $\overbrace{}^{*}$ & 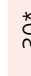 & & 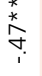 & $\stackrel{*}{\stackrel{*}{n}}$ & $\stackrel{\infty}{\circ}$ & $\stackrel{*}{\stackrel{*}{\sim}}$ & $\stackrel{*}{m}$ & & 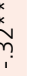 & $\stackrel{n}{n_{i}}$ & $\stackrel{*}{\stackrel{*}{\sim}}$ & $\stackrel{\infty}{\circ}$ & $\stackrel{*}{\nearrow}$ & $\begin{array}{l}\text { * } \\
\stackrel{*}{0} \\
\end{array}$ & & $\stackrel{*}{\stackrel{*}{?}}$ & 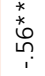 \\
\hline $\begin{array}{l}\frac{a}{g} \\
9 \\
0\end{array}$ & 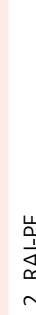 & 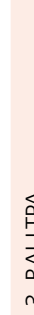 & & 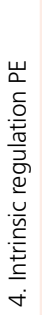 & 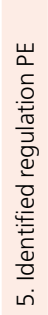 & 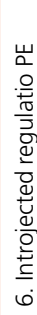 & 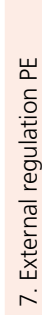 & 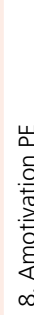 & 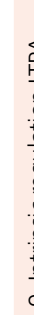 & 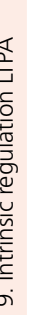 & 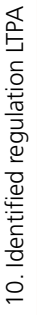 & 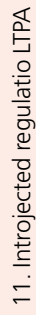 & 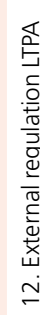 & 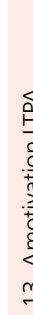 & 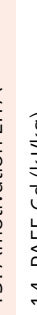 & & 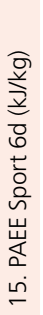 & 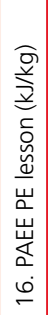 \\
\hline
\end{tabular}

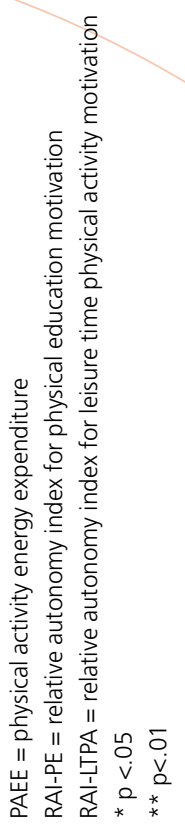




\section{Results}

Seven participants were discarded due to erroneous values or missing data resulting in 73 valid measurements. Table 6.1 gives an overview of the mean scores on all study variables for the study sample and for girls and boys separately. Various gender differences were identified. RAI-PE scores and RAI-LTPA were significantly higher for boys and boys scored higher on intrinsic regulation for PE and LTPA and identified regulation for PE. Girls had higher scores on external regulation and amotivation for PE and introjected regulation and amotivation for LTPA. Furthermore, boys had higher total PAEE, PAEE during PE and PAEE during sports. In addition, table 6.2 presents an overview of the bivariate correlations between the study variables. Moderate correlations were found between RAI-PE and total PAEE $(r=.31, p<.01)$ and between RAI-PE and PAEE during the PE/esson $(r=.40, p<.01)$. RAI-PE was unrelated to PAEE during sports $(r=.16, n . s$.$) . A moderate positive correlation was found between$ RAI-LTPA and PAEE during sports $(r=.40, p<.01)$, however no correlation was found between RAI-LTPA and total $\operatorname{PAEE}(r=.20$, n.s. $)$.

\section{Regression analyses}

Table 6.3 shows the outcome of the multiple regression analyses.

Total PAEE. Gender explained $15 \%$ of the variance in total PAEE whereas the addition of RAI-PA and RAI-PE added a non-significant 3\% explained variance. The best model fit was obtained with only gender as a predictor (model 1, $\left.F_{(1,71)}=12.719, p<.01\right)$. The $b$-values further indicated that gender had the largest individual contribution to total PAEE (.31), followed by RAI-PE (.16) and RAI-PA (.04).

PAEE during sports. Gender explained $8 \%$ of the variance in PAEE during sports, however the addition of RAI-PA significantly increased explained variance to $19 \%\left(F_{\text {change }(1,70)}=9,459, p<.01\right)$. The addition of RAI-PE in model 3 did not further increase the explained variance. Model 2, with gender and RAI-PA as predictors had the best model fit (model 2, $\left.F_{(2,70)}=8,062, p<.01\right)$ and RAI-PA had the largest individual contribution to the final model (.38) followed by gender (.21) and RAI-PE (.01).

PAEE during PE. Gender explained $31 \%$ of the variance in PAEE during the PE lesson. The addition of RAI-PE added $3 \%$ explained variance $\left(F_{\text {change }(1,70)}=3.093, p=.083\right)$. Gender had the largest individual contribution to the final model (-.48) followed by RAI-PE (.19). 
Table 6.3. Regression analyses for total PAEE, PAEE during sports and PAEE during PE.

\begin{tabular}{|c|c|c|c|c|c|}
\hline & $\mathbf{R}^{2}$ & $\Delta \mathbf{R}^{2}$ & B & SE B & B \\
\hline Total PAEE (kJ/kg) & & & & & \\
\hline Step 1: $F_{\text {change }}(1,71)=12.719 p<.01$ & .15 & & & & \\
\hline Constant & & & 486.95 & 45.04 & \\
\hline Gender & & & -102.00 & 28.60 & $-.39 * * *$ \\
\hline Step 2: $F_{\text {change }}(2,70)=6.630 p<.01$ & .16 & .01 & & & \\
\hline Constant & & & 445.62 & 69.54 & \\
\hline Gender & & & -95.07 & 30.02 & $-.36 * *$ \\
\hline RAI-LTPA & & & 2.56 & 3.28 & .09 \\
\hline Step 3: $F_{\text {change }}(3,69)=4.985 p<.01$ & .18 & .02 & & & \\
\hline Constant & & & 418.75 & 72.30 & \\
\hline Gender & & & -80.22 & 32.04 & $-.31 *$ \\
\hline RAI-LTPA & & & 1.01 & 3.48 & .04 \\
\hline RAI-PE & & & 2.94 & 2.29 & .17 \\
\hline
\end{tabular}

\begin{tabular}{|c|c|c|c|c|c|}
\hline PAEE during Sports $(\mathrm{kJ} / \mathrm{kq})$ & & & & & \\
\hline Step 1: $F_{\text {change }}(1,71)=5,500 p<.05$ & .08 & & & & \\
\hline Constant & & & 79.12 & 16.04 & \\
\hline Gender & & & -24.86 & 10.19 & $-28^{*}$ \\
\hline Step 2: $F_{\text {change }}(2,70)=3,877 p<.05$ & .19 & .11 & & & \\
\hline Constant & & & 24.52 & 23.35 & \\
\hline Gender & & & -15.70 & 10.08 & -.18 \\
\hline RAI-LTPA & & & 3.38 & 1.10 & $-.35 * *$ \\
\hline Step 3: $F_{\text {change }}(3,69)=4,899 p<.01$ & .19 & .00 & & & \\
\hline Constant & & & 29.72 & 24.47 & \\
\hline Gender & & & -18.57 & 10.84 & -.21 \\
\hline RAI-LTPA & & & 3.68 & 1.18 & $.38 * *$ \\
\hline RAI-PE & & & -.57 & .78 & -.01 \\
\hline
\end{tabular}

\begin{tabular}{|c|c|c|c|c|c|}
\hline \multicolumn{6}{|l|}{ PAEE during PE (kJ/kg) } \\
\hline Step 1: $F_{\text {change }}(1,71)=7,731 p<.05$ & .31 & & & & \\
\hline Constant & & & 30.57 & 2.31 & \\
\hline Gender & & & -8.34 & 1.47 & $-.56 * * *$ \\
\hline Step 2: $F_{\text {change }}(2,70)=36,728 p<.05$ & .34 & .03 & & & \\
\hline Constant & & & 27.19 & 2.98 & \\
\hline Gender & & & -7.10 & 1.61 & $-.48 * * *$ \\
\hline RAI-PE & & & 0.19 & 0.11 & .19 \\
\hline
\end{tabular}




\section{Discussion}

Motivating young people to adopt a physically active lifestyle has been put forward as an important goal for PE (Corbin, 2002; Pühse \& Gerber, 2004). The present study aimed to explore to what extent motivation in a PE context was related to objectively measured PAEE in Dutch adolescents in a leisure time context. To our knowledge this study is the first amongst several SDT-based PE studies to have linked motivational data to objectively measured physical activity energy expenditure in sports and PE. Our study results indicated that autonomous motivation for PE did not significantly predict total PAEE, PAEE during sports or PAEE during PE. However, we found pronounced gender differences on almost all study variables with boys having higher autonomous motivation and higher levels of physical activity within all physical activity contexts.

\section{Total Physical Activity Energy Expenditure}

In line with the tenets of SDT (Deci \& Ryan, 2000; Ryan \& Deci, 2000) and with the basic principles of the hierarchical model of intrinsic and extrinsic motivation (Vallerand, 1997) we hypothesized a trans-contextual association between autonomous motivation in a PE context with physical activity behaviour in a leisure time context. This contextual transfer of motivation from a PE setting to LTPA behaviour is presumed to be the foundation of one of the important aims of PE, which is to stimulate children and adolescents to adopt a physically active lifestyle (Corbin, 2002; Sallis et al., 2012). Although results from various studies have corroborated the association between PE motivation and physical activity behaviour outside of the school context (e.g. Cox et al., 2007; Haerens et al., 2010; Hagger et al., 2003; Standage et al., 2012; Taylor et al., 2010) in our sample autonomous motivation for PE was not a significant predictor of total physical activity energy expenditure (PAEE). Although correlational analysis showed a moderate positive association between the index for PE motivation (RAIPE) and total PAEE $(r=.31)$, it was actually gender that explained the majority of the variance in total PAEE, with autonomous motivation for LTPA and autonomous motivation for PE adding only $3 \%$ to the explained variance in total PAEE.

Given that boys consistently had higher scores on autonomous motivation for PE and motivation for LTPA as well as on total PAEE, these findings are not unexpected. Thus it appears that in our study gender was a stronger predictor of physical activity behaviour in adolescents than was motivation for PE or motivation for LTPA. In comparison, Taylor et al (2010) controlled their analyses for gender and found that intrinsic motivation for PE was a significant predictor of self-reported LTPA at the beginning of a school-trimester. Similarly, Haerens et al (2009) showed that students in autonomous and autonomous-controlled clusters reported higher physical activity outside of school than students in amotivated, controlled and lowly motivated clusters, irrespective of gender. Together, these studies implicate that being autonomously motivated for PE is related to more physical activity outside of school, regardless of gender.

An explanation for the alternative findings in our study compared to earlier work on the relation between motivation for PE and LTPA could be the use of combined sensing technology in our study to assess physical activity behaviour. Combining heart rate and accelerometry data enabled us to capture an objective image of the duration, intensity and frequency of adolescent boys' and girls' physical activity levels compared to self-report measures (Corder et al., 2008; Welk, Corbin, \& Dale, 2000). Recently, a review of physical activity questionnaires for youth concluded that no questionnaires are available with both acceptable reliability and validity (Chinapaw, Mokkink, van Poppel, van Mechelen, \& Terwee, 2010). An additional benefit of objective monitoring over selfreport is that self reported physical activity and self reported motivation for physical activity might have a concurrent bias, causing a spurious relationship between these variables. 
We found pronounced gender differences on almost all study variables. Most notably, boys in our study had higher autonomous motivation and were more physically active. This is in line with previous work that identified adolescent girls having lower autonomous motivation for PE than boys (Johnson et al., 2011; Wang, Chatzisarantis, Spray, \& Biddle, 2002), enjoying PE less (Napper-Owen, Kovar, Ermler, \& Mehrhof, 1999) and being physically less active (Kimm et al., 2002). According to SDT, students will experience self-determined motivation only if their basic psychological needs for competence (experiencing a feeling of effectiveness in dealing with certain tasks), autonomy (experiencing a sense of volition and choice) and relatedness (experiencing a sense of connectedness and friendship with significant others such as teachers or peers) are satisfied (Deci \& Ryan, 2000; Ryan \& Deci, 2000). We therefore speculate that in our study the PE environment might not have been optimally adapted to satisfy girls' needs for psychological well-being.

Previous studies have concluded that PE is generally more adapted to boys in terms of lesson subject, teacherstudent interactions, didactical delivery and evaluation methods (Johnson et al., 2011; Wright, 1997). For example, adolescent girls seem to have a preference for artistic sports (e.g. gymnastics, dance, aerobics) over team games (e.g. handball, football, basketball) (Stegeman, Bax, Hoekman, \& Slotboom, 2007), prefer self-referenced tests over norm- or peer-referenced tests (Johnson et al., 2011) and seem to dislike an emphasis on competitive activities (Johnson et al., 2011) especially when taught in coeducation (Lyu \& Gill, 2011). Also perceived autonomy support from the teacher has found to be lower in girls (Pihu \& Hein, 2007). All classes in our study were taught in coeducation and a pronounced focus on (competitive) team gameplay was present in all schools, a combination that has been identified to be detrimental to feelings of competence, autonomous motivation, effort and enjoyment in adolescent girls (Lyu \& Gill, 2011; Trost, 2004; Van Daalen, 2005). This might have been reinforced by the compulsory nature of PE as a school subject for all students in our sample, which for girls might have been perceived as a form of external regulation (girls are forced to participate by the teacher or the school) regarding the presence of a less optimal PE environment that does not satisfy girls' needs for competence, autonomy and relatedness. This might have contributed to lower autonomous PE motivation in the female sample, which is further illustrated by the finding of girls showing higher autonomous motivation for leisure time activities than for $\mathrm{PE}$ (table 6.1). As a consequence this might have reduced the association of girls' PE motivation with their physical activity behaviour outside of school resulting in PE motivation being a non-significant predictor for PAEE during leisure time. This could also imply that by providing choice and involving girls in decision making during PE, and by meeting girls' feelings of competence and relatedness autonomous motivation could be increased.

These findings give rise to the question if the PE curricula from the schools in our study were adequately equipped for both sexes in terms of establishing a transfer of skills, attitude and knowledge from a PE-context to a physical activity context outside of the school environment. Previous studies have shown that by creating an autonomysupportive PE environment, it is possible to increase PE motivation, intentions to be active and (self-reported) physical activity behaviour out of the school context (Chatzisarantis \& Hagger, 2009). This warrants further research on various topics regarding PE for girls: i.e. what is the impact of a more 'girl-friendly' PE curriculum on motivation and basic psychological needs? What should such a curriculum look like? How do we implement such a curriculum in a coeducational environment? 
Although our sample size restricted us in exploring the separate contribution of the motivational regulations (e.g intrinsic motivation, identified regulation) to the prediction of LTPA outcomes, in order to provide some insight, we reverted to the bivariate correlations between study variables. This is similar to procedures in a comparable study in university students by Standage et al. (Standage, Sebire, \& Loney, 2008). The bivariate correlations in table 6.2 indicated that both intrinsic $(r=.29)$ and identified $(r=.24)$ regulation within PE were positively related to physical activity behaviour beyond the school, while amotivation was negatively associated $(r=-.28)$. Surprisingly, none of the LTPA motivation regulations were associated with actual LTPA behaviour.

\section{Physical activity energy expenditure during sports and PE}

It is generally assumed that by introducing students to a variety of culturally relevant movement activities this should lead to an informed choice and active sport participation beyond the school (Bailey et al., 2009). In our sample $84 \%$ of the boys and $64 \%$ of the girls reported being a member in a sports club. Nevertheless, motivation for PE was not associated with the amount of PAEE during sports. This result is in agreement with findings by Haerens et al (2010) who found that almost two-third of university students retrospectively reported that PE had not prepared them to engage in sports activities outside of school. Interestingly, autonomous motivation for LTPA did predict PAEE during sports by explaining an additional $11 \%$ of the variance on top of the $8 \%$ explained by gender. Thus, although it appears that motivation for PE is not associated with the amount of physical activity during sports, it seems that a more context-specific motivation towards LTPA can be linked to sports participation. Possibly, motivation for PE is too distant as a construct to be related to the arnount of physical activity during sports, whereas LTPA motivation, being more proximal to actual sports participation, has a more direct influence. Another explanation could be that, while sports are rapidly evolving (e.g. free-running, bike trial, Nordic-walking etc.), the PE curriculum content in many schools has not changed much in the last three decades, mainly providing traditional team games such as basketball, handball and football, next to gymnastics, track and field and dance. Thus, PE in its current form might not be able to motivate students to become active in the contemporary sports culture.

Although PE has been assigned an important role in stimulating students to make an informed decision about adopting a physically active lifestyle, PE is also considered a valuable direct source of physical activity (Sallis et al., 2012; Slingerland \& Borghouts, 2011). Notably, for a large number of students PE provides the only structured weekly dose of physical activity (Mckenzie \& Lounsbery, 2009; Westerståhl, Barnekovv-Bergkvist, \& Jansson, 2005). Based on previous studies (Jaakkola, Liukkonen, Laakso, \& Ommundsen, 2008; Lonsdale et al., 2009) we expected autonomous motivation for PE to be a predictor of higher levels of PAEE during the PE lesson. However, again it was gender that explained the majority of the variance in PAEE during PE (31\%), with autonomous motivation for PE being responsible for an additional $3 \%$ of explained variance in PAEE during PE. In our study boys were found to be more active during PE than girls, which corresponds to previous work on this topic (Kulinna, Martin, Lai, Kliber, \& Reed, 2003; Laurson, Brown, Cullen, \& Dennis, 2008; Slingerland, Oomen, \& Borghouts, 2011). Aelterman et al (2012), reported that autonomous motivation for $P E$, accounted for a similar percentage of $4 \%$ of the between-student differences in moderate-to-vigorous physical activity (MVPA) while gender explained $6 \%$ of the between-student differences in MVPA. In contrast she also found that $19 \%$ of the between-class differences in MVPA were accounted for by the class topic. Taken together, we conclude that there is little evidence to support the notion that autonomous motivation for PE is strongly associated with the amount of physical activity in both PE and sports. 
A major strength of this study was the use of combined-sensing technology that allowed us to objectively assess total physical activity. The concurrent use of an activity diary also allowed us to assess levels of physical activity in the specific contexts of sports and PE. Together with the assessment of motivational regulations our study provides a unique insight into the association of motivation for PE, motivation for LTPA and objectively measured physical activity behaviour in related (PE) and more distal (LTPA) contexts. Despite these strengths, results of our study need to be considered in the light of some limitations. First, in our study we solely focused on motivation and gender to explain physical activity behaviour and as a result our findings explained only a portion of the total variance in PAEE. This indicates the need for a multidimensional approach focusing on different aspects that impact on physical activity behaviour in adolescents, such as perceived competence, autonomy and relatedness, effort, enjoyment, perceived barriers and social support. Also, recent findings have indicated that it might be important to distinguish between personal student motivation and class motivation, as classes that are more autonomously motivated as a whole are both more active and more engaged (Aelterman et al., 2012). Unfortunately, limited by our sample size we were unable to add more variables to our model and were unable to distinguish between student and class levels. Second, since our study was cross-sectional in nature we cannot infer on the causal relationships between motivation for PE and physical activity. For example, although we observed associations between motivation for LTPA and PAEE during sports we cannot rule out the possibility that adolescents have high autonomous motivation for LTPA only because they do a lot of sports. Longitudinal and experimental designs should be employed in future studies to draw conclusions on the causality of these relationships. Third, PE is a multi-activity school subject where motivation is different for specific activities even within the same context (i.e. PE; Vallerand, 1997). Although students in our sample were asked about their motivation on a contextual level (for PE in general) it is possible that the specific PE lesson they participated in that week influenced their responses in the questionnaire. This could have obscured the results to a certain extent. Future research should therefore preferably use a longitudinal research design, measuring at different time points, while monitoring the specific aspects of the PE lessons provided during the measurement period.

\section{Conclusions}

Motivation toward PE is considered an important determinant of adolescents' physical activity during PE lessons as well as beyond the context of the school. This study is the first in the rapidly growing body of SDT-based PE studies to employ an approach where combined-sensing and an activity diary were used to determine associations between motivation for PE, motivation for LTPA and objectively measured specific physical activity behaviours. Large gender differences in both motivation and physical activity were observed and results from our study show that gender is a more influential factor in predicting total physical activity and physical activity during both PE and leisure time sports, than autonomous motivation for PE is. In comparison, autonomous motivation for LTPA did predict physical activity during leisure time sports. The findings in this study give rise to the question if PE in its present form is adequately suited to bring about a transfer of physical activity behaviour from PE class to leisure time. 


\section{References}

Aelterman, N., Vansteenkiste, M., Van Keer, H., Berghe, L. V. D., Meyer De, J., \& Haerens, L. (2012). Students' objectively measured physical activity levels and engagement as a function of between-class and betweenstudent differences in motivation toward physical education. J Sport Exerc Psychol, 34, 457-480.

Bailey, R., Armour, K., Kirk, D., Jess, M., Pickup, I., \& Sandford, R. (2009). The educational benefits claimed for physical education and school sport: an academic review. Research Papers in Education, 24(1), 1-27.

Bandura, A. (1989). Human Agency in Social Cognitive Theory. American Psychologist, 44(9), 1175-11751184.

Barreira, T., Kang, M., Caputo, J., Farley, R., \& Renfrow, M. (2009). Validation of the Actiheart Monitor for the Measurement of Physical Activity. International Journal of Exercise Sciences, 2(1), 60-71.

Biddle, S.J.H., Gorely, T., \& Stensel, D. J. (2004). Health-enhancing physical activity and sedentary behaviour in children and adolescents. Journal of Sports Sciences, 22(8), 679-701.

Brage, S., Ekelund, U., Brage, N., Hennings, M., Froberg, K., Franks, P., \& Wareham, N. (2007). Hierarchy of individual calibration levels for heart rate and accelerometry to measure physical activity. Journal of Applied Physiology (Bethesda, Md.: 1985), 103(2), 682-692.

Brouwer, B., Aldershof, A., Bax, H., van Berkel, M., van Dokkum, G., Mulder, M. J., \& Nienhuis, J. (2011). Human movement and sports in 2028

Een blik in de toekomst van lichamelijke opvoeding/bewegingsonderwijs en sport op school. (B. Brouwer, Ed.), $1-80$.

camntech. (2010). The Actiheart user manual (4(null) ed., pp. 1-95). Cambridgeshire.

Cavill, N., Biddle, S., \& Sallis, J. (2001). Health Enhancing Physical Activity for Young People: Statement of the United Kingdom Expert Consensus Conference. Pediatric Exercise Science, 13(1), 12-25.

Chatzisarantis, Nikos, \& Hagger, M. (2009). Effects of an intervention based on self-determination theory on selfreported leisure-time physical activity participation. Psychology \& Health, 24.

Chinapaw, M. J. M., Mokkink, L. B., van Poppel, M. N. M., van Mechelen, W., \& Terwee, C. B. (2010). Physical activity questionnaires for youth: a systematic review of measurement properties. Sports Medicine, 40(7), 539-563.

Corbin, C. (2002). Physical Activity for Everyone: What Every Educator Should Know About Promoting Lifelong Physical Activity. Journal of Teaching in Physical Education, 21(2), 128-144.

Corder, K., Brage, S. R., Mattocks, C., Ness, A., Riddoch, C., Wareham, N., \& Ekelund, U. (2007). Comparison of Two Methods to Assess PAEE during Six Activities in Children. Medicine and Science in Sports and Exercise, 39(12), 2180-2188.

Corder, K., Brage, S. R., Wareham, N., \& Ekelund, U. (2005). Comparison of PAEE from Combined and Separate Heart Rate and Movement Models in Children. Medicine and Science in Sports and Exercise, 37(10), 1761-1767.

Corder, K., Ekelund, U., Steele, R., Wareham, N., \& Brage, S. (2008). Assessment of physical activity in youth. Journal of Applied Physiology, 105(3), 977-987.

Cox, A. E., Smith, A. L., \& Williams, L. (2008). Change in Physical Education Motivation and Physical Activity Behavior during Middle School. Journal of Adolescent Health, 43(5), 506-513. doi:10.1016/j. jadohealth.2008.04.020

Cox, A., Williams, L., \& Smith, A. (2007). Motivation in physical education and physical activity behavior outside of school. Journal of Sport and Exercise Psychology, 29, S154-S155.

Deci, E. L., \& Ryan, R. M. (1991). A Motivational Approach to Self: Integration in Personality. In R. Dienstbier (Ed.), Nebraska Symposium on Motivation: Perspectives on Motivation (Vol. 38, pp. 237-288). Lincoln, NE: University Of Nebraska Press. 
Deci, E. L., \& Ryan, R. M. (2000). The" what" and" why" of goal pursuits: Human needs and the selfdetermination of behavior. Psychological Inquiry, 11(4), 227-268.

Fairclough, S., \& Stratton, G. (2005). Physical Activity Levels in Middle and High School Physical Education: A Review. Pediatric Exercise Science, 17(3), 217-236.

Fairclough, S., Hilland, T., Stratton, G., \& Ridgers, N. (2012). 'Am I able? Is it worth it?' Adolescent girls' motivational predispositions to school physical education: Associations with health-enhancing physical activity. European Physical Education Review, 18(2), 147-158. doi:10.1177/1356336X12440025

Ferrer-Caja, E., \& Weiss, M. R. (2000). Predictors of intrinsic motivation among adolescent students in physical education. Research Quarterly for Exercise and Sport, 71(3), 267-279.

Field, A. (2009). Discovering Statistics Using SPSS (3rd ed.). London: Sage Publications Ltd.

Gillison, F., Osborn, M., Standage, M., \& Skevington, S. (2009). Exploring the experience of introjected regulation for exercise across gender in adolescence. Psychology of Sport and Exercise, 10(3), 309-319. doi:10.1016/j. psychsport.2008.10.004

Haerens, L., Kirk, D., Cardon, G., De Bourdeaudhuij, I., \& Vansteenkiste, M. (2010). Motivational Profiles for Secondary School Physical Education and Its Relationship to the Adoption of a Physically Active Lifestyle among University Students. European Physical Education Review, 16(2), 117-139.

Hagger, M., Chatzirantis, N., Culverhouse, T., \& Biddle, S. J. H. (2003). The Processes by Which Perceived Autonomy Support in Physical Education Promotes Leisure-Time Physical Activity Intentions and Behavior: A Trans-Contextual Model. Journal of Educational Psychology, 95, 784-795.

Hearst, M. O., Patnode, C. D., Sirard, J. R., Farbakhsh, K., \& Lytle, L. A. (2012). Multilevel predictors of adolescent physical activity: A longitudinal analysis. International Journal of Behavioral Nutrition and Physical Activity, 9(1), 8. doi:10.1186/1479-5868-9-8

Jaakkola, T., Liukkonen, J., Laakso, T., \& Ommundsen, Y. (2008). The relationship between situational and contextual self-determined motivation and physical activity intensity as measured by heart rates during ninth grade students' physical education classes. European Physical Education Review, 14(1), 13-31.

Johnson, T. G., Prusak, K. A., Pennington, T., \& Wilkinson, C. (2011). The Effects of the Type of Skill Test, Choice, and Gender on the Situational Motivation of Physical Education Students. Journal of Teaching in Physical Education.

Kimm, S., Glynn, N., Kriska, A., Barton, B., Kronsberg, S., Daniels, S., et al. (2002). Decline in physical activity in black girls and white girls during adolescence. New England Journal of Medicine, 347(10), 709-715.

Kulinna, P., Martin, J., Lai, Q., Kliber, A., \& Reed, B. (2003). Student physical activity patterns: grade, gender, and activity influences. Journal of Teaching in Physical Education, 22, 298-310.

Laurson, K., Brown, D., Cullen, R., \& Dennis, K. (2008). Heart rates of high school physical education students during team sports, individual sports, and fitness activities. Research Quarterly for Exercise and Sport, 79(1), 85-91.

Lim, B. S. C., \& Wang, C. K. J. (2009). Perceived autonomy support, behavioural regulations in physical education and physical activity intention. Psychology of Sport and Exercise, 10(1), 52-60. doi:10.1016/j. psychsport.2008.06.003

Lonsdale, C., Sabiston, C., Raedeke, T., Ha, A., \& Sum, R. (2009). Self-determined motivation and students' physical activity during structured physical education lessons and free choice periods. Preventive Medicine, 48, 69-73.

Lyu, M., \& Gill, D. (2011). Perceived physical competence, enjoyment and effort in same-sex and coeducational physical education classes. Educational Psychology, 31(2), 247-260. doi:10.1080/01443410.2010.545105 
Markland, D., \& Ingledew, D. (2007). The relationships between body mass and body image and relative autonomy for exercise among adolescent males and females. Psychology of Sport and Exercise, 8(5), 836-853.

Markland, D., \& Tobin, V. (2004). A modification to the Behavioural Regulation in Exercise Questionnaire to include an assessment of amotivation. Journal of Sport and Exercise Psychology, 26(2), 191-196.

McDavid, L., Cox, A. E., \& Amorose, A. J. (2012). The relative roles of physical education teachers and parents in adolescents' leisure-time physical activity motivation and behavior. Psychology of Sport and Exercise, 13(2), 99-107. doi:10.1016/j.psychsport.2011.10.003

Mckenzie, T. L., \& Lounsbery, M. A. F. (2009). School Physical Education: The Pill Not Taken. American Journal of Lifestyle Medicine, 3(3), 219-225. doi:10.1177/1559827609331562

Napper-Owen, G. E., Kovar, S. K., Ermler, K. L., \& Mehrhof, J. H. (1999). Curricula Equity in Required Ninth-Grade Physical Education. Journal of Teaching in Physical Education, 19, n1.

Ntoumanis, N. (2001). A self-determination approach to the understanding of motivation in physical education. British Journal of Educational Psychology, 71, 225-242.

Pate, R. R., O'Neill, J., \& Mclver, K. (2011). Physical Activity and Health: Does Physical Education Matter? Quest, 63, 19-35.

Pihu, M., \& Hein, V. (2007). Autonomy Support from Physical Education Teachers, Peers and Parents among School Students: Trans-Contextual Motivation Model. Acta Kinesiologae Universitatus Tartuensis, 12, 116-128.

Pühse, U., \& Gerber, M. (2004). International comparison of physical education: concepts, problems, prospects.

Ryan, R. M., \& Deci, E. L. (2000). Self-Determination Theory and the Facilitation of Intrinsic Motivation, Social Development, and Well-Being. American Psychologist, 55(1), 68-78.

Ryan, R. M., \& Deci, E. L. (2007). Active Human Nature: Self-Determination Theory and the Promotion and Maintenance of Sport, Exercise and Health. In M. D. Hagger \& N. L. D. Chatzisarantis (Eds.), Intrinsic Motivation and Self-Determination in Exercise and Sport. Human Kinetics Publishers.

Sallis, J. F., McKenzie, T. L., Beets, M. W., Beighle, A., Erwin, H., \& Lee, S. M. (2012). Physical Education's Role in Public Health: Steps Forward and Backward Over 20 Years and HOPE for the Future. Research Quarterly for Exercise and Sport, 125-135.

Silverman, S., \& Subramaniam, P. R. (1999). Student Attitude toward Physical Education and Physical Activity: A Review of Measurement Issues and Outcomes. Journal of Teaching in Physical Education, 19(1), 97-125.

Slingerland, M., \& Borghouts, L. (2011). Direct and indirect influence of physical education-based interventions on physical activity: a review. Journal of Physical Activity \& Health, 8(6), 866-878.

Slingerland, M., Oomen, J., \& Borghouts, L. (2011). Physical activity levels during Dutch primary and secondary school physical education. European Journal of Sport Science, 11(4), 249-257. doi:10.1080/17461391.2010.506661

Standage, M., Duda, J. L., \& Ntoumanis, N. (2006). Students' Motivational Processes and Their Relationship to Teacher Ratings in School Physical Education: A Self-Determination Theory Approach. Research Quarterly for Exercise and Sport, 77(1), 100-110. doi:10.5641/027013606X13080769704046

Standage, M., Duda, J., \& Ntoumanis, N. (2003). A Model of Contextual Motivation in Physical Education: Using Contructs From Self-Determination and Achievement Goal Theories to Predict Physical Activity Intentions. Journal of Educational Psychology, 95, 97-110.

Standage, M., Gillision, F. B., Ntoumanis, N., \& Treasure, D. C. (2012). Predicting Students' Physical Activity and Health-Related Well-Being: A Prospective Cross-Domain Investigation of Motivation Across School Physical Education and Exercise Settings. Journal of Sport and Exercise Psychology, 34, 37-60. 
Standage, M., Sebire, S. J., \& Loney, T. (2008). Does exercise motivation predict engagement in objectively assessed bouts of moderate-intensity exercise? A self-determination theory perspective. Journal of Sport and Exercise Psychology, 30(4), 337-352.

Stegeman, H., Bax, H., Hoekman, R., \& Slotboom, M. (2007). Aspecten van de Kwaliteit van LO (Aspects of the Quality of PE). In H. Stegeman (Ed.), Naar Beter Bewegingsonderwijs (Towards a Better Physical Education) (pp. 23-99). Nieuwegein: Arko Sports Media.

Taylor, I. M., Ntoumanis, N., Standage, M., \& Spray, C. M. (2010). Motivational predictors of physical education students' effort, exercise intentions, and leisure-time physical activity: a multilevel linear growth analysis. Journal of Sport and Exercise Psychology, 32(1), 99-120.

Trost, S. (2004). School physical education in the post-report era: an analysis from public health. Journal of Teaching in Physical Education, 23(4), 318-337.

Vallerand, R. (1997). Toward a Hierarchical Model of Intrinsic and Extrinsic Motivation. In M.P. Zanna (Ed.), Advances in Experimental Social Psychology, 271-360. San Diego: Academic Press.

Van Daalen, C. (2005). Girls' experiences in physical education: Competition, evaluation, \& degradation. The Journal of School Nursing, 21(2), 115-121.

Vansteenkiste, M., Sierens, E., Soenens, B., Luyckx, K., \& Lens, W. (2009). Motivational profiles from a selfdetermination perspective: The quality of motivation matters. Journal of Educational Psychology, 101(3), 671-688. doi:10.1037/a0015083

Wang, C., Chatzisarantis, N., Spray, C., \& Biddle, S. (2002). Achievement goal profiles in school physical education: Differences in self-determination, sport ability beliefs, and physical activity. British Journal of Educational Psychology, 72(3), 433-440.

Welk, G. (2008). The Role of Physical Activity Assessments for School-Based Physical Activity Promotion. Measurement in Physical Education and Exercise Science, 12(3), 184-206.

Welk, G., Corbin, C., \& Dale, D. (2000). Measurement Issues in the Assessment of Physical Activity in Children. Research Quarterly for Exercise and Sport, 71(2), 59-73.

Westerståhl, M., Barnekow-Bergkvist, M., \& Jansson, E. (2005). Low physical activity among adolescents in practical education. Scandinavian Journal of Medicine and Science in Sports, 15(5), 287-297. doi:10.1111/j.1600-0838.2004.00420.x

Wright, J. (1997). The Construction of Gendered Contexts in Single Sex and Co-educational Physical Education Lessons. Sport, Education and Society, 2(1), 55-72. doi:10.1080/1357332970020104 


\title{
CHAPTER 7
}

\begin{abstract}
DIFFERENCES IN PERCEIVED COMPETENCE AND PHYSICAL ACTIVITY LEVELS DURING SINGLEGENDER MODIFIED BASKETBALL GAME PLAY IN MIDDLE SCHOOL PHYSICAL EDUCATION
\end{abstract}

SLINGERLAND, M., HAERENS, L., CARDON, G. BORGHOUTS L.B.

EUROPEAN PHYSICAL EDUCATION REVIEW 2014 20(1), 20-35' 


\section{Summary}

Background: Creating environments in physical education that foster perceived competence and physical activity during gender-mixed game play lessons is a challenge, especially in adolescent girls. This study aimed to increase perceived competence and in-class physical activity in girls by applying a single-gender grouping strategy within co-educational classes.

Method: A final sample of 216 students (90 girls: 42\%) within 13 classes in grades 7-9 (age 11 - 15) played basketball in mixed-gender and in single-gender teams. Effects on perceived competence and MVPA were assessed using questionnaires and heart rate monitors respectively.

Results: Although girls' perceived competence was lower than that of boys, girls' perceived competence increased during single-gender gameplay. Physical activity levels were high during both mixed-gender and single-gender gameplay.

Conclusions: Playing invasion games (i.e. basketball, handball, soccer) in gender-specific groups could be a useful strategy for PE teachers to implement into their lessons in order to improve girls' perceived competence during invasion games. 


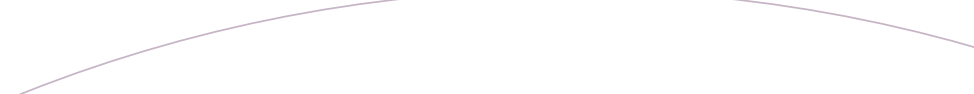

The importance of regular physical activity in young people is well established. Benefits of regular physical activity in children and adolescents include strong positive effects on musculoskeletal health, several components of cardiovascular health, adiposity, and blood pressure in adolescents (Strong, Malina, Blimkie, et al., 2005). Nevertheless, physical activity levels decline steeply during adolescence, especially in girls (Biddle, Gorely and Stensel, 2004; Kimm, Glynn, Kriska, et al., 2002). Consequently, girls are at a greater risk of developing health problems associated with insufficient physical activity. Physical education (PE) could contribute, at least in part, to combating decreasing physical activity levels in children and adolescents (Pate et al., 2011; Slingerland and Borghouts, 2011; Mckenzie and Lounsbery, 2009). From this viewpoint, recent studies have indicated the existence of a relationship between motivation for PE and leisure time physical activity behaviour in adolescents and young adults (Hagger et al., 2003; Ntoumanis and Standage, 2009; Biddle and Armstrong, 1992; Mullan et al., 1997; Wang et al., 2002). More specifically, PE aims to motivate young people to stay active during their adult life by teaching students adequate movement skills and by developing a positive attitude towards physical activity (Corbin, 2002; Fairclough, 2003; Haerens et al., 2011). In order to reach this activity and health related goal PE aims to establish a transfer of activities performed during PE lessons to activities outside of the curriculum (Haerens et al., 2010). It has been suggested that this transfer towards a healthy and active lifestyle outside physical education will be more easily obtained by providing personally relevant, interesting, and enjoyable activities that positively influence adolescents' motivation for physical education (Hassandra at al., 2003).

During the past two decades, studies on pupils' motivation have increasingly been conducted from the perspective of self-determination theory (SDT) (Ryan and Deci, 2000; Deci and Ryan, 2000). The attractiveness of SDT for the practice of education lies in its focus on the social environment and how it satisfies or dissatisfies pupils needs for autonomy (i.e. to be the initiator of and truly endorse an action or behaviour), competence (i.e. to feel effective in dealing with important challenges), and relatedness (i.e. to feel connected and loved by important others). Autonomy and competence are thought to directly influence motivation, whereas relatedness is seen as a more distal factor in enhancing motivation (Ryan and Deci, 2000; Deci and Ryan, 2000). Some authors suggest that competence is the most influential predictor of optimal forms of motivation in the context of physical education (Ferrer-Caja and Weiss, 2000; Ntoumanis, 2001; Corbin, 2002; Wang and Liu, 2007; Taylor et al., 2010) and perceived competence may be more influential than actual competence (Hannon and Ratliffe, 2005; Kulinna et al., 2003; Laurson et al., 2008). Previous research has found that students high in perceived competence showed more effort in PE, were more physically active and reported more leisure time physical activity (Taylor et al., 2010). Given the higher prevalence of inactivity in girls (Kimm et al., 2002; Sallis at al., 2000; Biddle et al., 2004), it is important to note that previous studies have shown that perceived physical competence levels in PE are generally lower in girls than in boys (Wang et al., 2002; Lyu and Gill, 2010; Kalaja et al., 2010).

The above findings suggest that environments that foster perceived competence might be able to enhance the likelihood of pupils being active during leisure time through their positive influence on pupils' motivation (Ryan and Deci, 2000). It has therefore been argued that PE can make special efforts to increase students', and especially girls', perceived competence (Corbin, 2002). Contextual factors such as class type or lesson content might enhance or diminish feelings of competence. Class type (co-education versus single-gender) has been found to influence students' levels of perceived competence (Derry and Phillips, 2005; Lyu and Gill, 2011) with girls feeling less competent in co-education PE classes as opposed to single-gender PE classes (Lyu and Gill, 2011). Often boys have superior physical competence and motor skills (Malina et al., 2004), which might lead to fewer opportunities for girls to play an active role in mixed-gender game play lessons. 
With regard to lesson content, competitive environments are known to be beneficial for those students who frequently experience success (i.e. the winners) and perceive their physical competence to be equal or better than their peers, whereas perceived competence and intrinsic motivation will decrease for the students who experience less favorable outcomes compared to their peers (i.e. the losers) (Vallerand et al., 1986b). Hence, one of the key factors of girls disliking PE and having lower levels of perceived competence during PE is the compulsory participation in competition, which is generally disliked by girls (Ntoumanis et al., 2004; Corbin, 2002). In addition, girls' perceived competence has been found especially low during competitive activities in mixed gender classes (Mullan et al., 1997; Van Daalen, 2005; Lyu and Gill, 2011). Peer comparison yields competence/incompetence information for both skilled and less-skilled students (Vallerand et al., 1986a) and is especially apparent during invasion games in PE (i.e. soccer, basketball, handball etc.). Since in many Western countries the PE curriculum tends to be dominated by team games (Pühse and Gerber, 2004; Slingerland et al. 2011; Trost, 2004) this poses a serious challenge for PE teachers trying not to dimishish girls' perceived competence levels in mixed gender PE. Thus, the competitive nature of invasion gameplay within a co-educational setting might have a negative impact on girls' perceived competence towards such PE activities (Van Daalen, 2005; Lyu and Gill, 2011).

Apart from optimally motivating pupils for PE through enhancing their perceived competence levels, PE could also directly contribute to physical activity (Slingerland and Borghouts, 2011) by increasing pupils' activity levels during the PE lesson itself (Mckenzie and Lounsbery, 2009; Fairclough and Stratton, 2005; Slingerland et al.,2011). Even more, for some students PE is the only time when they engage in moderate-to-vigorous physical activity (Westerståhl et al., 2005; Mckenzie and Lounsbery, 2009). Invasion games are amongst the most physically active lessons and have the potential to directly increase physical activity levels in adolescents (Slingerland et al., 2011; Kulinna et al., 2003; Laurson et al., 2008). However, recent research findings make clear that during mixed-gender invasion game lessons, especially boys are active and adolescent girls engage in lower physical activity levels compared to boys (Slingerland et al, 2011; Kulinna et al., 2003; Laurson et al., 2008). Therefore, the aim of the present study was to investigate the effects of providing gameplay in single-gender teams as opposed to gameplay in mixed gender teams on pupils' perceived competence and in-class physical activity levels. Additionally, the relationship between pupils' perceived competence and their in-class activity levels as well as the mediating role of perceived competition were investigated. It was hypothesized that within a co-educational setting, organizing gameplay in single-gender instead of mixed-gender teams yields positive effects on both perceived competence and physical activity levels, especially in students that perceive the lesson climate as competitive.

\section{Method \\ Participants}

The initial sample consisted of 294 students (134 girls: 46\%) within 13 classes in grades 7-9 (age 11 - 15 years) who attended the same secondary school in a middle large city in the south of the Netherlands. However, seventyeight students were excluded from data analysis due to various reasons: 44 students were absent the day the second (single-gender) lesson was provided, 16 students had more than 20\% missing heartrate data, 13 students did not complete the gameplay session due to an injury or due to corrective measures taken by the teacher and 5 students did not correctly fill in the questionnaire. Therefore the final sample consisted of 216 students (90 girls: $42 \%$ ). To test for differences between the drop-out sample and the final sample, dropout analysis was employed using t-tests. The analysis indicated no differences at baseline in any of the outcome variables between excluded students and the final sample (all $p>$.05). Classes contained an average of 24 students (range from 17 to 29) who were all enrolled in academic track. In the Netherlands, seventh and eight grade students participate in 150 minutes 
(one lesson of 100 minutes and one lesson of 50 minutes) of compulsory PE per week, whereas ninth grade students receive 100 weekly minutes (1 lesson) of compulsory PE. Prior to the study, students and parents filled in informed consents giving permission to partake in the study. Students were told they were free at all times to withdraw from the study. Permission was further obtained from the school board and PE teachers. The Fontys University of Applied Sciences research ethics committee approved the study.

\section{Instruments}

\section{Perceived competence.}

The sports/athletics subscale of the Children's Physical Self Perception Profile (C-PSPP)(Whitehead, 1995) was used to determine students' perceived competence for basketball during the single-gender and mixed-gender gameplay sessions. This scale consists of 6 items and was translated using the back-translation method. The C-PSPP is an adapted version of Fox and Corbin's Physical Self Perception Profile (Fox and Corbin, 1989) and is a reliable and valid measure of perceived competence in children across different grades and gender (Whitehead, 1995; Hagger et al., 2005). Previous studies have pointed out that children hold differentiated self-perceptions across various physical domains. For example, students can perceive themselves as competent in recreational and play activities but not in competitive activities (Mullan et al., 1997). Or more specific, students can perceive themselves competent in some sports but not in other sports (Feltz and Brown, 1984). Therefore, we adapted the C-PSPP to reflect students perceived competence in the basketball gameplay session during the past PE lesson by replacing the word "sports" with "basketball gameplay". An example was: Some kids do very well at playing basketball, BUT Other kids don't feel they are very good when it comes to basketball. The items were presented in a four-point structured-alternative format. Students indicated on a four point scale which statement was true for themselves, with high scores representing high levels of perceived competence. Internal consistency for the C-PSPP in our study was acceptable with a Cronbach's alpha value of $\alpha=.71$ (Cronbach and Shavelson, 2004).

\section{Percentage lesson time in MVPA.}

Physical activity levels during gameplay were assessed using Polar Team System heart rate (HR) monitors and expressed as the percentage of gameplay time spent in moderate-to-vigorous activity (MVPA) based on the classification as proposed by Stratton (Stratton, 1996, see table 3.1). Heart rates were averaged and stored every 5 seconds on an on-board chip, which made the use of a wristwatch redundant, thus ensuring student safety during gameplay. Afterwards, HR monitors were placed into a docking station where HR data was downloaded onto a laptop computer using Polar Precision Software 4. If students had more than $20 \%$ missing heartrate data (e.g. due to chest bands sliding down during activity) they were excluded from further analysis. See Slingerland, Oomen \& Borghouts (2011) for a detailed description of the heart rate data analysis protocol that was used.

\section{Perceived competitive climate.}

The way in which students perceived the climate as competitive was assessed using the Competitive Orientations subscale from the Learning and Performance Orientations in Physical Education Questionnaire (LAPOPEQ) (Papaioannou, 1994). The subscale consists of five items and was translated into Dutch using the back-translation method and adapted to reflect the basketball gameplay session of the past PE lesson. An example was: During the basketball gameplay session students were trying to outperform each other. Items were scored on a 5-point Likert scale, ranging from I Don't agree at all (1) to I Completely Agree (5). Internal consistency for this scale was satisfactory with an alpha value of $\alpha=.70$. 


\section{Procedures}

Each class received two identical basketball PE lessons within a co-educational setting. However, during the first lesson basketball gameplay was provided in mixed-gender teams, while in the second lesson basketball gameplay was provided in single-gender teams. Time between both lessons was two weeks. Single-gender teams played only against other teams of the same sex. Basketball was chosen as the lesson content since gender-specific characteristics (motor performance, strength) were expected to be particularly pronounced during this type of competitive gameplay. Also, basketball is amongst the most frequently provided team game sports within the national PE curriculum in the Netherlands (Stegeman et al., 2007). Each session consisted of three blocks: a brief warm-up (5 min.), a skill drill (15 min.) and gameplay (25 min.). During the gameplay session the grouping experiment was carried out. The gameplay session was an adapted form, 4-4 on a half court with two baskets. Four teachers ( 2 males and 2 females), with an average of 11.5 years $(S D=12.45$ ) of teaching experience provided the PE lessons. In order to assure lesson similarity across all classes, the participating PE teachers received an instructional training from the principal researcher prior to the start of the first PE lesson. In this training, lesson organisation, block duration, instructional strategy, time management and lesson content were predetermined and standardized in consultation with the PE teachers. All participating teachers approved the proceedings as proposed by the principal researcher. The principal researcher was present during each of the delivered lessons to ensure confidentiality to the research protocol. Before and during each lesson a strict research protocol was followed. Prior to lesson commencement all students were fitted with heartrate monitors. The principal investigator enacted the time schedule and recorded the exact time-points of the beginning and ending of the gameplay session. Directly after the gameplay session had finished, students were asked to sit down, hand in their HR monitors and fill out a set of questionnaires that related to the past PE lesson. It was made clear to the students that completing the questionnaires was an individual task and thus talking was prohibited. Completing the questionnaires took approximately 10-15 minutes.

\section{Data Analysis}

To determine time spent in physical activity of moderate to vigorous intensity during the gameplay session cut-off points based on percentage heart rate reserve were used based on Stratton's (Stratton, 1996) estimations of resting and maximal heart rate values by age. To account for the hierarchy in the data, multilevel analyses were employed with pupils at the first level nested within classes at the second level (Twisk, 2006). All analyses were carried out using MLwin version 2.23 (Rashbash et al., 2011). In order to determine effects of single-gender versus mixed-gender gameplay, two sets of analyses were employed with perceived competence and MVPA as two different dependent variables. First, a two-level null model, with only an intercept and no explanatory variables was estimated. This model discriminates the variance situated at the student level (level 1) from the variance situated at the class-level (level 2) and further serves as a baseline model to which subsequent analyses are compared. Predictors were then added to the model in a stepwise manner. In a first step gender was entered, in a second step gameplay (single versus mixed) was added, finally the interaction gender $x$ gameplay was added. By changing the reference group in the interaction term, post hoc analyses were conducted. Non-significant interactions were removed from the model before adding new predictors, whereupon separate main effects were assessed. A product-of-coefficient test was used to determine if perceived competitive climate, as measured by the Competitive Orientations subscale of the LAPOPEQ questionnaire, mediated the effect of single-gender or mixed-gender gameplay on perceived competence (Mackinnon et al., 2007). This test comprises (1) action theory test: the relationship between gameplay and competitive climate ( $\alpha$ coefficient) was estimated; (2) conceptual theory test: the independent relationship between competitive climate and perceived competence ( $B$ coefficient) was estimated; subsequently (3) the product of the two coefficients $(\alpha \beta)$ is computed, which represents the mediated effect; (4) $\alpha \beta$ is divided by its standard error. Finally, relationships among perceived competence and physical activity levels during gameplay were investigated. 
Table 7.1. Separate multilevel models for perceived competence and percentage of gameplay time in moderate-to-vigorous physical activity (MVPA)

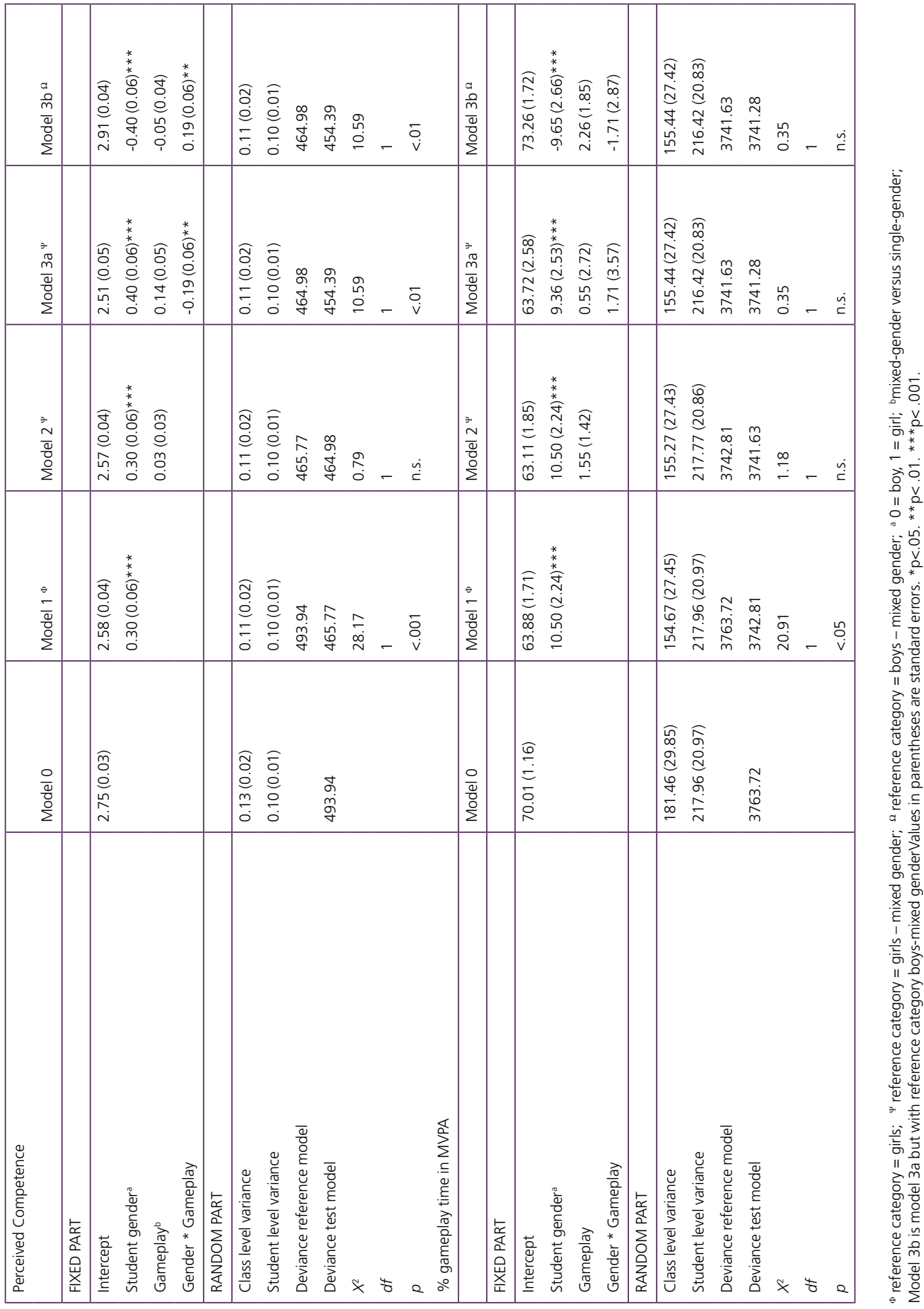




\section{Results}

\section{Perceived competence.}

The two-level null model for perceived competence (7.1 upper part) revealed an intercept of $2.75($ S.E. $=0.03)$, which is the average perceived competence score for all students irrespective of the type of gameplay. The random part of the null-model shows that variances at the student- $\left(x^{2}=54.31, \mathrm{df}=1, \mathrm{p}<.001\right)$ and class level $\left(x^{2}=108.00\right.$, $\mathrm{df}=1, \mathrm{p}<.001)$ significantly differed from zero, which provides justification for using multilevel modelling and indicated similarities in perceived competence between students within the same class. More specifically, the classand student level accounted for respectively $56 \%$ and $43 \%$ of the variability in perceived competence scores. The addition of gender in model 1 significantly improved the model. Overall, girls had lower perceived competence than boys $\left(x^{2}=28.17, d f=1, p<.001\right)$. Further, although the addition of gameplay in model 2 did not improve the model $\left(x^{2}=0.79, d f=1, n . s\right)$, the interaction between gender and gameplay did. Among girls, but not among boys perceived competence $\left(x^{2}=10.59, d f=1, p<.01\right)$ was significantly higher $(2.65$ S.E. $=0.05)$ during single-gender gameplay when compared to mixed-gender gameplay (2.51 S.E. $=0.05)$ (Figure 7.1).

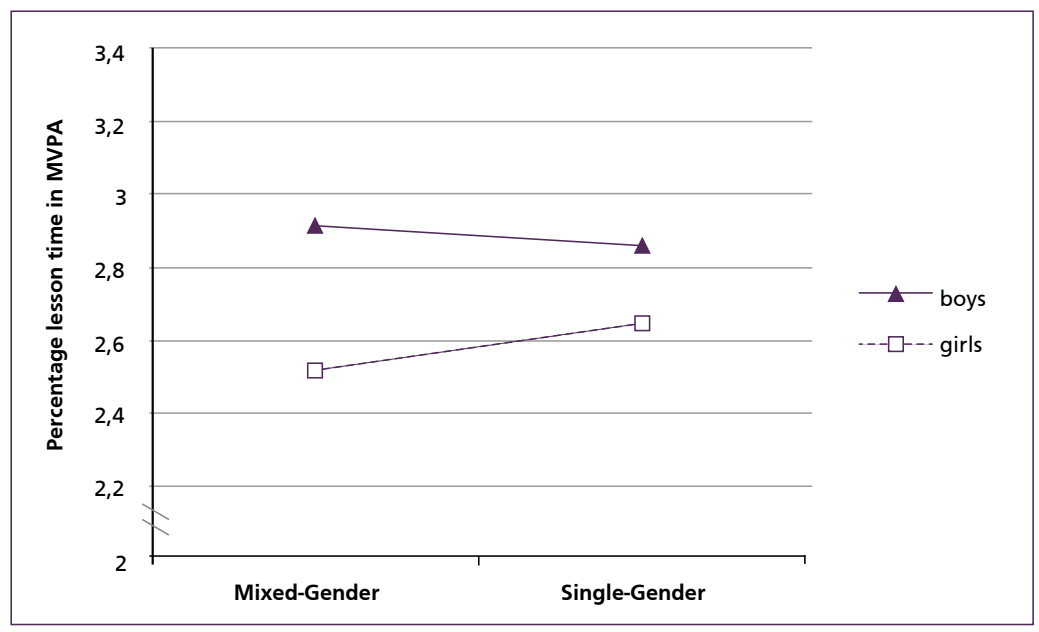

Figure 7.1 Perceived competence scores for boys and girls within mixed-gender (girls and boys) and single-gender (girls only or boys only) gameplay

\section{MVPA}

A two-level null model for MVPA was also estimated (Table 7.1 lower part), with the intercept of 70.01 (S.E. = 1.16) referring to the overall percentage of time students spent in MVPA during gameplay. The random part of the null-model shows that variances at the student- $\left(x^{2}=36.96, d f=1, p<.001\right)$ and class level $\left(x^{2}=108.00, d f=1, p\right.$ $<.05)$ significantly differ from zero. More specifically, the class- and student level accounted for respectively $45 \%$ and $55 \%$ of the variability in MVPA scores. The addition of gender in model 2 significantly improved the model $\left(x^{2}\right.$ $=30.99, \mathrm{df}=1, \mathrm{p}<.001)$ and upon further inspection a main effect of gender was found with girls being significantly less active than boys ( $64 \%$ vs. $74 \%$ of lesson time in MVPA $p<.001$ ). The addition of gameplay (mixed gender versus single gender) in model 3 did not improve the model $\left(x^{2}=1.18, d f=1, n . s\right.$.) indicating that there was no difference in MVPA between mixed-gender and single-gender gameplay for boys nor for girls. 
The interaction gender $x$ gameplay was not significant $\left(x^{2}=0.35, \mathrm{df}=1\right.$, n.s. $)$ indicating that the effect of gameplay on MVPA was similar for girls' and boys'.

\section{Mediation Analysis.}

The mediation analysis (Table 7.2) showed that in girls the gameplay type significantly related to perceived competitive climate (action theory, $\alpha$ coefficient). More specifically, girls perceived the gameplay climate as less competitive when playing in single-gender teams as opposed to playing in mixed-gender teams, whereas for boys there was no difference (Figure 7.2). However, perceived competitive climate did not significantly relate to students' levels of perceived competence (conceptual theory, B coefficient). Thus, the effect of gameplay type on perceived competence levels was not mediated by the perceived competitiveness of the gameplay climate.

Finally, regression analysis indicated a positive association between MVPA and perceived competence in the overall sample $\left(B=6.252(S E=2.075) x^{2}=9.076, d f=1, p<.01\right)$, irrespective of gameplay type and gender. However, no relation was found between perceived competence levels and percentage gameplay time in MVPA for girls or boys separately or for gameplay type.

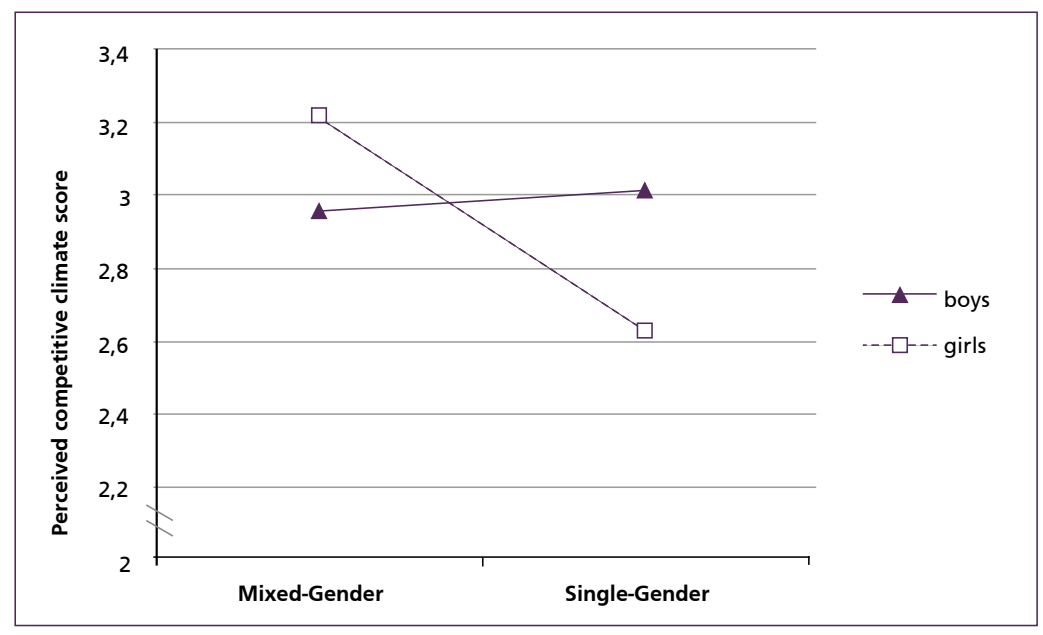

Figure 7.2 Perceived competitive climate scores for boys and girls within mixed-gender (girls and boys) and single-gender (girls only or boys only) gameplay 
Table 7.2. Mediation effect of perceived competitive climate for girls and boys

\begin{tabular}{|l|l|l|}
\multicolumn{1}{l}{} & Girls & \multicolumn{2}{l|}{ Boys } \\
\hline$\alpha(\mathrm{SE})$ & $-0.598(0.105) *$ & $-0.043(0.080)$ \\
\hline$\beta(\mathrm{SE})$ & $-0.006(0.031)$ & $-0.053(0.040)$ \\
\hline$\alpha \beta(\mathrm{SE})$ & $0.004(0.019)$ & $0.002(0.005)$ \\
\hline $95 \%$ Cl of $\alpha \beta$ & $-0.033,0.040$ & $-0.007,0.011$ \\
\hline$z$ & 0.193 & 0.498 \\
\hline$\%$ mediated effect & 2.6 & 4.2 \\
\hline
\end{tabular}

$\alpha=$ estimate of intervention effect (unstandardized regression coefficient) on residualized change score of competitive climate

$B=$ estimate of the independent effect of the mediator (unstandardized regression coefficient of residualized change scores) on residualized change score for perceived competence

$\alpha ß=$ product-of-coefficient estimate; mediated effect

$\mathrm{SE}=$ standard error

$95 \% \mathrm{Cl}$ of $\alpha \beta=95 \%$ confidence interval of the mediated effect

z standard deviate associated with mediated effect (used for significance testing)

${ }^{*} \mathrm{p}<.01$

\section{Discussion}

In accordance with our hypothesis, playing in single gender teams increased girls' perceived competence levels and decreased their perception of competitiveness. Physical activity levels did not change during single-gender gameplay. Thus, our results give some indication that by changing the lesson context in terms of grouping strategy, it is possible to enhance girls' perceptions of competence during invasion games. Our study furthermore showed that irrespective of gameplay type, boys had higher perceived competence scores for basketball gameplay than girls. This is in line with previous findings within a PE context (Lyu and Gill, 2011) and more general within a physical activity context (Wang et al., 2002; Biddle and Armstrong, 1992; Mullan et al., 1997; Lyu and Gill, 2011). Although girls' perceived competence levels seem to have increased during singlegender gameplay, this increase was relatively small. However, it should be noted that this result was obtained over the course of only one lesson in which single-gender groupings were applied. Further studies should be employed to investigate whether the result would be different if single-gender groupings were applied over a longer period.

Based on previous studies (Ntoumanis and Standage, 2009; Vallerand et al., 1986a) we hypothesized that the perception of competition (i.e. trying to show off skills rather than playing as a team, outperforming each other etc.) would mediate the relationship between gameplay and perceived competence levels. However, although girls perceived single-gender gameplay as less competitive and perceived competence was higher during singlegender gameplay, it was not the perception of competition that was responsible for the higher perceived competence scores in girls during single-gender gameplay. Therefore, we speculate with caution that it was the reference-group changing from male and female peers (mixed-gender) to female peers only (single-gender) that was responsible for the higher levels of perceived competence in girls during single-gender gameplay. In other words, the single-gender gameplay might have resulted in a reduction of the average ability level which in turn resulted in higher self-perception of competence in girls. 
According to the achievement goal theory (Nicholls, 1989) a performance climate predominates when social comparison and competition are emphasized, whereas a mastery climate involves effort and personal improvement. Although the perception of competition in our study was not related to perceived competence, girls playing in single-gender teams did perceive the motivational climate as less performance oriented compared to when playing in mixed-gender teams. This is an interesting finding, since perceptions of a performance climate have been linked to maladaptive outcomes such as extrinsic motivation (Cox and Williams, 2008), anxiety and boredom (Braithwaite et al., 2011). Although the element of competition was obviously still present during basketball gameplay in singlegender teams, girls might have experienced more room for self-improvement, for example through a better cooperation with other female team members leading to more ball contacts. Future research could employ an experimental study design using mixed-methods (e.g. direct observation and interviews) to confirm this.

Although research into other invasion games is needed, due to the large similarities between various invasion games we suspect playing in gender-specific groups could be a useful strategy for PE teachers to implement into their lessons in order to improve girls' perceived competence during invasion games in general. Our findings are in line with cross-sectional work by Lyu and Gill (2011) who found that girls reported higher scores in perceived competence, effort and enjoyment during PE in single-gender classes compared to co-educational classes. Presently, classes are predominantly taught in co-education in most western countries since it is generally seen as a better reflection of western society, might help break down sex-specific role patterns and could contribute to equality of the sexes. In addition, there seems to be no conclusive evidence in favour of teaching PE in either single-gender or mixed-gender classes with regard to the educational benefits, mainly due to a lack of research on this topic (Hannon and Williams, 2008). We therefore believe that changing the educational setting entirely to single-gender education in PE would be undesirable. Nevertheless, in order to provide equal learning opportunities it is important to provide female students with a physically and emotionally safe PE environment. In this respect, Gabbei (2004) argued that single-gender grouping strategies might be beneficial to ensure safety during units that involve contact activities, to provide an opportunity to achieve higher skills and to prevent students being adversely affected by evaluation standards. Additionally, results from our study indicate that playing in single-gender teams during invasion games might also be a good strategy for improving girls' perceived competence levels. Nevertheless, it could be argued that by using an ability grouping strategy rather than, or in addition to, a gender grouping strategy students' perceived competence levels could further increase, since grouping by gender could undermine feelings of competence in girls with high ability (who are playing within groups where the reference is generally female students of lower ability) and in boys with low ability (who are playing within groups where the reference is generally male students of higher ability). Furthermore, since previous research has found positive relationships between autonomy support and perceived competence (Halvari et al., 2009), ability groups using self-selection could also enhance perceived competence. In future studies, this hypothesis can be further examined.

Physical education lessons can be a valuable direct source of physical activity for many adolescents (Fairclough and Stratton, 2005; Slingerland and Borghouts, 2011). In this respect, invasion games have been proven to be a suitable subject for ensuring high levels of physical activity (Mersh and Fairclough, 2010). Previous studies have found that girls are generally less active than boys during mixed-gender invasion gameplay (Slingerland et al., 2011; Laurson et al., 2008; Kulinna et al., 2003). Hence, a second purpose of the present study was to look into the effects of grouping strategy (mixed gender versus single gender) on pupils' MVPA levels during invasion games. Our study confirmed the findings of previous studies that girls are less active than boys in mixed-gender invasion game play. However, the differences between boys and girls were not unique to playing in mixed-gender 
teams, since playing in single-gender teams did not bring about any changes in the percentage of gameplay time in MVPA for girls or for boys. It should be noted that girls' physical activity levels were quite high, as around $64 \%$ of gameplay time was spent in MVPA. This could be due to the fact that students played a modified gameplay form ( 4 on 4 basketball on a smaller court). Modified gameplay forms have been found to increase physical activity levels in both boys and girls (Acker et al., 2010). Consequently, this could have led to a ceiling effect since boys and girls were already engaged in significant amounts of physical activity leaving no room for the grouping strategy to increase activity levels in these types of lessons.

Perceived competence is considered a key motivational determinant in PE (Hassandra et al., 2003; Ntoumanis and Standage, 2009), which has been related to other positive outcomes such as intrinsic motivation, enhanced effort, concentration, positive affect and a preference for challenging tasks in PE (Taylor et al., 2010; Standage et al., 2005; Ntoumanis and Standage, 2009; Haerens et al., 2010). In our study perceived competence was also related to the amount of MVPA during basketball. More specifically, students with higher perceived competence were more active during gameplay. However, these differences were not present for boys and girls separately. This could be due to our relatively small sample size. Therefore, more studies are needed to confirm these findings.

\section{Limitations}

Our study results need to be interpreted in light of some limitations. First of all, while in the present study valid and reliable instruments were used, the fact that students were measured only once during single-gender gameplay and once during mixed-gender gameplay is a limitation. In order to determine the long-term effects of playing in singlegender teams on psychological outcomes, future studies could employ a longitudinal research design. For example, single-gender gameplay could be implemented in the school PE curriculum for the duration of a school-semester or an entire school year. Second, teachers can have a major influence on student behaviour during PE class, for example through feedback delivery (Mouratidis et al., 2008; Roberts and Fairclough, 2011) and social support (Shen et al., 2010). Although the teachers that participated in our study had similar teaching convictions, which they recorded in an official school PE document, all teachers have their own teaching style. In addition, teacher gender could also influence student behaviour and psychological responses. For example, it was shown that boys tend to receive more praise and more invested time from female teachers than girls (Nicaise et al, 2007). We did not assess if and how teacher variables influenced our results. Therefore, future studies on this topic should use systematic observation and qualitative research methods to monitor student and teacher behaviours. Third, we did not assess motivational regulations. Since perceived competence is an important precursor of pupils' motivation it would be interesting to see if increases in perceived competence lead to more optimal forms of motivation and in turn to higher activity levels during and outside $\mathrm{PE}$, thereby using multilevel structural equation modeling techniques. Finally, while in our study basketball was the only provided lesson subject, it would be interesting to apply the same grouping strategy to other invasion games such as football, field hockey, handball etc. 


\section{Conclusions}

Creating environments that foster perceived competence in co-educational game play lessons is a challenge, especially for the group of female students. Results from this study suggest that applying a single-gender grouping strategy during competitive gameplay could lead to higher levels of perceived competence in girls, but not in boys, while maintaining high levels of physical activity. Although perceived competence in PE has been hypothesized to be mediated by perception of competition, we found no such relationship even though girls' perception of competitiveness was lower during single gender gameplay. Further research should employ a longitudinal design and study the effects of grouping students by actual competence level of self-selection.

\section{References}

Acker R, Costa F D, Bourdeaudhuij I D, et al. (2010) Sex equity and physical activity levels in coeducational physical education: exploring the potential of modified game forms. Physical Education and Sport Pedagogy 15(2): 159-173.

Biddle S and Armstrong N (1992) Children's physical activity: an exploratory study of psychological correlates. Social Science and Medicine 34(3): 325-331.

Biddle S, Gorely T and Stensel D (2004) Health-enhancing physical activity and sedentary behaviour in children and adolescents. Journal of Sports Sciences 22(8): 679-701.

Braithwaite R, Spray C M, Warburton V E (2011) Motivational climate interventions in physical education: A meta analysis. Psychology of Sport and Exercise 12(6): 628-638.

Corbin C (2002) Physical activity for everyone: What every educator should know about promoting lifelong physical activity. Journal of Teaching in Physical Education 21(2): 128-144.

Cox, A and Williams, L (2008) The roles of perceived teacher support, motivational climate, and psychological need satisfaction in students' physical education motivation. Journal of Sports and Exercise Psychology 30(2): 222-239.

Cronbach LJ and Shavelson RJ (2004) My current thoughts on coefficient alpha and successor procedures. Educational and Psychological Measurement 64(3): 391-418.

Deci EL and Ryan RM (2000) The" what" and' why' of goal pursuits: Human needs and the self-determination of behavior. Psychological Inquiry 11(4): 227-268.

Derry J and Phillips D (2005) Comparisons of selected student and teacher variables in all-girls and coeducational physical education environments. Physical Educator 61(1): 23-34.

Fairclough S (2003) Girls' physical activity during high school physical education: influences of body composition and cardiorespiratory fitness. Journal of Teaching in Physical Education 22(4): 382-395.

Fairclough S and Stratton G (2005) Physical activity levels in middle and high school physical education: A review. Pediatric Exercise Science 17(3): 217-236.

Feltz DW and Brown EW (1984) Perceived competence in soccer skills among young soccer players. Journal of Sport and Exercise Psychology 6(4): 385-394.

Ferrer-Caja E and Weiss MR (2000) Predictors of intrinsic motivation among adolescent students in physical education. Research Quarterly For Exercise And Sport 71(3): 267-279.

Fox K and Corbin C (1989) The physical self-perception profile: Development and preliminary validation. Journal of Sport and Exercise Psychology 11(4): 408-430.

Gabbei R, Achieving balance: Secondary physical education gender-grouping options: Can teachers legally use occasional single-gender groupings, within coed physical education, to the benefit of all students? Journal of Physical Education, Recreation and Dance 75(3): 23-30. 
Haerens L, Kirk D, Cardon G, et al. (2010) Motivational profiles for secondary school physical education and its relationship to the adoption of a physically active lifestyle among university students. European Physical Education Review 16(2): 117-139.

Haerens L, Kirk D, Cardon G, et al. (2011) Toward the development of a pedagogical model for health-based physical education. Quest 63: 321-338.

Hagger M, Biddle SJH and Wang CKJ (2005) Physical self-concept in adolescence: Generalizability of a multidimensional, hierarchical model across gender and grade. Educational and Psychological Measurement 65: 297-322.

Hagger M, Chatzirantis N, Culverhouse T, et al. (2003) The processes by which perceived autonomy support in physical education promotes leisure-time physical activity intentions and behavior: A trans-contextual model. Journal of Educational Psychology 95: 784-795.

Halvari H, Ulstad SO, Bag TE, et al. (2009) Autonomy support and its links to physical activity and competitive performance: Mediations through motivation, competence, action orientation and harmonious passion, and the moderator role of autonomy support by perceived competence. Scandinavian Journal of Educational Research 53(6): 533-555.

Hannon JC and Ratliffe T (2005) Physical activity levels in coeducational and single-gender high school physical education settings. Journal of teaching in physical education 24(2): 149-164.

Hannon JC and Williams SM (2008) Should secondary physical education be coeducational or single-sex? Journal of Physical Education, Recreation and Dance 79(2): 6-8.

Hassandra M, Goudas M and Chroni S (2003) Examining factors associated with intrinsic motivation in physical education: a qualitative approach. Psychology of Sport and Exercise 4(3): 211-223.

Kimm S, Glynn N, Kriska A, et al. (2002) Decline in physical activity in black girls and white girls during adolescence. New England Journal of Medicine 347(10): 709-715.

Kalaja S, Jaakkola A, Watt A, Liukkonen J, Ommundsen Y (2010) The associations between seventh grade Finnish students' motivational climate, perceived competence, self-determined motivation, and fundamental movement skills. European Physical Education Review 15(3): 315-335.

Kulinna P, Martin J, Lai Q, et al. (2003) Student physical activity patterns: grade, gender, and activity influences. Journal of Teaching in Physical Education 22: 298-310.

Laurson K, Brown D, Cullen R, et al. (2008) Heart rates of high school physical education students during team sports, individual sports, and fitness activities. Research Quarterly For Exercise And Sport 79(1): 85-91.

Lyu M and Gill D (2011) Perceived physical competence, enjoyment and effort in same-sex and coeducational physical education classes. Educational Psychology 31(2): 247-260.

Malina RM, Bouchard C and Bar-Or O (2004) Growth, maturation, and physical activity. 2nd ed. Champaign, Human Kinetics.

Mckenzie TL and Lounsbery MAF (2009) School physical education: The pill pot taken. American Journal of Lifestyle Medicine 3(3): 219-225.

Mersh R and Fairclough S (2010) Physical activity, lesson context and teacher behaviours within the revised English National Curriculum for Physical Education: A case study of one school. European Physical Education Review 16(1): 29-45.

Mouratidis A, Vansteenkiste M, Lens W, et al. (2008) The motivating role of positive feedback in sport and physical education: evidence for a motivational model. Journal of Sport and Exercise Psychology 30(2): 240-268. 
Mullan E, Albinson J and Markland D (1997) Children's perceived physical competence at different categories of physical activity. Pediatric Exercise Science 9: 237-242.

Nicaise V, Bois J E, Fairclough S J, Amorose A J, and Cogérino G (2007). Girls' and boys' perceptions of physical education teachers' feedback: Effects on performance and psychological responses. Journal of Sports Sciences 25(8): 915-926.

Nicholls, J (1989) The competitive ethos and democratic education. Harvard University Press, Cambridge, MA.

Ntoumanis N (2001) A self-determination approach to the understanding of motivation in physical education. British Journal of Educational Psychology 71: 225-242.

Ntoumanis N and Standage M (2009) Motivation in physical education classes: A self-determination theory perspective. Theory and Research in Education 7(2): 194-202.

Ntoumanis N, Pensgaard A, Martin C, et al. (2004) An idiographic analysis of amotivation in compulsory school physical education. Journal of Sport and Exercise Psychology 26: 197-214.

Papaioannou A (1994) Development of a questionnaire to measure achievement orientations in physical education. Research Quarterly For Exercise And Sport 65(1): 11-20.

Pate RR, O'Neill J and Mclver K (2011) Physical activity and health: Does physical education matter? Quest 63: 19-35.

Pühse U and Gerber M (2004) International comparison of physical education: concepts, problems, prospects. Meyer and Meyers Sport, Oxford.

Rashbash J, Charlton C, Browne WJ, et al. (2011) MLwin 2.23. Centre for Multilevel Modelling, University of Bristol.

Roberts S and Fairclough S (2011) Observational analysis of student activity modes, lesson contexts and teacher interactions during games classes in high school (11--16 years) physical education. European Physical Education Review 17(2): 255-268.

Ryan RM and Deci EL (2007) Active human nature: Self-determination theory and the promotion and maintenance of sport, exercise and health. In: Hagger MD and Chatzisarantis NLD (eds), Intrinsic motivation and selfdetermination in exercise and sport. Champaign, IL: Human Kinetics Publishers, pp 1-19.

Ryan RM and Deci EL (2000) Self-determination theory and the facilitation of intrinsic motivation, social development, and well-being. American Psychologist 55(1): 68-78.

Sallis J, Prochaska J and Taylor W (2000) A review of correlates of physical activity of children and adolescents. Medicine And Science In Sports And Exercise 32(5): 963-975.

Shen B, Li W, Sun H, et al. (2010) Maturational differences in physical self-perceptions and the relationship with physical activity in early adolescent girls. Journal of Teaching in Physical Education 29: 417-432.

Slingerland $M$ and Borghouts $L$ (2011) Direct and indirect influence of physical education-based interventions on physical activity: a review. Journal of Physical Activity and Health, 8(6), 866-878.

Slingerland M, Oomen J and Borghouts L (2011) Physical activity levels during Dutch primary and secondary school physical education. European Journal of Sport Science 11(4): 249-257.

Standage M, Duda J and Ntoumanis N (2005) A test of self-determination theory in school physical education. British Journal of Educational Psychology 75: 411-433.

Stegeman H, Bax H, Hoekman R, et al. (2007) Aspecten van de kwaliteit van LO (Aspects of the quality of PE). In: Stegeman $\mathrm{H}$ (ed.), Naar beter bewegingsonderwijs (Towards an improved physical education), Nieuwegein, Arko Sports Media, pp. 23-99.

Stratton G (1996) Children's heart rates during physical education lessons: a review. / Frequences cardiaques des enfants pendant les cours d'education physique: revue. Pediatric Exercise Science 8(3): 215-233. 
Strong W, Malina R, Blimkie C, et al. (2005) Evidence based physical activity for school-age youth. The Journal Of Pediatrics 146(6): 732-737.

Taylor IM, Ntoumanis N, Standage M, et al. (2010) Motivational predictors of physical education students' effort, exercise intentions, and leisure-time physical activity: a multilevel linear growth analysis. Journal of Sport and Exercise Psychology 32(1): 99-120.

Trost S (2004) School physical education in the post-report era: an analysis from public health. Journal of Teaching in Physical Education 23(4): 318-337.

Twisk JWR (2006) Applied multilevel analyssis. Cambridge: University Press

Vallerand R, Gauvin L and Halliwell W (1986a) Effects of zero-sum competition on children's intrinsic motivation and perceived competence. Journal of Social Psychology 126(4): 465-472.

Vallerand R, Gauvin L and Halliwell W (1986b) Negative effects of competition on children's intrinsic motivation. Journal of Social Psychology 126(5): 649-657.

Van Daalen C (2005) Girls' experiences in physical education: Competition, evaluation, and degradation. The Journal of School Nursing 21(2): 115-121.

Wang C, Chatzisarantis N, Spray C, et al. (2002) Achievement goal profiles in school physical education: Differences in self-determination, sport ability beliefs, and physical activity. British Journal of Educational Psychology 72(3): 433-440.

Wang CJ and Liu W (2007) Promoting enjoyment in girls' physical education: The impact of goals, beliefs, and selfdetermination. European Physical Education Review 13(2): 145-164.

Westerståhl M, Barnekow-Bergkvist M and Jansson E (2005) Low physical activity among adolescents in practical education. Scandinavian Journal of Medicine and Science in Sports 15(5): 287-297.

Whitehead J (1995) A study of children's physical self-perceptions using an adapted physical self-perception profile questionnaire. Pediatric Exercise Science 7: 132-132. 


\section{CHAPTER 8}

GENERAL DISCUSSION

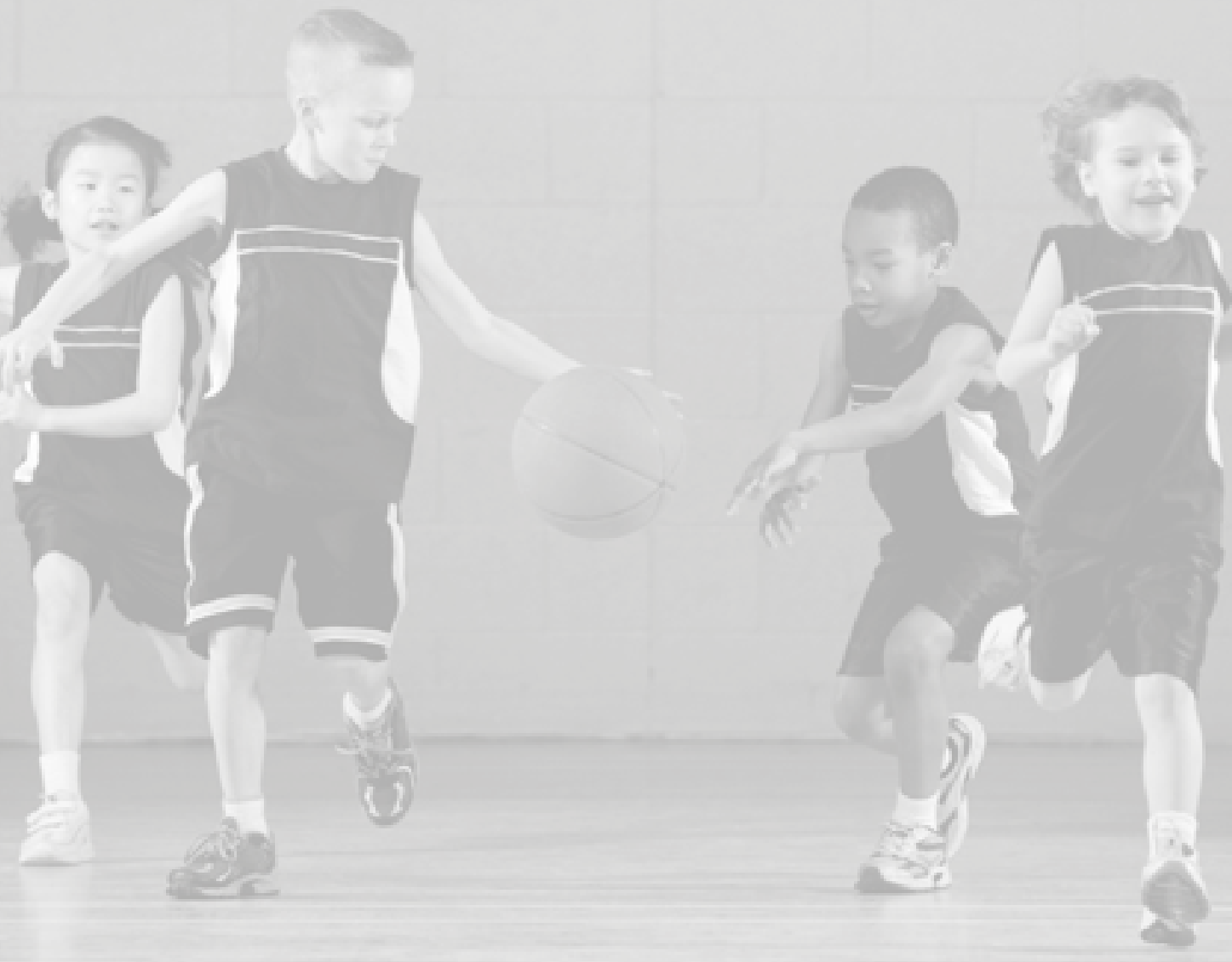


Historically, PE has been attributed many different aims which can be broadly classified within the physical (motor), social, cognitive and affective domain (Bailey et al., 2009). Prompted by the growing prevalence of physical inactivity, overweight and obesity in children and adolescents in the last two decades (Currie et al., 2008; Janssen et al., 2005), and by the preventive role of physical activity in this matter (Dishman, Heath, \& Lee, 2004; WHO, 2012) PE has captured the interest of researchers, governments and policy makers in many western countries (Corbin, 2002; Pate, O'Neill, \& Mclver, 2011; Seghers, 2009). This interest seems rational since PE is a compulsory school subject within the educational systems of most countries (Pühse \& Gerber, 2004) and regardless of what aims PE strives for, it remains the only school subject in which physical activity is the central issue. As such it reaches virtually all children and adolescents and has the potential to make a substantial impact on children's and adolescents' physical activity behaviour (Fairclough \& Stratton, 2005; Payne \& Morrow, 2009). Recent healthrelated PE approaches regard physical education as a means to develop knowledge, skills, attitudes and confidence in order to be able to participate in physical activities within and beyond the school. For example, Sallis et al. (Sallis et al., 2012) allot an important role to PE within public health by defining a Health-Optimizing Physical Education (HOPE). HOPE aims at "physical education that encompasses curriculum and lessons focused on health-related physical activity and fitness; keeps students active for at least 50\% of class time; engages all students, regardless of physical ability; and significantly contributes to students' overall physical activity participation, thereby improving their health" (p. 131-132). A different approach is taken by Haerens et al. (Haerens, Kirk, Cardon, \& Bourdeaudhuij, 2011), who advocate a pedagogical framework for the development of a Health-Based Physical Education (HBPE) model in which "pupils valuing a physically active life, so that they learn to value and practice appropriate physical activities that enhance health and wellbeing for the rest of their lives" is central. Nevertheless, both papers also identify a number of barriers and tensions, such as: PE not being a core school subject and the limited or reduced time allotted to PE (Sallis et al., 2012), the prioritising of PE attainment goals (affective, cognitive, motor), a lack of consensus on the type of activities that should be included in the curriculum and how to establish a transfer of learning beyond the school (Haerens et al., 2011). Both authors envision an important role for PE in stimulating children and adolescents to adopt a physically active lifestyle, however they differ in how to reach this goal. Sallis et al (2012) place an emphasis on active classes, with all students engaged, optimizing lessons to contribute to overall physical activity. Haerens et al (2011) acknowledge this viewpoint as important, however they particularly stress the importance of the intended transfer of learning from the context of the school to a leisure time context. The basic assumption of this transfer of learning from the school PE context to physical activity beyond the school or physical activity in adult life is that PE provides children and adolescents with prerequisite skills and experience in various games and sports so they will find at least one physical activity they will continue to practise beyond the school PE context (Kirk, 2010).

Although the Dutch PE curricula are generally not embedded within a health-related PE model, a recent PE position statement paper does acknowledge the important role of PE in stimulating physically active lifestyles. It states that within multidisciplinary programs schools are able to contribute to children's and adolescents' physically active lifestyle as 'a long-term investment that certainly will be reimbursed' (Bax, Driel, Jansma, \& Palen, 2011). More specifically this will be attained 'if students learn adequate movement activities from a young age in a climate where physical activity is positively valued' (Bax et al., 2011) (p. 20). In addition, a recent expert meeting on the future of Dutch PE yielded similar convictions reporting in a consensus statement that 'the main goal for Human Movement \& Sports (PE) is to educate school youth from a pedagogical perspective to acquire (better) skills and as a consequence be able to participate in sports- and movement activities, as a part of a healthy and active lifestyle' (Brouwer et al., 2011). Akin with health-related PE models, the importance of a physically active 
lifestyle is acknowledged and posited as the ultimate end goal of PE as a school subject, achieved within a pedagogical context.

However, to what extent PE is reaching these goals has never been thoroughly investigated, especially in the Netherlands where systematic research into PE has been scarce. The most plausible explanation for the lack of thorough PE research programmes is that it has never been embedded within a university program and academic research programs on this subject were rare1. Physical Education Teacher Education (PETE) in the Netherlands is positioned within higher professional education ( $\mathrm{HBO}$ ) where emphasis is traditionally placed on the transmission of practical knowledge, skills and attitudes and not on academic issues as is the case in countries such as the UK and Australia (Kirk, 2010). Perhaps as a consequence, the Dutch PE curriculum and its pedagogy have not changed much over the last three decades whereas society in general and the physical culture in particular have experienced significant changes (although similar issues have been identified in the UK, USA and Australia (Kirk, 2010).

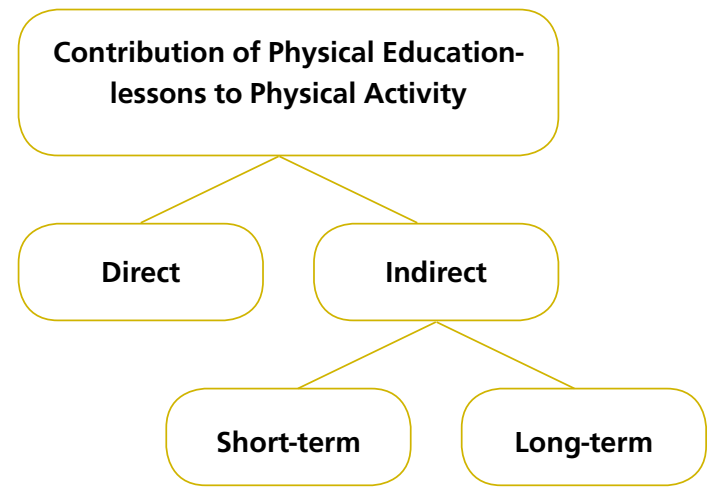

Figure 8.1 Direct and indirect contribution of physical education to physical activity

With decreasing levels of physical activity and an increase in sedentary behaviour, adverse health outcomes such as overweight, obesity and type II diabetes have become more prevalent (WHO, 2012). Given that physical activity is a central issue in $\mathrm{PE}$, it has become an interesting school subject from a public health perspective. However, the question is whether PE in its current form can make a meaningful contribution to physical activity in Dutch youth.

1 An exception is the Interfaculty of Physical Education founded in 1971 at the Vrije Universiteit Amsterdam where a small staff group (most notably B. Crum and H. Stegeman) conducted research into didactical practice within school-PE. Unfortunately, after a reorganisation in 1987 the focus of the interfaculty was shifted towards sports, movement and health and specific PE research ceased to exist (see also http://www.canonlo.nl/venster/30). Another exception is the work of Kemper and colleagues who mainly focused on physiological and anthropometric PE-outcomes. 
In this thesis one review and five original research papers have been presented that sought to explore these questions. For clarification and to provide a framework for the studies in this thesis, in chapter 2 a model was introduced in which a distinction was made between the direct and indirect influence of PE on physical activity levels of young people (see figure 8.1). According to this model, PE potentially provides a direct source of in-class physical activity that is accumulated during the lesson and directly contributes to daily physical activity levels. Indirectly, PE aims to motivate children and adolescents to adopt a physically active lifestyle outside of the school environment as well as later in life. A review of the literature was conducted into intervention programs that employed a school-based physical activity intervention with a PE component aimed at increasing physical activity during and/or beyond school hours. We found evidence supporting a role for PE as a direct source of physical activity, especially when lesson strategies are employed that explicitly aim at maximising in-class physical activity. However, no convincing evidence was found to support the influence of PE lessons on physical activity beyond the context of the school or more long-term as an adult later in life. The studies in this thesis are organized according to the model described above. First, three studies that explored the direct influence of PE on PA are presented, followed by two studies that touched on the topic of the indirect influence of PE on physical activity. These studies are briefly discussed in the following sections, and subsequently placed in a broader perspective.

\section{Chapter 3 - Contribution of PE, active transport and leisure time sports to total physical activity energy expenditure}

Several studies have measured physical activity energy expenditure (PAEE) in an adolescent population (Bratteby, Sandhagen, Lötborn, \& Samuelson, 1997; Corder et al., 2010; Ekelund \& Sjostrom, 2000; Vermorel, Vernet, Bitar, Fellmann, \& Coudert, 2002). Results from these studies showed a large variability in total PAEE (range $51 \mathrm{~kJ} / \mathrm{kg} /$ day - $149 \mathrm{~kJ} / \mathrm{kg} /$ day). However, in these studies PAEE was either assessed using the doubly-labelled water technique or using heart rate-monitoring. Doubly-labelled water is perceived as the most accurate measurement of EE but is unable to assess PAEE originating from specific activities during the measurement period, while heart ratemonitoring alone is not a valid assessment method for habitual energy expenditure due to the non-linear heart rate-PAEE relationship at low intensity activities (Welk, Corbin, \& Dale, 2000). As a consequence, not much is known about the contribution of PE and other school- and leisure time physical activities (active transport to school, leisure time sports, work-related activities) to the total volume of daily PAEE. This provided the rationale for the study described in chapter 3 , in which combined-sensing technology (heart rate monitoring and accelerometry) was used in combination with an activity diary to determine levels of PAEE in adolescents from three urban schools. In addition, the separate contributions of PE, active transport and leisure time sports were determined. In short, we found that $30 \%$ and $17 \%$ of total PAEE during the school day originated from active transport to school and $\mathrm{PE}$, respectively. On a weekday with $\mathrm{PE}, 30 \%$ of all PAEE on that day came from the PE lesson. Overall, boys were more active than girls and had higher PAEE during PE, leisure time sports and work-related activities. Girls had higher PAEE during leisure time active transport. When comparing adolescents with a high physical activity level (PAL) to students with medium - and low PAL it became clear that high-PAL students had a higher PAEE during leisure time sports and work-related activities, but not during PE or active transport to school. This indicates that PE provides a certain amount of physical activity to all students, regardless of their physical activity level.

\section{Chapter 4 - Physical activity during PE lessons}

The amount of MVPA during elementary and secondary school PE has been extensively studied, mostly within the UK and the USA. Findings have revealed that between $27-40 \%$ of lesson time is spent in MVPA, depending on the method of measurement and educational context (elementary or secondary school). However, the situation in 
the UK and USA is not comparable to the Dutch PE situation in terms of lesson content, mode of delivery, available resources and educational context (e.g. coeducation versus single sex classes). In addition, the influence of contextual variables on the amount of MVPA accrued during PE lessons has been understudied. Therefore, in chapter 4 we focused on the amount of physical activity that Dutch PE lessons yielded as well as on various contextual factors which could be of influence. A cross-sectional study design was employed across a large nationwide sample $(n=913)$ of primary and secondary school students that wore heart rate monitors during their PE lesson, while lesson characteristics were simultaneously recorded. This provided insight into the amount of moderate-to-vigorous physical activity (MVPA) during PE as well as the accompanying variables that affected active lesson time (e.g. gender, lesson content, number of students per class etc.).

The study was the first to investigate the intensity of non-intervention PE lessons in the Netherlands. Results indicated that Dutch PE classes spend similar amounts of lesson time in MVPA compared with studies in the UK and the USA. Secondary school students spend an average of $40 \%$ lesson time in MVPA, whereas in primary school students this is $47 \%$. Similar to study 1 , boys were found to be more active than girls during secondary school PE, but not during primary school PE. Lesson content appeared to be an important determinant of in-class physical activity, with invasion games lessons (team games such as basketball, football or handball) generating more MVPA than individual activities (e.g. track and field, racquet games). Interestingly, while games lessons elicited similar amounts of MVPA in primary school boys and girls, adolescent girls were significantly less active during games lessons in secondary school. Recently published studies have further confirmed PE's contribution to total levels of MVPA.

\section{Chapter 5 - Increasing physical activity levels in PE}

In chapters 3 and 4 it was established that PE could play an important role for youth in accumulating healthoptimising amounts of physical activity. From various studies evidence-based strategies have emerged aimed at increasing the level of physical activity during PE (cf. chapter 2). However, to date the effectiveness of such strategies has primarily been tested within a primary school PE context, whereas the studies that targeted secondary schools solely focused on single-sex classes, whereas PE in the Netherlands is mainly provided in coeducation. This led us to design an intervention study in which easy-to-implement teaching strategies aimed at increasing in-class physical activity for all students were employed through teacher professional learning. Teachers were instructed in a range of possible intervention strategies, from which they were asked to choose one or two. Using these strategies, they constructed an intervention lesson that was optimally adapted to their situation in terms of physical activity. An incidental circumstance in this study was that teachers mainly chose lesson subjects they experienced as being usually very inactive, such as softball and gymnastics. Results from this study showed that time spent within MVPA during the lessons increased from 13\% (6 minutes) in the regular lessons to $26 \%$ (11 minutes) in the intervention lessons. More time was devoted to gameplay, whereas less time was spent on class management and knowledge transfer. These findings provide indications that through a relatively simple teacher-training program, with an emphasis on changes in lesson content, didactical approach, class management or instruction, active lesson time can be increased. Importantly, increases in active lesson time (MVPA) were realised without teachers making adjustments to original lesson goals (e.g. social, cognitive, motor skills). Two recently published review studies (Dudley, Okely, Pearson, \& Cotton, 2011; Lonsdale et al., 2013) corroborated these results. They found an average of $10 \%$ more lesson time was spent in MVPA within intensified PE lessons, resulting in an average of $24 \%$ of lesson time spent in MVPA per lesson, which is comparable to our findings (Lonsdale et al., 2013). Direct instruction teaching methods and providing teachers with sufficient and on-going professional development were identified as the most effective means to attain this goal (Dudley et al., 2011). 


\section{Insights gained into the direct effect of PE on physical activity}

The studies described above provide evidence for PE's role in directly stimulating physical activity and being an addition to the total volume of physical activity in young people. One lesson yielded approximately 18 minutes of MVPA in primary school PE lessons and 21 minutes in secondary school PE lessons. This comprises one third of the recommended total daily amount of physical activity. Considering improvements in active lesson time through teacher-instruction could result in at least a 10\% increase (depending on the lesson subject and strategies used), PE's contribution to daily physical activity could even be enhariced. In the US and the UK a 50\% MVPA target has been proposed for PE lessons (AfPE, 2008; USDHHS, 2000). We suggest that the inclusion of such a directive in the Netherlands, for example within the "PE teacher profession profile" (Bax et al., 2011) could inform Dutch PE teachers about the importance of providing active lessons. Importantly, such a guideline should always be complemented by a justification based on contemporary research on this topic. In this respect, an often-heard opinion in the field of PE is that physical activity intensity goals should never dominate over other PE goals, such as introducing students to a variety of different sports and games and teaching the required skills and rules. Indeed, a dreadful image of PE springs to mind here with lessons consisting entirely of fitness-drills and running, and with students vigorously active for the entire lesson without any learning whatsoever. However, since evidence emerging from this thesis as well as from other studies has indicated that increasing in-class physical activity levels while retaining original PE lesson goals is fairly easy to achieve through a small investment in teacher professional training, the implementation of such strategies within Physical Education Teacher Education (PETE) curricula would seem a good starting point. However, recent research into British PETE post-graduate students' knowledge of PE's role in physical activity and health has indicated that the current PETE curriculum is not successful in attaining such goals (Harris, 2013). Based on these findings, Dutch PETE institutions should critically review their curricula in order to identify any theoretical and practical gaps in the PETE-curriculum about PE's (potential) role in physical activity and public health. In addition, it is posed that a special emphasis should be placed on skills and knowledge to establish gender equity in PE.

Although PE's (non-intensified) contribution to physical activity on days with a PE lesson was considerable, with a maximum of two to three lessons per week it still comprises a relatively small portion of the total weekly physical activity volume in children and adolescents. Nevertheless, the study in chapter 3 also indicated that PE lessons were a consistent source of physical activity for all students, including those with a low PAL level. From this perspective, PE (and sport) in school at least does assert a minimum of physical activity, that might be specifically important for the least active group of students. Especially within urban areas, with a large population of low-income families, limited playground facilities and sometimes unsafe neighbourhoods, PE and school sport may provide the only opportunities to be physically active, in a pedagogical context and safe environment created by a specialised PE teacher. Findings indicate that special attention should be devoted to providing equal opportunities for girls to be active during PE, since a consistent finding in the studies in this thesis was that girls were less physical activity than boys. Since girls are also generally less physically active during leisure time, PE might pre-eminently be the place were girls have the opportunity to be equally active and accumulate important minutes of MVPA. 
Nevertheless, the results from chapters 3-5 also indicate that the most effective way for PE to play a significant role in combating physical inactivity would be by increasing the amount of weekly PE lessons. To illustrate, previous research has provided evidence of increased physical activity and fitness through the provision of daily compulsory PE lessons by PE-specialists and supplemented by activity breaks (Kriemler et al., 2010). According to the authors, key elements for the success within this particular intervention program were the mandatory nature of the physical activity components, the deployment of physical education experts and the enjoyment experienced during the program by students and teachers. Unfortunately, realising such increases in the amount of weekly PE lessons is a complicated matter due to competing demands within the school curriculum. Schools perceive considerable governmental pressure to emphasize the development of their students' numeracy and literacy, prioritising courses such as mathematics and languages as a consequence. At the same time the development of physical literacy ${ }^{2}$ (Mandigo et al., 2009) is often perceived as less important, merely considered as a moment of leisure ("letting off steam") and sometimes completely overlooked. Despite the available scientific evidence that indicates substituting classroom hours for PE hours is not detrimental for students' cognitive performances (Bailey et al., 2009; Donnelly \& Lambourne, 2011) many schools are either unwilling or unable to include more PE lessons into their school curriculum. Another argument that is often put forward by schools not prioritizing PE are the relatively high costs of to materials and accommodation. Taught time differs significantly between European countries, in primary education varying from 37 hours per year in Ireland to 108 hours in France (Eurydice, 2013). Although no such data is present for the Netherlands ${ }^{3}$, based on two 45 minute lessons per week and 40 school weeks, with about 60 hours the Netherlands would be somewhere in the middle. A shift in governmental policy seems necessary in order to bring about significant changes. In this respect, in the Netherlands a small window of opportunity seems to have opened since the minister of Health, Welfare \& Education has ordered a benchmark investigation into the quantity of PE lessons preceding a possible decision for an increase in the recommended amount of weekly primary school PE lessons from two to three (Schippers, 2013).

Although increasing the intensity, duration and/or frequency of weekly PE lessons may seem a promising way of combating physical inactivity, to date it is unclear whether students compensate for such an 'extra dose' of physical activity by being less active beyond school hours. The scientific evidence on this topic is not only very limited but also inconsistent. Some authors suggest that students indeed compensate the extra hours of physical education and school sport by being less active after school (Bugge et al., 2012; Frémeaux, Mallam, \& Metcalf, 2011), whereas another study found a contrary effect; students that received more PE were even more active after school (Alderman, Benham-Deal, \& Beighle, 2012). More research is clearly required to provide more insight on this important issue.

2 Individuals who are physical literate move with competence in a wide variety of physical activities that benefit the development of the whole person (Mandigo, Francis, Lodewyk, \& Lopez, 2009)

3 The Netherlands, together with Switzerland and Luxembourg have not contributed to the EURYDICE report. 
Although future policy changes might underline the significance of physically active PE lessons, a more widely supported aim for PE is to stimulate students to adopt an active lifestyle beyond school and later as an adult. Nevertheless, the results from the review of studies in chapter 2 has indicated that effects of PE on physical activity during leisure time are modest at best. However, we also indicated that most studies employed a multi-activity program that did not distinguish between the effects of PE and other components of the program on out-ofschool physical activity. In this respect, in the last decade an increasing volume of PE research, grounded in socialpsychology, has adopted a motivational approach in exploring PE's role to stimulate active lifestyles (Van den Berghe, Vansteenkiste, Cardon, Kirk, \& Haerens, 2012) that is mainly grounded in self determination theory. Selfdetermination theory is a theory of human motivation that provides a useful framework in exploring why people engage and persist in certain behaviours (Deci \& Ryan, 2000; Ryan \& Deci, 2000). Motivation in SDT is regarded as a multidimensional concept and as such both the quantity and quality of motivation are predictive of engagement in certain behaviours (Vansteenkiste, Sierens, Soenens, Luyckx, \& Lens, 2009). One of the tenets of SDT is that if a person's psychological needs for autonomy, competence and relatedness are met that person will experience autonomous motivation, which is contrasted by controlled motivation and amotivation (absence of motivation). Recent research has identified autonomous motivation and its underlying nutriments as key aspects not only for adaptive outcomes within the PE lesson but also for the learning of the skills, knowledge and attitudes in a school PE context and their subsequent transfer into a leisure time context. Therefore, to further explore PE's role in stimulating students to adopt a physically active lifestyle the two final studies of this thesis have employed a motivational approach employing self-determination theory (SDT) as a theoretical framework. The study in chapter 6 focused on the relation of PE motivation and objectively measured PAEE during leisure time, PE and sports, whereas the study in chapter 7 investigated the effect of a grouping strategy on levels of perceived competence in girls' during invasion gameplay.

\section{Chapter $\mathbf{6}$ - the relation between motivation for PE and total PAEE}

A considerable amount of research rooted within self-determination theory has linked autonomous motivation for PE to adaptive outcomes such as physical activity behaviour beyond the school context (e.g. Cox, Williams, \& Smith, 2007; Standage, Gillision, Ntoumanis, \& Treasure, 2012). However, since most of these studies stem from psychology research they almost exclusively rely on self-report data of leisure-time physical activity (LTPA). Unfortunately, self-report measures have been found to be subject to error and bias due to varying cognitive abilities and recall problems, especially in youth populations (Welk, 2008; Welk et al., 2000). No questionnaires are presently available that measure physical activity with sufficient reliability and validity in this age-group (Chinapaw, Mokkink, van Poppel, van Mechelen, \& Terwee, 2010). In addition, self-report measures are unable to accurately measure physical activity intensity, which hinders a precise assessment of physical activity. To determine if motivation for PE is linked to objectively measured physical activity, combined sensing was employed in conjunction with an activity diary in this study. This allowed simultaneous measurement of total daily physical activity levels with the possibility to distinguish particular physical activity behaviours (e.g. PE and sports) or certain periods where physical activity was accumulated (e.g. in school and after school). Based on contemporary literature we hypothesized autonomous motivation for PE to be an important predictor of PAEE, PAEE during sport and PAEE during PE. Contrary to our expectations however, we found gender to be the largest predictor of total PAEE and PAEE during PE, while PAEE during sports was predicted both by gender and autonomous motivation for LTPA. The finding that girls had a lower quality of motivation for PE, but not for LTPA suggested that the PE environment might not be adequately adapted to suit girls' needs for autonomy, competence and relatedness. This gives rise to questions about the suitability of PE curricula in terms of gender equity. An issue that was explored in chapter 7 . 


\section{Chapter 7 - Increasing girls' perceived competence during gameplay}

A combination of findings in chapter 4 and 6; namely adolescent girls in secondary school having lower physical activity during PE games lessons than boys and having lower autonomous motivation and higher controlled motivation for PE; formed the rationale for the study described in chapter 7. It was hypothesized that male dominance during gameplay prevented girls from being equally actively involved, which possibly led to lower levels of perceived competence and physical activity in this group. To test this hypothesis an adapted grouping strategy was employed within a small experimental study that aimed to increase girls' feelings of competence and physical activity levels during gameplay. During the first lesson gameplay was mixed-gender, while during the next lessons teams were segregated by gender, only playing with and against students of the same sex. Physical activity levels were high in both conditions, probably due to the use of an adapted gameplay form, but girls' perceived competence levels were higher in the single-gender condition. Although more research is needed to determine the long-term effects of grouping strategies on feelings of competence, it was concluded that playing invasion games in single-gender groups might be a valuable alternative for PE teachers to use in their lessons in order to maximise the involvement of girls within PE lessons.

\section{INDIRECT}

\section{Insights gained into the indirect effect of PE on physical activity}

From the results in chapter 2 it was concluded that, although enhanced PE classes resulted in more in-class physical activity, these programs were generally not successful in increasing physical activity levels out-of-school. This finding might not be very surprising, considering the large variety of physical activity correlates for children and adolescent (Sallis, Prochaska, \& Taylor, 2000), and the modest impact school PE can make on this within the limited amount of scheduled time. Nevertheless, contemporary motivational research has consistently linked autonomous forms of student motivation for PE to adaptive outcomes such as physical activity behaviour beyond the context of the school (Ntoumanis \& Standage, 2009; Van den Berghe et al., 2012). The rationale behind this motivational approach to PE is that motivation in a specific context, such as PE, is able to influence motivation in a related yet more general context, such as leisure time physical activity (Vallerand, 1997). Interestingly however, the study in chapter 6 did not corroborate findings that directly link PE motivation to objectively measured physical activity behaviour out-of-school. However, another finding from this thesis was that girls' motivation quality for PE as well as their level of perceived competence was significantly lower than boys'. These findings provide an indication that PE might not be successful in attaining its health-related physical activity goals for all students. Although the research evidence from this thesis not sufficient to draw definite conclusion, this does give rise to the question if the current PE curriculum is adequately adapted to suit all students' psychological needs sufficiently and whether it is able to ensure maximum involvement for both boys and girls. It seems doubtful that a gamesdominated curriculum characterised by an emphasis on competition and on the learning of (often decontextualized) sport-techniques, is able to evoke enjoyment in all students, especially in (less-skilled) girls (O'Sullivan \& Dyson, 1994). Such a curricular approach probably does not appeal to female students and therefore might not result in active lifestyles beyond school (Flintoff \& Scraton, 2001). Various aspects have been identified to support students' psychological needs such as autonomy supportive behaviour by the teacher, providing structure and optimal challenges within the PE environment and creating a durable relationship with teachers and peers (Van den Berghe et al., 2012). In this respect, the provision of teacher need-support has been studied frequently and intervention studies indicate positive effects on self-determined motivation for curricula with an emphasis on task-involvement, autonomy-support and goal-setting (e.g. Cheon, Reeve, \& Moon, 2012; Jaakkola \& Liukkonen, 2006). However, increasing perceived competence has received much less attention, although 
feelings of competence have been identified as one of the most consistent predictors of autonomous motivation in PE and physical activity intentions outside of the PE context (I. M. Taylor, Ntoumanis, Standage, \& Spray, 2010). From a leisure time physical activity participation perspective, it is arguable whether a mixed-gender games-based PE curriculum, with a large emphasis on competition, is best suited for bringing about adequate levels of perceived competence for all students and especially girls. To illustrate, the differentiation by age, gender and/or skill level that is common practice in all sports clubs is virtually absent in PE lessons. Consequently, instead of lowering the threshold for sport participation by providing age-/gender-/skill level appropriate introductions in various sports and providing students with the self-confidence to take advantage of the contemporary movement culture, PE is putting up barriers for at least part of the students. In addition, it is questionable if a traditional multi-activity PE curriculum with a lesson frequency of only twice a week is able to increase student's sport skills and techniques (actual competence) to a considerable level. Therefore, it could be argued that the development of perceived competence in $\mathrm{PE}$, by providing attainable challenges to all students, might even be more important than the development of actual competence, i.e. ability level. In addition to studies that primarily focused on increasing feelings of autonomy, this thesis has provided indications that through simple changes in organisation of the PE lesson feelings of competence can be increased in girls during games lessons. This is important because if PE is able to increase feelings of competence this could prevent drop-out from physical activity later in life when compulsory physical activity is no longer present through PE. However, more research is needed to confirm and extend these assumptions. It would be interesting to see research aimed at increasing perceived competence continued within various other didactical and organisational approaches, different lesson subjects, different age-groups and preferably monitored over a longer period of time.

In order for PE to fulfil it's expectations for preparing children and adolescents to lead active and healthy lifestyles and to establish a balanced curriculum in terms of gender equity, curricular changes seem inevitable. According to Kirk (2010) radical reform is imperative and he advocates a physical education away from what he defines as 'physical-education-as-sport-techniques' towards a PE with a life-course development perspective aimed at a strong transfer of learning, very much aligned with the pedagogical model for health-based PE as proposed by Haerens et al (2011). Consequently, curricular changes should manifest themselves in all aspects of PE. This could imply changes in content areas, for instance including more activities that have a 'carry-over' value into leisure time and later in life (Fairclough, Stratton, \& Baldwin, 2002), active learning strategies with an emphasis on enjoyment (Dudley et al., 2011), and different pedagogy and didactical approaches such as Teaching Games for Understanding (Bunker \& Thorpe, 1982). However, changing learning content and didactical delivery also implies changing the assessment methods used to evaluate what is learned. Current assessment and evaluation methods are often solely summative and focus on skill performance according to norm-referenced criteria. Such methods tend to be demotivating especially for the less-abled students (Johnson, Prusak, Pennington, \& Wilkinson, 2011). Importantly, it is these students that are at risk of 'dropping out' in the pursuit of a physically active lifestyle. Alternatively, motivating assessment methods could be used that aim at learning, mastery and self-improvement (Johnson et al., 2011; Martin, Kulinna, \& Cothran, 2002). Unfortunately, such practices have not been widely employed in PE and more research is necessary into the effectiveness and implementation of such practices (López-Pastor, Kirk, Lorente-Catalán, MacPhail, \& Macdonald, 2012). Another practice that is uncommon in most schools is involving students in curriculum development, while there are indications that this might aid in creating a more widely supported PE curriculum (Penney \& Jess, 2004). 
There are important barriers to take before reforms such as described above can result in a PE curriculum that is more effective in motivating students to adopt active lifestyles. As previously mentioned, PE teaching in the Netherlands is provided by teachers that have been educated in PETE institutions that largely focused on transmitting practical knowledge. Consequently, although most teachers possess a high level of didactical and practical skills, systematic evaluation of the effectiveness of teaching practices is often absent. Hence, it might not be plausible to expect change from within the PE community within the near future. In addition, the relatively secure position of contemporary PE in the Dutch school curriculum may prevent a sense of urgency for PE to reform.

\section{Recommendations}

The findings in this thesis, complemented by the underlying review of the contemporary literature on the topic of $P E$, physical activity and motivation, have resulted in various practical recommendations. They apply to teacher professionalism, the PE curriculum and policy and are listed below. In the final part of this discussion suggestions for further research are provided.

\section{Teacher professionalism.}

- Regardless of lesson goals, PE teachers are advised to always and consistently aim at maximising student participation in terms of physical activity engagement. Furthermore, it would be prudent to communicate a guideline on physical activity engagement in PE classes, similar to the guideline for PE lessons in the UK and USA to engage students at least for half of the lesson time in MVPA. Dissemination could take place through governmental guidelines, professional teacher profiles, publications in professional journals and in-service teacher training.

- Current PE teachers should be encouraged to adopt skills and knowledge needed to create PE environments that suit both boys and girls in terms of involvement, physical activity and satisfaction of feelings of competence, autonomy and relatedness. In-service training, symposia and refresher courses could assist PE teachers in acquiring a basic skill-set needed to employ health-based PE. To illustrate, evidence exists that professional teacher training is able to influence teachers to develop a more autonomy-supportive teaching style (Cheon et al., 2012) that endured in the long-term (Cheon \& Reeve, 2013). Since Dutch PE teachers mainly keep up their professionalism through self-reflection and informal debates with colleagues (Oldeboom, 2007), the provision of continuing in-service professional teacher training through workshops and symposia might result in a better informed and well equiped PE teacher population.

- PETE institutions should review their curriculum on the topic of PE's role in stimulating physical activity and a physically active lifestyle. Theory and practice on important subjects such as optimising in-class physical activity, creating an adaptive motivational climate that nourishes students' needs for competence, autonomy and relatedness and theories of behavioural change should have a prominent place in all PETE years. Given that knowledge turnover on these topics is rapid, this should be based on up-to-date scientific knowledge.

- At present, the highest level of PE-teacher qualification in the Netherlands is a bachelors degree. In the previous section of this general discussion, a PE-curricular reform was advocated. In addition, a need was established to advance the field of PE 'from within' by teachers critically researching their own school practices. Introduction of a professional masters degree in PE might help to bring about the desired changes. Such a masters course should be specifically aimed at the advancement of PE and school sports, as opposed to a more general, scientific kinesiology curriculum. Given the recent governmental efforts for a larger proportion of masterseducated teachers, this might be the time to seize the opportunity for renewal. 


\section{PE curriculum}

- Physical education curricula should have their foundation within pedagogy and didactical approaches that have been scrutinised within ecologically sound academic research studies. This may implicate rejecting the current 'traditional curriculum' with its focus on games and competition, and replacing it with a curriculum that is more adapted to bringing about a transfer of knowledge, skills and attitudes beyond the PE context.

- A paradigm shift might be needed in the manner in which we view PE as a school subject, in order to bring about significant changes to the PE curriculum (Kirk, 2010). This includes all aspects of PE, its aspirations and its place within the school. In line with Haerens et al.'s (2011) notion that a traditional disciplinary mastery orientation to PE is not able to provide the motivational changes essential for a physically active lifestyle, alternative PE programs should be constructed and scrutinised.

- Special attention should be paid to gender equity in curriculum development, especially in secondary schools. Providing equal opportunities to engage and be active in-class and meeting the needs of both boys and girls, has proven to be a challenge within coeducational PE classes. Curricular changes in terms of didactial approaches, lesson organization and lesson content seem promising ways to establish a better-balanced PE program in terms of gender-equity.

\section{Policy}

- From a public health point-of-view, increasing the weekly amount of PE lessons could provide a substantial amount of physical activity for all children and adolescents, and might be especially important for youth with limited access to physical activity opportunities. Daily PE lessons provided by a specialist teacher would probably be most effective, although such a scenario might not be feasible. Alternatively, initiatives that aim at three compulsory PE lessons per week supplemented with extra-curricular physical activities moments might be promising, provided that the basic principles underlying such an approach are maximum student involvement (boys, girls, high-ability, low-ability) and maximization of physical activity levels.

- Current educational requirements for PE teachers might not be sufficient in reaching public health goals related to a physically active lifestyle. More in general, systematic evaluation of the effectiveness of teaching practices is often absent. Establishing a master's degree in PE should be considered. In addition, there is a need for a clear policy on the continuing professional development for PE teachers.

\section{Research recommendations}

- The study in chapter 5 has shown that instructing teachers to adopt strategies for increasing student physical activity during PE lessons can be effective. However, to gain more insight into long-term effects of such strategies both in terms of adherence by teachers and intervention effects in students, different approaches should be implemented over a longer period of time.

- Although multiple studies have investigated motivational aspects of PE and its relation to physical activity engagement beyond school, the study in chapter 6 using objective physical activity monitoring has produced conflicting results. Therefore, future studies should further explore the motivational sequence of basic psychological needs - motivation for PE - motivation for LTPA - LTPA behaviour. Importantly, such studies should assess LTPA using valid and reliable objective measures of physical activity, preferably in a large representative sample of students. The majority of studies conducted on this topic have employed crosssectional research designs. To gain more insight into the dynamics of motivation, especially in the light of gender differences, it is proposed that future studies adopt a longitudinal research design. 
- There is a need for high-quality intervention studies into health-enhancing PE. Such research programs, preferably spanning multiple school years, could expose the effects and dynamics of specific PE curricula designed to establish healthy and active lifestyles beyond the context of the school. Importantly, such a study should encompass the transition from primary to secondary school. This has been shown to be a crucial phase in terms of physical activity engagement, especially in girls. Long term follow-up studies should be employed to investigate if any effects of an adapted PE curriculum manifest themselves in adulthood.

- In order to inform and support curricular changes in $P E$, more research seems imperative on various motivational aspects of PE:

o Research on basic psychological needs in PE has to date primarily been focused on the autonomy supportive behaviour by the teacher. Although the importance of this is acknowledged, the concept of perceived competence in PE is underexposed. For example, not much is known about the effects of various didactical approaches (differentiation and adaptive group organisation, students adopting different roles etc.) on levels of perceived competence in PE. Given the proven relationship between perceived competence and PA behaviour, this provides various points of departure for promising intervention research.

o Research could be employed to investigate the 'gender appropriateness' of the Dutch PE curriculum. A thorough nation-wide survey in both primary and secondary schools could provide PE researchers with important information on motivation, need satisfaction, lesson subjects, teacher behaviour and the way in which these aspects are related. Results could inform both curriculum development in PE as well as didactical approaches by PE teachers.

- Assessment and evaluation within PE is often deemed a problematic issue by PE teachers (López-Pastor et al., 2012). Assessment of learning is dominant, often by employing norm-referenced tests that evaluate (technical) skills. It is plausible that such assessment methods do not align with student's needs for competence, autonomy and relatedness and thus do not lead to more intrinsic forms of motivation. Promising alternative forms of assessment in PE have shifted their focus from assessment of learning to assessment for learning and include assessments using adaptive norms, peer-assessment and the use of portfolios. Future research should focus on the effects of such alternative forms of assessment on student motivation. 


\section{References}

Association for Physical Education (afPE) (2008). "Health Position Paper." Physical Education Matters, 3, 8-12.

Alderman, B. L., Benham-Deal, T., \& Beighle, A. (2012). Physical Education's Contribution to Daily Physical Activity Among Middle School Youth. Pediatric Exercise Science, 24, 634-648.

Bailey, R., Armour, K., Kirk, D., Jess, M., Pickup, I., \& Sandford, R. (2009). The educational benefits claimed for physical education and school sport: an academic review. Research Papers in Education, 24(1), 1-27.

Bax, H., Driel, G. V., Jansma, F., \& Palen, H. V. D. (2011). Beroepsprofiel leraar lichamelijke opvoeding. Den Haag, Nederland: Arko Sports Media.

Bratteby, L. E., Sandhagen, B., Lötborn, M., \& Samuelson, G. (1997). Daily energy expenditure and physical activity assessed by an activity diary in 374 randomly selected 15 -year-old adolescents. European Journal of Clinical Nutrition, 51(9), 592-600.

Brouwer, B., Aldershof, A., Bax, H., van Berkel, M., van Dokkum, G., Mulder, M. J., \& Nienhuis, J. (2011). Human movement and sports in 2028: Een blik in de toekomst van lichamelijke opvoeding/bewegingsonderwijs en sport op school. Enschede, Nederland: SLO (nationaal expertisecentrum leerplanontwikkeling)

Bugge, A., El-Naaman, B., Denkcer, M., Froberg, K., Holme, I. M. K., McMurray, R. G., \& Andersen, L. B. (2012). Effects of a Three-Year Intervention: The Copenhagen School Child Intervention Study. Medicine And Science In Sports And Exercise, 44(7), 1310-1317. doi:10.1249/MSS.0b013e31824bd579

Bunker, D., \& Thorpe, R. (1982). A model for the teaching of games in the secondary school. Bulletin of Physical Education, (10), 9-16.

Cheon, S. H., \& Reeve, J. (2013). Do the Benefits from Autonomy-Supportive PE Teacher Training Programs Endure?: A One-Year Follow-Up Investigation. Psychology of Sport and Exercise, 1-44. doi:10.1016/j. psychsport.2013.02.002

Cheon, S. H., Reeve, J., \& Moon, I. S. (2012). Experimentally based, longitudinally designed, teacher-focused intervention to help physical education teachers be more autonomy supportive toward their students. Journal of Sport and Exercise Psychology, 34(3), 365-396.

Chinapaw, M. J. M., Mokkink, L. B., van Poppel, M. N. M., van Mechelen, W., \& Terwee, C. B. (2010). Physical activity questionnaires for youth: a systematic review of measurement properties. Sports Medicine, 40(7), 539-563.

Corbin, C. (2002). Physical Education as an Agent of Change. Quest, 54(3), 181-195.

Corder, K., Brage, S., Wright, A., Ramachandran, A., Snehalatha, C., Yamuna, A., et al. (2010). Physical activity energy expenditure of adolescents in India. Obesity, 18(11), 2212-2219.

Cox, A., Williams, L., \& Smith, A. (2007). Motivation in physical education and physical activity behavior outside of school. Journal of Sport and Exercise Psychology, 29, S154-S155.

Currie, C., Gabhain, S. N., Godeau, E., Roberts, C., Smith, R., Currie, D., et al. (2008). Inequalities in young people's health: HBSC international report from the 2005/2006 Survey. Health Policy for Children and Adolescents, 5, 1-224.

Deci, E. L., \& Ryan, R. M. (2000). The" what" and" why" of goal pursuits: Human needs and the selfdetermination of behavior. Psychological Inquiry, 11(4), 227-268.

Dishman, R., Heath, G., \& Lee, I. (2004). Physical activity epidemiology (2nd ed.). Champaign, Illinois: Human Kinetics.

Donnelly, J. E., \& Lambourne, K. (2011). Classroom-based physical activity, cognition, and academic achievement. Preventive Medicine, 52(S), S36-S42. doi:10.1016/j.ypmed.2011.01.021 
Dudley, D., Okely, A., Pearson, P., \& Cotton, W. (2011). A systematic review of the effectiveness of physical education and school sport interventions targeting physical activity, movement skills and enjoyment of physical activity. European Physical Education Review, 17(3), 353-378. doi:10.1177/1356336X11416734

Ekelund, U., \& Sjostrom, M. (2000). Total daily energy expenditure and pattern of physical activity measured by minute-by-minute heart rate monitoring in 14--15 year old Swedish adolescents. European Journal of Clinical Nutrition, 54(3), 195-202.

Eurydice (2013). Physical Education and Sport at School in Europe Eurydice Report Luxembourg: Publications Office of the European Union.

Fairclough, S., \& Stratton, G. (2005). 'Physical education makes you fit and healthy'. Physical education"s contribution to young people"s physical activity levels. Health Education Research, 20(1), 14-23.

Fairclough, S., Stratton, G., \& Baldwin, G. (2002). The contribution of secondary school physical education to lifetime physical activity. European Physical Education Review, 8(1), 69-84.

Flintoff, A., \& Scraton, S. (2001). Stepping into Active Leisure? Young Women's Perceptions of Active Lifestyles and their Experiences of School Physical Education. Sport, Education and Society, 6(1), 5-21. doi:10.1080/713696043

Frémeaux, A., Mallam, K., Metcalf, B., Hosking, J., Voss, L.D. \& Wilkin, T.J. (2011). The impact of school-time activity on total physical activity: the activitystat hypothesis (EarlyBird 46). International Journal of Obesity, 35(10), 12-77-1283. doi: 10.1038/ijo.2011.52.

Haerens, L., Kirk, D., Cardon, G., \& Bourdeaudhuij, I. D. (2011). Toward the Development of a Pedagogical Model for Health-Based Physical Education. Quest, 63, 321-338.

Harris, J. (2013). Physical education teacher education students' knowledge, perceptions and experiences of promoting healthy, active lifestyles in secondary schools. Physical Education and Sport Pedagogy, 1-15. doi:10 .1080/17408989.2013.769506

Jaakkola, T., \& Liukkonen, J. (2006). Changes in students' self determined motivation and goal orientation as a result of motivational climate intervention within high school physical education classes. International Journal of Sport and Exercise Psychology, 4(3), 302-324.

Janssen, I., Katzmarzyk, P., Boyce, W., Vereecken, C., Mulvihill, C., Roberts, C., et al. (2005). Comparison of overweight and obesity prevalence in school-aged youth from 34 countries and their relationships with physical activity and dietary patterns. Obesity Reviews, 6(2), 123-132.

Johnson, T. G., Prusak, K. A., Pennington, T., \& Wilkinson, C. (2011). The Effects of the Type of Skill Test, Choice, and Gender on the Situational Motivation of Physical Education Students. Journal of Teaching in Physical Education.

Kirk, D. (2010). Physical Education Futures. London, UK: Routledge.

Kriemler, S., Zahner, L., Schindler, C., Meyer, U., Hartmann, T., Hebestreit, H., et al. (2010). Effect of school based physical activity programme (KISS) on fitness and adiposity in primary schoolchildren: cluster randomised controlled trial. BMJ (Clinical research ed), 340, c785.

Lonsdale, C., Rosenkranz, R. R., Peralta, L. R., Bennie, A., Fahey, P., \& Lubans, D. R. (2013). A systematic review and meta-analysis of interventions designed to increase moderate-to-vigorous physical activity in school physical education lessons. Preventive Medicine, 56(2), 152-161. doi:10.1016/j.ypmed.2012.12.004

López-Pastor, V. M., Kirk, D., Lorente-Catalán, E., MacPhail, A., \& Macdonald, D. (2012). Alternative assessment in physical education: a review of international literature. Sport, Education and Society, 1-20. doi:10.1080/1357 3322.2012 .713860 
Mandigo, J., Francis, N., Lodewyk, K., \& Lopez, R. (2009). Physical Literacy for Educators. Physical and Health Education Journal, 75(3), 27-30.

Martin, J., Kulinna, P., \& Cothran, D. (2002). Motivating students through assessment. Journal of Physical Education, Recreation \& Dance, 73(8), 18-19.

Ntoumanis, N., \& Standage, M. (2009). Motivation in physical education classes: A self-determination theory perspective. Theory and Research in Education, 7(2), 194-202.

O'Sullivan, M., \& Dyson, M. (1994). Rules, routines and expectations of 11 highschool physical education teachers. Journal of Teaching in Physical Education, 13, 361-374.

Oldeboom, B. (2007). De professionalisering van leraren lichamelijke opvoeding. Lichamelijke Opvoeding, 9, $16-17$

Pate, R. R., O’Neill, J., \& Mclver, K. (2011). Physical Activity and Health: Does Physical Education Matter? Quest, 63, 19-35.

Payne, V. G., \& Morrow, J. R., Jr. (2009). School physical education as a viable change agent to increase youth physical activity. The President's Council on Physical Fitness and Sports Research Digest, 10(2), 1-8.

Penney, D., \& Jess, M. (2004). Physical education and physically active lives: a lifelong approach to curriculum development. Sport, Education and Society, 9(2), 269-287. doi:10.1080/1357332042000233985

Pühse, U., \& Gerber, M. (2005). International Comparison of Physical Education: Concepts, Problems, Prospects. Oxford, UK: Meyer \& Meyer Sports.

Ryan, R. M., \& Deci, E. L. (2000). Self-Determination Theory and the Facilitation of Intrinsic Motivation, Social Development, and Well-Being. American Psychologist, 55(1), 68-78.

Sallis, J. F., McKenzie, T. L., Beets, M. W., Beighle, A., Erwin, H., \& Lee, S. M. (2012). Physical Education's Role in Public Health: Steps Forward and Backward Over 20 Years and HOPE for the Future. Research Quarterly For Exercise And Sport, 125-135.

Sallis, J., Prochaska, J., \& Taylor, W. (2000). A review of correlates of physical activity of children and adolescents. Medicine And Science In Sports And Exercise, 32(5), 963-975.

Schippers, E. I. (2013). Verzamelbrief sport. Ministerie van Volksgezondheid, Welzijn en Sport, 1-6.

Seghers, J., Martelaere, K., Cardon, G. (2009). Young people's health as a challenge for physical education in schools in the twenty-first century: the case of Flanders (Belgium). Physical Education and Sport Pedagogy, 14(4), 407-420.

Standage, M., Gillision, F. B., Ntoumanis, N., \& Treasure, D. C. (2012). Predicting Students' Physical Activity and Health-Related Well-Being: A Prospective Cross-Domain Investigation of Motivation Across School Physical Education and Exercise Settings. Journal of Sport and Exercise Psychology, 34, 37-60.

Taylor, I. M., Ntoumanis, N., Standage, M., \& Spray, C. M. (2010). Motivational predictors of physical education students' effort, exercise intentions, and leisure-time physical activity: a multilevel linear growth analysis. Journal of Sport and Exercise Psychology, 32(1), 99-120.

USDHHS. (2000). Healthy People 2010. Washington D.C.: Government Printing Office.

Vallerand, R. (1997). Toward a Hierarchical Model of Intrinsic and Extrinsic Motivation. In M.P. Zanna (Ed.), Advances in Experimental Social Psychology, 271-360. San Diego: Academic Press.

Van den Berghe, L., Vansteenkiste, M., Cardon, G., Kirk, D., \& Haerens, L. (2012). Research on self-determination in physical education: key findings and proposals for future research. Physical Education and Sport Pedagogy, 1-25. doi:10.1080/17408989.2012.732563 
Vansteenkiste, M., Sierens, E., Soenens, B., Luyckx, K., \& Lens, W. (2009). Motivational profiles from a selfdetermination perspective: The quality of motivation matters. Journal of Educational Psychology, 101(3), 671-688. doi:10.1037/a0015083

Vermorel, M., Vernet, J., Bitar, A., Fellmann, N., \& Coudert, J. (2002). Daily energy expenditure, activity patterns, and energy costs of the various activities in French 12-16-y-old adolescents in free living conditions. European Journal of Clinical Nutrition, 56(9), 819-829.

Welk, G. (2008). The Role of Physical Activity Assessments for School-Based Physical Activity Promotion. Measurement in Physical Education and Exercise Science, 12(3), 184-206.

Welk, G., Corbin, C., \& Dale, D. (2000). Measurement Issues in the Assessment of Physical Activity in Children. Research Quarterly For Exercise And Sport, 71(2), 59-73.

WHO. (2012). Childhood Obesity Prevention (pp. 1-54). Geneva, World Health Organization. 


\section{Samenvatting}

Toenemende prevalentie van overgewicht en obesitas onder jeugd wordt, in ieder geval ten dele, veroorzaakt door te weinig fysieke activiteit. Omdat ieder kind een groot deel van zijn of haar jeugdige leven op school doorbrengt kunnen scholen een centrale rol spelen in het tegengaan van deze bewegingsarmoede. Het meest voor de hand liggende schoolvak lijkt hierbij de lichamelijke opvoeding ${ }^{1}$ (LO) te zijn. De belangrijkste doelstelling van het schoolvak LO is immers om leerlingen dusdanig te motiveren en enthousiast te maken voor sport en bewegen zodat dit uiteindelijk resulteert in een actieve leefstijl, zowel buiten school als in het verdere leven. Daarnaast is LO tevens het enige verplichte schoolvak waar fysieke activiteit een centrale plek inneemt; de les zelf is in potentie ook een structurele bron van fysieke activiteit. Globaal gezien kan LO dus op een indirecte en een directe manier bijdragen aan de fysieke activiteit van leerlingen, een tweedeling die werd geïntroduceerd in hoofdstuk $\mathbf{1}$. Waar echter tot op heden onduidelijkheid over bestaat, zeker wat betreft de Nederlandse situatie, is hoe groot de bijdrage van de LO aan dagelijkse fysieke activiteit feitelijk is. De vraag die daarom centraal staat in dit proefschrift is in hoeverre het vak LO, zoals dat op dit moment gegeven wordt op basis- en voortgezet onderwijs, een bijdrage levert aan de fysieke activiteit van kinderen en adolescenten, zowel direct (de les als bron van fysieke activiteit), als indirect (motivatie voor een actieve leefstijl).

Voor de beantwoording van deze vraag zijn een aantal studies uitgevoerd. Allereerst is in hoofdstuk $\mathbf{2}$ door middel van een literatuurstudie onderzocht in hoeverre interventies met een LO-component effectief zijn in het stimuleren van fysieke activiteit. Hieruit blijkt dat er alleen overtuigend bewijs bestaat voor een directe bijdrage van de les LO aan de fysieke activiteit van kinderen en adolescenten. Oftewel, in de les LO zelf wordt er matig-tot-intensief bewogen. De effecten van interventies met een LO component op de fysieke activiteit buiten school of in het latere leven zijn minder overtuigend of zelfs afwezig. In hoofdstuk $\mathbf{3}$ wordt een cross-sectionele studie beschreven waarin middels het combineren van gegevens vanuit een hartslag-versnellingsmeter met de gegevens uit een activiteitendagboek voor het eerst inzicht verkregen wordt in de daadwerkelijke bijdrage van een reguliere les LO (naast andere fysieke activiteiten zoals fietsen) aan de totale dagelijkse fysieke activiteit van middelbare scholieren. De resultaten wijzen uit dat $17 \%$ van de totale hoeveelheid beweging onder schooltijd zijn oorsprong vindt in de lessen LO en dat op dagen dat een leerling een les LO heeft, deze les verantwoordelijk is voor ongeveer $30 \%$ van de totale fysieke activiteit op die dag. Opvallend is daarnaast dat 15\% van de totale fysieke activiteit op een weekdag zijn oorsprong vindt in het actief transport naar school, voornamelijk fietsen. Hoofdstuk $\mathbf{4}$ beschrijft een studie waarin de focus ligt op de intensiteit van lessen LO in het voortgezet onderwijs (VO) en het basisonderwijs (BO). Tevens is gekeken naar factoren die de intensiteit van een les beïnvloeden. De resultaten wijzen uit dat $47 \%$ en $40 \%$ van een les LO op respectievelijk het VO en het BO voldoet aan de intensiteit van bewegen zoals omschreven in de Nederlandse Norm voor Gezond Bewegen (matig-tot-intensief fysiek actief). Dit komt overeen met ongeveer een derde van de dagelijks aanbevolen hoeveelheid beweging voor deze doelgroep. Opvallend is dat op het VO jongens significant actiever zijn tijdens de lessen LO dan meisjes. Dit verschil blijkt zijn oorsprong te hebben in lessen waarin competitieve spelvormen (basketbal, voetbal etc.) centraal staan. Mogelijkerwijs verhindert de dominantie van jongens tijdens spelvormen dat meisjes in een les even actief kunnen zijn als jongens. Dit is een serieuze beperking van de mate waarin een les LO kan bijdragen aan het totale beweeggedrag van meisjes, gezien het feit dat ongeveer $60 \%$ van het Nederlandse LO curriculum uit (veelal competitieve) spelvormen bestaat.

1 Er zijn meerdere namen in omloop voor het vak op de middelbare school: Bewegen en Sport, Human Movement and Sports, Bewegingsonderwijs. De gebruikelijke benaming in het basisonderwijs is Bewegingsonderwijs. Wanneer in deze samenvatting over LO gesproken wordt, wordt daarmee het vak bedoeld dat onder al deze verschillende benamingen bekend staat. 
In hoofdstuk $\mathbf{5}$ wordt een quasi-experimentele studie beschreven waarin het doel is om lessen LO te intensiveren zonder afbreuk te doen aan oorspronkelijke lesdoelen. Matig-tot-intensief fysieke activiteit blijkt door deze interventie te stijgen van $13 \%$ in de voormeting naar $26 \%$ in de nameting. Docenten besteden door de interventie met name minder tijd aan uitleg en organisatorische zaken en meer tijd aan actieve spelvormen. In hoofdstuk 6 word vanuit het theoretisch kader van de zelfdeterminatie theorie de relatie tussen motivatie voor LO en beweeggedrag in de vrije tijd onderzocht. Objectief gemeten beweeggedrag wordt gerelateerd aan verkregen data vanuit vragenlijsten omtrent de kwaliteit van motivatie van leerlingen voor het vak LO en voor bewegen in de vrije tijd. Niet motivatie voor LO, maar geslacht blijkt de grootste voorspellende factor te zijn van fysieke activiteit in de vrije tijd. Tevens komt uit de resultaten naar voren dat meisjes minder gemotiveerd zijn voor het vak LO dan jongens, terwijl dit verschil niet aanwezig is ten aanzien van motivatie voor bewegen in de vrije tijd. Mogelijkerwijs sluit de inhoud van het LO-curriculum niet goed aan bij de interesses van adolescente meisjes. Hoofdstuk $\mathbf{7}$ bouwt verder op de resultaten vanuit hoofdstuk 4 en hoofdstuk 6 . In een quasi-experimentele studie speelden leerlingen partijvormen basketbal in achtereenvolgens gemengde (jongens en meisjes) en gescheiden teams (meisjes tegen meisjes, jongens tegen jongens). De resultaten wijzen uit dat gescheiden partijvormen weliswaar niet direct leiden tot een hogere activiteitsgraad bij meisjes (waarschijnlijk door de gebruikte spelvorm vier tegen vier), maar dat het gevoel van competentie bij hen wel toeneemt. Competentiegevoel is een belangrijke voorwaarde voor autonome vormen van motivatie en regelmatig toepassen van een dergelijke strategie zou door docenten dus gebruikt kunnen worden om motivatie te bevorderen. In hoofdstuk 8 worden de resultaten van de beschreven studies in beschouwing genomen en in een groter geheel geplaatst. Concluderend kan gezegd worden dat lessen LO, zeker in een geïntensiveerde vorm, een substantiële bijdrage zouden kunnen leveren aan de dagelijkse fysieke activiteit van leerlingen. Echter, zolang het wekelijkse aantal lessen LO niet is opgevoerd, zal LO met name beschouwd moeten worden als een belangrijke aanvulling op andere beweeginitiatieven in en rond de school. Een ander opvallend aspect binnen de verschillende studies is dat bij meisjes de doelstelling van LO om bij te dragen een actieve leefstijl onvoldoende bereikt lijkt te worden. Oorzaak hiervan kan zijn dat een groot deel van de docenten LO didactisch een weinig innovatief lesprogramma hanteren, dat bovendien zwaar leunt op competitieve spelvormen en normatieve evaluaties. Om gevoelens van competentie en autonome vormen van motivatie onder meisjes te bevorderen zou de docent LO (nog) meer rekening kunnen houden met de verschillen in geslacht, bijvoorbeeld door meer differentiatie te bieden tijdens lessen en door alternatieve vormen van evaluatie toe te passen. Om dergelijke veranderingen teweeg te brengen lijkt het noodzakelijk om huidige en toekomstige docenten LO meer inzicht bij te brengen in pedagogische en didactische methoden die bewezen effectief zijn daar waar het gaat om het verhogen van lichamelijke activiteit, gevoelens van competentie en de kwaliteit van motivatie binnen het vak LO. Daarnaast lijkt het wenselijk, in ieder geval vanuit het perspectief van de fysieke activiteit en gezondheid, dat de overheid de mogelijkheden onderzoekt van het opvoeren van het aantal wekelijkse lessen LO op basis- en voortgezet onderwijs. 


\section{Dankwoord}

Ondanks dat het schrijfproces van dit proefschrift zich grotendeels individueel heeft voltrokken, is het achterliggende denkwerk, het brainstormen over zaken als onderzoeksopzet en uitvoering van de verschillende studies niet mogelijk zonder hulp. Gelukkig heb ik die hulp in ruime mate gehad. Bij deze doe ik een poging jullie allemaal te bedanken daarvoor.

Allereerst heel hartelijk dank aan alle jongens en meisjes die hebben meegewerkt aan de in dit boekje beschreven onderzoeken. Door het dragen van hartslagmeters, actihearts, het zich laten observeren en door het invullen van talloze vragenlijsten hebben zij ervoor gezorgd dat we nu iets meer weten dan voorheen. Ik was echter nooit in contact gekomen met deze enorme groep proefpersonen zonder de hulp van de directies en alle docenten LO van het Beatrix College, Theresialyceum, Willem II College in Tilburg en het Stedelijk Gymnasium in Breda. Tevens dank aan de studenten van de Academies voor Lichamelijk Opvoeding in Den Haag, Nijmegen, die in het kader van stages en afstudeerprojecten grote hoeveelheden bruikbare data hebben verzameld op scholen door heel Nederland.

Een aantal personen wil ik in het bijzonder bedanken:

Lars Borghouts, ik ken niemand die zo snel en oplossingsgericht denkt en schakelt als jij. Jouw rol als copromotor is niet alleen van onschatbare waarde geweest voor de totstandkoming van dit proefschrift, maar minstens net zoveel voor mijn eigen ontwikkeling als onderzoeker. Daarvoor ben ik je veel dank verschuldigd. Ik hoop dat we in de toekomst nog vele projecten samen op kunnen pakken, inclusief de onvermijdelijke congresbezoeken uiteraard.....

Mathijs Hesselink, jouw rol als promotor was door de bijzondere constructie Fontys-UM inhoudelijk wellicht beperkter in omvang dan je gewend was. Toch heb je een belangrijk bijdrage geleverd aan dit proefschrift en tevens aan de organisatorische zaken aan het einde van de rit. Dank daarvoor!

Joost Oomen, jouw Excel macro's hebben ertoe bijgedragen dat ik in mijn vakanties af en toe ook echt vakantie had. Dat je na elke verwerkte dataset in Excel een pop-up scherm ingebouwd had met de tekst "Joost is de beste" en ik enkel de knop "Ja" in kon drukken om verder te gaan vergeef ik je dan ook graag. Joost, dank dat je mijn paranimf wilt zijn. Je bent de beste!

Willem Gosens, dank dat je mijn paranimf wil zijn. Jouw rol was binnen de verschillende studies wellicht niet groot, toch heb je de afgelopen jaren een belangrijke rol gespeeld. Stoom afblazen is binnen onze immer "dynamische" organisatie af en toe van levensbelang. Jouw humor werkte hierin enorm relativerend. Ik hoop dat je fysiek snel weer de oude bent.

Liesbeth Jans, samen hebben wij het SOFIT instrument aangepast en vertaald naar de Nederlandse situatie. Dit is ons beiden goed van pas gekomen in onze onderzoeken. Weinig mensen werken secuurder dan jij, dank je wel voor je inzet. 
Pieter Cornelissen, geweldig dat je de opmaak en vormgeving van dit proefschrift zo snel hebt op kunnen pakken.

Stef Kremers, Kenneth Meijer, Jan Seghers en Chris Visscher, heel veel dank dat jullie de moeite wilden nemen om dit proefschrift tegen het academische licht te houden.

Leen Haerens, dank voor je medewerking aan de studie in hoofdstuk 7. Fijn dat de samenwerking tussen de Universiteit Gent en de Fontys Sporthogeschool voortgezet wordt in het project Punt voor Gym.

Greet Cardon, dank dat je wilde inspringen bij de revisie van het artikel in hoofdstuk 7 .

Papa en Mama, jullie onvoorwaardelijke steun in alles wat ik heb gedaan en doe heeft een belangrijke bijdrage gehad in waar ik nu sta. Daar ben ik jullie heel erg dankbaar voor.

Noa, jouw geboorte zette mijn wereld op zijn kop, in positieve zin. De beste vertraging die een proefschrift ooit kon hebben. Misschien lees je dit werk later nog wel eens en zeg je "die ouwe van mij had soms nog wel iets zinnigs te melden"

Soraya, de prestatie die jij hebt geleverd staat niet in verhouding tot het werk in dit proefschrift. De grandeur van "La douce France" verwisselen voor het kleine, koude Nederland, je razendsnel aanpassen, de taal leren en een baan en tevens je plek vinden hier. Het roept bij mij ontroering en bewondering op. De vakanties zijn vanaf nu helemaal van ons drieën. Soraya en Noa, je vous aime! 


\section{Curriculum Vitae}

Menno Slingerland was born in Rotterdam (Netherlands) on November 27, 1978. He attended secondary school, VWO, at the Comenius College in Capelle aan den IJssel and graduated there in 1997. He decided to study Physical Education at the University of Applied Sciences in The Hague (graduation 2001) and Human Movement Sciences at the University of Groningen (graduation 2005). For his master thesis he investigated the effectiveness of a postoperative program aimed at the recovery of patients with total hip and knee arthroplasty under the supervision of dr. Martin Stevens and dr. Inge Scheek. After his graduation he obtained a position as a PE teacher at two secondary schools in Schiedam. In 2007 he got the opportunity to start a PhD project at the Fontys University of Applied Sciences, School of Sports Studies in Tilburg (as from 2012 in Eindhoven), in collaboration with Maastricht University, investigating the role of PE in stimulating physical activity in children and adolescents. This project resulted in this thesis. During this period he also taught a number of bachelor courses (research methods, physiology, motivational concepts) and supervised many bachelor theses. Current occupations, besides teaching various courses in both bachelor and master curricula, include the research coordination of a comprehensive elementary school physical activity program (Brabantse Basisscholen in Beweging) and the co-supervision (with colleague Lars Borghouts) of a project on motivational methods of evaluation within PE (Een Punt voor Gym). 


\section{Publications in peer reviewed journals}

Slingerland, M., Haerens, L., Cardon, G., \& Borghouts, L. (2013). Differences in perceived competence and physical activity levels during single-gender modified basketball game play in middle school physical education. European Physical Education Review. Published online before print, doi:10.1177/1356336X13496000

Slingerland, M., Borghouts, L. B., \& Hesselink, M. K. C. (2012). Physical Activity Energy Expenditure in Dutch Adolescents: Contribution of Active Transport to School, Physical Education and Leisure Time Activities. Journal of School Health, 82(5), 225-232.

Slingerland, M., \& Borghouts, L. (2011). Direct and indirect influence of physical education-based interventions on physical activity: a review. Journal of Physical Activity \& Health, 8(6), 866-878.

Slingerland, M., Oomen, J., \& Borghouts, L. (2011). Physical activity levels during Dutch primary and secondary school physical education. European Journal of Sport Science, 11(4), 249-257. doi:10.1080/17461391.2010.506661

\section{Other publications}

Slingerland M., Vervoort J. \& Verheijen, S. (2013) Brabantse Basisscholen in Beweging, Thomas van Aquino, 73, 39-41.

Borghouts L., Slingerland, M \& Dokkum, G.J. (2013) Krijgen we een Punt voor Gym? Beoordelen in de lichamelijke opvoeding, Thomas van Aquino, 73, 19-22.

Slingerland, M. (2013) Motivatie en activiteit van leerlingen in de les LO, Thomas van Aquino, 73, 12-15.

Slingerland, M., \& Jans, L. (2012). Brabantse Basisscholen in Beweging. Zorg Primair, 8, 6-9.

Slingerland, M. (2011a). Bij modern bewegingsonderwijs wordt..... bewogen! Lichamelijke Opvoeding, 5, 28-30.

Slingerland, M. (2011b). Fysieke activiteit gedurende de schooldag: de bijdrage van lichamelijke opvoeding en actief transport naar school. Lichamelijke Opvoeding, 2, 12-15.

Slingerland, M. (2010). Intensiteit van lessen lichamelijke opvoeding in Nederland gemeten. Lichamelijke Opvoeding, 1, 10-13.

Slingerland, M. (2009). Motorische vaardigheid, fysieke activiteit en de rol van het bewegingsonderwijs. Lichamelijke Opvoeding, 8, 15-18.

Slingerland, M., \& Borghouts, L. (2008). Kan LO bijdragen aan de Beweegnorm? Lichamelijke Opvoeding, 8, 12-15.

\section{International Conference proceedings}

Slingerland, M \& Borghouts, L. (2009) Contribution of Physical Education Lessons to Physical Activity Levels of Dutch Primary and Secondary School Students. $14^{\text {th }}$ annual Congress of the European College of Sport Science, June 24-26, Oslo (Norway). Poster presentation.

Slingerland, M \& Borghouts L. (2010) Physical activity levels during Dutch primary and secondary school physical education. AIESEP World Congress, October 26-29, La Coruna (Spain). Poster presentation.

Slingerland, M, Borghouts, L. \& Hesselink, M. (2010) Contribution of physical education and school-related activity to energy expenditure in adolescents. AIESEP World Congress, October 26-29, La Coruna (Spain). Oral presentation.

Slingerland M., Haerens L., Borghouts, L. (2011) Psychological Correlates of Girls' Physical Activity Levels During Mixed-Gender Physical Education Lessons. 16 $6^{\text {th }}$ annual Congress of the European College of Sport Science, July 6-9, Liverpool (United Kingdom). Oral presentation.

Slingerland M., Haerens L., Borghouts, L. (2012) Single-gender Gameplay in Physical Education: Effects on Perceived Competence, Motivation and Physical activity in Girls. $17^{\text {th }}$ annual Congress of the European College of Sport Science, July 4-7, Bruges (Belgium). Poster presentation. 
Slingerland M., Haerens L., Cardon, G., Borghouts L. (2013) Differences in perceived competence and physical activity levels during single-gender modified basketball game play in middle school physical education. International Society for Behavioural Nutrition and Physical Activity Conference, May 22-25, Ghent (Belgium). Invited symposium.

Slingerland M. \& Borghouts L. (2014) Physical education and stimulating physical activity: An overview of studies. Accepted for presentation, Physical Education World Congress, Auckland, New Zealand.

Slingerland M. \& Sanders, Y, (2014) Primary schools in motion. Accepted for presentation, Physical Education World Congress, Auckland, New Zealand.

Borghouts, L \& Slingerland, M. (2014) Assessment practices in PE. Accepted for presentation, Physical Education World Congress, Auckland, New Zealand.

\section{National Conference proceedings}

Slingerland M. Stimuleert Bewegingsonderwijs een Actieve Leefstijl? (2007) Fontys Onderzoekscongres, 31 oktober, Eindhoven.

Slingerland M. \& Jans, L. Doorwerking lectoraat FSH naar het onderwijs. (2009) Fontys Onderzoekscongres, 22 april, Eindhoven.

Slingerland M., Borghouts L \& Hesselink, M. (2010) Bijdrage van lichamelijke opvoeding en actief transport aan het energieverbruik van adolescenten. Dag van het Sportonderzoek, 7 oktober, Amsterdam.

Slingerland, M. (2010) Workshop intensiveren van bewegingsonderwijs. Thomas Orientatiedag, 10 december, Tilburg.

Slingerland M. (2011) De gezonde gymles? Een evidence-based vakconcept. Studiemiddag CALO Zwolle, 16 november, Zwolle.

Slingerland, M. (2011) Invloed van het spelen van spelvormen in gemengde teams op de bewegingsintensiteit, competentie-gevoelens en motivatie bij meisjes in het voortgezet onderwijs. Symposium HBO-Sportonderzoek, 1 juni, Nijmegen.

Slingerland, M. (2011) De relatie tussen motivatie voor bewegingsonderwijs, motivatie voor bewegen en de hoeveelheid fysieke activiteit van middelbare scholieren. Dag van het Sportonderzoek, 4 november, Amsterdam.

Slingerland, M. (2012) Brabantse Basisscholen in Beweging, Dag van het Sportonderzoek, 12 oktober, Den Haag.

Slingerland, M. (2012) Brabantse Basisscholen in Beweging. Symposium HBO-Sportonderzoek, 16 mei, Groningen.

Slingerland, M. (2013) De (mogelijke) rol van de lichamelijke opvoeding in het stimuleren van bewegen: een overzicht van studies. Jaarlijks symposium van de Vereniging voor Bewegingswetenschappen Nederland, 22 maart, Garderen.

Slingerland M. \& Borghouts L. (2013) De (mogelijke) rol van lichamelijk opvoeding in het stimuleren van fysieke activiteit. Dag van het Sportonderzoek, Eindhoven.

Slingerland M. \& Sanders, Y. (2013) Brabantse Basisscholen in Beweging, Dag van het Sportonderzoek, Eindhoven. 


\title{
Stellingen behorende bij het proefschrift:
}

\author{
Physical Education's Contribution to Levels of Physical Activity in Children and Adolescents
}

Menno Slingerland

1. Een uur Lichamelijke Opvoeding per dag kan bij kinderen en adolescenten resulteren in een bijdrage van 30-35\% van de aanbevolen hoeveelheid dagelijkse fysieke activiteit (dit proefschrift). De 'gymles' zou alleen al daarom dagelijks op het programma moeten staan op alle scholen in Nederland.

2. Gezien het belang van ervaren competentie voor de motivatie (Deci \& Ryan, 2000), en de beperkte wekelijkse beweegtijd in de les LO (dit proefschrift), zou de ontwikkeling van ervaren competentie als vakdoelstelling prioriteit moeten krijgen boven de ontwikkeling van de daadwerkelijke senso-motorische competentie.

3. LO curricula in het voortgezet onderwijs komen over het algemeen onvoldoende tegemoet aan de behoeften van meisjes, met name in de keuze van lesonderwerpen, maar ook in de keuze van de gehanteerde didactische aanpak (dit proefschrift).

4. "If exercise is medicine, then physical education is the pill not taken" (Thomas L. McKenzie).

5. De mogelijkheden van de LO om, direct en indirect, de bijdrage aan fysieke activiteit van leerlingen te optimaliseren zouden een veel prominentere rol moeten krijgen in het curriculum van de lerarenopleidingen LO.

6. In plaats van discussiëren over de belangrijkste doelstellingen voor het vak LO, kan de vakwereld zich beter richten op hoe de verschillende doelstellingen effectief te bereiken.

7. How might a school subject that continues to be practised in a form that was considered to be cutting edge 60 years ago fulfill [it's] ambitions? (David Kirk).

8. Een auteur van een peer reviewed artikel moet voorafgaand aan publicatie minstens vijf keer controleren of zijn eigen naam goed gespeld is in de eindversie. Is dat het geval, dan daarna nóg minimaal één keer (Menno Singerland).

9. Als sport de belangrijkste bijzaak in het leven is (Kees Jansma), dan is fysieke activiteit de hoofdzaak. 


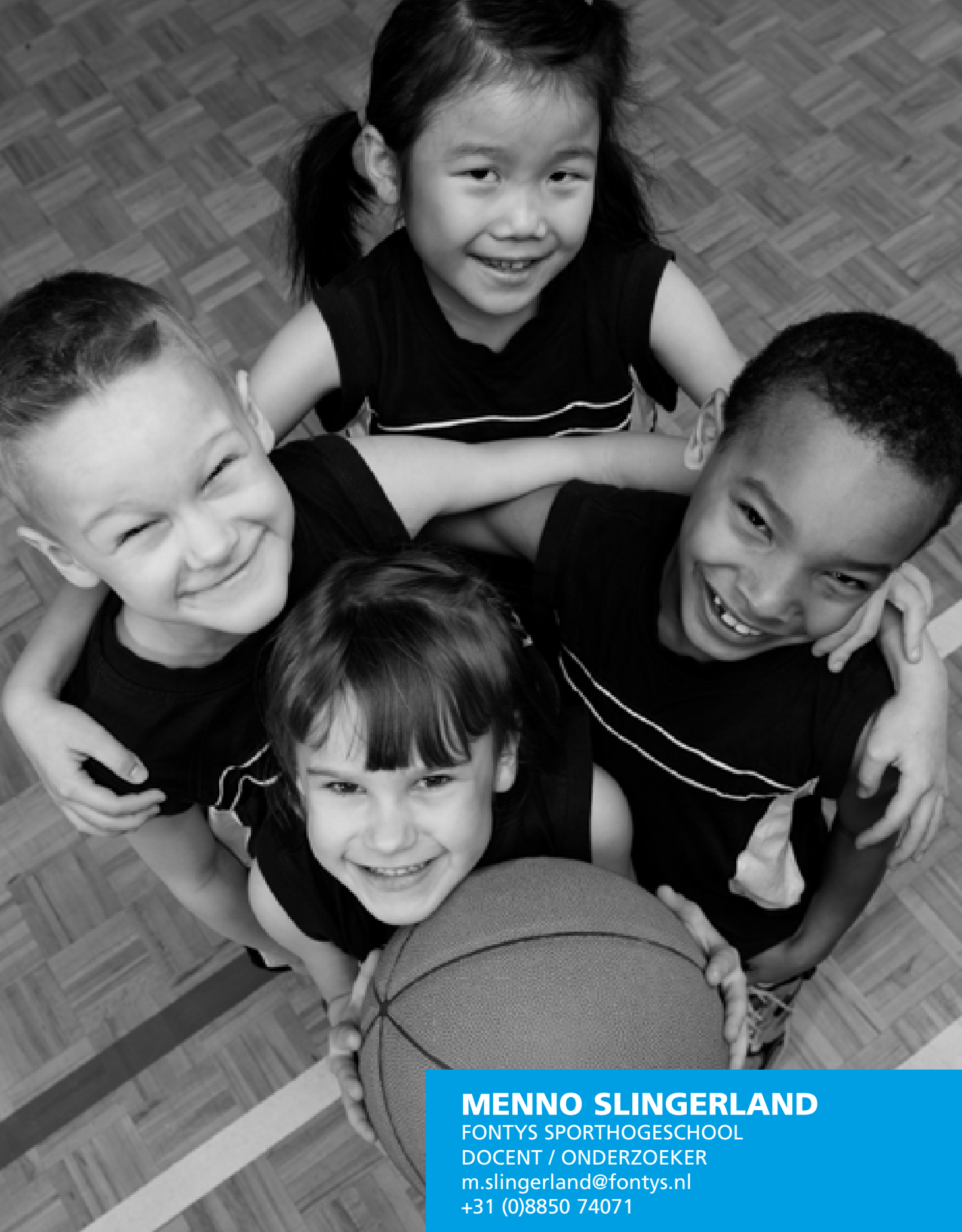

